\title{
RISCOS DE TRANSMISSÃO DA DOENÇA DE CHAGAS \\ POR TRANSFUSÃO SANGUÍNEA NO ESTADO DE
}

SANTA CATARINA, BRASIL

ALCIDES MILTON DA SILVA

Tese apresentada ao Departamento de Epidemiologia da Faculdade de Saúde Pública da Universidade de São Paulo para obtenção do grau de Doutor.

Área de concentração: Epidemiologia

ORIENTADOR: PROF. TITULAR

DR. JOSÉ MARIA SOARES BARATA

São Paulo

2002

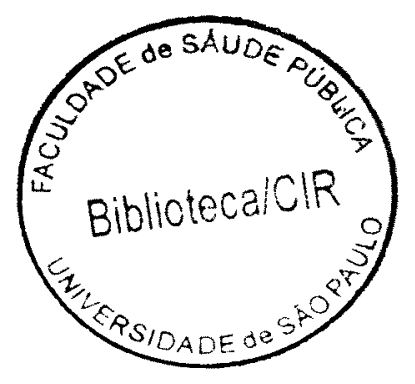




\title{
RISCOS DE TRANSMISSÃO DA DOENÇA DE CHAGAS \\ POR TRANSFUSÃo SANGUÍNEA NO ESTADO DE
}

\section{SANTA CATARINA, BRASIL}

\author{
ALCIDES MILTON DA SILVA
}

Tese apresentada ao Departamento de Epidemiologia da Faculdade de Saúde Pública da Universidade de São Paulo para obtenção do grau de Doutor.

Área de concentração: Epidemiologia

ORIENTADOR: PROF. TITULAR

DR. JOSÉ MARIA SOARES BARATA

São Paulo

2002 
De di c a tória 
Aos meus pais João e Erotildes, que com amor foram os precursores de tudo de bom em minha vida e pelo eterno, incansável e inesgotável apoio ao meu crescimento.

A Mariazinha, esposa, pelo carinho, incentivo, e infinita paciência, pela preocupação com meu bem estar ajudando a administrar minha vida pessoal, durante esse nosso sublime conviver.

Aos filhos Alcides e Renato, grandes companheiros e amigos, pela compreensão e tolerância nos longos periodos em que estive ausente, pelo apoio, incentivo e enorme paciencia sobretudo por acreditarem $e$ valorizarem este trabalho. 
Agradecimentos 


\section{Agradecimentos}

Ao Prof. Dr. José Maria Soares Barata, principal incentivador nesta caminhada, que sempre com amizade, pelos inestimáveis ensinamentos, incontestável apoio, por sua orientação segura e principalmente pela confiança que demonstrou em meu trabalho.

Ao Prof. Dr. Mário Steindel, do Departamento de Microbiologia e Parasitologia da Universidade Federal de Santa Catarina - UFSC, pelo companheirismo, apoio, incentivo constante, pelas sugestões e recomendações apresentadas na condução deste trabalho.

A $\operatorname{Dr}^{\mathrm{a}}$ Maria Esther de Carvalho, do Laboratório de Imunoepidemiologia da Superintendência de Controle de Endemias - SUCEN, de São Paulo, pelos ensinamentos relativos ao diagnóstico da infecção chagásica pelos exames imunoenzimáticos nas atividades de estágio, pela solidariedade, amizade, incentivo, pela boa vontade, prestimosa colaboração na execução deste projeto.

À Prof Dra. Lygia Busch Iversson, componente da banca examinadora, a quem dedico profunda admiração e respeito, pela sua contribuição em suas sugestões e crítica pertinente ao trabalho.

Ao Prof. Dr. Sérgio Bydlowski, membro da comissão examinadora, pelas excelentes sugestões na qualificação e ao longo da pesquisa, por sua maneira sempre disponível em receber-me e por meio de comentários contribuir para o aperfeiçoamento deste trabalho

A Prof ${ }^{a} . \mathrm{Dr}^{\mathrm{a}}$ Eunice Aparecida Bianchi Galati, membro suplente, pelas sugestões dadas por ocasião do exame de qualificação. 
A Prof $\mathrm{Dr}^{\mathrm{a}}$ Maria de Lourdes de Souza e ao Prof. Dr. Rodolfo Bruno Schlemper, pela amizade, companheirismo, colaboração espontânea e o apoio com que me incentivaram neste projeto.

Ao Pesquisador Científico da saudosa Superintendência de Campanhas de Saúde Pública - SUCAM. Senhor Joaquim Alves Ferreira Neto, que sempre com amizade, companheirismo, paciência, compreensão e bom humor, orientou-me com seu valioso saber, incentivando com sugestões na condução do projeto.

Ao Prof. Dr. Delsio Natal, do Departamento de Epidemiologia da FSP/USP, pelo companheirismo, incentivo e sugestões na condução deste projeto.

À Prof Dr $^{\mathrm{a}}$ Elza Berger Salema Coelho, Chefe do Departamento de Saúde PúblicaSPB. Centro de Ciências da Saúde, da Universidade Federal de Santa Catarina UFSC, que juntamente com o corpo docente incentivaram e autorizaram a realização deste Curso de Pós-graduação junto ao Departamento de Epidemiologia da Faculdade de Saúde Pública da Universidade de São Paulo-USP.

Ao Prof. Dr. Emil Kupek, do Departamento de Saúde Pública - SPB/UFSC, pela colaboração, boa vontade, orientação na montagem do banco de dados e auxilio na análise estatística.

Ao Prof. Dr. Carlos Alberto Justo da Silva, Diretor e funcionários do Centro de Ciências da Saúde da Universidade Federal de Santa Catarina - UFSC, pelo apoio, incentivo e viabilização do projeto.

Ao Diretor Geral Dr. Teodoro Correa Brugmam. Jane Terezinha Martins, João Carlos Biazotto. Diná de Almeida, Neila Simara Zanon, do Centro de Hemoterapia do Estado de Santa Catarina - HEMOSC, pelas facilidades oferecidas para realização das atividades de estágio: a Marilda dos Santos Bittencourt do Centro de Estudos Dr. Mário Roberto Kasniakowsky - CEMARK e funcionários pela colaboração durante a coleta de dados relativos aos doadores de sangue no período estudado. 
Ao Senhor Diretor Nilson Dorl, Andréa Petry e funcionários do Hemocentro Regional de Joaçaba, pela colaboração e ajuda na montagem do banco de dados para realização deste trabalho.

Ao Prof. Dr. Pedro Luiz Silva Pinto, da Divisão de Biologia Médica do Instituto Adolfo Lutz - IAL e as colaboradoras Dra. Maria de Fátima L. Araujo e Dra. Carmem S. Guilherme pelos ensinamentos relativos a preparação de triatomíneos e técnica do xenodiagnóstico, quando das atividades de estágio.

Ao Dr. Udson Piazza e funcionários da Diretoria de Vigilância Epidemiológica DVE e ao Dr. Antônio Anselmo Granzotto de Campos, Dr. Luiz Carlos e funcionários da Diretoria de Vigilância Sanitária - DVS, da Secretaria de Estado da Saúde, pela realização de atividades de estágio e fornecimento de dados.

Ao Prof. Dr. Jovino dos Santos Ferreira, diretor e funcionários do Serviço de Hemoterapia do Hospital Universitário - HU/UFSC, pelo apoio e colaboração em todas as atividades do estágio desenvolvidas para viabilização do projeto.

À Pesquisadora Científica do Laboratório de Protozooses por Flagelados, da SUCEN de Mogi-Guaçu. Dra.Vera Lúcia Cortiço Corrêa Rodrigues e funcionários responsáveis pelo Programa de Controle Vetorial da Doença de Chagas, pelas facilidades na obtenção de dados e colaboração nos trabalhos de campo.

Ao Dr.Rubens Antônio da Silva, da Divisão de Orientação Tecnológica, da SUCEN de São Paulo, pela colaboração no fornecimento de dados concernentes ao Programa de Controle da Doença de Chagas no Estado de São Paulo.

Aos Professores Nilza Nunes da Silva. Almério de Castro Gomes. Helena Ribeiro, do Curso de Pós-graduação da USP, que imprimiram suas orientações ao meu aperfeiçoamento acadêmico. 
Aos funcionários da Biblioteca da FSP, pela simpatia e costumeira disposição com que sempre acolheram os alunos desta Faculdade, pelas orientações concernentes as referências e funcionários do setor de equipamentos audio-visuais, pelo apoio e atenção dispensada a este humilde usuário nas diversas vezes que deles necessitei.

Às funcionárias da Comissão de Pós-graduação, Serviço de Aprimoramento da Faculdade de Saúde Pública da USP, Ângela Maria Pereira da Silva, Márcia Aparecida Garcia da Silva, Maria Aparecida Mendes e Renilda Maria de Figueiredo, pela atenção dispensada em todos os momentos que sempre me atenderam nas questões formais, durante o curso de pós-graduação.

Aos amigos Lisardo Osório Quintero, Walter Ceretti Júnior, Ozinaldo Oliveira dos Santos, Paulo Roberto Urbinatti, Carlos Frederico Loyola, Marcos Takashi Obara, dentre tantos, do Departamento de Epidemiologia da FSP/USP, pela amizade, companheirismo, incentivo, respeito e confiança.

À Coordenação de Aperfeiçoamento de Pessoal de Nível Superior - CAPES, pelo apoio financeiro concedido.

Ao Prof. Senhor Nelson Luiz da Silva, que com disposição e paciência, pela revisão minuciosa e criteriosa do texto.

A todos as pessoas que, de forma direta ou indireta, contribuíram com o desenvolvimento deste trabalho. da minha formação como pesquisador e ser humano, os sinceros agradecimentos. 


\section{RESUMO}

Silva AM. Riscos de transmissão da doença de Chagas por transfusão sanguínea no Estado de Santa Catarina, Brasil São Paulo, 2002. [Tese de Doutorado Faculdade de Saúde Pública da Universidade de São Paulo]

Introdução: A doença de Chagas atualmente é um problema de saúde pública não somente de áreas endêmicas da América Latina, mas também de áreas que sofreram com a imigração de indivíduos infectados. O Estado de Santa Catarina, considerado indene para esta enfermidade, recebeu nas últimas décadas elevado número de doadores de sangue naturais de áreas endêmicas que o expõe aos riscos da transmissão transfusional. Objetivo: Estimar a prevalência da infecção por Trypanosoma cruzi entre doadores de sangue e avaliar o risco de transmissão entre receptores nas Unidades Hemoterápicas das Regiōes da Grande Florianópolis e Joaçaba, Estado de Santa Catarina, no período de 1990 a 1999. Material e Métodos: Trata-se de um estudo que tem como modelo estatístico uma coorte histórica retrospectiva, onde se pesquisou uma população de 159.829 doadores de sangue que realizaram doações em 3 Unidades Hemoterápicas do Estado de Santa Catarina, no período de 1990 a 1999. Para identificar a prevalência à infecção pelo T. cruzi nos participantes, foram empregados os exames de Elisa, Hemaglutinação Passiva e Imunofluorescência e avaliado o risco de transmissão transfusional entre receptores de sangue, nos serviços de hemoterapia do Hemocentro Regional de Florianópolis HRF e Serviço de Hemoterapia do Hospital Universitário - SHHU/UFSC, localizados na Região da Grande Florianópolis e Hemocentro Regional de Joaçaba na Região de Joaçaba, Estado de Santa Catarina. No estudo de prevalência foram realizadas a análise descritiva de variáveis com distribuição de freqüências segundo a naturalidade, faixa etária, sexo, estado civil e ocupação. Para o cálculo do Risco Residual de Transmissão Transfusional utilizou-se o modelo (Incidência Ajustada $x$ Periodo de Janela imunológica) descrito por CANUTTI JUNIOR, 1998, que mede a possibilidade de uma unidade hemoterápica transfundida transmitir doença. Resultados: Em 204.025 doações efetuadas, foram encontrados 294 casos de infecção por $T$. cruzi, observando-se uma prevalência de $150,53 / 100.000$ primodoadores e 170,47/100.000 doadores de repetição na Região da Grande Florianópolis; 171,69/100.000 primodoadores e 0,00/100.000 em doadores de repetição na Região de Joaçaba, e 151,93 entre 100.000 primodoadores e 136,88 por 100.000 doadores de repetição no conjunto das 3 Unidades Hemoterápicas estudadas no Estado de Santa Catarina. O cálculo do Risco Residual de Transmissão Transfusional da doença de Chagas, indicou para a Região da Grande Florianópolis um resultado de 3,38 possiveis contaminações por 100.000 doações efetuadas; 0,00/100.000 para a Região de Joaçaba; e de 2,42/100.000 doações para o Estado de Santa Catarina. Conclusões: Os dados mostram a presença de individuos infectados pelo T.cruzi que são detectados na triagem sorológica entre os candidatos a doação de sangue no Estado de Santa Catarina. Indicam também a existência do Risco Residual de transmissão transfusional da doença de Chagas no Estado, considerado indene livre de qualquer tipo de transmissão, o que sugere a necessidade de maior atenção de vigilância epidemiológica a essa enfermidade

Descritores: Doença de Chagas. Trypanosoma cruzi. Doadores de sangue. Prevalência. Risco Residual de transmissão transfusional. 


\section{SUMMARY}

Silva AM. The risk of Chagas disease transmission via blood transfusion in the Federal State of Santa Catarina, Brazil. São Paulo, 2002. [Tese de Doutorado Faculdade de Saúde Pública da Universidade de São Paulo]

Introduction: Chagas disease is an actual public health problem not only in endemic areas of Latin America but also in urban where the infected population is migrating to. The Federal State of Santa Catarina, considered free of this disease, received in the last decades an elevated number of blood donors from endemic areas, thus increasing the risk of the disease transmission via blood transfusion. Objective: To estimate the prevalence of Trypanosoma cruzi infection among blood donors and to evaluate the residual risk for receiving blood contaminated with $T$. cruzi in the blood banks of the state capital Florianópolis and a city in the interior of the state, Joaçaba, during the period 1990-1999. Material and Methods: A retrospective study included 159.829 blood donors from 3 blood banks in the State of Santa Catarina during the period 1990-1999. Enzyme-linked immunosorbent assay (ELISA), hemagglutination and immunofluorescence methods were used to diagnose the infection by $T$. cruzi. These laboratory tests are routinely used to screen blood donations in the Regional Blood Bank in Florianópolis (RBBF), University Hospital Blood Bank (UHBB) in Florianópolis and the Regional Blood Bank in Joaçaba $(\mathrm{RBBJ})$. The prevalence of Chagas disease was described with respect to migration, age, sex, marital status and occupation. Residual risk for transfusing Chagas disease contaminated blood was calculated as the product of adjusted incidence and duration of immunological window period. The calculation followed the description by CANUTTI JUNIOR, 1998. Results: Among 204.025 blood donors from all 3 blood barks analyzed, 294 cases of infection by $T$. cruzi were found. In the Florianópolis area, the Chagas disease prevalence per 100.000 donors was 150,53 among first-time donors and 170,47 among repeat donors. In the Joaçaba area, the prevalence per 100.000 donors was 171,69 in first-time donors and 0,00 in repeat donors. Chagas disease prevalence per 100.000 donors from all 3 blood banks analyzed, was 151,93 for first-time donors and 136,88 for repeat donors for the State of Santa Catarina. Average number of Chagas disease contaminated transfusion units per 100.000 blood donations was estimated at 3,38 in the Florianópolis area, 0,00 in Joaçaba, and 2,42 for the pool of the 3 blood banks analyzed. Conclusions: The data confirmed the presence of T.cruzi in blood donors in the State of Santa Catarina, as well as the associated residual transfusion risk. These findings underline the need for enhanced epidemic surveillance of Chagas disease in the state

Keywords: Chagas disease. Trypanosoma cruzi. Blood donors. Prevalence. Residual transfusion risk. 


\section{RELAÇÃO DE TABELAS}

$N^{\circ}$

$\mathrm{pg}$

1 - Distribuição dos órgãos de atividade hemoterápica, segundo a modalidade de serviços e Regional de Saúde - RS. Estado de Santa Catarina, 2000

2 - Distribuição dos órgãos de atividade hemoterápica, segundo a categoria de serviços. Estado de Santa Catarina. 2000

3 - Número de doações, primodoadores, doadores de repetição, total de doadores, casos (positivos e indeterminados). Hemocentro Regional de Florianópolis, Serviço de Hemoterapia do Hospital UniversitárioHU/UFSC e Hemocentro Regional de Joaçaba.Estado de Santa Catarina, 1990 A 1999

4 - Distribuição do número de doações e soropositividade para todas as doenças e doença de Chagas nas Unidades Hemoterápicas de Florianópolis (HRF e SHHU/UFSC). Região da Grande Florianópolis. Estado de Santa Catarina. 1990 a 1999

5 - Distribuição do número de doadores de sangue e da infecção por T. cruzi nas Unidades Hemoterápicas do Hemocentro Regional de Florianópolis e Serviço de Hemoterapia do HU/UFSC. Região da Grande Florianópolis, Estado de Santa Catarina. 1990 a 1999

6 - Distribuição dos doadores de sangue soropositivos e indeterminados para infecção por T. cruzi por ano. Região da Grande Florianópolis. Estado de Santa Catarina, 1990 a 1999

7 - Distribuição dos doadores de sangue soropositivos e indeterminados para infecção por T. cruzi, quanto a naturalidade. Região da Grande Florianópolis. Estado de Santa Catarina., 1990 a 1999

8 - Distribuição dos doadores de sangue soropositivos para infecção por $T$. cruzi por faixa etária e ano de doação. Região da Grande Florianópolis. Estado de Santa Catarina. 1990 a 1999

9 - Distribuição dos casos positivos e indeterminados para infecção por $T$. cruzi por sexo, nas Unidades Hemoterápicas (HRF e SHHU/UFSC). Região da Grande Florianópolis. Estado de Santa Catarina, 1990 a 1999

10 - Distribuição dos casos positivos e indeterminados para infecção por $T$. cruzi quanto o estado civil, nas Unidades Hemoterápicas (Hemocentro Regional de Florianópolis e Serviço de Hemoterapia do HU/UFSC). Região da Grande Florianópolis. Estado de Santa Catarina, 1990 a 1999 
11 - Distribuição dos casos positivos e indeterminados para infecção por $T$. cruzi segundo a ocupação. Região da Grande Florianópolis. Estado de Santa Catarina, 1990 a 1999

12 - Taxa de prevalência da infecção por $T$. cruzi entre primodoadores, doadores de repetição e total de doadores. Região da Grande Florianópolis. Estado de Santa Catarina, 1990 a 1999

13 - Taxa de prevalência da infecção por $T$. cruzi entre primodoadores, doadores de repetição e total de doadores. Região da Grande Florianópolis. Estado de Santa Catarina, 1990 a 1999

14 - Taxa de incidência da infecção por $T$. cruzi entre doadores de repetição nas Unidades Hemoterápicas do Hemocentro Regional de Florianópolis, Serviço de Hemoterapia do HU/UFSC e Região da Grande Florianópolis. Estado de Santa Catarina, 1990 a 1999

15 - Risco Residual de Transmissão Transfusional de infecção por T. cruzi nas Unidades Hemoterápicas do Hemocentro Regional de Florianópolis, Serviço de Hemoterapia do HU/UFSC e Região da Grande Florianópolis. Estado de Santa Catarina, 1990 a 1999

16 - Distribuição do número de doadores de sangue e infecção por T. cruzi, por ano. Unidade Hemoterápica do Hemocentro Regional de Joaçaba. Região de Joaçaba. Estado de Santa Catarina, 1995 a 1999

17 - Distribuição do número de doadores de sangue soropositivos e indeterminados para infecção por $T$. cruzi, por ano. Hemocentro Regional de Joaçaba. $8^{\mathrm{a}}$ Regional de Saúde. Estado de Santa Catarina, 1995 a 1999

18 - Distribuição quanto a naturalidade dos doadores de sangue soropositivos e indeterminados para infecção por T. cruzi, no Hemocentro Regional de Joaçaba. $8^{a}$ Regional de saúde. Estado de Santa Catarina. 1995 a 1999

19 - Distribuição dos doadores de sangue soropositivos e indeterminados para infecção por $T$. cruzi, por ano e faixa etária. Hemocentro Regional de Joaçaba. $8^{\text {a }}$ Regional de saúde. Estado de Santa Catarina, 1995 a 1999

20 - Distribuição dos doadores de sangue soropositivos e indeterminados para infecção por T. cruzi, por sexo. Região de Joaçaba. $8^{\mathrm{a}}$ Regional de saúde. Estado de Santa Catarina, 1995 a 1999

21 - Distribuição dos doadores de sangue soropositivos e indeterminados para infecção por $T$. cruzi, quando o estado civil. Hemocentro Regional de Joaçaba. 8ª Regional de Saúde. Estado de Santa Catarina, 1995 a 1999 
22 - Distribuição dos doadores de sangue soropositivos e indeterminados para infecção por $T$. cruzi, segundo a ocupação. Hemocentro Regional de Joaçaba. $8^{\mathrm{a}}$ Regional de Saúde. Estado de Santa Catarina, 1995 a 1999

23 - Taxa de prevalência da infecção por $T$. cruzi entre primodoadores, doadores de repetição e total de doadores. Hemocentro Regional de Joaçaba. $8^{a}$ Regional de Saúde. Estado de Santa Catarina, 1995 a 1999

24 - Taxa de incidência da infecção pelo $T$. cruzi entre doadores de sangue de repetição no Hemocentro Regional de Joaçaba. $8^{a}$ Regional de Saúde. Estado de Santa Catarina, 1995 a 1999

25 - Risco Residual de Transmissão Transfusional e Intervalo de Confiança, entre os doadores de repetição. Hemocentro Regional de Joaçaba. $8^{\mathrm{a}}$ Regional de Saúde. Estado de Santa Catarina. 1995 a 1999

26 - Distribuição quanto a naturalidade dos doadores de sangue soropositivos e indeterminados para infecção por $T$. cruzi, no conjunto das Unidades Hemoterápicas (HRF, SHHU/UFSC e HRJ). Estado de Santa Catarina, 1990 a 1999

27 - Distribuição dos doadores de sangue soropositivos e indeterminados para infecção por $T$. cruzi por faixa etária e ano de doação, nas Unidades Hemoterápicas estudadas (HRF, SHHU/UFSC e HRJ). Estado de Santa Catarina, 1990 a 1999

28 - Distribuição de doadores de sangue soropositivos e indeterminados para infecção por $T$. cruzi, por sexo, nas Unidades Hemoterápicas estudadas (HRF, SHHU/UFSC e HRJ). Estado de Santa Catarina, 1990 a 1999

29 - Distribuição de doadores de sangue soropositivos e indeterminados para infecção por $T$. cruzi, quanto ao estado civil, nas Unidades Hemoterápicas estudadas (HRF, SHHU/UFSC e HRJ). Estado de Santa Catarina, 1990 a 1999

30 - Distribuição de doadores de sangue soropositivos e indeterminados para infecção por T. cruzi, segundo a ocupação, nas Unidades Hemoterápicas estudadas (HRF, SHHU/UFSC e HRJ). Estado de Santa Catarina, 1990 a 1999

31 - Taxa de prevalência da infecção por $T$. cruzi entre primodoadores, doadores de repetição e total de doadores no Hemocentro Regional de Florianopolis, Serviço de Hemoterapia do HU/UFSC, Hemocentro Regional de Joaçaba e Estado de Santa Catarina. 1990 a 1999

32 - Taxa de prevalência da infecção por $T$. cruzi entre primodoadores, doadores de repetição e total de doadores. Estado de Santa Catarina, 1990 a 1999 
33 - Taxa de incidência da doença de Chagas entre doadores de repetição no Hemocentro Regional de Florianópolis, Serviço de Hemoterapia do HU/UFSC e Hemocentro Regional de Joaçaba. Estado de Santa Catarina. 1990 a 1999

34 - Risco Residual de Transmissão Transfusional da infecção por T. cruzi no Hemocentro Regional de Florianópolis, Serviço de Hemoterapia do HU/UFSC e Hemocentro Regional de Joaçaba. Estado de Santa Catarina, 1990 a 1999 


\section{RELAÇÃO DE FIGURAS}

1 - Mapa do Estado de Santa Catarina com as divisões Regionais de Saúde 8

2 - Mapa do Estado de Santa Catarina com a indicação das Regionais de Saúde da Grande Florianópolis e Joaçaba

3 - Mapa da Regional de Saúde da Grande Florianópolis, Estado de Santa Catarina

4 - Mapa da Regional de Saúde de Joaçaba, Estado de Santa Catarina 50

5 - Distribuição dos doadores de sangue soropositivos e indeterminados para infecção por T. cruzi, por ano. Região da Grande Florianópolis. Estado de Santa Catarina, 1990 a 1999

6 - Distribuição dos doadores de sangue soropositivos e indeterminados para infecção por $T$. cruzi, quanto a naturalidade. Região da Grande Florianópolis. Estado de Santa Catarina., 1990 a 1999

7 - Distribuição dos doadores de sangue soropositivos para infeç̧ão por $T$. cruzi por faixa etária e ano de doação. Região da Grande Florianópolis. Estado de Santa catarina. 1990 a 1999

8 - Distribuição dos doadores de sangue soropositivos e indeterminados para infecção por T. cruzi, por sexo. Região da Grande Florianópolis. Estado de Santa Catarina, 1990 a 1999

9 - Distribuição dos casos positivos e indeterminados para infecção por $T$. cruzi quanto o estado civil, nas Unidades Hemoterápicas (HRF e SHHU/UFSC). Região da Grande Florianópolis. Estado de Santa Catarina, 1990 a 1999

10 - Taxa de prevalência da infecção por $T$. cruzi entre primodoadores, doadores de repetição e total de doadores. Região da Grande Florianópolis. Estado de Santa Catarina, 1990 a 1999

11 - Taxa de incidência da infeção por $T$. cruzi entre doadores de sargue de repetição no Hemocentro Regional de Florianópolis, Serviço de Hemoterapia do HU/UFSC e Região da Grande Florianópolis. Estado de Santa Catarina, 1990 a 1999

12 - Risco Residual de Transmissão Transfusional da infecção por T.cruzi nas Unidades Hemoterápicas do Hemocentro Regional de Florianópolis, Serviço de Hemoterapia do HU/UFSC e Região da Grande Florianópolis. Estado de Santa Catarina, 1990 a 1999 
13 - Distribuição do número de doadores de sangue e infecção por $T$. cruzi no Hemocentro Regional de Joaçaba. $8^{\mathrm{a}}$ Regional de Saúde. Estado de Santa Catarina, 1995 a 1999

14 - Distribuição quanto a naturalidade dos doadores de sangue soropositivos e indeterminados para infecção por T. cruzi. Hemocentro Regional de Joaçaba. $8^{a}$ Regional de Saúde. Estado de Santa Catarina. 1995 a 1999

15 - Distribuição dos doadores de sangue soropositivos e indeterminados para infecção por $T$. cruzi, por faixa etária. Hemocentro Regional de Joaçaba. $8^{\mathrm{a}}$ Regional de Saúde. Estado de Santa Catarina, 1995 a 1999

16 - Distribuição dos doadores de sangue soropositivos e indeterminados para infecção por $T$. cruzi, por sexo. Hemocentro Regional de Joaçaba. $8^{\mathrm{a}}$ Regional de Saúde. Estado de Santa Catarina, 1995 a 1999

17 - Distribuição dos doadores de sangue soropositivos e indeterminados para infecção por T. cruzi, quando o estado civil. Hemocentro Regional de Joaçaba. $8^{a}$ Regional de Saúde. Estado de Santa Catarina, 1995 a 1999

18 - Taxa de prevalência da infecção por $T$. cruzi entre primodoadores, doadores de repetição e total de doadores. Hemocentro Regional de Joaçaba. $8^{\text {a }}$ Regional de Saúde. Estado de Santa Catarina, 1995 a 1999

19 - Distribuição quanto a naturalidade dos doadores de sangue soropositivos e indeterminados para infecção por T. cruzi, no conjuntos das Unidades Hemoterápicas (HRF, SHHU/UFSC e HRJ). Estado de Santa Catarina, 1990 a 1999

20 - Distribuição dos doadores de sangue soropositivos e indeterminados para infecção por $T$. cruzi, por faixa etária e ano de doação, nas Unidades Hemoterápicas estudadas (HRF, SHHU/UFSC e HRJ). Estado de Santa Catarina, 1990 a 1999

21 - Distribuição de doadores de sangue soropositivos e indeterminados para infecção por $T$. cruzi, por sexo nas Unidades Hemoterápicas estudadas (HRF, SHHU/UFSC e HRJ). Estado de Santa Catarina, 1990 a 1999

22 - Distribuição de doadores de sangue soropositivos e indeterminados para infecção por T. cruzi, quanto ao estado civil, nas Unidades Hemoterápicas estudadas (HRF, SHHU/UFSC e HRJ). Estado de Santa Catarina, 1990 a 1999

23 - Taxa de prevalência da infecção por T.cruzi entre primodoadores, doadores de repetição e total de doadores. Estado de Santa Catarina. 1990 a 1999 
24 - Taxa de incidência da da infecção por $T$.cruzi entre doadores de repetição no Hemocentro Regional de Florianópolis, Serviço de Hemoterapia do Hospital Universitário-HU/UFSC, Hemocentro Regional de Joaçaba e Estado de Santa Catarina. 1990 a 1999

25 - Risco Residual de Transmissão Transfusional da infecção por T.cruzi no Hemocentro Regional de Florianópolis, Serviço de Hemoterapia do Hospital Universitário-HU/UFSC, Hemocentro Regional de Joaçaba e total observado no Estado de Santa Catarina. 1990 a 1999 


\section{ABREVIATURAS E SIGLAS}

DVS - Diretoria de Vigilância Sanitária

ELISA - Enzime Linked Immunosorbent assay

FC - Fixação de Complemento

FNS - Fundação Nacional de Saúde

HA - Hemaglutinação passiva

HAI - Hemaglutinação Indireta

HEMOSC - Centro de Hematologia e Hemoterapia do Estado de Santa Catarina

HRF - Hemocentro Regional de Florianópolis

HRJ - Hemocentro Regional de Joaçaba

HU - Hospital Universitário

IFI - Imunofluorescência Indireta

MS - Ministério da Saúde

RS - Regional de Saúde

SES/SC - Secretaria de Estado da Saúde de Santa Catarina

SHHU - Serviço de Hemoterapia do Hospital Universitário

SUCAM - Superintendência de Campanhas de Saúde Pública

SUCEN - Superintendência de Controle de Endemias.

UFSC - Universidade Federal de Santa Catarina 


\section{SUMÁRIO}

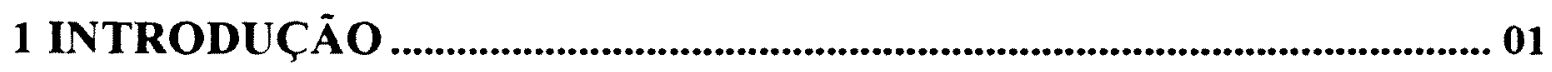

1.1 História Natural da doença de Chagas ............................................. 09

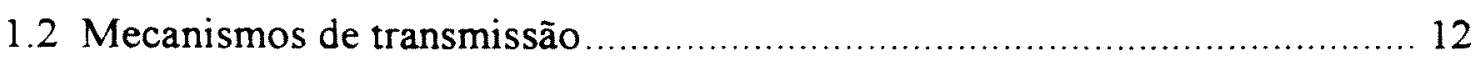

1.2.1 Transmissão vetorial ......................................................... 13

1.2.2 Transmissão transfusional .................................................... 14

1.2.3 Outros mecanismos de transmissão …......................................... 18

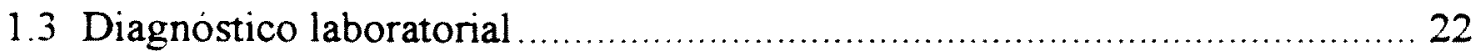

1.4 A doença de Chagas no Estado de Santa Catarina ................................... 29

1.4.1 O controle das transfusões e os riscos de transmissão

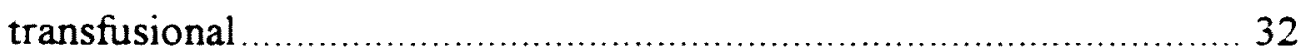

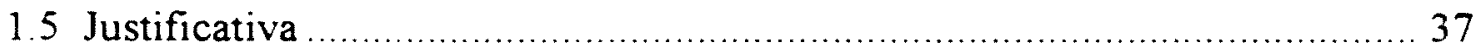

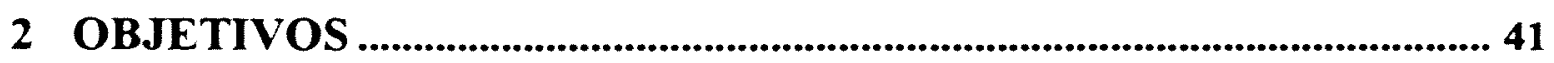

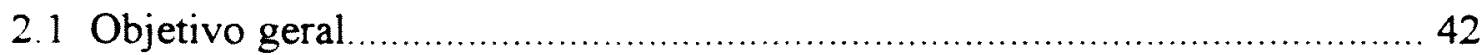

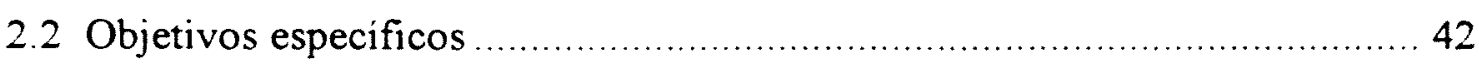

3 MATERIAL E MÉTODOS .....................................................................43

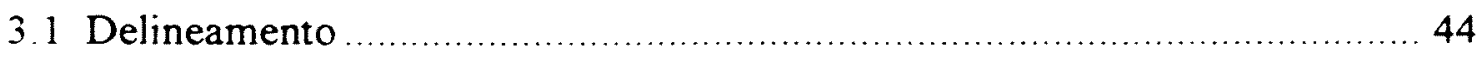

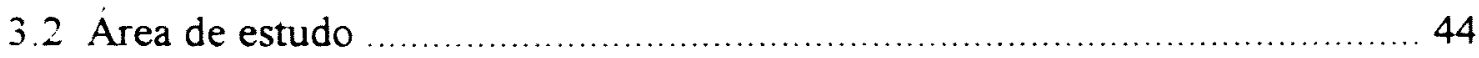

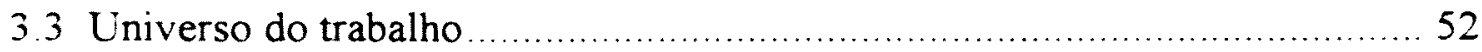

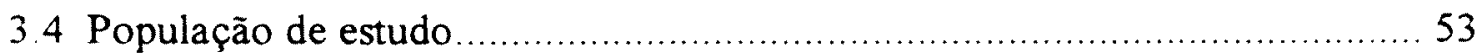

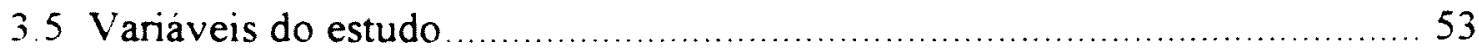

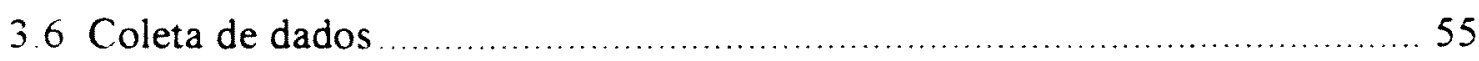

37 Periodo de seleção e população analisada ........................................ 56

3.8 Análise e interpretação dos resultados ........................................... 56

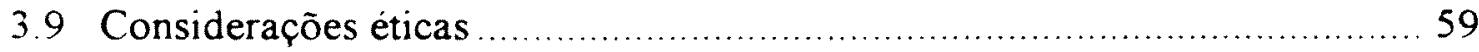




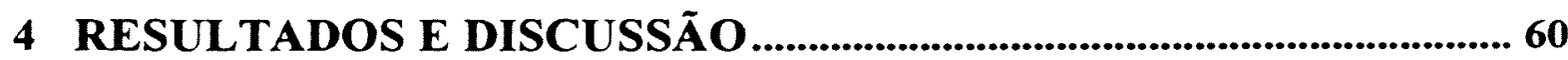

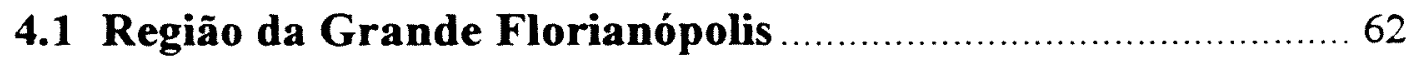

4.1.1 Caracterização da população sorologicamente positiva para Trypanosoma cruzi (naturalidade, faixa etária, sexo, estado

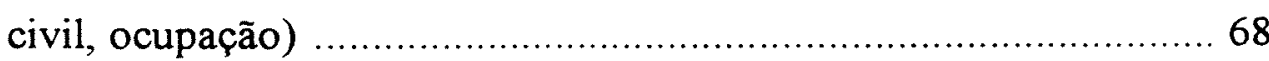

4.1.2 Prevalência da infeç̧ão por T. cruzi ........................................... 76

4.1.3 Incidência da infeç̧ão por T. cruzi ............................................. 78

4.1.4 Risco Residual de Transmissão Transfusional ............................... 80

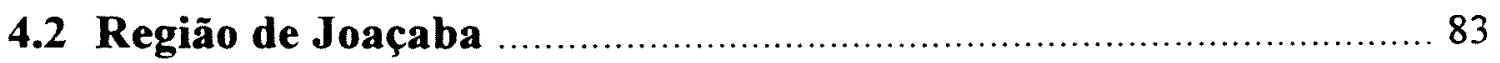

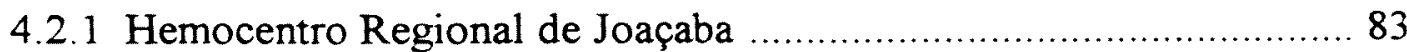

4.2.1.1 Caracterização da população sorologicamente positiva para Trypanosoma cruzi (naturalidade, faixa etária, sexo, estado

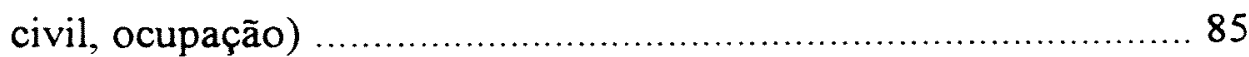

4.2.1.2 Prevalência da infeç̧ão por T. cruzi ......................................... 92

4.2.1.3 Incidência da infeç̧ão por T. cruzi ......................................... 93

4.2.1.4 Risco Residual de Transmissão Transfusional ............................ 94

\subsection{Estado de Santa Catarina (Região da Grande Florianópolis}

e Joaçaba)

4.3.1 Caracterização da população sorologicamente positiva para Trypanosoma cruzi (naturalidade, faixa etária, sexo, estado civil, ocupação) 95

4.3.2 Prevalência da infecção por T. cruzi .......................................... 103

4.3.3 Incidência da infeç̧ão por T. cruzi ............................................. 107

4.3.4 Risco Residual de Transmissão Transfusional ............................ 109 


\section{ANEXOS}

I - Lista de Regionais de Saúde e municípios da Figura 1

II - Lista de municipios, população e área geográfica da Figura 3. $18^{\mathrm{a}}$

Regional de Saúde. Região da Grande Florianópolis

III - Lista de municipios, população e área geográfica da Figura 4. $8^{\mathrm{a}}$

Regional de Saúde. Região de Joaçaba.

IV - Hospitais atendidos pelo Hemocentro Regional de Florianópolis, Serviço de Hemoterapia do Hospital Univesitário - HU, da Universidade Federal de Santa Catarina - UFSC e Hemocentro Regional de Joaçaba. Estado de Santa Catarina, 2000

V - Ficha Cadastro do Doador

VI - Prevalência da infecção por T.cruzi no Hemocentro Regional de Florianópolis, Serviço de Hemoterapia do HU/UFSC e Região da Grande Florianópolis. Estado de Santa Catarina (cálculos).

VII - Incidência da infecção por $T$. cruzi no Hemocentro Regional de Florianópolis, Serviço de Hemoterapia do HU/UFSC e Região da Grande Florianópolis. Estado de Santa Catarina (cálculos).

VIII - Risco Residual de Transmissão Transfusional do T. cruzi no Hemocentro Regional de Florianópolis, Serviço de Hemoterapia do HU/UFSC e Região da Grande Florianópolis. Estado de Santa Catarina (cálculos)

IX- Prevalência da infecção por $T$. cruzi no Hemocentro Regional de Joaçaba. Região de Joaçaba. Estado de Santa Catarina (cálculos).

X - Incidência da infecção por T. cruzi no Hemocentro Regional de Joaçaba. Região de Joaçaba. Estado de Santa Catarina (cálculos).

XI - Risco Residual de Transmissão Transfusional do $T$. cruzi no Hemocentro Regional de Joaçaba. Região de Joaçaba. Estado de Santa Catarina (cálculos)

XII - Prevalência da infecção para $T$. cruzi no Hemocentro Regional de Florianópolis, Serviço de Hemoterapia do HU/UFSC, Hemocentro Regional de Joaçaba e Estado de Santa Catarina (cálculos).

XIII - Incidência da infecção por $T$. cruzi no Hemocentro Regional de Florianopolis, Serviço de Hemoterapia do HU/UFSC, Hemocentro Regional de Joaçaba e Estado de Santa Catarina (cálculos). 
XIV - Risco Residual de Transmissão Transfusional do T. cruzi no Hemocentro Regional de Florianópolis, Serviço de Hemoterapia do HU/UFSC, Hemocentro Regional de Joaçaba e Estado de Santa Catarina (cálculos).

XV - Classificação das Unidades Hemoterápicas, de acordo com a natureza ou modalidade de serviços, atualizada segundo o Ministério da Saúde 


\section{INTRODUÇÃO}




\section{INTRODUÇĀO}

A doença de Chagas, conhecida também como Tripanossomiase americana, representa um problema de saúde pública em grande parte dos paises da América Latina, estendendo-se desde o México ao norte da Argentina e sul do Chile (ALENCAR 1977; WHO 1990; MILES 1992; TANOWITZ e col. 1993; MORAESSOUZA e col. 1994; GRIJALVA e col. 1997; GOLDENBERG 1998; DIAS e SCHOFIELD 1998; SCHMUÑIS 1999a).

Sua transmissão ocorre primariamente pelo contato com excretas contaminadas de insetos vetores (Hemíptera Reduviidae) infectados com o agente causal, o Trypanosoma cruzi.

Estima-se que no continente americano existam de 16 a 18 milhões de indivíduos infectados e cerca de 100 milhões expostos ao risco de contrair a enfermidade (OMS 1991).

Constitui também ameaça permanente para paises da América do Norte, Europa e outros não endêmicos, devido a grandes migrações, considerando ser a transfusão sangüinea a segunda mais importante via de transmissão (OMS 1991; WENDEL 1993a, 1993b; WENDEL e col. 1993; SCHMUNIS 1999b).

No Brasil, a área endêmica foi delimitada por extensos inquéritos nacionais realizados entre 1975 e 1980. Um entomológico, efetuado em grande parte do território brasileiro, com exceção do Estado de São Paulo e Região da Amazônia considerada indene (SILVEIRA e col. 1984); e outro inquérito, sorológico, que apenas não incluiu o Distrito Federal e o Estado de São Paulo (CAMARGO e col. 1984).

Esta área endêmica corresponde a $36 \%$ do território nacional, com 3,5 milhões de quilômetros quadrados, que se estende do Maranhão até o Rio Grande do Sul, atingindo mais de 2.450 municípios de 19 estados, envolvendo grande parte das Regiões Nordeste, Sudeste, Centro-Oeste e Sul. Taxas de prevalência são observadas com o predominio na Região Sul, no Estado do Rio Grande do Sul, 8,8\% e Região Sudeste, no Estado de Minas Gerais, com igual valor, 8,8\%; seguido da Região Nordeste, nos Estados de Sergipe, 6\% e Bahia 5,4\%; e os outros Estados com prevalências que variam de $5,4 \%$ a $0,1 \%$ (DIAS 1987; CASTRO FILHO e 
SILVEIRA 1979; PEREIRA 1984; DIAS e JATENE 1992; DIAS 1994; PEREIRA 1995; FRANÇA e ABREU 1996; BRENER e col. 2000).

No inquérito entomológico foram identificadas 30 diferentes espécies de triatomíneos na área estudada. Entre elas, encontram-se aquelas conhecidas como responsáveis pela transmissão da doença de Chagas, como: Triatoma infestans Klug, 1834; Panstrongylus megistus Burmeister, 1835; Triatoma sordida Stal, 1859; Triatoma brasiliensis Neiva, 1911 e Triatoma pseudomaculata Corrêa e Espíndola, 1964 (SILVEIRA e col. 1984).

$\mathrm{O}$ inquérito sorológico estimou uma prevalência média de 4,2\%, correspondendo a cerca de 5 milhões de indivíduos infectados pelo $T$. cruzi e 25 milhões residindo em áreas sob risco, em aproximadamente 3,6 milhões de $\mathrm{km}^{2}$, o que equivale a $44,5 \%$ do território nacional, sendo que as maiores taxas ocorreram nas camadas populacionais menos favorecidas do ponto de vista sociocultural (CAMARGO e col. 1984; DIAS 1987; DIAS e JATENE 1992; FRANÇA e ABREU 1996).

A mais elevada taxa de soropositividade, em 1993, para a doença de Chagas, foi encontrada no Estado de Alagoas com uma prevalência de 5,03\% (MINISTÉRIO DA SAÚDE, 1993b).

Na Região Sul do Brasil, o Estado do Rio Grande do Sul é considerado área endêmica importante da doença de Chagas humana. Em inquéritos sorológicos realizados, a taxa de infecção pelo $T$. cruzi em diferentes municípios da região sul do Estado, apresentou percentuais variando de 17,6\% a 19,6\% (BARUFFA 1979, 1979, $1985,1994)$.

As ações de controle implementadas, baseadas no controle químico do vetor no início dos anos 80 , foram eficazes, reduzindo a extensão da área de dispersão do T. infestans, um dos principais vetores responsáveis pela transmissão vetorial (DIAS e JATENE 1992).

A doença de Chagas é uma enfermidade debilitante e incapacitante. Embora o controle vetorial da doença tenha reduzido drasticamente a transmissão do parasita no Brasil. mais de 11.000 mortes foram registradas nos anos de 1989 e 1990 , representando uma perda de 220.000 anos potenciais de vida antes da aposentadoria. com um custo estimado em de U\$ 650 milhões (DIAS e DIAS 1979; DIAS 
1987; DIAS e JATENE 1992; YASUDA 1998). Considerando-se que, aproximadamente, $10 \%$ dos individuos infectados evoluam para cardiopatia grave ou comprometimento digestivo, o custo do tratamento desses casos atingiria a cifra de US\$ 250 milhões. De forma similar, o absenteismo de 75 mil trabalhadores chagásicos brasileiros com cardiopatia grave representaria uma perda de US\$ 5.625.000 por ano (DIAS 1987; WANDERLEY 1994b).

A assistência ao chagásico é difícil, de alto custo e, freqüentemente, pouco consistente; portanto, devemos lembrar que o peso médico-social da enfermidade é bastante elevado, significando perdas médicas acima de US\$ 80 milhões/ano somente em custos hospitalares (DIAS e JATENE 1992).

Os custos direto e indireto estimados da doença de Chagas, como o tratamento médico, horas de trabalho perdidas e outros, por coorte de 100.000 infectados, pode ultrapassar aos US\$ 50 milhões/ano. O número estimado de anosvida perdidos por incapacitação em 1993 foi de US\$ 2.740.000 na América Latina (DIAS 1979, 1985, 1993; SILVEIRA e SAKAMOTO 1983; WORLD BANK 1993; WHO 1995; YASUDA 1998).

De característica de área rural, a enfermidade chagásica vem se transformando numa doença urbana, em decorrência, principalmente, da crescente migração interna de chagásicos de áreas rurais para as cidades (SILVEIRA 1983; COURA 1984).

O fenômeno é agravado pela existência de doentes crônicos, oligo ou assintomáticos. que podem transmitir a infecção por meio de doações de sangue realizadas anos após terem saido de áreas endêmicas, sendo responsável pela disseminação da endemia nas áreas urbanas, assim como sua manutenção (COURA 1984: MILES 1992).

Foi PELLEGRINO. em 1949, com a realização do primeiro inquérito sorológico entre doadores e candidatos a doadores de sangue em Belo Horizonte, que detectou a presença de anticorpos anti-T. cruzi, com a prevalência de 1,7\% (SALGADO e PEREGRINO 1968; DIAS e BRENER 1984). Em 1952, esta via de transmissão foi também comprovada por FREITAS e col. em pacientes receptores de sangue. de transfusões realizadas no Hospital das Clínicas do Estado de São Paulo. 
A partir dessa época, outros inquéritos utilizando, principalmente, a reação de Fixação de Complemento, foram realizados em Bancos de Sangue de, praticamente, toda a América Latina. Para estes, os percentuais de positividade mostraram grandes variações devidas, principalmente, á endemicidade da região, do tipo de doadores, se selecionados ou não e do método diagnóstico empregado (BECK e col. 1993). Estes percentuais, segundo levantamentos realizados situaram-se, em sua maioria, entre 2,9 e 16,9\% (SAGUA e col. 1982; PLATERO e col. 1983; WEINBORN e col. 1983; LORCA e col. 1988).

No Brasil, os percentuais variaram de 0,2 a 25,8\% (DIAS 1949; TOLEZANO e col. 1980). Amplo inquérito sorológico nacional foi realizado em 1.525 serviços de hemoterapia no Brasil, em 1988/89, onde apresentou uma taxa média de infecção de $14 \%$. Mostrou também que apenas $35 \%$ dos serviços utilizavam corretamente duas ou mais técnicas sorológicas para a triagem de doadores (YASUDA 1998).

No periodo de 1989/90, foi realizado outro grande Inquérito Nacional de Prevalência da Infeção chagásica em doadores de sangue, coordenado pela Divisão de Doença de Chagas, da Superintendência de Campanhas de Saúde Pública do Ministério da Saúde, hoje Fundação Nacional da Saúde, e pela Faculdade de Medicina do Triângulo Mineiro. O objetivo deste levantamento foi obter uma "radiografia" da situação da doença de Chagas em Bancos de Sangue, uma vez que a via transfusional vinha sendo considerada a principal forma de transmissão da endemia no Brasil. O critério de seleção dos municípios foi populacional. Dados preliminares obtidos em 850 municípios apontaram prevalência média de $0,97 \%$ de infecção chagásica entre 628.485 doadores, com variação entre os Estados (MORAES-SOUZA 1994; MORAES-SOUZA e col. 1994).

Semelhante avaliação, foi realizada no ano de 1993, junto aos serviços oficiais pertencentes à rede nacional de Hemocentros, que apresentou um percentual de positividade para doença de Chagas de 0,7\% em 1.099.601 testes realizados por diferentes técnicas. As taxas nas diferentes macrorregiões foram: Norte, com $0,2 \%$; Nordeste e Sudeste, com 0,5\%; Sul, com 1,4\%; e Centro-Oeste, com 2,8\% (SLLA e col. 1988; MINISTÉRIO DA SAÚDE 1993a).

No rastreamento sorológico para doenças infecciosas realizado em bancos de sangue na cidade de Goiás, observou-se a soroprevalência de 3,3\% para doença de 
Chagas (ANDRADE e col. 1989). A prevalência da infecção chagásica em candidatos a doadores de sangue, do banco de sangue da Santa Casa da Misericórdia de Pelotas, Rio Grande do Sul, chegou a 3,91\% (BARUFFA 1979). Estes indices devem-se, principalmente, a diferenças entre o número de hemotransfusões recebidas, a prevalência na área estudada e o tempo de armazenamento do sangue a baixas temperaturas, o que faz com que o agente infectante $T$. cruzi perca sua viabilidade depois de 3 semanas no refrigerador (CORRÊA e MIRANDA FILHO 1995; SIQUEIRA-BATISTA e col. 1996).

O quadro de transmissão transfusional da doença de Chagas revela-se preocupante quando se considera que no Brasil existem cerca de 6 milhões de indivíduos chagásicos (WHO 1990). Embora a via transfusional tenha sido apontada como importante mecanismo de transmissão da doença e se conheça o potencial de indivíduos chagásicos no Brasil desde fins da década 70, apenas no final dos anos 80 , com o surgimento da Síndrome da Imunodeficiência Adquirida - SIDA, é que foram tomadas iniciativas legais para o controle do uso de sangue e seus derivados (SILVEIRA e SAKAMOTO 1983).

O Estado de Santa Catarina, por ser considerado indene para enfermidade, inexiste o seu controle; contudo, abriga migrantes de áreas endêmicas de vários Estados, o que leva a riscos da transmissão transfusional da doença, conforme foi constatado quando em estudos relativos à naturalidade dos doadores de sangue na distribuição dos casos soropositivos e indeterminados para infecção por T. cruzi, dos hemocentros da Região da Grande Florianópolis e Joaçaba (Estudos preliminares).

Tem como características, uma área de $95.442,9 \mathrm{~km}^{2}$, que corresponde a $1,12 \%$ do território brasileiro, e a $16,57 \%$ da área da Região Sul do Brasil. limitandose ao norte com o Estado do Paraná, ao sul com o Rio Grande do Sul, a oeste com a República da Argentina e a leste com o Oceano Atlântico.

Situa-se entre os paralelos $25^{\circ} 57^{\prime} 41^{\prime \prime}$ e $29^{\circ} 23^{\prime} 55^{\prime \prime}$ de latitude sul e entre os meridianos $48^{\circ} 19^{\prime} 37^{\prime \prime}$ e $53^{\circ} 50^{\prime} 00^{\prime \prime}$ de longitude oeste. A hora legal no Estado corresponde a $-3 \mathrm{~h}$ em relação ao fuso horário de Greenwich.

Possui uma posição privilegiada como centro geográfico da região de maior capacidade de consumo e mais alta renda, tanto do continente quanto do País. Num 
raio de $1500 \mathrm{~km}$ a partir de Florianópolis, estão situadas as capitais do Brasil, da Argentina, Paraguai e Uruguai, além de importantes cidades como São Paulo, Rio de Janeiro, Belo Horizonte, Curitiba e Porto Alegre.

O Estado de Santa Catarina, que tem como capital Florianópolis, é constituído por 293 municípios, com uma população residente estimada, em 1998, de 5.028.339 habitantes, o que equivale a $3 \%$ da população brasileira, sendo que $73,11 \%$ vivem na área urbana (FUNDAÇÃO IBGE 1999; SECRETARIA DE ESTADO DE DESENVOLVIMENTO ECONÔMICO E INTEGRAÇÃO AO MERCOSUL 1999).

Administrativamente, os municipios foram agrupados pela Secretaria de Estado da Saúde, formando 18 (dezoito) Regionais de Saúde, o que corresponde às Associações de Municípios do Estado de Santa Catarina (Figura 1, Anexo I).

O clima no Estado decorre da atuação das massas de ar intertropicais e polares, o que lhe confere caráter mesotérmico, isto é, predominantemente subtropical temperado super-úmido. A temperatura média anual oscila entre $13^{\circ} \mathrm{C}$ e $25{ }^{\circ} \mathrm{C}$. No planalto, em função da altitude, os invernos são rigorosos, com temperaturas, eventualmente, inferiores a $0{ }^{\circ} \mathrm{C}$ e ocorrências ocasionais de precipitações de neve.

Possui a maior produção alimentícia do Brasil. O setor integra a lavoura, agropecuária com a criação principalmente de suínos e aves, além da indústria. Exporta $90 \%$ dos suínos e $60 \%$ dos frangos produzidos no Brasil (SECRETARIA DE ESTADO DO DESENVOLVIMENTO ECONÔMICO E INTEGRAÇÃO AO MERCOSUL 1999).

Neste, foi estudada a população de doadores, que efetuaram doações junto às Unidades Hemoterápicas localizadas na $18^{\mathrm{a}}$ Regional de Saúde ou Região da Grande Florianópolis, litoral, parte leste geográfica; e $8^{a}$ Regional de Saúde, Região de Joaçaba, situada no planalto catarinense, no periodo de 1990 a 1999, o que corresponde a cerca de $40 \%$ de cobertura, em termos de atendimento hemoterápico no Estado de Santa Catarina.

Dentro desse contexto e na perspectiva de contribuir para o esclarecimento da presença e riscos de transmissão da doença de Chagas no Estado de Santa Catarina, que este trabalho se insere. 


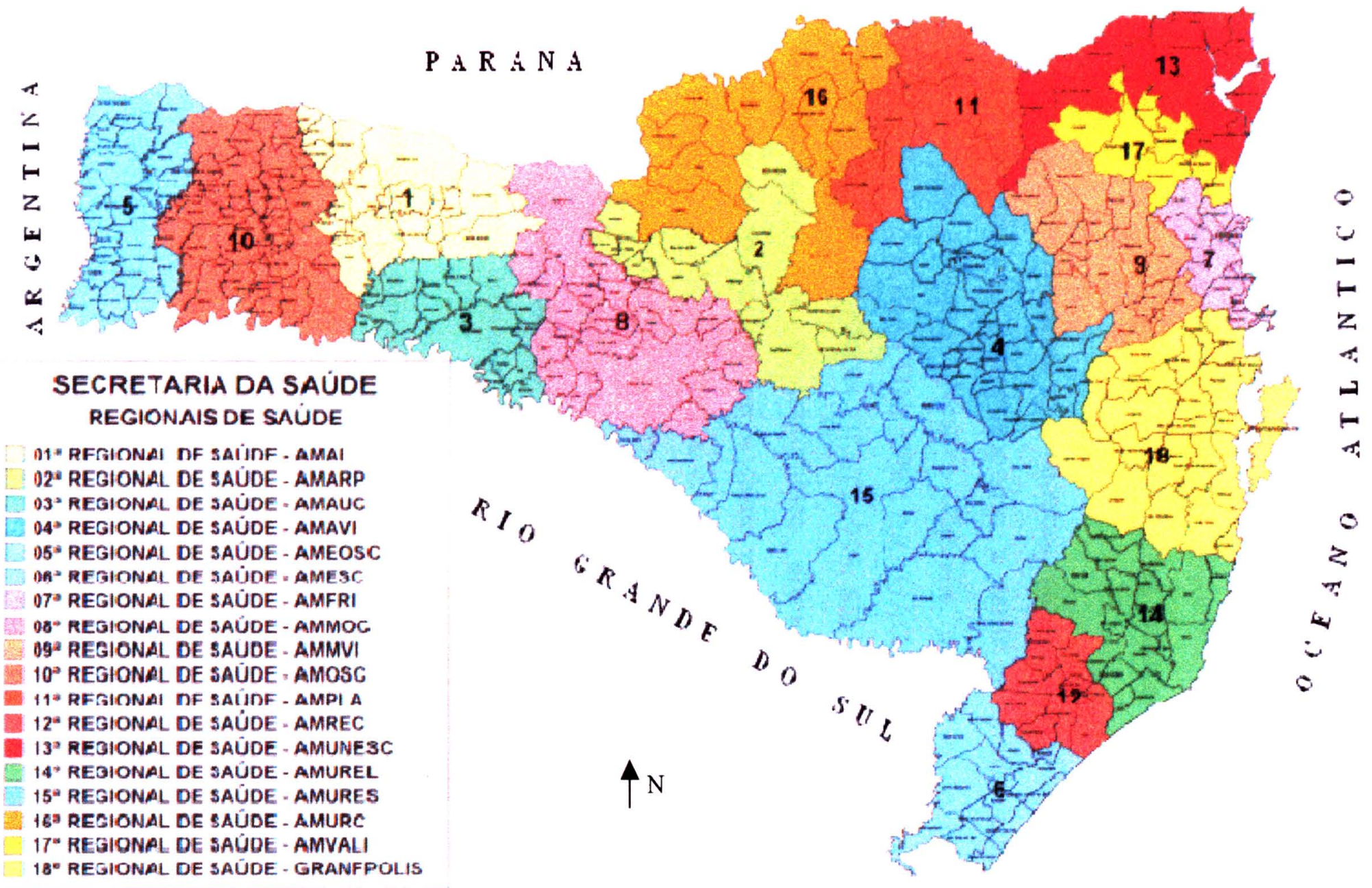

Figura 1 - Mapa do Estado de Santa Catarina com as divisões Regionais de Saúde.

Fonte: Secretaria de Estado do Desenvolvimento Econômico e Integração ao Mercosul. 


\subsection{História natural da doença de Chagas}

A doença de Chagas é uma antropozoonose causada pelo protozoário hemoflagelado, o Trypanosoma cruzi.

Sua transmissão natural se faz pela contaminação da pele ou mucosas, pelas fezes dos vetores insetos hematófagos da família Triatominae (Hemiptera: Reduviidae), conhecidos genericamente por triatomíneos. Um inseto deste grupo é denominado vulgarmente "barbeiro", com formas infectantes de T. cruzi. (AMATO NETO 1988).

A doença primitivamente uma zoonose, passou a se constituir em problema de patologia humana, uma antropozoonose, a partir da domiciliação dos vetores deslocados de seus ecótopos silvestres originais, pela ação do homem sobre o ambiente (DIAS 1947; FORATTINI 1980; ARAGÃO 1983a, 1983b; TOLEZANO e col. 1992; CORREAA e MIRANDA FILHO 1995; SILVEIRA e VINHAES 1998).

No momento que o triatomíneo abandonou o ambiente silvestre, domiciliando-se, o homem passou a fazer parte da sua cadeia epidemiológica (FORATTINI 1980; ARAGÃO 1983a).

Com o êxodo rural, o parasita acompanhou o homem para as cidades, passando a ser transmitido por mecanismos secundários como a transfusão sanguínea ou transplante de órgãos, deixando de ser uma infecção exclusivamente rural para tornar-se uma infecção urbana (WENDEL 1993; CORRÊA e MIRANDA FILHO 1995).

A distribuição espacial da doença descrita por Carlos Chagas, depende da distribuição dos vetores que, por sua vez, está relacionada com a distribuição da pobreza e das condições por ela proporcionada, que determina o convívio do homem com o vetor no ambiente domiciliar. Então, afora os determinantes de natureza biológica ou ecológica, existem aqueles de natureza econômica e social que facilitam a transmissão da doença de Chagas.

Além da veiculação vetorial, o $T$. cruzi pode ser transmitido pela via transfusional, e outras vias de transmissão. Dentre várias possibilidades de veiculação da doença, assume especial importância epidemiológica a transmissão por transfusão de sangue. que pode levar a enfermidade para áreas sem a transmissão 
natural, inclusive para grandes centros populacionais; e a transmissão congênita, que pode representar risco duradouro com a produção de novos casos e a manutenção da endemia chagásica (AMATO NETO 1988; SILVEIRA e VINHÃES 1998).

A interação do parasito e hospedeiro é bastante dinâmica, resultado de múltiplos fatores ligados ao T. cruzi, como a virulência, tamanho do inócuo, via de infecção e fatores ligados ao hospedeiro humano e meio ambiente.

Desta forma, a infecção atinge indiscriminadamente os diferentes grupos sociais expostos ao $T$. cruzi, como também indistintamente o sexo, procedência ou ocupação. Todavia, o impacto médico-social é maior no sexo masculino, que apresenta maior freqüência de quadros cardio-digestivos crônicos e graves, levando à incapacidade, aposentadoria precoce e morte (SILVEIRA e VINHÃES 1998).

É uma doença infecciosa, de curso clínico crônico, que se caracteriza por uma fase inicial aguda, com sinais ou sintomas quase sempre inespecíficos, quando presentes, e que pode evoluir, em cerca de 10 a $20 \%$ dos casos não tratados, para a fase crônica, com comprometimento cardiaco (cardiopatia chagásica) ou problemas digestivos severos (megaesôfago e megacolon) (DIAS 1970; OMS 1991; SILVEIRA e VINHAES 1998).

Após uma ou duas semanas de incubação a doença se apresenta caracterizada por febre, erupção, adenopatias e hepatoesplenomegalias. A fase aguda perdura de 1 a 2 meses, que pode passar despercebida. Torna-se mais grave em crianças de pouca idade e individuos imunodeprimidos, ocasionando uma letalidade que oscila em torno de 2 a $7 \%$ devido, principalmente, a meningoencefalite e a falência cardiaca, ocasionada por miocardite aguda (PESSOA 1982; RASSI e col. 1992; SIQUEIRABATISTA 1995).

Aos poucos a febre desaparece com os demais sintomas, iniciando-se a fase crônica assintomática, também chamada de indeterminada, com lenta evolução e baixa parasitemia, porém, com elevada quantidade de anticorpos anti-T.cruzi, eletrocardiograma normal, coração, esôfago e cólon radiologicamente normais.

Considerando que a picada do triatomíneo é indolor e os sintomas da fase aguda são transitórios e passam despercebidos, os indivíduos na forma indeterminada da doença, desconhecem que são portadores assintomáticos da infecção pelo T.cruzi, 
constituindo-se em reservatórios domésticos do parasito e, conseqüentemente, tornam-se potenciais transmissores (DIAS 1989).

A fase crônica sintomática é aquela, do ponto de vista epidemiológico, que causa os maiores impactos médico-sociais da enfermidade. Os chagásicos apresentam alterações viscerais com comprometimento cardíaco, em aproximadamente, 20 a $40 \%$ dos enfermos. É responsável por grandes problemas individuais e sociais, como a perda de produtividade, absenteísmo, impedimento ao trabalho, custos médicos-previdenciários elevados, etc. A cardiopatia chagásica é a principal causa de morte entre os chagásicos com mais de 30 anos, principalmente, em indivíduos do sexo masculino (SIQUEIRA-BATISTA e col.1996 e BRENER e col. 2000). Outras são as formas digestivas da doença, com alterações que comprometem o tubo digestivo e intestino grosso, especialmente a esofagopatia e a colopatia, causadoras de desconforto, ou ocasionar óbitos, além de, freqüentemente, incorrer a complicadas cirurgias. A pior evolução se dá para os graus mais graves do megacólon, que pode levar a óbito se não houver pronta intervenção. De maneira geral, 8 a 15\% dos pacientes chagásicos apresentam alterações de esôfago ou colon (BRENER e col. 2000).

O tratamento da doença de Chagas é parcialmente eficaz e encontra-se ainda em fase experimental, após exaustivos estudos sobre fármacos capazes de atuar de forma a estabelecer um balanço entre eficácia, tolerância e toxicidade aceitável. Muitos foram os quimioterápicos testados desde o descobrimento da enfermidade, porém, dois estão sendo utilizados: o benzonidazol e o nifurtimox.

O benzonidazol (N-benzil-2-nitro-1-imidazo-lacitamida), produzido pela Hoffman-La Roche sob a denominação de Rochagan, introduzido na Argentina e no Brasil, em 1978. Tem sido empregado no tratamento específico de pacientes chagásicos, na fase aguda, promovendo curas de 50 a $70 \%$ dos casos. No tratamento de pacientes chagásicos crônicos, os resultados são significamente inferiores. Possui efeito apenas contra formas sanguíneas do $T$. cruzi e apresenta como efeitos colaterais a anorexia, perda de peso, vertigens, dermatites urticariformes, cefaléia, sonolência e dores abdominais.

O nifurtimox \{1,1-dióxido da tetraidro-3-metil-4[(5-nitrofurfurilideno) amino]-2H-1,4-tiazina\}, um nitrofurano lançado pela Bayer, em 1972, sob 
denominação de lampit. Com este medicamento, foram tratados 500 casos agudos da doença de Chagas na Argentina, constatando-se após 24 meses, 81\% de cura dos pacientes.

Em estudos realizados, foi observado um percentual de cura em cerca de $47 \%$ dos casos tratados. São relatados como efeitos adversos, distúrbios neurológicos, parasitemia, mialgia, astenia, perda de peso, distúrbios gastrintestinais, diarréia, náuseas, dentre outros. Esta droga não vem sendo mais produzida desde o começo dos anos 90, sendo, portanto, retirada do mercado (DIAS 1990; SIQUEIRABATISTA e col. 1995; BRENER e col. 2000).

O tratamento da doença de Chagas é indicado nos casos agudos, independente da forma de transmissão, nas reagudizações de pacientes em imunossupressão, em crianças e nos transplantes de órgãos (DIAS 1990; BRENER e col. 2000).

$\mathrm{Na}$ fase crônica indeterminada, a indicação terapêutica deve ser avaliada conforme o caso. Para casos crônicos de baixa idade, crianças com sorologia positiva ou infecção recente, o tratamento específico tem sido indicado. A conduta básica nesta fase é de observação periódica dos pacientes, conscientizando-os para a não doação de sangue, como prevenção da transmissão transfusional do $T$. cruzi.

Outros recursos terapêuticos têm sido utilizados, como a cirurgia, no caso de megaesôfago e megacólon e a medicação sintomática. (DIAS 1994; BRENER e col. 2000).

\subsection{Mecanismos de transmissão}

O mecanismo de transmissão da doença de Chagas se dá, primariamente, pela via vetorial, pelo contato com dejeções de triatomíneos infectados.

Entretanto, além da via vetorial, segundo AMATO NETO (1988), por mecanismos secundários de transmissão o parasita, pode ser transmitido por transfusão sangüinea, congenitamente, aleitamento, via oral pela ingestão de alimentos contaminados, transplante de órgãos, contato sexual e a transmissão acidental, ocasionada pela manipulação de caças e acidentes de laboratório. Considerando que todo individuo soropositivo pode transmitir a doença, tem especial 
importância epidemiológica além da transmissão vetorial, aquela ocasionada por transfusão de sangue, que pode levar a enfermidade para áreas indenes, sem transmissão natural, inclusive para grandes centros urbanos populacionais (TANOWITZ e col. 1993).

\subsubsection{Transmissão vetorial}

A transmissão vetorial, se faz através da contaminação da pele ou mucosas, pelas fezes dos vetores insetos hematófagos da família Triatominae (Hemiptera: Reduviidae), genericamente, conhecidos por triatomíneos e vulgarmente, por barbeiro, chupão, fincão, bicho de parede, bicudo, furão, pito, procotó, com formas infectantes de T. cruzi (AMATO NETO 1988). É importante que sejam consideradas a espécie, a antropofilia, a densidade por domicilio e a contaminação do triatomíneo envolvido. Pode ocorrer mediante uma das principais espécies vetoras domiciliárias, como: Triatoma infestans, T. brasiliensis, T. dimidiata, T. sordida, Panstrongylus megistus, Rhodnius prolixus e $R$ pallescens, entre outras.

Esta foi, por várias décadas, a principal via de transmissão da doença, devido, principalmente a precariedade das habitações rurais, que possibilitavam a domiciliação dos vetores e a posterior infecção do homem (OMS 1991; CORRÊA e MIRANDA FILHO 1995)

Além do agente etiológico, dos vetores, do hospedeiro e reservatório humano, os reservatórios domésticos (cão, gato, roedores e outros), os reservatórios silvestres (marsupiais, edentados, roedores, morcegos e carnivoros de pequeno porte) são importantes na cadeia de transmissão. As aves e os animais de sangue frio são refratários à infecção por $T$. cruzi. Sendo a transmissão vetorial o mecanismo primário de difusão da doença, dela dependem as outras formas de transmissão.

A transmissão vetorial no interior do Brasil foi reduzida drasticamente, graças aos trabalhos desenvolvidos com a participação comunitária, pela Superintendência de Campanha de Saúde Pública - SUCAM, em âmbito federal e pela e Superintendência de Controle de Endemias - SUCEN, no âmbito do Estado de São 
Paulo (DIAS e GARCIA 1978; DIAS JCP e DIAS RB 1985; WANDERLEY 1994a; SIQUEIRA-BATISTA e col. 1996).

\subsubsection{Transmissão transfusional}

Entre os mecanismos de transmissão da infecção pelo $T$. cruzi, a transfusão de sangue é proeminente e, inclusive, está adquirindo importância ainda maior, por tornar-se preocupação até em países não endêmicos (SCHMUÑIS 1991,1994; SAÉZ-ALQUEZAR 1998). Constitui a segunda forma de transmissão da doença de Chagas, que transcende as áreas endêmicas de transmissão vetorial (MARTIN 1991; PINTO e col. 1993).

A possibilidade de transmissão da infecção pelo $T$. cruzi por transfusão de sangue foi admitida pela primeira vez, na Argentina, por MAZZA e col. em 1936 (BARUFFA 1979; DIAS e BRENER 1984; BARUFFA 1985; ROMERO 1992).

Com o controle da via vetorial de transmissão nos paises latino americanos, passou a se constituir no principal mecanismo de perpetuação desta endemia (RAMIREZ 1992; SILVEIRA 1992; BELLOTTI e BOCH 1994).

Desde 1952, com a publicação dos primeiros casos humanos da infecção póstransfusional por $T$. cruzi, a importância desse mecanismo de transmissão encontrase cabalmente demonstrada. A doença de Chagas originada por transfusão de sangue procedente de um doador parasitado é uma contingência clínica repetidamente observada (AMATO NETO 1968, 1988; BALDY e col. 1978; BERGOGLIO 1984; CAMPOS e col. 1988; SALLES e col. 1996; GOLDEMBERG 1998).

A transmissão sangüinea vem adquirindo elevada relevância na epidemiologia da doença de Chagas, sendo a principal via de transmissão na zona urbana, onde habitam $70 \%$ da população das Américas (MORAES-SOUZA e col. 1985; SOUZA e col 1985; AMATO NETO 1988; WANDERLEY e col. 1988; MARTIN 1991; WENDEL e col. 1992; CORRÊA e MIRANDA FILHO 1995; SIQUEIRA-BATISTA e col. 1996).

A partir dos primeiros casos comprovados de transmissão transfusional, inúmeros inquéritos sorológicos foram realizados no Brasil e em outros países da 
América Latina, onde mostraram índices de infecção em doadores e candidatos a doadores de sangue, variando entre 0 a 63\% (OMS 1991; TOLEZANO e col. 1992; CONTRERA e col. 1993).

Pesquisas realizadas com doadores de sangue no ano de 1993, em 10 paises da América do Sul e Central, buscando-se uma referência quanto a possibilidade de recepção de sangue de doadores infectados em cada país, observou-se a prevalência que variou de $1.096 / 10.000$ transfusões na Bolívia, 13,02 / 10.000 em Honduras, 13,86 na Venezuela, onde a triagem de cobertura foi de $100 \%$. Mensurando-se a probabilidade de transmissão do T. cruzi, foi de 219 / 10.000 na Bolívia, 24 / 10.000 na Colômbia, 17 em El Salvador e de 2 a 12 / 10.000 em outros países (CARRASCO e col. 1990; SCHMUÑIS 1999b).

Estudos realizados na Colômbia, demonstraram ser a transfusão sangüinea um mecanismo artificial importante na transmissão da enfermidade de Chagas, e constitui um sério problema de saúde pública (GUHL e col. 1987).

Como forma de controlar a transmissão transfusional da enfermidade chagásica, Honduras e outros países da América Central estão desenvolvendo bons programas, mediante triagem sorológica respaldada em leis normativas. (PONCE 1999).

Desde 1998, que todos os países latinos americanos, com exceção de El Salvador e Nicarágua, criaram legislação específica que regem a produção e uso do sangue, para selecionar doadores que tenham doenças infecciosas, incluindo a doença de Chagas. Com a migração da população rural para área urbana, atualmente aumentou a possibilidade de infecção por $T$. cruzi em receptores de sangue. Outras regiões com áreas indenes como Estados Unidos, Canadá, nos países da Europa Ocidental, Austrália ou Japão, a situação é agravada pela não realização de sorologia para $T$. cruzi, com a devida sensibilidade e especificidade, que assegure qualidade à unidade transfundida (OMS 1991; WENDEL 1993; WENDEL e GONZAGA 1993; SCHUMINTIS 1991, 1994, 1999b).

Em estudos realizados em Santiago, RUIZ e col. (1984) detectaram um percentual médio de $2,8 \%$ soropositividade em doadores de sangue. Em outra região do pais, GUAJARDO e col., (1984) encontraram uma prevalência de 29,2\% soropositivos. 
A transmissão da doença de Chagas por transfusão de sangue vem assumindo importância crescente no Brasil, sendo responsável pela disseminação da endemia nas áreas urbanas, e constituindo fator expressivo para sua manutenção. $\mathrm{O}$ número de doadores sorologicamente positivos corresponde a cerca de 55.000 por ano, e chegase admitir que de 1.500 a 3.000 pessoas adquirem a infecção por $T$. cruzi, como decorrência de transfusões de sangue. (TOLEZANO e col. 1980, 1992; AMATO NETO 1993).

Em Belo Horizonte, em 1980, 20\% dos casos comprovadamente diagnosticados de doença de Chagas foram contraidos através de transfusão sangüínea (MORAES-SOUZA 1985; STEFFENS 1994).

Cerca de 1 milhão de transfusões são realizadas anualmente no Brasil. A doença com característica de área rural vem se transformando numa doença urbana, em decorrência, principalmente, da intensa e crescente migração interna de chagásicos de áreas rurais para as cidades, à procura de melhores condições de vida. Este fenômeno é agravado pela existência de doentes crônicos, principalmente os assintomáticos, que podem transmitir a infecção por meio de doação de sangue realizada anos após terem saído de zonas endêmicas (BROFEN e CHIARI 1988; DIAS e SCHOFIELD 1998).

Em áreas altamente endêmicas, a soropositividade de doadores ultrapassa 20\%. Em 1945, DIAS já havia formalmente chamado a atenção sobre a possibilidade de transmissão da enfermidade pela transfusão de sangue no Brasil, podendo transformar-se em problema de saúde pública (FREITAS e col., 1952; BARUFFA 1979; BARUFFA, 1985).

Determinados profissionais, julgam provável que a todos os anos, muitos individuos passem a sofrer de doença de Chagas no Brasil, como consequeencia da transfusão sangüinea (AMATO NETO 1988; OMS 1991; ROMERO e col. 1992; CORRÊA E MIRANDA FILHO 1995; SIQUEIRA-BATISTA e col. 1996).

Nas grandes cidades como São Paulo, Rio de Janeiro, Buenos Aires, Caracas e Santiago, a soropositividade em bancos de sangue oscila entre $0,5 \%$ a $2,0 \%$ (SIQUEIRA-BATISTA e col. 1996; DIAS e SCHOFIELD 1998). 
A ocorrência de infecção chagásica transmitida pela via transfusional depende, obviamente, da prevalência da parasitose nos candidatos à doação, do volume e do número de transfusões recebidas (TOLEZANO e col. 1992).

Portanto, a prevalência da doença de Chagas em bancos de sangue é notória, conforme observado também em outros levantamentos, como os efetuados por SOUZA e col. (1985), onde constataram percentuais que variam de $6,9 \%$ a $16,6 \%$ em doadores no triângulo mineiro. TAKAOKA e col. (1979/1980), considerando os testes empregados encontrou valores em torno de $7,4 \%$ em doadores do Banco de Sangue do Hospital Universitário de Londrina, Paraná. Outro inquérito sorológico realizado entre doadores, detectou também a presença da enfermidade no Distrito Federal (LIMA e col. 1981).

Utilizando dados obtidos do controle de qualidade do Ministério da Saúde, em 1998, SÁEZ-ALQUEZAR e col., verificaram que a taxa de erro dos testes sorológicos nos bancos de sangue oscilou em torno de $3,7 \%$, quando se utilizou apenas um exame, a técnica de hemaglutinação passiva, o que, em geral, utilizavam mais do que um teste na triagem sorológica (CHIEFFI e AMATO NETO 2000).

A transmissão do T. cruzi pela transfusão de sangue proveniente de doadores contaminados representa um risco de 12 a $20 \%$ para o receptor suscetível que receba $500 \mathrm{ml}$ de sangue. Além disso, o risco depende também de outros fatores como a cepa do parasita, o estado imunológico do receptor, o número de hemotransfusões, a presença de parasitemia no momento da doação e o tempo de armazenamento do sangue a baixas temperaturas, pois o parasito sobrevive até 3 semanas no refrigerador (CERISOLA e col. 1972; SIQUEIRA-BATISTA e col. 1996).

A infecção pós-transfusional pelo $T$. cruzi ainda é comum no Brasil e em outros países da América Latina, representando expressivo problema no âmbito da saúde pública (PINOTTI e col. 1982; AMATO NETO 1993; DIAS e SCHOFIELD 1998).

A segurança da transfusão sangüínea depende, tanto da existência no país, de leis, decretos ou regulamentos que normatizam a obtenção, produção e uso do sangue e seus derivados, quanto da decisão governamental de fazer cumpri-las, como da capacitação de profissionais de saúde para obter sangue e hemoderivados com a garantia de qualidade máxima. A partir da década de 1980, sabendo-se da possível 
transmissão sangüínea do vírus HIV, aumentou a preocupação pelas enfermidades transmitidas pelo sangue. (ROSENFELD 1989; WANDERLEY e col. 1992; GONÇALVES JUNIOR e col. 1993; GONÇALVES JUNIOR 1998).

Segundo alguns autores (TOLEZANO e col. 1980; WANDERLEY e col. 1988), o número de registros de casos de transmissão por transfusão deve estar subdimensionado, e isso acontece em razão da falta de interesse na questão; desinteresse intencional em informar acidentes transfusionais; dificuldades na associação entre o quadro agudo e uma transfusão ocorrida anteriormente; ocorrência provável de grande número de casos de transmissão assintomática e oligossintomática; dificuldades técnicas de diagnóstico e, finalmente, desestímulo a publicações científicas, notificando uma ocorrência que deixou de constituir raridade.

\subsubsection{Outros mecanismos de transmissão}

\section{- Congênita}

Esta via de transmissão transplacentária foi aventada por Carlos Chagas, já em 1911. O T.cruzi pode ser transmitido de uma mãe infectada para o feto, entre o $5^{\circ}$ e o $9^{\circ}$ mês de gestação, podendo causar prematuridade, retardo de crescimento intrauterino e morte. Ocorre tanto nas zonas rurais, quanto em áreas urbanas (ANDRADE e MARTELLI 1994; CORRÊA e MIRANDA FILHO 1995)

Trata-se de um mecanismo de perpetuação da doença, que vem crescendo de importância nas últimas décadas nas regiões endêmicas e urbanas, onde se concentram grande número de imigrantes com a doença de Chagas (CHIEFFI e AMATO NETO 2000).

Já foram notificados casos de transmissão congênita na Argentina, Bolivia, Brasil, Chile e Uruguai (TELLO e col. 1982; PLATERO e col. 1983; OMS 1991; ROMERO 1992).

Estudos realizados na Argentina, apresentaram uma prevalência de infecção congênita, variando de 0,75\% e 3,5\% entre crianças de mães portadoras (BIOCCA e SEQUTRA 1985; BITTENCOURT 1987). 
Na Bolívia, a prevalência deste tipo de transmissão oscilou de $5 \%$ a $8 \%$. No Chile observou-se uma prevalência de $18,8 \%$, quando as mães eram soropositivas. No Uruguai, a soropositividade oscilou entre 0,1 e 1,6\% (AMATO NETO 1988; SIQUEIRA-BATISTA e col. 1996)

$\mathrm{O}$ risco de transmissão congênita foi estimado em 0,5 a $10 \%$ no Brasil (BITTENCOURT, 1987; SCHMUÑIS e col. 1994; CORRÊA, 1995; YASUDA, 1998 e BASOMBRIO e col. 1999).

A transmissão congênita da doença de Chagas constitui sério problema de saúde pública em áreas endêmicas e não endêmicas, devido a freqüente migração das populações, principalmente em áreas com transmissão vetorial controlada ou livre da doença. Pode representar o risco mais duradouro de produção de novos casos e de manutenção da endemia chagásica (BLANCO 1999; BRENER e col. 2000; CARVALHO e col. 2000).

\section{- Via oral}

A transmissão do $T$. cruzi ocorre, habitualmente, pela participação do triatomíneo, porém, outros mecanismos de veiculação, como a via oral, estão atualmente documentados (AMATO NETO 1988; ROMERO 1992).

Esta é também considerada como mecanismo primário de transmissão e ocorre por ingestão de alimentos contaminados pelo parasito. Vários casos de transmissão oral foram relatados. Segundo MAZZA, em 1940, e BRAVERMAN, em 1962, relataram a infecção chagásica pela ingestão de carne crua de animais silvestres (CHIEFFI e AMATO NETO 2000).

Em 1965, no município de Estrela, Rio Grande do Sul, ocorreu um surto epidêmico da doença de Chagas, com 17 pessoas apresentando sintomas da enfermidade, tendo sido cogitada a possibilidade de contaminação oral por ingestão de carne de porco (SILVA e col. 1968).

No Estado do Pará, DIAS, em 1979, relatou casos de pessoas que se infectaram ao ingerir alimentos contaminados com fezes de triatomineos (DIAS, 1979). Uma microepidemia familiar, em 1999, com 11 casos da doença também foi 
obervada no município de Abaetetuba, neste Estado, com suspeita de transmissão oral pela ingestão de suco de açai (VALENTE e col. 1999; PINTO e col. 1999 e 2001). Outro episódio de doença de Chagas aguda, envolvendo 7 pessoas, foi relatado por VALENTE e col. (2000), no município de Bagre, nordeste do Estado do Pará, com a mesma suspeita de transmissão.

Caso com indicios de contaminação digestiva foi relatado no Estado do Acre (BARATA e col. 1988).

Em estudo realizado na Paraiba, 14 individuos que participaram de uma festa numa fazenda, foram submetidos a xenodiagnóstico e testes sorológicos. Destes, nove apresentaram resultados positivos; anticorpos IgG foram encontrados em todos os pacientes. No local onde estas pessoas pernoitaram, não foi encontrado nenhum vetor. Porém, observaram-se altas taxas de gambás infectados por $T$. cruzi. As observações relativas aos alimentos consumidos sugerem que a contaminação dos alimentos tenha ocorrido por intermédio de excrementos de gambás infectados ou a partir de triatomineos infectados, que podem ter sido esmagados durante o preparo do caldo de cana (YASUDA 1998).

Existe, portanto, um perigo potencial deste tipo de transmissão, por meio da ingestão de carnes de animais ou de alimentos contaminados por fezes de triatomineos infectados (CORRÊA e MIRANDA FILHO 1995; SIQUEIRABATISTA e col.1996; SHIKANAI-YASUDA e col. 1999; VALENTE e col. 1999; PINTO e col. 1999 e 2001).

\section{- Leite materno}

A possibilidade deste tipo de infecção ocorrer é muito baixa, sendo contestada por vários pesquisadores. Não existem evidências de que haja transmissão da doença de Chagas pelo leite, na fase crônica da doença (BITTENCOURT 1987; CORRÊA e MIRANDA FILHO 1995).

Contudo, em 1936, em Salta, Argentina, MAZZA e col. relataram a presença de formas tripomastigotas do $T$. cruzi no leite de uma mãe que sofria de moléstia de 
Chagas aguda (CORREA e MIRANDA FILHO 1995; SIQUEIRA-BATISTA e col. 1996; CHIEFFI e AMATO NETO 2000).

Em estudo realizado na Bahia com amostras do leite, o colostro de 78 chagásicas crônicas apresentou resultado negativo. Destas, cinco mães possuiam a parasitemia detectável, quando o leite foi coletado (CORRÊA e MIRANDA FILHO 1995; ROMERO e col. 1992).

Não existem, portanto, razões para restringir a amamentação de filhos de mulheres infectadas, pois o risco de óbito por desnutrição seria muito maior do que aquele de contrair a doença, uma vez que a maior incidência é encontrada em regiões carentes. $\mathrm{O}$ risco de transmissão em crianças amamentando parece ocorrer quando há sangramento mamilar, de mães chagásicas (SIQUEIRA-BATISTA e col. 1996; BITTENCOURT 1987; OMS 1991; YASUDA 1998).

\section{- Por transplante de órgãos}

A transmissão por transplante de órgãos é pouco comum, tendo em vista, principalmente, a pouca freqüência com que são realizados estes procedimentos.

Porém, casos de transplante de órgãos, como coração, figado, medula óssea ou rim de pacientes chagásicos já foram documentados.

Pacientes que recebem órgãos de doentes com moléstia de Chagas crônica podem apresentar a doença aguda. Já se registraram alguns casos fatais em pacientes submetidos a terapias imunossupressivas, pois esta aumenta enormemente a sua susceptibilidade a infecção (AMATO NETO 1988; OMS 1991; SIQUEIRABATISTA e col. 1996; YASUDA 1998; CHIEFFI e AMATO NETO 2000).

\section{- Transmissão sexual}

Esta via de infecção foi inicialmente descrita por NATTAN LARRIER, em 1921. Posteriormente, alguns investigadores relataram a presença do $T$. cruzi no sangue menstrual de pacientes chagásicas crônicas. 
Atualmente, admite-se a existência da transmissão sexual da doença de Chagas, ainda que sua importância epidemiológica não seja conhecida (SIQUEIRABATISTA e col. 1996).

\section{- Por acidentes}

Esta via de infecção é também pouco freqüente, porém, o risco, principalmente, para as pessoas que trabalham em laboratórios de análises clínicas e em laboratório de pesquisas, é evidente (OMS 1991; YASUDA 1998).

Casos foram documentados na França, Argentina e Brasil. Geralmente, a infecção ocorre por acidentes com agulhas contaminadas, biotérios mal equipados e iluminados, aspiração por pipetas e o contato de material contaminado com as conjuntivas

Outros mecanismos de transmissão, dito acidentais, como a manipulação de caças, talvez não seja tão raro, onde essa prática é comum, porém não notificada devido a sua incursão em crime. Contudo, considerando o pequeno número de casos descritos na literatura, não devem constituir problema de saúde pública e podem ser evitados através de procedimentos simples com conteúdo educativo (FORATTINI 1980; FORATTINI e col. 1981; FORATTINI e BARATA 1982; AMATO NETO 1988; ROMERO e col. 1992; SIQUEIRA-BATISTA e col. 1996).

\subsection{Diagnóstico Laboratorial}

O diagnóstico da infeç̧ão pelo Trypanosoma cruzi deve ser apoiado pela epidemiologia, pela clínica e confirmado quanto à etiologia pelo diagnóstico laboratorial. Sua importância é notória se levarmos em conta que apenas $5 \%$ dos individuos infectados apresentam os sinais e sintomas caracteristicos da doença de Chagas (SIQUEIRA-BATISTA e col. 1996; BRENER e cols. 2000) 
O diagnóstico laboratorial pode ser realizado por meio da busca do parasito (métodos parasitológicos) ou da resposta imune do hospedeiro infectado, isto é, o encontro de anticorpos dirigidos contra o parasito (métodos sorológicos).

Os exames laboratoriais devem ser direcionados em função da fase da infecção. Nos casos de suspeita de fase aguda, em face de elevada parasitemia, devem ser priorizados os exames parasitológicos, enquanto que na suspeita de infecção crônica, a solicitação deve ser dirigida à pesquisa de anticorpos específicos.

Embora o diagnóstico laboratorial seja efetuado habitualmente usando-se sangue venoso, pode-se pesquisar o parasito ou anticorpos em outros liquidos ou tecidos orgânicos (liquor, urina, líquido pericárdico, cortes de tecidos), como também em outros suportes como o papel filtro (FERREIRA e col. 1982; BRENER e col. 2000).

Em todo exame laboratorial, é necessário conhecer sua especificidade e sensibilidade. A especificidade indica a capacidade do teste em detectar a população não infectada; e a sensibilidade, pelo contrário, indica a capacidade do teste de indicar os indivíduos infectados.

Pelo fato de não existir teste com $100 \%$ de especificidade e sensibilidade (DIAS 1992), pode-se utilizar algumas estratégias, como o emprego de mais de um teste, a repetição da coleta de material e, nos exames sorológicos, o uso de diferentes pontos de corte, também chamados de cut-off que, arbitrariamente, representam a concentração de anticorpos que delimita a população não infectada da infectada.

Dentre os métodos utilizados para diagnóstico da infecção por $T$. cruzi, os parasitológicos são de extrema especificidade (100\%), pois o agente causal é demonstrado, porém, apresenta baixa sensibilidade; por outro lado, os sorológicos apresentam elevada sensibilidade, 98 a $99 \%$, e menor especificidade, 92 a $95 \%$ (LUQUETTI e RASSI 2000). O diagnóstico parasitológico, quando positivo, é de serteza; e o sorológico dá a probabilidade.

Os parasitológicos podem ser utilizados tanto na fase aguda como na fase crônica. Na fase aguda são usados métodos diretos de pesquisa do parasito na corrente sanguinea, como o exame a fresco, gota espessa, microhematócrito, esfregaço sanguíneo, punção biópsia de linfonodos, etc., que possuem especificidade de $100 \%$. Na fase crônica, devido ao baixo número de parasitos circulantes, são 
utilizados métodos indiretos, como a inoculação em animais sensiveis, a hemocultura e o xenodiagnóstico (LUZ e col. 1994).

O xenodiagnóstico, idealizado por BRUMPT em 1914, é um procedimento invasivo que apresenta uma alta especificidade e baixa sensibilidade, em torno de $50 \%$. Consiste no diagnóstico, que pode ser realizado utilizando-se como meio o próprio vetor habitual da doença parasitária. Esta técnica permite pesquisar o parasito no conteúdo intestinal dos insetos vetores, algumas semanas após terem sido alimentados com sangue do paciente sob suspeita de infecção chagásica. Se utilizado na fase aguda da doença, apresenta resultados melhores, de 85 a 100\%. Para o acompanhamento do paciente chagásico, a hemocultura é uma metodologia adequada, estejam eles submetidos ou não a tratamento específico (FERNANDES e col. 1999)

Outra técnica utilizada em laboratórios especialmente destinados para tal fím, é a técnica de Reação em Cadeia da Polimerase (PCR - polymerase chain reaction) que detecta quantidades minimas do DNA de $T$. cruzi em materiais biológicos infectados com o parasito. Possui alta sensibilidade, superior ao xenodiagnóstico e a hemocultura, sendo utilizado para pesquisar a eventual presença de parasitos circulantes em pacientes tratados (RIBEIRO DOS SANTOS e col. 1999; LUQUETTI e RASSI 2000).

O diagnóstico sorológico pode ser realizado por meio de métodos de variadas sensibilidades e especificidades, que detectam a presença de anticorpos contra frações antigênicas do T. cruzi, como: Imunoensaio-enzimático - ELISA (Enzime Linked Immmunossorbent Assay), HAI - Hemaglutinação Indireta, AD2ME Aglutinação direta com 2-mercapto-etanol e IFI - Imunofluorescência Indireta. Pela característica da doença, torna-se necessária a execução de, pelo menos, dois métodos de diagnóstico sorológico, de metodologia, sensibilidade e especificidades diferentes, recorrendo-se a um terceiro método confirmatório, em caso de dúvidas. $\mathrm{O}$ método utilizado deve detectar anticorpos nas fases aguda e crônica, com adequada sensibilidade e especificidade para diagnóstico em pacientes e para triagem de doadores de sangue, a fim de reduzir a expansão da doença pela via transfusional (FUCHS e col. 1980; LUZ e col. 1993; BRASL 1993; MINISTÉRIO DA SAÚDE 
1993a; FERREIRA e AVILA 1994; VASCONCELOS e col. 1994; SIQUEIRABATISTA E QUINTAS 1995; CARVALHO 2000; LUQUETTI e RASSI 2000).

Os métodos sorológicos são de destacada relevância na fase crônica da enfermidade quando, via de regra, a parasitemia é inconstante. A vida média das imunoglobulinas, 23 dias para IgG, permite que ausências temporárias do parasito na circulação não impeçam a deteç̧ão de anticorpos específicos, sendo, então, os métodos diagnósticos indicados para a fase crônica. Pelo fato de serem exames indiretos, com o contexto de resultados em termos de probabilidades e para assegurar melhor eficácia em termos de resultados, devemos realizar pelo menos duas técnicas de princípios diferentes (LUQUETTI e RASSI 2000).

Esses métodos são utilizados para inquéritos soroepidemiológicos, para selecionar doadores de sangue, para o acompanhamento da terapêutica antiparasitária, para confirmar ou excluir uma suspeita clínica. São a melhor alternativa na fase crônica da doença, quando se verifica baixa parasitemia, e elevados títulos de anticorpos especificos que, assim, permanecem pelo resto da vida. Considerando que os resultados dos testes sorológicos são influenciados por fatores como a sensibilidade, a especificidade e o estado clínico do paciente, conduziu a OMS - Organização Mundial da Saúde, a recomendar a realização de duas ou mais técnicas sorológicas, numa mesma amostra, visando assegurar melhor qualidade ao resultado (OMS 1991).

No Brasil, o Ministério da Saúde, através de legislação pertinente, recomenda o emprego de, pelo menos duas, das seguintes técnicas: ELISA, IFI ou HAI, para o diagnóstico sorológico da doença de Chagas (BRASIL 1988b, 1993; MINISTÉRIO DA SAÚDE, 1993a).

O teste de ELISA é amplamente utilizado na sorologia da doença de Chagas, principalmente na triagem de doadores, por possuir boa sensibilidade, especificidade e possivel automação. CAMARGO, 1998, destaca como vantagem deste método, ser o seu resultado a expressão direta da capacidade de ligação dos anticorpos de forma continua e não por titulação, onde a intensidade da cor indicará a concentração de anticorpos existentes na amostra de soro. De várias avaliações efetuadas, observou-se uma sensibilidade de 97,7 a $100 \%$ e especificidade de 93,3 a $100 \%$. 
O teste HAI, amplamente utilizado desde 1962 (CERISOLA e col. 1972) e padronizado por CAMARGO e col. 1971, é utilizado para fins diagnósticos e inquéritos soroepidemiológicos. É recomendado para triagem de doadores de sangue, por ser de fácil execução, prático, de baixo custo, não necessitando de equipamentos adicionais. Deve-se ressaltar que o teste HAI detecta apenas anticorpos da classe IgG, não sendo, portanto, indicado para utilização do diagnóstico sorológico na fase aguda da doença. Em geral, possui sensibilidade em torno de 95\%, e especificidade cerca de $98 \%$.

O teste IFI, utilizado universalmente para o diagnóstico sorológico de diversas doenças infecciosas, desde 1950, foi padronizado para infecção chagásica por CAMARGO, em 1966. Permite, com auxílio de microscópio com luz ultravioleta, utilizando um reagente o conjugado de anticorpos-IgG humano marcado com isotiocianato de fluoresceína para diferentes doenças, com variação apenas do antígeno a ser utilizado, diagnosticar o agente etiológico. Quando utilizado para diagnóstico de infecção aguda, devem ser empregados conjugado IgM humana e IgG nas infecções crônicas. Apresenta sensibilidade absoluta e especificidade em torno de $94 \%$, quando comparado a outros testes (BRENER e col. 2000).

Podem, entretanto, apresentar reações cruzadas com outras infecções, principalmente quando são utilizados antígenos não purificados. As reações mais freqüentes são observadas em pacientes com calazar, leishmaniose e o Trypanosoma rangeli, ocasionando resultados falso-positivos (STEINDEL 1993; GRISARD 1999; BRENER e col. 2000).

Com o calazar, ocorre reação cruzada devida ao elevado aumento de imunoglobulinas e os exames IFI, HAI e ELISA, apresentam-se reagentes com títulos elevados. As diferenças são principalmente clínicas, pois, em geral, é uma doença grave, febril, consumptiva, diferente do individuo infectado pelo $T$. cruzi. Se a dúvida persistir, é necessário recorrer ao diagnóstico usando-se antígenos recombinantes, disponíveis em centros especializados.

Nas reações cruzadas com leishmaniose tegumentar, com freqüência, o título obtido com o exame IFI é baixo. Em caso de dúvida, usa-se o teste IFI com antígeno de leishmânia, que fornecerá titulos mais elevados. O exame de HAI, geralmente é 
negativo, e o ELISA apresenta valores limitrofes. Existindo a dúvida, deve-se empregar no teste antígenos purificados ou recombinantes.

Em regiões onde está presente o $T$. rangeli, reações cruzadas também poderão ocorrer. É um parasita hemoflagelado, de tamanho avantajado de 26 a $34 \square \mathrm{m}$ de comprimento, quase que o dobro do T.cruzi, que mede 15 a $20 \mathrm{Jm}$. Apresenta distribuição geográfica na América do Sul e Central, semelhante à do $T$. cruzi. Possibilita a ocorrência de infecções únicas ou mistas, tanto nos hospedeiros invertebrados como em vertebrados, sendo sua presença assinalada em vários reservatórios e vetores silvestres no Estado de Santa Catarina (STEINDEL 1993; GRISARD 1999).

Mesmo não sendo considerado patogênico para o homem, a infecção pelo $T$. rangeli induz uma resposta imune humoral com elevados títulos de anticorpos, determinando reações sorológicas cruzadas com o T. cruzi, falsificando o diagnóstico sorológico da doença de Chagas, principalmente na fase crônica. Compartilha cerca de $60 \%$ de sua constituição antigênica solúvel com o $T$. cruzi, o que, possivelmente, explica a reatividade cruzada observada quando da realização de exames, como ELISA, Imunofluorescência e Western blot, o que pode ocasionar falsa inferência epidemiológica (GRIZARD 1999). Estudos continuam sendo aprofundados, com o intuito de esclarecer esses resultados. Procedimentos alternativos têm sido propostos, tais como a reação com anticorpos monoclonais, que permitem detectar, especificamente nos infectados por $T$. rangeli, o comportamento biológico do parasita (STEINDEL 1993; BRENER e col. 2000).

Existem outros exames, como o teste de fixação do complemento - FC, introduzido por Guerreiro e Machado, em 1913, que se encontra em desuso, devido sua alta complexidade técnica. Sua sensibilidade varia de $35 \%$ na fase aguda, e de 95\% nas infecções crônicas (WENDEL e GONZAGA 1993).

Neste contexto, entendemos que para o diagnóstico laboratorial da doença de Chagas, dois grandes grupos de métodos são utilizados: os parasitológicos, para diagnósticos, principalmente, na fase aguda; e os sorológicos, de utilização rotineira, para confirmação da doença na fase crônica. 
Nos casos em que ambos fornecem resultados negativos, afasta-se possivelmente, a hipótese de etiologia chagásica, e quando positivos, com títulos elevados, confirma-se a existência da infecção pelo $T$. cruzi .

Um grande problema com o qual estamos convivendo é o elevado número de resultados inconclusivos às provas sorológicas para doença de Chagas, em bancos de sangue, com importante repercussão, principalmente, econômica em vista do descarte de bolsas de sangue. Sem dúvida, o desenvolvimento de técnicas sorológicas capazes de detectar a presença de agentes causadores das doenças hemotransmissiveis em conjunto com outros cuidados já dedicados à hemoterapia podem garantir ao máximo o descarte de doadores infectados.

Na Fundação Pró-Sangue do Hemocentro de São Paulo o descarte alcançou indices de $2,5 \%$ a $3 \%$ em 1991 e 1992 , e de 1,6\% em 1993. Destes, mais da metade foram descartados devido a testes com resultados inconclusivos (YASUDA 1998).

Segundo SOARES e MORAES SOUZA (2000), analisando o comportamento sorológico de 34.887 doações de sangue no Hemocentro Regional de Uberaba, Minas Gerais, no periodo de janeiro de 1998 a dezembro de 1999, observaram 177 bolsas soropositivas e $75(0,21 \%)$ do total de doações, apresentaram resultados inconclusivos em $2^{a}$ amostra para infecção por $T$. cruzi que foram descartadas.

Análise efetuada junto ao Ambulatório de doença de Chagas, do Hospital da Universidade Federal de Minas Gerais, no ano de 1998, mostrou a ocorrência de 5\% de sorologias duvidosas ou inconclusivas, que continuavam a reatividade limitrofe em apenas um dos exames sorológicos efetuados (SOARES e MORAES SOUZA 2000)

Atualmente, a aplicação de testes sorológicos na triagem de doadores de sangue é uma atividade necessária e obrigatória para a prevenção da transmissão transfusional da doença de Chagas (MINISTÉRIO DA SAÚDE 1993a,b; WENDEL e GONZAGA 1993).

Os casos de sorologia duvidosa devem ser encaminhados a um centro de referência, onde a maioria poderá ser corretamente elucidada (BRENER 1993; BRENER e col. 2000). 


\subsection{A doença de Chagas no Estado de Santa Catarina}

Os conhecimentos sobre a doença de Chagas no Estado de Santa Catarina, parecem ainda escassos e imprecisos, talvez, devidos à existência de raros casos clínicos da doença ou de poucos trabalhos publicados a respeito do assunto.

A subnotificação por parte dos profissionais de saúde e a ausência de investigações epidemiológicas dos casos soropositivos levam, ainda, ao desconhecimento clínico e epidemiológico da doença.

O primeiro diagnóstico de caso autóctone da doença de Chagas no Estado foi demonstrado em 1970, em um paciente residente no município de Gaspar, natural de Blumenau que, pelo fato de ter sido encontrado tripanosomas circulantes, nunca ter saído da região, não ter recebido transfusão de sangue, comprova a característica autóctone do caso (OLIVEIRA e col. 1970). Dois outros casos de transmissão autóctone semelhante, não publicados, ocomeram no município de Florianópolis e Santo Amaro da Imperatriz, ambos na Região da Grande Florianópolis. Entre as hipóteses relativas à transmissão, os autores dão ênfase à invasão domiciliar por triatomíneos silvestres, provavelmente, atraídos pela luz e/ou em busca de alimentação, considerado um acidente de baixa probabilidade, porém, de ocomência possivel (SCHLEMPER JUNIOR e col. 1983, 1985; NASCIMENTO e col. 1999).

Em vista do que foi observado nessa época, os autores sugeriram para os individuos que sempre residiram no Estado de Santa Catarina a inclusão da doença de Chagas no diagnóstico diferencial das cardiopatias.

$O$ inquérito sorológico nacional para a doença de Chagas, realizado pela SUCAM - Superintendência de Campanhas de Saúde Pública, na década de 70, utilizando o teste de IFI, revelou elevadas prevalências da infecção chagásica nos municipios de Maracajá (16,2\%) localizado na $6^{a}$ Regional de Saúde; Urussanga $(8,0 \%)$ na $12^{\mathrm{a}}$ Regional de Saúde; Armazém (14,4\%) e São Martinho (12,7\%) na $14^{\mathrm{a}}$ Regional; e Canoinhas (7,6\%), Irineópolis (41,3\%) e Três Barras (9,0\%) na $16^{\mathrm{a}}$ Regional de Saúde do Estado de Santa Catarina (Figura 1, Anexo 1). Entretanto, estudos posteriores realizados na mesma região não confirmaram estes resultados, revelando percentuais próximos a $1 \%$, demonstrando, assim, a inexistência de transmissão da infecção chagásica em niveis endêmicos, nas áreas trabalhadas no 
Estado de Santa Catarina (SCHLEMPER JUNIOR e col. 1983; CAMARGO e col. 1984). O mesmo inquérito revelou para os Estados vizinhos do Paraná e Rio Grande do Sul, extensa área endêmica para a infecção chagásica, estimando índices de prevalência de $4,0 \%$ e 8,84\%, respectivamente (CAMARGO e col. 1984).

Outro inquérito sorológico humano para a doença de Chagas foi desenvolvido por SCHLEMPER JUNIOR e col. 1989, apoiado pela SUCAM, no distrito de Lagoa da Conceição, Florianópolis, Santa Catarina. Neste, foram analisadas 1.543 amostras de sangue da população residente, examinadas por Imunofluorescência - IFI e Hemaglutinação passiva - HA, encontrando-se uma prevalência de 2,1\%, o que indica a ocorrência de casos autóctones da enfermidade nesta região.

Informações relativas à fauna de triatomíneos têm seu primeiro registro nos mapas de DIAS, 1954, apud FERREIRA NETO e col. 1971, que assinalaram a presença do Triatoma infestans numa localidade da zona Oeste do Estado e o Panstrongylus megistus na Região de São Francisco do Sul, atualmente $13^{a}$ Regional de Saúde, na $18^{\mathrm{a}}$ Regional de Florianópolis e $8^{\mathrm{a}}$ Regional de Saúde, em Joaçaba.

BUSTAMANTE, em 1957, registrou também a ocorrência do T. infestans nos municípios São Miguel do Oeste e Palmitos situados na $5^{\mathrm{a}}$ e $10^{\mathrm{a}}$ Regionais de Saúde.

Amplo inquérito triatomínico foi também realizado no Estado de Santa Catarina, iniciado na década de 1950, pela Superintendência de Campanhas de Saúde Pública - SUCAM em todo o território, quando encontrou o vetor Triatoma infestans em domicílios e em galinheiros de 4 municípios da região oeste do Estado (FERREIRA NETO e col. 1971).

Foi em 1961, que LEAL e col. executaram pesquisas sobre triatomíneos silvestres na Ilha de Santa Catarina, município de Florianópolis. Nesta, foram capturados em ninhos de animais silvestres localizados em touceiras de gravatás (bromeliáceas) ou em buracos de pau, 335 exemplares de Panstrongylus megistus e 46 de Rhodnius domesticus. As duas espécies estavam parasitadas pelo $T$. cruzi, na proporção de, respectivamente, 40 a $70 \%$ dos exemplares examinados. Foi observada a presença de um único exemplar de $P$. megistus dentro da casa, o que sugere que esses insetos não colonizam os domicílios. Os conhecimentos até então existentes mostram a endemia ainda em estágio de zoonose, com ausência da doença humana 
no Estado de Santa Catarina (FERREIRA NETO e col. 1971; BARRACO e col. 1984)

O primeiro encontro de $P$. megistus colonizando ecótopo artificial, em uma casa antiga desabitada com depósito de materiais diversos, contaminado com $T$ cruzi, sugerindo a existência do risco desta espécie vir a se adaptar no domicílio humano, ocorreu no município de Florianópolis (SCHLEMPER JUNIOR e col. 1984a, 1985, 1986)

Outros estudos revelaram a presença do $P$. megistus e demonstraram ser a espécie de triatomíneo de hábito silvestre, predominante nas diferentes regiões do Estado de Santa Catarina (LEAL e col. 1961; ARAGÃO 1983b). As taxas de infecção natural dessa espécie pelo $T$. cruzi são, freqüentemente, elevadas, e formas aladas do inseto invadem os domicílios e anexos domiciliares nas épocas quentes do ano, podendo formar pequenas colônias nestes ecótopos (SCHLEMPER JÚNIOR e col. 1985; STEINDEL e col. 1985, 1994).

Com intuito de verificar a colonização de ecótopos artificiais pelo $P$. megistus, no distrito de Lagoa da Conceição, Florianópolis-SC, STEINDEL e col., em 1994, num período de 10 anos, examinaram 779 domicílios e anexos peridomiciliares. Destes, 2 domicílios, 1 escola, 3 galinheiros e 1 rancho, estavam colonizados por $P$. megistus, que apresentaram um índice de infecção de $53,3 \%$ de 329 exemplares examinados. Semelhante índice de infecção $(56,5 \%)$, foi também encontrado em exemplares adultos de $P$. megistus, oriundos dos ecótopos silvestres capturados por moradores da região. Submetidos ao teste de precipitina, os insetos examinados revelaram presença de sangue humano em $80,6 \%$ dos adultos e em $5,8 \%$ das ninfas capturadas nos domicílios. Estes resultados sugerem a necessidade da adoção de medidas de vigilância epidemiológica com a participação comunitária, face o risco potencial de domiciliação dessa espécie, considerando também o desmatamento ocorrido na ilha de Florianópolis, SC (CARUSO 1990).

Estudos relativos ao ciclo silvestre e cepas de $T$. cruzi no Estado, revelaram que 26\% (6/23) dos gambás (Didelphis marsupialis) examinados estavam contaminados; e que o $P$. megistus e o $R$ domesticus exibiram índices de infecção surpreendentemente elevados de $84,4 \%$ (114/135) e 66,6\% (6/9), respectivamente. 
Quanto ao estudo morfo-biológico experimental efetuado do agente etiológico da doença de Chagas, este evidenciou cepas de $T$. cruzi, com predomínio de formas tripomastigotas muito largas, sugerindo o aspecto característico de cepas anteriormente detectadas no extremo sul do país. Submetidos a testes relativos a virulência, demonstraram o predomínio de cepas com baixa e média virulência do $T$. cruzi nos animais silvestres e seres humanos, respectivamente (SCHLEMPER JUNIOR 1984a, 1984b, 1985).

Quando observada a distribuição geográfica desta enfermidade, na região Sul do Brasil, a doença de Chagas é, comprovadamente endêmica nos Estados do Paraná e Rio Grande do Sul (BARRETO 1979; BARUFFA 1985; CUNHA 1987). O número estimado de individuos infectados pelo T. cruzi no Estado do Rio Grande do Sul foi de 700.000 , apresentando a maior estimativa de prevalência $(8,84 \%)$ na população estudada no inquérito sorológico efetuado no periodo de 1975 a 1980 (BARUFFA 1979, 1985; CAMARGO e col. 1984).

Em Santa Catarina, no ano de 1993, foi encontrada uma prevalência de $0,27 \%$ para doença de Chagas, e 0,04\% e 0,09\% em Florianópolis, nos anos anteriores de 1989 e 1990, respectivamente (MINISTÉRIO DA SAÚDE 1993a, STEFFENS 1994).

O Estado de Santa Catarina não se constitui em área endêmica da doença de Chagas humana, uma vez que não existem vetores domiciliados, porém, está localizado entre Estados comprovadamente endêmicos (SÃO THIAGO 1982). Todavia, sua população é constituida em grande parte por pessoas oriundas de Estados endêmicos para a doença, como Rio Grande do Sul, Paraná e São Paulo, o que eleva o risco de transmissão transfusional da enfermidade (SCHLEMPER JÚNIOR e col. 1984a, 1984b, 1985 e 1986).

\subsubsection{O controle das transfusões e os riscos de transmissão transfusional}

A intensa migração para os centros urbanos vem conferindo à transfusão de sangue, um aspecto de importância epidemiológica crescente, pela disseminação inter-humana da infecção chagásica nas grandes cidades. 
No momento em que houve a urbanização da doença de Chagas, o controle da transmissão transfusional tornou-se prioritário, sendo a triagem sistemática nos bancos de sangue, em nível nacional, a principal ação de vigilância (MORAESSOUZA 1987,1992; BRASLL 1993; MINISTÉRIO DA SAÚDE 1993a).

A transfusão sangüinea, atualmente, tem adquirido expressiva relevância na epidemiologia da doença de Chagas, transformando-se na principal via de transmissão na zona urbana, na qual residem $70 \%$ da população das Américas. Constitui o segundo mais freqüente mecanismo de transmissão do $T$. cruzi (SCHLEMPER JÚNIOR 1978; BONAMETTI e col. 1998).

Para o controle das transfusões de sangue podem ser adotadas duas medidas. A primeira, é a exclusão dos candidatos à doação de sangue que apresentarem sorologia reagente aos testes anti-T. cruzi; e a segunda, é a quimioprofilaxia pela adição no sangue, de substâncias tripanossomicidas, como a violeta genciana. Estudos revelaram que esta substância juntamente com o cristal violeta, quando empregados na concentração de 1:4000, esterilizam totalmente o sangue após 24 horas de contato a uma temperatura de $4{ }^{\circ} \mathrm{C}$. Porém, este procedimento apresenta alguns inconvenientes como a coloração violácea conferida ao sangue, microaglutinação e aglomerados de hemácias, sensibilidade diferenic entre as várias cepas de $T$. cruzi, e o tempo necessário de 24 horas a $4{ }^{\circ} \mathrm{C}$, para ação tripanossomicidas (SCHLEMPER JÚNIOR 1978; RAMIREZ 1992; BASSO 1999).

A triagem sorológica para detecção da infecção pelo $T$. cruzi em doadores de sangue foi introduzida no Brasil em 1969, pela Portaria $\mathrm{n}^{\circ}$ 04/69, datada de 25.11.1969 (MINISTÉRIO DA SAÚDE 1969). Por muito tempo, a coleta de sangue no Brasil realizou-se sem a mínima avaliação clínico-epidemiológica do doador. A transfusão de sangue era realizada nos hospitais, de forma rudimentar, apenas como uma prática complementar dos procedimentos clínicos e cirúrgicos.

Todavia, a melhoria do controle do sangue e hemoderivados no Brasil realmente aconteceu de forma eficaz a partir de 1980, com a criação do Programa Nacional de Sangue e Hemoderivados (Pró-Sangue). (MINISTÉRIO DA SAÚdE 1989; COVAS 1993).

Outro marco importante, na década de 80 , para a política do sangue foi a proibição de todo tipo de comercialização do sangue e seus derivados em qualquer de 
suas fases de coleta, processamento ou transfusão, pela Constituição Nacional de 1988 (BRASIL 1988a; FURT ADO 1989).

Foi em 1986, que a $8^{a}$ CONFERÊNCIA NACIONAL DE SAÚDE destinou especial atenção ao tema Sangue e Hemoderivados, constituindo-se no início da definição de uma política nacional na área de sangue e derivados, considerando que "é dever do Estado prover os meios para um atendimento hematológico e hemoterápico de acesso universal e de boa qualidade" (MINISTÉRIO DA SAÚDE 1986)

Essa política buscou como objetivos: a doação voluntária de sangue; formação de recursos humanos e desenvolvimento tecnológico, visando proporcionar ao país auto-suficiência em hemoderivados, reagentes e insumos, e controle de qualidade com a criação de centros de referência; e a integração entre os hemocentros e órgãos públicos encarregados pela Vigilância Sanitária, para a fiscalização e orientação, garantindo uma triagem sorológica com detecção de doenças transmitidas pela transfusão.

Foi também o aparecimento da Síndrome de Imunodeficiência Adquirida SIDA/AIDS, como doença transfusional, que reforçou a importância do doador dentro do Sistema Nacional de Sangue e Hemoderivados (COVAS 1993).

Com o advento da Lei $n^{\circ} 7.649 / 88$ e, posteriormente, as Portarias $n^{\circ} 721 / 89$, alterada pela de $\mathrm{n}^{\circ} 1.376 / 93$, o Brasil passou a dispor de uma legislação que disciplinou a prática da hemoterapia como um todo, recomendando que o sangue dos doadores fosse submetido à triagem de anticorpos anti- $T$. cruzi, mediante o uso de, pelo menos, duas técnicas sorológicas, e a doação voluntária de sangue, definindo com maior clareza a política do sangue, o que resultou uma melhoria nos serviços das unidades hemoterápicas (BRASIL 1988b; MINISTÉRIO DA SAÚDE 1989, 1993a; ANDRADE e col. 1992)

Este dispositivo legal estabeleceu a obrigatoriedade do cadastramento dos doadores de sangue com as seguintes informações: nome, sexo, idade, local de trabalho, documento de identidade, histórico patológico, data da coleta e resultados dos exames, bem como a realização de exames laboratoriais no sangue coletado para Hepatite B, Sífilis, Doença de Chagas, Malária e AIDS, visando a prevenir a propagação de doenças (BRASIL 1988b). 
Estimativas de AMATO NETO (1988) apontaram a possivel ocorrência de 20.000 casos novos de doença de Chagas por transfusão de sangue ao ano, no Brasil, baseando-se no número médio de 4 milhões de transfusões anuais, com uma taxa de prevalência de $20 \%$ de doadores chagásicos nos bancos de sangue, e no risco da transmissão da doença por doadores infectados situar-se na proporção de 1:5 até 1:8 das transfusões (WANDERLEY e col. 1992, WANDERLEY 1994b).

Em inquérito realizado no período de 1988 a 1990, em 850 municípios brasileiros, observou-se que $66,9 \%$ dos serviços de hemoterapia faziam triagem prévia para doença de Chagas. Destes, 55,3\% realizavam um único teste sorológico para seleção dos doadores, contrariando as recomendações legais de utilização de, pelo menos, duas técnicas na triagem. Neste inquérito, a prevalência de infecção pelo T. cruzi, encontrada entre os serviços que realizavam esta prova, foi de $1,0 \%$ (MORAES-SOUZA e col 1994).

Foi a Portaria do Ministério da Saúde $\mathrm{n}^{\circ} 721$, de 09.08.89, que aprovou as normas técnicas neste sentido e criou Centros Regionais de Referência em hemocentros estaduais, os quais são responsáveis pela capacitação de recursos humanos (BRENER 1993).

Também, o Ministério da Saúde, através da Portaria $\mathrm{n}^{\circ} 1.376$, de 19 de novembro de 1993, obrigou a realização na triagem de todos os doadores de sangue, com testes para a pesquisa de hepatites B e C, AIDS, Sífilis, doença de Chagas, dosagem da TGP/ALT, anti-HBc e anti-HTLV I/II (BRASIL 1993; MINISTÉRIO DA SAÚDE 1993a).

Tendo em vista que os serviços de hemoterapia são instituições públicas, privadas ou filantrópicas, cujos exames laboratoriais são executados de forma independente, que o Ministério da Saúde, em 1994, lançou um programa de avaliação sistemática da qualidade dos rastreamentos ou triagem sorológicas, para detecção de doenças transmissiveis por transfusão de sangue. Realizados pelos bancos de sangue do serviço público, constatou-se na primeira fase do programa, que $30 \%$ dos 57 serviços de hemoterapia utilizavam apenas um só teste para triagem de doadores soropositivos para infecção pelo $T$. cruzi. Na última fase, este percentual reduziu-se para $11,5 \%$, significando que houve uma melhoria acentuada na qualidade 
da triagem de doadores (CARNEIRO e ANTUNES 1994; SAEZ-ALQUEZAR e col. 1994).

Em pesquisa realizada por BONAMETTI e col. (1998), em Londrina, Paraná, a taxa de positividade dos testes sorológicos para $T$. cruzi, em candidatos a doadores de sangue foi de 1,3\%. Este índice é semelhante à atual taxa média aproximada de $1 \%$, encontrada por MORAES-SOUZA e col. 1994; MORAES-SOUZA 1999, em todo o pais.

A decisão da transfusão de sangue e seus derivados deve ser baseada na avaliação do beneficio terapêutico para o receptor, bem como os riscos potenciais entre eles, com possibilidade de transmitir vírus, bactérias e parasitas.

Estudos mostraram que $60 \%$ dos chagásicos crônicos apresentam, permanentemente, $T$. cruzi circulando em seu sangue. A transmissão do $T$. cruzi, através da transfusão de sangue proveniente de doador infectado, representa sério risco porque o parasita sobrevive, pelo menos, 10 dias em componentes de sangue refrigerados (SHULMAN e APPLEMAN 1991; ANGULO e TAVARES 1993).

Calcula-se que o risco teórico estimado de um receptor contrair a infecção com uma única transfusão sangüinea, varia de 12,5 a 25\% (DIAS, 1987; WHO, 1990; OMS, 1991; WANDERLEY e col. 1993; YASUDA 1998).

A questão é agravada, considerando-se que cada unidade de sangue colhido pode produzir 4 hemocomponentes distintos, como: concentrado de hemácias, plaquetas, plasma e crioprecipitado ou fator de coagulação VIII e IX. Se estes hemocomponentes infectados fossem transfundidos, pode-se avaliar a dimensão do problema, tanto do ponto de vista econômico quanto do risco a que estariam sendo expostos os receptores de sangue e hemoderivados, bem como o comprometimento da população de individuos sadios que, posteriormente, seriam contaminados.

A ocorrência da transmissão, além da parasitemia do doador, pode ser influenciada também pelo tipo de cepa do $T$. cruzi transfundido, pela resistência e suscetibilidade do receptor e pela quantidade de sangue transfundido. $O$ risco de transmissão aumenta em relação direta com o número de transfusões (DIAS e BRENER 1984; ANDRADE e col. 1989, 1992; VARELLA e col. 1993).

Torna-se importante lembrar, que a transmissão transfusional é proporcional à prevalência de portadores de infecção chagásica entre os candidatos a doadores de 
sangue, e a freqüência de doadores chagásicos está relacionada, por sua vez, à prevalência da enfermidade na região determinada (ROMERO e col. 1992; DIAS e SCHOFIELD 1998).

A segurança da transfusão sangüinea depende de vários fatores, sendo que os mais importantes são a seleção da população de doadores, triagem clínica e a realização de testes imunohematológicos para a triagem sorológica (CUMMINGS e col. 1989; CONTRERAS 1992).

\subsection{Justificativa}

A doença de Chagas, atualmente, é um grande problema de saúde pública, não somente em áreas endêmicas da América Latina, mas, também, em países indenes com imigrantes dessas áreas como, por exemplo, os Estados Unidos, Canadá, paises da Europa ocidental, Austrália, Japão, entre outros (WENDEL e GONZAGA 1993; SCHMUÑIS 1991, 1994, 1999b; BARRETT 1997).

A transfusão sanguínea vem ganhando relevância na epidemiologia da enfermidade, na área urbana, sendo a principal via de transmissão onde habitam $70 \%$ da população.

Pela importância de sua transmissão, através da via transfusional, a doença de Chagas passou a constituir importante problema em grandes cidades, devido ao elevado número de doadores soropositivos provenientes de áreas rurais de zonas endêmicas (DIAS e JATENE 1992).

No Brasil, nos anos 70, sugeriu-se uma incidência anual, de 10.000 a 20.000 casos transfusionais adquiridos de doadores infectados, entre 4 milhões de transfusões realizadas ao ano

Na década de 1980, a transmissão da doença de Chagas por transfusão de sangue assumiu expressiva importância, sendo responsável pela disseminação da endemia nas áreas urbanas. O número de doadores sorologicamente positivos correspondeu à época, cerca de 55.000 por ano, chegando-se admitir que de 1.500 a 3.000 pessoas adquirissem a infecção por $T$. cruzi, como decorrência de transfusões de sangue. (TOLEZANO e col. 1980, 1992; AMATO NETO 1993). 
A prevalência do Trypanosoma cruzi em bancos de sangue no Brasil, aumenta no sentido Norte-Sul com valores de $0,22 \%$ na região Norte, $0,46 \%$ no Nordeste, $0,54 \%$ no Sudeste, $1,13 \%$ na região Centro-Oeste e 1,45 na Região Sul. Em Santa Catarina, em 1993, foi encontrada uma prevalência de 0,27\% para infecção chagásica, entre os doadores de sangue (MINISTÉRIO DA SAÚDE 1993b; STEFFENS 1994; BRENER e col. 2000).

Dados levantados junto aos hemocentros e centrais sorológicas do Estado, no período de 1994 a 1997, mostraram a crescente percentagem de doadores soropositivos para a doença de Chagas no teste de ELISA, que foi de $0,30 \%$ (35/11.575) no ano de 1994, de 0,25\% (116/46.862) em 1995, de 0,39\% (225/57.683) em 1996 e de 0,52\% (251/48.665) em 1997.

O Estado de Santa Catarina, não se constitui em área endêmica para a doença de Chagas humana, uma vez que não existem vetores domiciliados (SCHLEMPER JUNIOR e col. 1985).

Entretanto, informações a respeito quanto à procedência de doadores soropositivos, observadas em outros estudos, indicam que estes, na slia maioria, são procedentes do Estado de Santa Catarina, porém, contribui com elevadas proporções o Rio Grande do Sul, Paraná e São Paulo, respectivamente. Análises realizadas pelo Laboratório de Protozoologia do Departamento de Microbiologia e Parasitologia da Universidade Federal de Santa Catarina - UFSC, mostraram que, de 41 doadores soropositivos encaminhados por diferentes serviços do Estado, para confirmação diagnóstica, $90 \%$ são oriundos de municípios endêmicos para doença de Chagas do Rio Grande do Sul. Nove dos indivíduos submetidos a hemocultura com resultados positivos para $T$. cruzi, já haviam realizado doações de sangue antes do diagnóstico (RELATÓRIO não publicado).

Estudo preliminar, efetuado junto às Unidades Hemoterápicas, do Hemocentro Regional de Florianópolis e Serviço de Hemoterapia do Hospital Universitário - HU / UFSC, na Região da Grande Florianópolis, indicou um percentual médio de $0,16 \%$ de infecção por $T$. cruzi, entre as 172.124 doações efetuadas no periodo de 1990 a 1999 (Tabela 4).

A triagem sorológica tem um significado importante e especial para as transfusões, pois significa que o sangue e seus hemocomponentes, possuem 
qualidade suficientemente adequada para serem transfundidos, ou seja, não possuir agentes causadores de doenças hemotransmissíveis como o vírus da hepatite $\mathrm{B}$, hepatite C, outros virus da hepatite, HIV I e HIV II, citomegalovírus, HTLV I e HTLV II, Epstein-Barr virus, parvovirus B19 e outros. Também são transmitidos pela transfusão sangüínea, parasitas como Trypanosoma cruzi (doença de Chagas), Plasmodium (agente da malária), Toxoplasma gondii (toxoplasmose) e Babesia microti (babesiose) (CONTRERAS 1992; GONÇALVES JÚNIOR e col. 1993; WANDERLEY e col. 1993; KUPEK 2000).

Certamente, para o controle das unidades sangüineas transfundidas, com objetivo de implantar em todo território brasileiro um eficiente sistema de coleta e fracionamento de sangue, desenvolvimento técnico e científico da área e, principalmente, atingir a auto-suficiência para $o$ fornecimento de sangue $e$ hemoderivados, é que foi criado, em 1980, o Programa Nacional de Sangue e Hemoderivados (Pró-Sangue) (COVAS 1993).

Outros dispositivos legais emitidos pelo Ministério da Saúde, como a Lei $n^{\circ}$ 7.649, de 25.01 .88 e, posteriormente, as Portarias $n^{\circ} 721$, datada de 09.08.89, alterada pela de $\mathrm{n}^{\circ} 1.376$, de 19.11.93, disciplinou a prática da hemoterapia, recomendando que o sangue de todos os doadores fosse submetido à triagem sorológica para infecção chagásica em, pelo menos, duas técnicas diferentes, e a doação voluntária de sangue, definiu com clareza a politica de sangue, o que culminou com uma melhoria nos serviços das unidades hemoterápicas (BRASIL 1988b; MINISTÉRIO DA SAÚDE, 1989, 1993a).

No Estado de Santa Catarina, a Portaria $n^{\circ}$ 22/SES/93 normatizou o controle da qualidade do sangue, componente e hemoderivados, objetivando a diminuição da ocorrência de doenças hemotransmissíveis, determinando o cadastramento de doadores com dados de identificação, exame clínico e resultado de provas laboratoriais para tipo sanguíneo; fator $\mathrm{Rh}$; nivel de hemoglobina; sífilis; doença de Chagas; virus da hepatite B, virus HIV. Esta determinação se aplica aos Serviços de Hemoterapia, Bancos de Sangue, Agências Transfusionais e Postos de Coleta de sangue. Determina também que, para a pesquisa da doença de Chagas, sífilis e vírus da hepatite, sejam obrigatoriamente realizados, em cada caso, no mínimo duas 
reações sorológicas adequadas e diferentes (SECRETARIA DE ESTADO DA SAÚDE 1989, 1993a,b)

Atualmente, considerando a necessidade de melhor esclarecimento diagnóstico da enfermidade no Estado, houve, através da Portaria $n^{\circ} 754 / 2001$, o reconhecimento do Laboratório de Protozoologia do Departamento de Microbiologia e Parasitologia (MIF) da Universidade Federal de Santa Catarina, como sendo o Laboratório de Referência no Estado de Santa Catarina para o diagnóstico da Doença de Chagas e Leishmaniose, visando contribuir com a elucidação dos resultados laboratoriais (SECRETARIA DE ESTADO DA SAÚDE 2001).

Nesse contexto, observando-se o crescente aumento do número de doadores de sangue soropositivos para infecção por $T$. cruzi, verificado nos últimos anos nas diferentes Regionais de Saúde do Estado de Santa Catarina, torna-se oportuno realizar uma avaliação do cumprimento das disposições legais estabelecidas, bem como realizar um estudo epidemiológico da doença de Chagas, para mensurar a prevalência de portadores e avaliar os riscos da transmissão transfusional, e para conhecer melhor a magnitude da problemática da transmissão da doença no Estado, considerando a sua prevalência entre os candidatos a doadores de sangue. 
2 OBJETIVOS 


\section{OBJETIVOS}

\subsection{Objetivo Geral}

Analisar a situação atual de controle do sangue em relação à doença de Chagas e avaliar o risco de transmissão de Trypanosoma cruzi por meio da transfusão sanguinea, nas regiões da Grande Florianópolis e Joaçaba, do Estado de Santa Catarina, no periodo de 1990 a 1999.

\subsection{Objetivos Específicos}

Estudar a prevalência da infecção por $T$. cruzi entre os doadores dos bancos de sangue das regiões da Grande Florianópolis, no período de 1990-1999, e Joaçaba, no periodo de 1995-1999, Estado de Santa Catarina

Estudar a distribuição dos doadores infectados pelo T. cruzi, segundo a variável naturalidade, idade, sexo, estado civil e ocupação, nas regiões da Grande Florianópolis e Joaçaba, do Estado de Santa Catarina.

Medir a incidência da infecção por $T$. cruzi nos doadores de repetição, das regiões da Grande Florianópolis e Joaçaba, do Estado de Santa Catarina.

Quantificar o risco da transmissão transfusional da doença de Chagas entre os receptores nas regiões da Grande Florianópolis e Joaçaba, do Estado de Santa Catarina

Contribuir para o esclarecimento da transmissão transfusional da doença de Chagas no Estado de Santa Catarina. 
3 MATERIAL E MÉTODOS 


\section{MATERIAL E MÉTODOS}

\subsection{Delineamento}

Foram realizados estudos relativos à prevalência da soropositividade à infecção pelo Trypanosoma cruzi, dos doadores de sangue, e avaliado o risco de transmissão transfusional entre os receptores de sangue, nos serviços de hemoterapia de três Unidades Hemoterápicas localizadas na Região da Grande Florianópolis e Joaçaba, do Estado de Santa Catarina, no periodo de 1990/99 e de 1995/99, respectivamente (Figura 2 ).

\section{2 Área de estudo}

O estudo foi realizado junto àquelas Unidades Hemoterápicas localizadas na Região da Grande Florianópolis e Joaçaba, do Estado de Santa Catarina. O Estado, atualmente, dispõe de 194 órgãos com atividades hemoterápicas devidamente cadastrados na Diretoria de Vigilância Sanitária-DVS, da Secretaria de Estado da Saúde - SES

A localização destes órgãos ou unidades hemoterápicas, segundo as Regionais de Saúde do Estado, apresenta uma distribuição, onde se destaca uma maior concentração com $32(16,49 \%)$ na $18^{a}$ Regional de Saúde, localizada em Florianópolis, capital do Estado de Santa Catarina, seguida de 21 (10,82\%) unidades na $10^{\mathrm{a}}$ Regional de Saúde de Chapecó; $16(8,25 \%)$ na $8^{\mathrm{a}}$ Regional de Saúde de Joaçaba e, igualmente, na $9^{a}$ Regional de Saúde de Blumenau e $15^{\text {a }}$ de Lages; e, finalmente, com menor concentração, encontra-se a $7^{\mathrm{a}}$ e $11^{\mathrm{a}}$ Regionais de Saúde, com $2(1,03 \%)$ unidades hemoterápicas (Tabela 1$)$. 


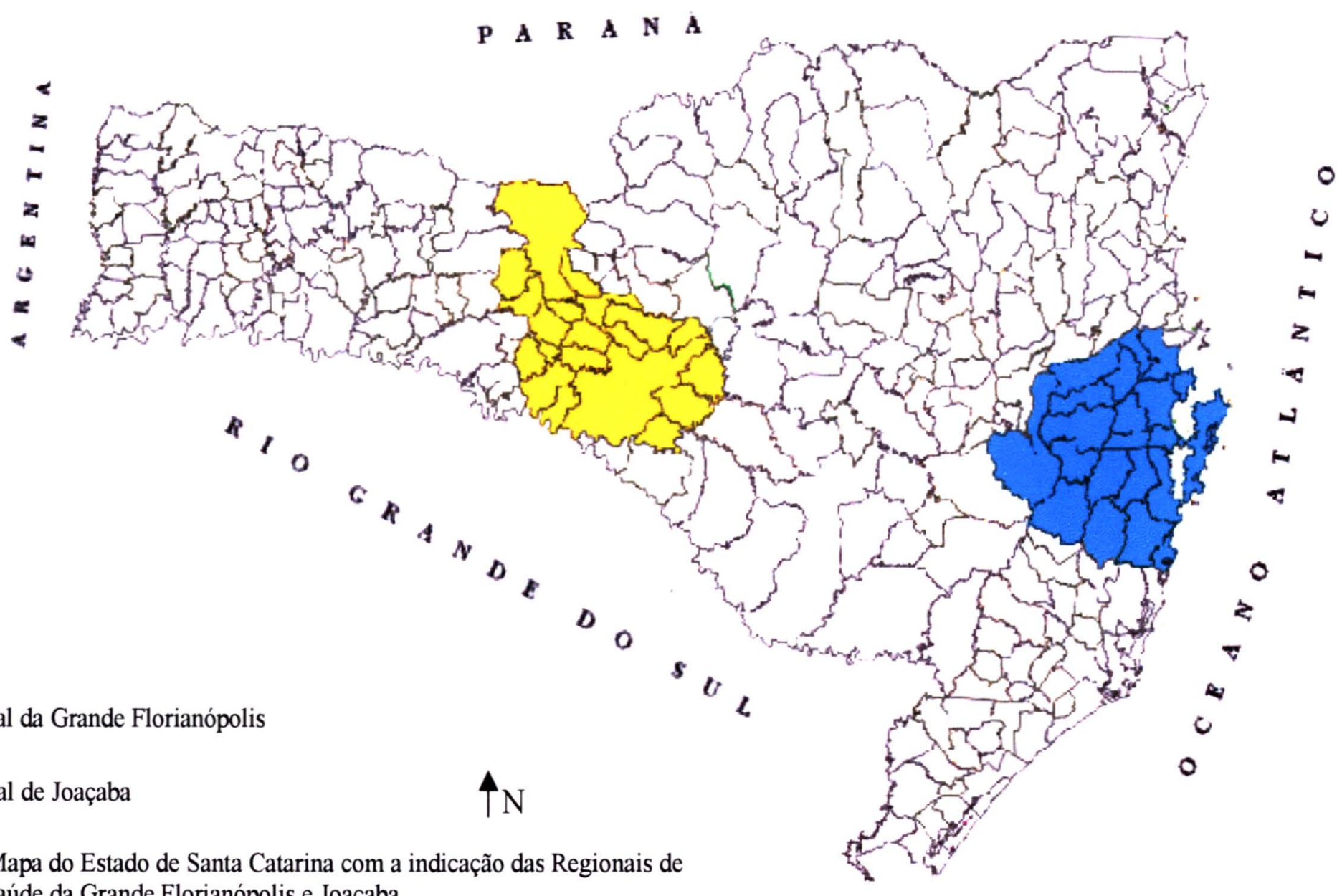
Saúde da Grande Florianópolis e Joaçaba.

Fonte: Secretaria de Estado do Desenvolvimento Econômico e Integração ao Mercosul (modificado). 
Tabela 1 - Distribuição dos órgãos de atividade hemoterápica, segundo a modalidade de serviços e Regional de Saúde - RS, Estado de Santa Catarina, 2000.

\begin{tabular}{|c|c|c|c|c|c|c|}
\hline \multirow{2}{*}{ RS } & \multirow{2}{*}{ Hemocentro } & \multirow{2}{*}{$\begin{array}{c}\text { Serviço de } \\
\text { hemoterapia }\end{array}$} & \multicolumn{2}{|c|}{ Agência Transfusional* } & \multicolumn{2}{|c|}{ Total } \\
\hline & & & Tipo I & Tipo II & $\mathrm{N}^{\mathrm{o}}$ & $\%$ \\
\hline 1 & - & - & 2 & 10 & 12 & 6.19 \\
\hline 2 & - & - & 2 & 4 & 6 & 3.09 \\
\hline 3 & - & - & 2 & 9 & 11 & 5.67 \\
\hline 4 & - & - & 2 & 2 & 4 & 2.06 \\
\hline 5 & - & - & 6 & 9 & 15 & 7.73 \\
\hline 6 & - & - & 1 & 7 & 8 & 4.12 \\
\hline 7 & - & - & 1 & 1 & 2 & 1.03 \\
\hline 8 & 1 & - & 3 & 12 & 16 & 8.25 \\
\hline 9 & - & 1 & 6 & 9 & 16 & 8.25 \\
\hline 10 & 1 & - & 3 & 17 & 21 & 10.82 \\
\hline 11 & - & - & 1 & 1 & 2 & 1.03 \\
\hline 12 & 1 & - & 3 & 8 & 12 & 6.19 \\
\hline 13 & 1 & - & 5 & 2 & 8 & 4.12 \\
\hline 14 & - & - & 4 & 1 & 5 & 2.58 \\
\hline 15 & 1 & - & 4 & 11 & 16 & 8.25 \\
\hline 16 & - & - & 3 & 2 & 5 & 2.58 \\
\hline 17 & - & 1 & 2 & - & 3 & 1.55 \\
\hline 18 & 1 & 1 & 5 & 25 & 32 & 16.49 \\
\hline TOTAL & 6 & 3 & 55 & 130 & 194 & 100.00 \\
\hline
\end{tabular}

* Agência Transfusional: Tipo I -armazena e transfunde sangue; Tipo II - transfunde sangue

Fonte: Diretoria de Vigilância Sanitária -DVS / SES

Relativamente à categoria dos serviços de hemoterapia no Estado de Santa Catarina, observam-se maiores percentuais daqueles com características de serviços privados $85(43,82 \%)$, públicos representam $39(20,10 \%)$ e sem especificação 70 $(36,08 \%)$. (Tabela 2$)$.

Tabela 2 - Distribuição do número de Unidades Hemoterápicas, segundo a categoria de serviços. Estado de Santa Catarina, 2000.

\begin{tabular}{|c|c|c|c|c|c|c|c|}
\hline \multirow{2}{*}{ Categoria } & \multicolumn{3}{|c|}{ Privado } & \multicolumn{2}{|c|}{ Público } & \multirow{2}{*}{$\begin{array}{c}\text { Sem } \\
\text { Especificação } \\
\%\end{array}$} & \multirow{2}{*}{ Total } \\
\hline & $\mathrm{n}^{\circ}$ & $\%$ & $\mathrm{n}^{\circ}$ & $\%$ & $n^{\circ}$ & & \\
\hline & 85 & 43,82 & 39 & 20,10 & 70 & 36,08 & 194 \\
\hline
\end{tabular}

Fonte: Diretoria de Vigilância Sanitária - DVS / SES. 
Embora, em termos numéricos, a categoria de serviços privados seja tão expressiva (85\%); o mesmo não acontece com relação à coleta de sangue, onde o percentual de bolsas contribuídas pelos serviços públicos representa aproximadamente $72 \%$ das unidades hemoterápicas coletadas.

A maior rede pública de serviços no Estado de Santa Catarina é representada pelo Centro de Hematologia e Hemoterapia de Santa Catarina - HEMOSC, constituído de um Hemocentro Coordenador, situado em Florianópolis, e uma rede de 5 (cinco) Hemocentros Regionais localizados nas cidades de Lages, Joaçaba, Joinville, Criciúma, Chapecó, e um em fase de planejamento e construção, na cidade de Blumenau.

O HEMOSC, criado em 1987, é uma unidade da Secretaria de Estado da Saúde - SES, com sede localizada em Florianópolis, que tem como missão "assegurar o fornecimento de sangue, hemocomponentes e serviços hematológicos e hemoterápicos de qualidade, ensino e pesquisa, visando assistência e segurança à comunidade". Tem a responsabilidade pela capacitação de recursos humanos e de desenvolver o programa de interiorização das atividades em todas as regiões do Estado, suprindo suas necessidades, em cumprimento às normatizações da Portaria $\mathrm{n}^{\circ}$ 721, de 09.08.89 (MINISTÉRIO DA SAÚDE 1989).

$\mathrm{Na}$ Região da Grande Florianópolis, estudou-se a população de doadores que realizaram suas doações no Hemocentro Regional de Florianópolis - HRF e Serviço de Hemoterapia do HU/UFSC, ambos situados em Florianópolis, capital do Estado de Santa Catarina.

Esta região, composta por 22 municípios, constitui a $18^{a}$ Regional de Saúde e está localizada na parte leste geográfica, litoral, do Estado de Santa Catarina. Foi classificada por vários anos pela Organização Mundial das Nações Unidas (ONU), como aquela com um dos melhores índices de qualidade de vida. Possui uma economia baseada, principalmente, na agricultura, pesca, comércio e turismo. Sua população é composta de 704.247 habitantes, distribuídos numa área de $7.100,9 \mathrm{~km}^{2}$ $\left(99,17 \mathrm{hab} . / \mathrm{km}^{2}\right)$. (IBGE, 1998). (Figura 3 e Anexo III).

$\mathrm{Na}$ Região de Joaçaba, situada no planalto, estudou-se aqueles indivíduos que realizaram doações no Hemocentro Regional de Joaçaba - HRJ. Composta por 21 municípios, constitui a $8^{a}$ Regional de Saúde, localizada na parte Centro-Oeste do 
Estado de Santa Catarina. Tem uma economia baseada, principalmente, na agricultura e pecuária. Sua população é composta por 166.688 habitantes, distribuidos em $7.126,8 \mathrm{~km}^{2}$, o que corresponde a uma densidade demográfica de 23,38 habitantes $/ \mathrm{km}^{2}$. (Figura 4 e Anexo IV). 


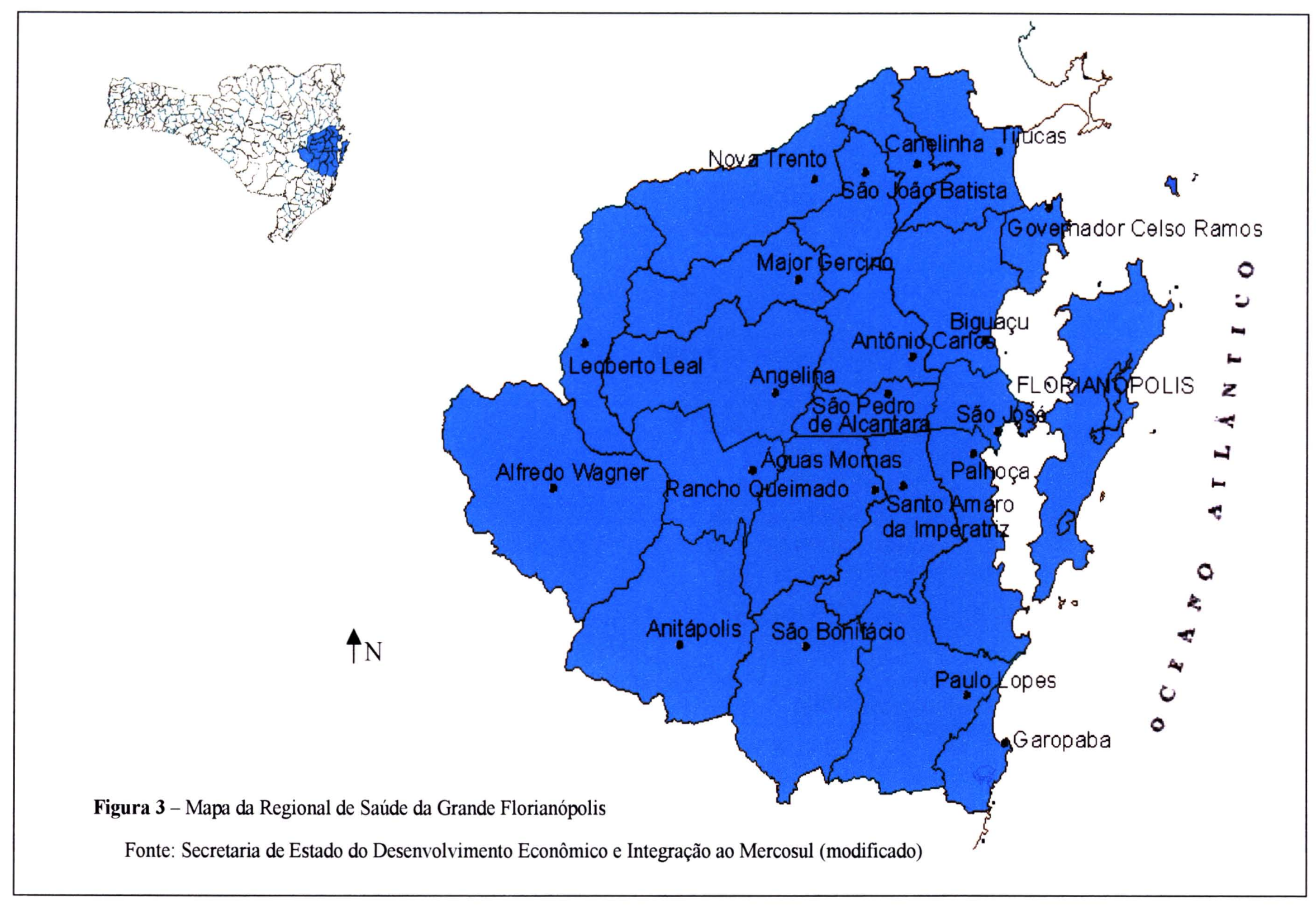




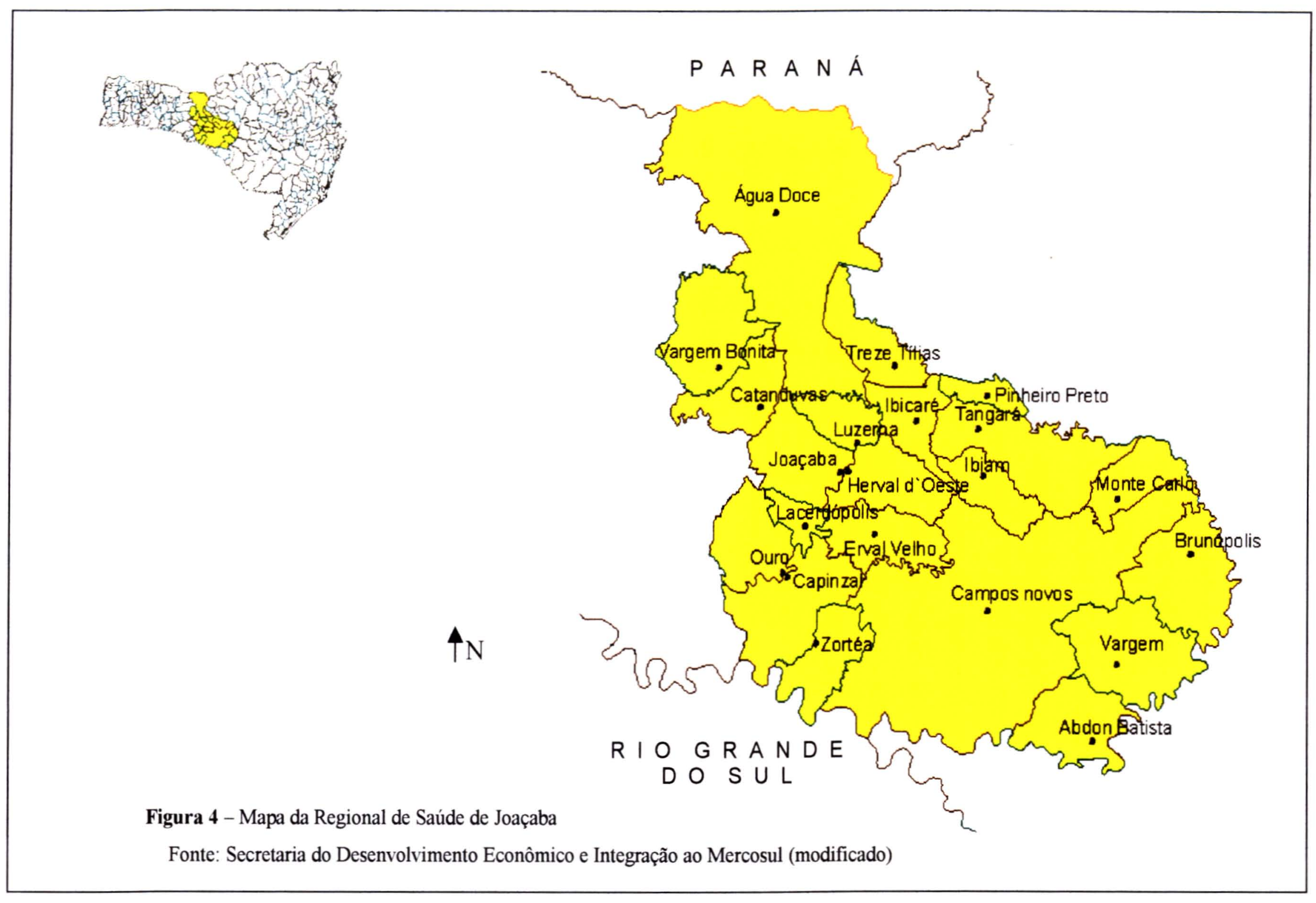


Os motivos pelos quais as Regiões da Grande Florianópolis e Joaçaba, foram selecionadas para este estudo são: o fato de localizar na capital do Estado de Santa Catarina, o Hemocentro Regional de Florianópolis - HRF e o Serviço de Hemoterapia do Hospital Universitário, da Universidade Federal de Santa Catarina SHHU/UFSC, onde acorrem os maiores contingentes de candidatos à doação de sangue, nativos da região e de outros Estados; a existência de hemocentros com arquivos de dados sistematizados ou parcialmente informatizados para os anos do estudo; o fato da Região de Joaçaba possuir um dos Hemocentros Regionais melhor estruturado e estar situado próximo à regiões endêmicas para infecção por $T$. cruzi do Estado vizinho do Rio Grande do Sul, conforme pesquisa soroepidemiológica realizada no final da década de 1970; aliado ainda às intensas migrações populacionais. (OLIVEIRA e col. 1970; FERREIRA NETO e col. 1971; SCHLEMPER JÚNIOR e col. 1974, 1983, 1985, 1989; STENDEL e col. 1984, 1994)

A totalidade de Unidades Hemoterápicas do Estado não foi possivel estudar, em vista da indisponibilidade de informações em outras áreas ainda não inseridas no sistema informatizado dos hemocentros com sede na Capital, Florianópolis, como também devido a escassez de material existente, no periodo estudado. De forma semelhante não foi possivel estudar a série histórica do periodo estabelecido na recomendação inicial no Hemocentro Regional de Joaçaba, pois apenas a partir de 1995 pôde-se contar com informações sistemáticas, ano de sua implantação

Para este estudo foram também utilizados dados cadastrados na Diretoria de Vigilância Sanitária (DVS), da Secretaria de Estado da Saúde (SES), que recebe relatórios mensais de serviços prestados pelas Unidades Hemoterápicas, públicas e privadas, localizadas nas 18 Regionais de Saúde (RS), integrantes da estrutura administrativa da Secretaria de Estado da Saúde, e classificadas, segundo o MINISTÉRIO DA SAÚDE (2001), em categorias, como: hemocentros, núcleos de hamatologia-hemoterapia, serviço de hemoterapia, banco de sangue e agência transfusional (Anexo XV)

Estes serviços informam mensalmente por meio de impresso próprio, atendendo a legislação pertinente, o número de candidatos à doação, submetidos à 
triagem clínica e sorológica, o número de doações e o número de transfusões realizadas

As transfusões são informadas de acordo com a forma e a fração do sangue utilizada, distribuidas em categorias, quais sejam: sangue total; concentrado de hemácias; plasma; plaquetas e crio-precipitado (fator VIII e IX). Os resultados dos exames sorológicos para sífilis, doença de Chagas, SIDA e hepatite, também são informados.

Para efeito de análise foram considerados:

Doador: todo individuo saudável que doou o seu sangue, após aprovação, que se submeteu à triagem clinica;

Primodoador: doador que realizou apenas uma doação de sangue;

Doador de repetição: doador que realizou duas ou mais doações de sangue.

Número de doações: número de doações realizadas pelos indivíduos que, uma vez aprovados na triagem clínica, realizaram a doação.

Candidato inapto na triagem sorológica: aquele individuo que, aprovado na triagem clínica, fez a doação, porém, seu sangue não foi usado, pois na triagem sorológica apresentou reação positiva para os testes realizados na unidade de sangue coletada. Estes testes são determinados pela legislação pertinente ou por consenso técnico científico.

\subsection{Universo do trabalho}

O universo estudado no presente trabalho é constituído pelas áreas onde residem e as pessoas que doaram sangue no Hemocentro Regional de Florianópolis e Serviço de Hemoterapia do Hospital Universitário-HU/UFSC, Região da Grande Florianópolis, no periodo de 10 anos (1990-99); e Hemocentro Regional de Joaçaba, Região de Joaçaba, no periodo de 5 anos (1995-99). 


\subsection{População do estudo}

A população-alvo estudada constituiu-se da totalidade de pessoas que, voluntariamente, doaram sangue, nas Unidades Hemoterápicas, como o Hemocentro Regional de Florianópolis, do Centro de Hematologia e Hemoterapia de Santa Catarina - HEMOSC e Serviço de Hemoterapia do Hospital Universitário - HU / UFSC, localizados em Florianópolis, Capital; e Hemocentro Regional de Joaçaba, também do HEMOSC, da Região de Joaçaba, Estado de Santa Catarina, no período de 1990 a 1999. Essa população corresponde a, aproximadamente, 40\% de cobertura, em termos de atendimento na área da hemoterapia no Estado de Santa Catarina. Os doadores foram classificados, quanto ao número de doações, em: primodoadores e doadores de repetição

Foram estudados 159.829 doadores, que realizaram um total de 204.025 doações de sangue no referido período. Esses dados referem-se ao número de doadores e de doações, pois um doador sadio pode doar sangue mais de uma vez, sendo classificado como doador de repetição, o que é vedado aos doadores impedidos, recusados após a $1^{\circ}$ doação, por apresentarem sorologia positiva. Entretanto, podem ocorrer casos de um doador de repetição, apresentar soconversão, ou seja, apresentar resultados de exames positivos, em doações posteriores.

Esta população caracteriza-se por apresentar idade entre 18 a 60 anos, peso superior a 50 quilos e ser considerada hígida após a triagem clínica

\subsection{Variáveis do Estudo}

- Doadores de sangue soropositivos por infecção pelo $T$. cruzi.

Foram considerados soropositivos os individuos identificados pelos serviços de hemoterapia em, pelo menos, um dos exames laboratoriais realizados como ELISA, Hemaglutinação Indireta ou Imunofluorescência Indireta, tornando-se inaptos por doença de Chagas, para doar sangue, constando, portanto, da Relação de Doadores Impedidos do Sistema de Controle Hemoterápico. Definiu-se ainda, para 
os estudos de prevalência e avaliação do risco de transmissão transfusional, como "caso de doença de Chagas", todo indivíduo com sorologia positiva em, pelo menos, dois exames diferentes realizados numa primeira amostra, com confirmação sorológica em segunda amostra, prevalecendo, dentre os vários exames, a Imunofluorescência Indireta.

Os casos com resultados sorológicos indeterminados para doença de Chagas observados nas Unidades Hemoterápicas estudadas, principalmente do Serviço de Hemoterapia do HU/UFSC, foram, na sua maioria, encaminhados ao Laboratório de Protozoologia do Departamento de Microbiologia e Parasitologia - MIP, da Universidade Federal de Santa Catarina - UFSC, atualmente reconhecido como Laboratório de Referência no Estado de Santa Catarina para o diagnóstico da doença de Chagas, para esclarecimentos.(SECRETARIA DE ESTADO DA SAÚDE, 2001).

Os infectados chagásicos são encaminhados ao Hospital Universitário da UFSC, clínicas, e para a rede básica de saúde do Sistema Único de Saúde - SUS, para tratamento.

\section{- Naturalidade}

A origem ou local de nascimento do doador soropositivo foi estudada, procurando-se saber a porcentagem de indivíduos originários de outros Estados com áreas endêmicas para doença de Chagas, que migraram para o Estado de Santa Catarina, onde realizaram doações de sangue, levando a riscos de transmissão transfusional.

\section{- Idade}

Para o estudo desta variável foram utilizadas 5 faixas etárias, como: de 18 a 20; de 21 a 30; de 31 a 40; de 41 a 50 e de 51 a 60 anos, conforme observado em outros trabalhos (BARUFFA 1985; BASSO 1999). 
- Sexo

Quando a indicação específica, quanto a variável sexo, não constava na ficha "Cadastro do doador", este foi considerado como ignorado.

\section{-Ocupação}

A ocupação do doador soropositivo foi observada, com o intento de esclarecer possível relação entre esta variável com a ocorrência da enfermidade. Para tanto foram agrupadas de acordo com a Classificação Brasileira de Ocupações CBO, do Ministério do Trabalho e Emprego - TEM (MINISTÉRIO DO TRABALHO E EMPREGO 2002).

\section{- Estado Civil}

Esta variável foi distribuída, considerando-se 2 categorias, como: solteiro e casado. Os casos não registrados foram identificados como de estado civil ignorado.

\subsection{Coleta de dados}

Foram coletados no Hemocentro Regional de Florianópolis, do Centro de Hematologia e Hemoterapia do Estado de Santa Catarina - HEMOSC, e Serviço de Hemoterapia do Hospital Universitário - HU/UFSC. Aqueles relativos ao período de 1990 a 1996, ainda não informatizados, foram coletados diretamente das fichas "Cadastro do doador" (Anexo V), devidamente arquivadas na sua forma original ou microfilmadas e organizadas por ordem alfabética. Foram também utilizados Relatórios Diários ou Mensais de Doadores Impedidos, existentes na Divisão de Vigilância Sanitária, da Secretaria de Estado da Saúde do Estado de Santa Catarina. 
Aqueles dados concernentes ao período de 1997 a 1999, já informatizados, foram extraídos de relatórios gerados pelo Sistema de Controle Hemoterápico.

No Hemocentro da Região de Joaçaba, os dados existentes apenas a partir do ano de 1995, foram extraidos diretamente das fichas "Cadastro do doador", arquivadas na sua forma original, e organizadas por municípios que compõem a região, disponibilizadas em ordem alfabética.

\subsection{Período de seleção e população analisada.}

Estão incluídos no estudo, todos os indivíduos que se apresentaram nas Unidades Hemoterápicas das regiões anteriormente citadas, para doação espontânea na coleta interna ou externa de sangue, com sorologia positiva em, pelo menos, um dos exames Elisa - Enzime Linked Immunosorbent Assay, HI-Hemaglutinação Indireta ou IFI-Imunofluorescência Indireta, realizados no período de 1990 a 1999. Dos 159.829 doadores que procuraram as Unidades Hemoterápicas de Florianópolis e Joaçaba, 21.289 preencheram os critérios de elegibilidade como doadores de repetição, após triagem sorológica.

Destes, considerando a disponibilidade dos dados para o estudo da incidência, foram observadas 2 soroconversões positivas e 3 indeterminadas, no Hemocentro Regional de Florianópolis, no período de 01.01 .97 a $18.06 .99 ; 1$ soroconversão e 10 indeterminadas no Serviço de Hemoterapia do HU/UFSC, no periodo de 01.01 .90 a 31.12 .99 ; e apenas uma soroconversão indeterminada, no Hemocentro Regional de Joaçaba, no periodo de 01.01 .95 a 31.12.99, detectadas nos doadores de repetição, quando da triagem sorológica que os habilitaria à transfusão.

\subsection{Análise estatística e interpretação dos resultados.}

Trata-se de um estudo que tem como modelo estatístico uma coorte histórica retrospectiva, onde foi estudada a ocorrência dos casos de doença de Chagas entre 
doadores dos bancos de sangue, no periodo de 1990 a 1999, na Região da Grande Florianópolis, e de 1995 a 1999 na Região de Joaçaba, Estado de Santa Catarina.

Um banco de dados em programa Epi Info V. A6 (DEAN e col. 1994), foi elaborado, para processar informações sobre as populações incluidas neste trabalho

No estudo de prevalência, foi realizada a análise descritiva dos dados com distribuição de freqüências, segundo a naturalidade ou procedência, ano, faixa etária, sexo, estado civil e ocupação.

A taxa de prevalência dos doadores de sangue soropositivos para a infecção pelo $T$. cruzi, foi calculada, utilizando-se o número de doadores soropositivos como numerador e como denominador, o número de primodoadores, doadores de repetição ou total de doadores de sangue. Considerou-se também, para maior precisão dos resultados nos cálculos de prevalência e incidência, os casos indeterminados. Para tanto, foi estimado o número de possiveis confirmações dos resultados indeterminados, utilizando-se a "taxa de confirmação" diagnóstica verificada a partir dos resultados de exames observados em primeira amostra, no momento da doação, e em segunda amostra, colhida após 30 dias da doação do sangue

A relação entre a data de doação, idade do doador, as taxas de prevalência e o risco de transmissão transfusional com respectivos intervalos de $95 \%$ de confiança, foram calculados, usando-se o programa citado.

Para o estudo da incidência, foi utilizado o modelo estatístico de uma coorte não controlada entre doadores de repetição, para detectar a positividade nas soroconversões anti-T. cruzi. Para o seu cálculo utilizou-se o número de doadores de repetição soroconvertidos para infecção por $T$. cruzi, no período estudado, dividido pelo somatório de tempo decorrido entre a penúltima e a última doação efetuada por todos os doadores de repetição observados, que participaram do estudo, chamado pessoa-tempo, aqui denominado pessoa-dia

Utilizou-se, para o cálculo da incidência no Hemocentro Regional de Florianópolis, uma casuistica menor de aproximadamente 2 anos e meio, periodo de 01.01.97 a 18.06.99, o fato de ter os dados já informatizados e apresentados em publicações científicas (KUPEK 2001b), o que entendemos facilitar a sua coleta e denotar fidedignidade 
Foi calculado o "Risco residual" de infecção nos receptores de sangue, nos serviços de hemoterapia das Unidades Hemoterápicas do Hemocentro Regional de Florianópolis - HRF, no período de 01.01.97 a 18.06.99, e Serviço de Hemoterapia do Hospital Universitário - HU / UFSC, no período de 01.01.90 a 31.12.99, localizados em Florianópolis, Capital, correspondendo neste estudo à Região da Grande Florianópolis; e Hemocentro Regional de Joaçaba - HRJ, no período de 01.01.95 a 31.12.99, da região de Joaçaba, do Estado de Santa Catarina.

Para tanto, utilizou-se o modelo descrito por CANUTTI JÚNIOR (1998), que consiste em multiplicar a incidência ajustada da doença de Chagas pelo periodo de janela imunológica. Este foi o método usado no Brasil pelo autor, para calcular o Risco Residual de Transmissão Transfusional de várias doenças transmissíveis pelo sangue, a partir do estudo de 5.688 doadores de repetição, do Hemocentro Regional da Faculdade Estadual de Medicina de Marília - FAMEMA, São Paulo.

No referido estudo utilizou-se a definição convencional de "período de janela imunológica", ou seja, o tempo que decorre entre a infecção até à formação de anticorpos detectáveis pelos testes sorológicos. Para o agente etiológico T. cruzi, transcorre um período médio de 28 dias.

\section{$\underline{\text { Risco Residual }}=\underline{\text { Incidência Ajustada }} \times$ Período de janela imunológica}

Risco Residual é a possibilidade remanescente de uma unidade hemoterápica, de transmitir doença, mesmo após triagem clínica (entrevista e exame físico) e sorologia adequadas. (KORELITZ e col. 1994, 1997; LACKRITZ e col. 1995; SCHREIBER e col. 1996; CANUTTI JÚNIOR 1998).

$\mathrm{O}$ modelo Incidência Ajustada x Período de Janela imunológica, utiliza a mensuração indireta do risco através de uma hipótese que possa ser aplicada a populações especificas e bem definida. Tem como principio a utilização de duas medidas comuns de risco em pesquisa médica, que são a prevalência e incidência. $A$ prevalência fornece dados sobre o número e percentuais de indivíduos que estão afetados pela doença. Nos parece mais importante, a questão relacionada aos doadores negativos que se tornaram positivos, ou seja, apresentaram uma soroconversão. A taxa de soroconversão relaciona-se com a incidência, sendo uma variável importante para estimar o número de doações soronegativas infectantes. 
Para o estudo da incidência ajustada o denominador da expressão "pessoatempo", foi ajustado àqueles doadores que se tornaram positivos no acompanhamento, ou seja, assumir que a soroconversão tenha se dado no ponto médio entre as últimas doações. Considerado para fins de cálculo, como a metade do tempo decorrido entre a penúltima e a última doação que apresentou o resultado soropositivo.

Este método tem como vantagem expressar o risco residual com base no número de unidades transfundidas e não no número de receptores que se tornaram positivos. (ZUCK 1995; SCHREIBER e col. 1996; KORELITZ 1997; CANUTTI JUNIOR 1998).

Várias são as causas que levam à permanência do risco residual. Dentre as razões pelas quais a transmissão do agente infeccioso pode ocorrer, podemos citar: doador no periodo de janela imunológica, ou seja, o tempo que decorre entre a infecção pelo $T$. cruzi até à detecção pelos testes sorológicos da presença de anticorpos; - resultado falso-negativo, decorrente de títulos de anticorpos abaixo do limite de detecção do teste; - resultado falso-negativo, devido a perda de sensibilidade do teste, conseqüente da variação genética do agente; - resultados falsonegativos, decorrentes de erros laboratoriais. (MARTELLI e col. 1992; LANGHI JUNIOR 1998; KLEINMAN e col. 1988,1997; CANUTTI JUNIOR 1998).

\subsection{Considerações Éticas}

A pesquisa foi desenvolvida após aprovação do projeto intitulado " $R$ iscos de transmissão da doença de Chagas por transfusão sanguínea, no Estado de Santa Catarina", pelo Comitê de Ética em Pesquisas - COEP, da Faculdade de Saúde Pública da Universidade de São Paulo (Protocolo $n^{\circ} 329$, Sessão Ordinária realizada em 15 de agosto de 2000).

O nome dos doadores, constante da Relação dos Doadores Impedidos, foi excluido do banco de dados, após ter sido utilizado para a elucidação de variáveis e revisão de dados das fichas Cadastro do Doador, salvaguardando-se, assim, suas identidades. 
4 RESULTADOS E DISCUSSÃO 


\section{RESULTADOS E DISCUSSÃO}

Foram analisados dados referentes a 204.025 doações de sangue efetuadas por 159.829 doadores, nas Unidades Hemoterápicas do: Hemocentro Regional de Florianópolis (HRF); Serviço de Hemoterapia do Hospital Universitário, da Universidade Federal de Santa Catarina (SHHU/UFSC), Florianópolis; e Hemocentro Regional de Joaçaba (HRJ), localizadas, respectivamente, nas Regionais de Saúde da Grande Florianópolis e Joaçaba, no Estado de Santa Catarina.

Estas doações foram realizadas por 128.908 doadores, no período de 01.01 .90 a 31.12.99, no Hemocentro Regional de Florianópolis; 17.553 efetuaram, no mesmo periodo, suas doações no Serviço de Hemoterapia do HU/UFSC - Florianópolis; e 13.368, no período de 01.01.95 a 31.12.99, no Hemocentro Regional de Joaçaba, observando-se 186 casos soropositivos e 108 indeterminados para infecção por T. cruzi, entre o total de doadores de sangue (Tabela 3 ).

Tabela 3 - Número de doações, primodoadores, doadores de repetição, total de doadores, casos (positivos e indeterminados). Hemocentro Regional de Florianópolis, Serviço de Hemoterapia do HU/UFSC - Florianópolis e Hemocentro Regional de Joaçaba. Estado de Santa Catarina, 1990 a 1999.

\begin{tabular}{|c|c|c|c|c|c|c|c|c|c|c|}
\hline \multirow{2}{*}{$\begin{array}{l}\text { Unidade } \\
\text { Hemoterápica }\end{array}$} & \multirow{2}{*}{ Doaçôes } & \multirow{2}{*}{$\begin{array}{l}\text { Primo- } \\
\text { doadores }\end{array}$} & \multicolumn{2}{|c|}{ Casos } & \multirow{2}{*}{$\begin{array}{c}\text { Doadores } \\
\text { de } \\
\text { repetição }\end{array}$} & \multicolumn{2}{|c|}{ Casos } & \multirow{2}{*}{$\begin{array}{l}\text { Total de } \\
\text { doadores }\end{array}$} & \multicolumn{2}{|c|}{ Casos } \\
\hline & & & Pos. & Ind. & & Pos. & Ind. & & Pos. & Ind \\
\hline $\begin{array}{l}\text { Hemocentro } \\
\text { Regional de } \\
\text { Florianópolis }\end{array}$ & 147.962 & 114.844 & 114 & 30 & 14.064 & 22 & 10 & 128.908 & 136 & 40 \\
\hline $\begin{array}{l}\text { Serviço de } \\
\text { Hemoterapia } \\
\text { HU / UFSC }\end{array}$ & 24.162 & 14.523 & 34 & 56 & 3.030 & 1 & 10 & 17.553 & 35 & 66 \\
\hline $\begin{array}{l}\text { Hemocentro } \\
\text { Regional de } \\
\text { Joaçaba* }\end{array}$ & 31.901 & 9.173 & 15 & 1 & 4.195 & - & 1 & 13.368 & 15 & 2 \\
\hline TOTAL & 204.025 & 138.540 & 163 & 87 & 21.289 & 23 & 21 & 159.829 & 186 & 108 \\
\hline
\end{tabular}

* Periodo: 01.01 .95 a 31.01 .99

Fonte: Centro de Hematologia e Hemoterapia do Estado de Santa Catarina HEMOSC / SES. Hospital Universitário - HU/UFSC. 
Foram observados, 23 casos com sorologia chagásica positivos e 21 indeterminados, entre os doadores de repetição nas Unidades Hemoterápicas estudadas. Destes, foram encontrados 22 soropositivos e 10 indeterminados no Hemocentro Regional de Florianópolis; 1 soropositivo e 10 indeterminados no Serviço de Hemoterapia do HU/UFSC, no período de 01.01.90 a 31.12.99: e apenas 1 caso com sorologia indeterminada no Hemocentro Regional de Joaçaba, no período de 01.01 .95 a 31.12 .99 .

Os resultados obtidos dessa análise são apresentados a seguir. Inicialmente, são apresentados os dados referentes ao estudo realizado nas 02 Unidades Hemoterápicas (HRF e SHHU/UFSC) da Região da Grande Florianópolis, onde localiza-se a Capital do Estado de Santa Catarina que recebe doadores não somente dos municípios que compõem a Regional de Saúde de Florianópolis, mas também de outros Estados da Federação; e, em seguida, aqueles do HRJ, situado na Região de Joaçaba, considerada importante por receber doadores de 48 municípios, sendo 21 que compõem a Regional de Saúde do mesmo nome e mais 27 outros de sua área de abrangência, considerada pólo de atração comercial da região (Figuras 2, 3 e 4; Anexos II e III).

O Hemocentro Regional de Florianópolis atende necessidades hemoterápicas de 24 hospitais localizados na Região da Grande Florianópolis e 6 de outras regiões; - Serviço de Hemoterapia do HU/UFSC atende pacientes internados no próprio hospital; e o Hemocentro Regional de Joaçaba, 35 hospitais de sua região de abrangência (Anexo IV).

\subsection{Região da Grande Florianópolis}

Neste capítulo, são apresentados os resultados das análises efetuadas com os dados obtidos junto às Unidades Hemoterápicas do Hemocentro Regional de Florianópolis e Serviço de Hemoterapia do Hospital Universitário - HU, da Universidade Federal de Santa Catarina - UFSC, localizadas em Florianópolis, Região da Grande Florianópolis, Estado de Santa Catarina. 
O município de Florianópolis concentra as atividades de hemoterapia dos hospitais localizados nos 22 municípios que compõem a GRANFPOLIS Associação dos municípios da Grande Florianópolis ou $18^{\mathrm{a}}$ Regional de Saúde e outros 6 municipios (Anexo IV).

Embora considerado indene para infecção por T. cruzi, Florianópolis, Capital do Estado de Santa Catarina, recebe doadores procedentes das mais diversas áreas endêmicas de outros Estados da Federação.

Todos os serviços hemoterápicos, além da triagem clínica, realizaram a triagem sorológica nos candidatos à doação de sangue, e foram orientados pela legislação vigente a descartar o sangue proveniente de doador infectado por qualquer doença. Não se detectou a prática da quimioprofilaxia do sangue, pela adição de violeta genciana, em nenhum serviço.

Apresentou o maior número de doações de sangue registrada no período, ou seja, 172.124 bolsas de sangue foram identificadas. Estas, após serem submetidas a triagem sorológica com a realização de exames para doença de Chagas e outras doenças como a sifilis, hepatite e AIDS, no periodo estudado de 1990 a 1999, 15.806 $(9,18 \%)$ foram consideradas soropositivas para todas as doenças, e $277(0,16 \%)$ apresentaram sorologia positiva para infecção chagásica (Tabela 4).

Tabela 4 - Distribuição do número de doações e soropositividade para todas as doenças e doença de Chagas nas Unidades Hemoterápicas de Florianópolis (HRF, SHHU/UFSC). Região da Grande Florianópolis. Estado de Santa Catarina, 1990 a 1999.

\begin{tabular}{|c|c|c|c|c|c|c|c|}
\hline \multirow{2}{*}{ Ano } & \multirow{2}{*}{ Doações } & \multirow{2}{*}{ Soropositivos } & \multirow{2}{*}{$\%$} & \multicolumn{3}{|c|}{ Doença de Chagas } & \multirow{2}{*}{$\%$} \\
\hline & & & & Pos. & Indet. & Total & \\
\hline 90 & 11.010 & 437 & 3,96 & 18 & 3 & 21 & 0,19 \\
\hline 91 & 12.762 & 738 & 5,78 & 19 & 1 & 20 & 0,16 \\
\hline 92 & 12.721 & 766 & 6,02 & 23 & 2 & 25 & 0,20 \\
\hline 93 & 14.153 & 918 & 6,49 & 25 & 5 & 30 & 0,21 \\
\hline 94 & 14.257 & 1.942 & 13,62 & 19 & 13 & 32 & 0,22 \\
\hline 95 & 16.727 & 2.183 & 13,05 & 23 & 10 & 33 & 0,20 \\
\hline 96 & 17.950 & 1.648 & 9,18 & 15 & 14 & 29 & 0,16 \\
\hline 97 & 22.514 & 2.394 & 10,63 & 15 & 19 & 34 & 0,15 \\
\hline 98 & 24.941 & 2.311 & 9,26 & 11 & 26 & 37 & 0,15 \\
\hline 99 & 25.089 & 2.469 & 9,84 & 3 & 13 & 16 & 0,06 \\
\hline TOTAL & 172.124 & 15.806 & 9,18 & 171 & 106 & 277 & 0,16 \\
\hline
\end{tabular}


Quando se analisa na triagem sorológica, o conjunto das doações efetuadas no Hemocentro Regional de Florianópolis e Serviço de Hemoterapia do HU/UFSC, a distribuição percentual da soropositividade para todas as doenças, observa-se uma variação com incremento percentual de 3,96\% em 1990, elevando-se para $13,62 \%$ no ano de 1994 e diminuindo para 9,84\% no ano de 1999, tendo um percentual médio de $9.18 \%$ de positividade. Da mesma forma, verifica-se um aumento de soropositividade para infecção por $T$. cruzi, de 0,19 a 0,22 no período de 1990 a 1994, decrescendo, entretanto, para 0,06 em 1999, com percentual médio de positividade de 0,16\% no período de 1990 a 1999 (Tabela 4).

Resultados semelhantes, concernentes à triagem sorológica, foram encontrados em Belo Horizonte, Minas Gerais, no ano de 1998, onde foi observado que $10 \%$ das doações efetuadas junto à hemorrede pública foram rejeitadas por inaptidão sorológica por diversas causas. Em relação à infecção chagásica, estudos realizados no mesmo local, em 1995, tiveram confirmação diagnóstica em 1,47\% das doações realizadas (GONTIJO 2000).

LOPES, em 1996, mostrou na Fundação Hemocentro de São Paulo, que o indice de descarte de bolsas por positividade da sorologia para infecção chagásica no ano de 1991 , foi cerca de $3 \%$, e de $2,5 \%$ no ano de 1992 . Observou ainda o descarte de $1,62 \%$, entre doadores de sangue, no ano de 1993 .

Segundo BASSO (1999), este seria um índice esperado para uma área considerada não endêmica, conforme inquérito soroepidemiológico realizado anteriormente, na década de 1970.

O número de doadores de sangue no período de 1990 à 1999, no conjunto das Unidades Hemoterápicas da Região da Grande Florianópolis, como o Hemocentro Regional de Florianópolis e Serviço de Hemoterapia do HU/UFSC, localizadas em Florianópolis, Capital do Estado de Santa Catarina, foi de 146.461 individuos, dos quais $171(0,12 \%)$ foram soropositivos e $106(0,07 \%)$ casos indeterminados para infecção por T. cruzi. O Hemocentro Regional de Florianópolis apresentou um percentual médio de $0,13 \%$ de positividade entre seus 128.908 doadores, enquanto que no Serviço de Hemoterapia do Hospital Universitário da Universidade Federal de Santa Catarina - SHHU/UFSC, observou-se um percentual de 0,57\% para infecção por T.cruzi, em 17.553 doadores (Tabela 5). 
Quando analisados na sua totalidade os dados das duas Unidades Hemoterápicas, aparentemente, não houve variação importante da proporção de soropositivos no período de 1990 a 1999, que variou de $0,21 \%$ em 1990 à $0,19 \mathrm{em}$ 1998, porém, decresceu significativamente à taxa de 0,07\%, em 1999 .

Apresentou, entretanto, uma prevalência de infecção para T. cruzi, de 0,19\% entre os 146.461 doadores estudados na Região da Grande Florianópolis, o que indica a presença da infecção chagásica nos doadores de sangue (Tabela 5). 
Tabela 5 - Distribuição do número de doadores de sangue e da infecção por T. cruzi nas Unidades Hemoterápicas do Hemocentro Regional de Florianópolis e Serviço de Hemoterapia do HU/UFSC. Região da Grande Florianópolis. Estado de Santa Catarina, 1990 a 1999.

\begin{tabular}{|c|c|c|c|c|c|c|c|c|c|c|c|c|c|c|c|}
\hline \multirow{2}{*}{ ANO } & \multicolumn{5}{|c|}{ Hemocentro Regional de Florianópolis } & \multicolumn{5}{|c|}{$\begin{array}{c}\text { Serviço de Hemoterapia do } \\
\text { HU / UFSC }\end{array}$} & \multicolumn{5}{|c|}{$\begin{array}{l}\text { Região da Grande Florianópolis } \\
\text { (HRF + SHHU/UFSC) }\end{array}$} \\
\hline & Doadores & Pos. & Ind. & Total & $\%$ & Doadores & Pos. & Ind. & Total & $\%$ & Doadores & Pos. & Ind. & Total & $\%$ \\
\hline 1990 & 8886 & 5 & - & 5 & 0,05 & 1255 & 13 & 3 & 16 & 1,27 & 10141 & 18 & 3 & 21 & 0,21 \\
\hline 1991 & 10454 & 18 & - & 18 & 0,17 & 1395 & 1 & 1 & 2 & 0,14 & 11849 & 19 & 1 & 20 & 0,17 \\
\hline 1992 & 9986 & 17 & 1 & 18 & 0,18 & 1271 & 6 & 1 & 7 & 0,55 & 11257 & 23 & 2 & 25 & 0,22 \\
\hline 1993 & 9872 & 21 & 4 & 25 & 0,25 & 1468 & 4 & 1 & 5 & 0,34 & 11340 & 25 & 5 & 30 & 0,26 \\
\hline 1994 & 10535 & 18 & 5 & 23 & 0,22 & 1961 & 1 & 8 & 9 & 0,46 & 12496 & 19 & 13 & 32 & 0,26 \\
\hline 1995 & 13292 & 21 & 4 & 25 & 0,19 & 1762 & 2 & 6 & 8 & 0,45 & 15054 & 23 & 10 & 33 & 0,22 \\
\hline 1996 & 13607 & 11 & 6 & 17 & 0,12 & 1786 & 4 & 8 & 12 & 0,67 & 15393 & 15 & 14 & 29 & 0,19 \\
\hline 1997 & 15659 & 12 & 8 & 20 & 0,13 & 1985 & 3 & 11 & 14 & 0,70 & 17644 & 15 & 19 & 34 & 0,19 \\
\hline 1998 & 16493 & 10 & 10 & 20 & 0,12 & 2430 & 1 & 16 & 17 & 0,70 & 18923 & 11 & 26 & 37 & 0,19 \\
\hline 1999 & 20124 & 3 & 2 & 5 & 0,02 & 2240 & - & 11 & 11 & 0,49 & 22364 & 3 & 13 & 16 & 0,07 \\
\hline TOTAL & 128908 & 136 & 40 & 176 & 0,13 & 17553 & 35 & 66 & 101 & 0,57 & 146461 & 171 & 106 & 277 & 0,19 \\
\hline
\end{tabular}

Fonte: Centro de Hematologia e Hemoterapia do Estado de Santa Catarina - HEMOSC / SES. Hospital Universitário - HU/UFSC. 
A distribuição dos casos positivos e indeterminados ao longo do período estudado, 1990 a 1999, na Região da Grande Florianópolis, revela que houve na sua totalidade um aumento significativo, em termos percentuais, de 7,58\% em 1990 para 13,36 em 1998, decrescendo para 5,78 em 1999. Observa-se também no período, uma inversão da proporcionalidade dos casos soropositivos em relação aos indeterminados (Tabela 6; Figura 5).

Tabela 6 - Distribuição dos doadores de sangue soropositivos e indeterminados para infecção por T. cruzi, por ano. Região da Grande Florianópolis. Estado de Santa Catarina, 1990 a 1999.

\begin{tabular}{ccccccc}
\hline \multirow{2}{*}{ Casos } & \multicolumn{2}{c}{ Soropositivo } & \multicolumn{2}{c}{ Indeterminado } & \multicolumn{2}{c}{ Total } \\
\cline { 2 - 7 } Ano & $\mathrm{N}^{\mathrm{o}}$ & $\%$ & $\mathrm{~N}^{\mathrm{o}}$ & $\%$ & $\mathrm{~N}^{\circ}$ & $\%$ \\
\hline 1990 & 18 & 6,50 & 3 & 1,08 & 21 & 7,58 \\
1991 & 19 & 6,86 & 1 & 0,36 & 20 & 7,22 \\
1992 & 23 & 8,30 & 2 & 0,73 & 25 & 9,03 \\
1993 & 25 & 9,03 & 5 & 1,80 & 30 & 10,83 \\
1994 & 19 & 6,86 & 13 & 4,69 & 32 & 11,55 \\
1995 & 23 & 8,30 & 10 & 3,61 & 33 & 11,91 \\
1996 & 15 & 5,42 & 14 & 5,05 & 29 & 10,47 \\
1997 & 15 & 5,41 & 19 & 6,86 & 34 & 12,27 \\
1998 & 11 & 3,97 & 26 & 9,39 & 37 & 13,36 \\
1999 & 3 & 1,08 & 13 & 4,70 & 16 & 5,78 \\
\hline TOTAL & 171 & 61,73 & 106 & 38,27 & 277 & 100,00 \\
\hline
\end{tabular}

Fonte: Centro de Hematologia e Hemoterapia do Estado de Santa Catarina - HEMOSC / SES. Hospital Universitário - HU/UFSC.

A pequena porcentagem de casos, observada no final do período estudado, em 1999, possivelmente pode ter ocorrido, como resultado das ações de controle da enfermidade, empreendido nas regiões endêmicas de origem de muitos indivíduos que realizaram doações de sangue nas Unidades Hemoterápicas localizadas na Região da Grande Florianópolis, como àqueles oriundos dos Estados do Rio Grande do Sul, Paraná, São Paulo, entre outros (WANDERLEY 1994a; BASSO 1999; CARVALHO 2000). 


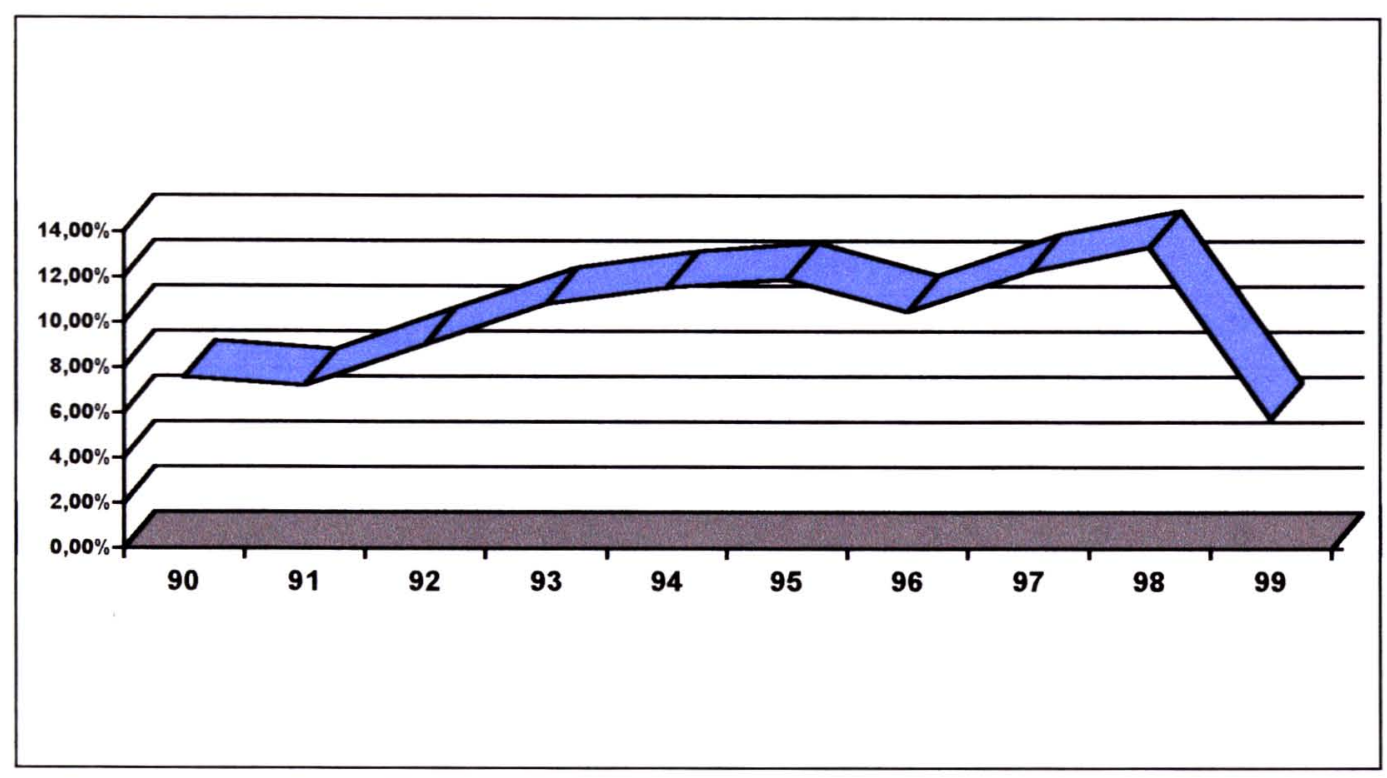

Figura 5 - Distribuição dos doadores de sangue soropositivos e indeterminados para infecção por T. cruzi, por ano. Região da Grande Florianópolis. Estado de Santa Catarina, 1990 a 1999.

\subsubsection{Caracterização da população sorologicamente positiva para Trypanosoma cruzi}

\section{- Naturalidade}

Quando se observa a distribuição da variável naturalidade dos doadores de sangue soropositivos e indeterminados para doença de Chagas, na Região da Grande Florianópolis (HRF e SHHU/UFSC), esta apresenta um percentual expressivo de, aproximadamente, $60 \%$ de doadores naturais do Estado de Santa Catarina.

Revela também, uma considerável população procedente de outros Estados, muitos dos quais de áreas endêmicas, com elevado percentual de doadores soropositivos, no período estudado, naturais de Estados como o Rio Grande do Sul $(19,86 \%)$, Paraná (4,69\%), São Paulo (3,25\%), entre outros (Tabela 7, Figura 6).

Esta procedência significativa de doadores de áreas endêmicas mostra a presença da infecção chagásica em indivíduos residentes, assim como, indica uma possível elevação do risco de transmissão transfusional da enfermidade no Estado de Santa Catarina. 
Tabela 7 - Distribuição dos doadores de sangue soropositivos e indeterminados para infecção por T.cruzi, quanto à naturalidade. Região da Grande Florianópolis. Estado de Santa Catarina, 1990 a 1999.

\begin{tabular}{|c|c|c|c|c|c|c|c|c|}
\hline \multirow[t]{2}{*}{ Naturalidade } & \multicolumn{3}{|c|}{$\begin{array}{l}\text { Hemocentro Regional de } \\
\text { Florianópolis }\end{array}$} & \multicolumn{3}{|c|}{$\begin{array}{c}\text { Serviço de Hemoterapia do } \\
\text { HU / UFSC }\end{array}$} & \multicolumn{2}{|c|}{ TOTAL } \\
\hline & Pos. & Ind. & Total & Pos. & Ind. & Total & $\mathbf{N}^{\circ}$ & $\%$ \\
\hline SC & 77 & 29 & 106 & 18 & 42 & 60 & 166 & 59,93 \\
\hline RS & 37 & 9 & 46 & 5 & 4 & 9 & 55 & 19,86 \\
\hline PR & 5 & - & 5 & 2 & 6 & 8 & 13 & 4,69 \\
\hline SP & 6 & 1 & 7 & - & 2 & 2 & 9 & 3,25 \\
\hline $\mathbf{R J}$ & 4 & 1 & 5 & 1 & 1 & 2 & 7 & 2,53 \\
\hline BA & 2 & - & 2 & - & - & - & 2 & 0,72 \\
\hline PB & 2 & - & 2 & - & - & - & 2 & 0,72 \\
\hline MT & 1 & - & 1 & - & - & - & 1 & 0,36 \\
\hline DF & 1 & - & 1 & - & - & - & 1 & 0,36 \\
\hline PE & 1 & - & 1 & - & - & - & 1 & 0,36 \\
\hline $\mathrm{CE}$ & - & - & - & 1 & - & 1 & 1 & 0,36 \\
\hline $\mathrm{IG}^{*}$ & - & - & - & 8 & 11 & 19 & 19 & 6,86 \\
\hline TOTAL & 136 & 40 & 176 & 35 & 66 & 101 & 277 & 100,00 \\
\hline
\end{tabular}

* Procedência ignorada

Fonte: Centro de Hematologia e Hemoterapia do Estado de Santa Catarina -HEMOSC / SES. Hospital Universitário - HU/UFSC

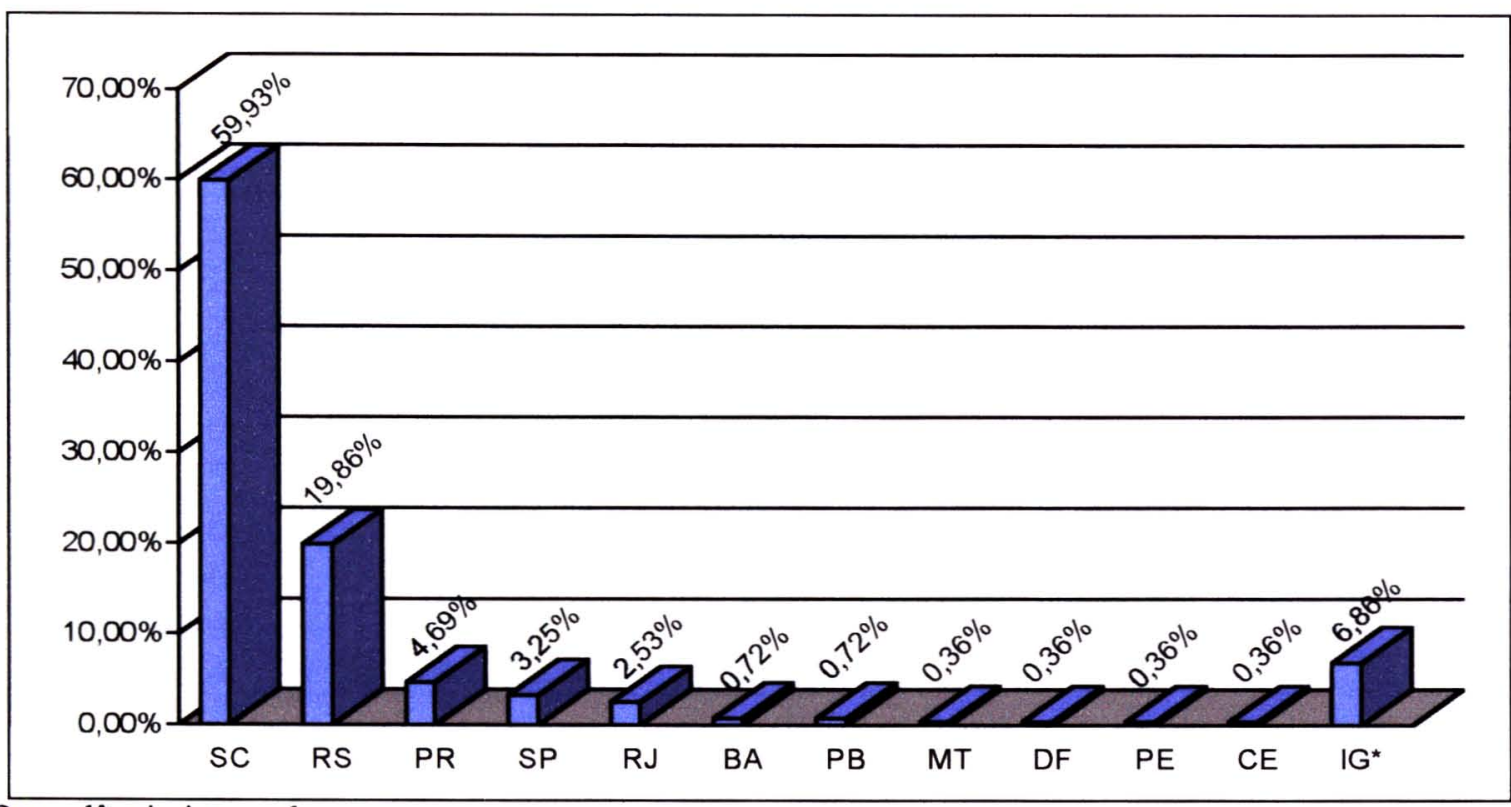

* Procedência ignorada

Figura 6 - Distribuição dos doadores de sangue soropositivos e indeterminados para infecção por T.cruzi, quanto à naturalidade. Região da Grande Florianópolis. Estado de Santa Catarina, 1990 a 1999. 


\section{- Faixa etária}

A distribuição dos doadores soropositivos e indeterminados, da Região da Grande Florianópolis, no periodo de 1990 a 1999, segundo a faixa etária, foi a seguinte: $62(22,39 \%)$ tinham entre 18 a 20 anos; 84 (30,32\%), entre 21 a 30 anos; 57 (20,58\%) entre 31 a 40 anos; $50(18,05 \%)$ entre 41 a 50 anos; e $24(8,66 \%)$ entre 51 a 60 anos de idade (Tabela 8; Figura 7)

Ao se analisar a distribuição por faixa etária, ao longo do periodo de 1990 a 1999, observa-se que houve uma maior concentração de doadores sorologicamente positivos, 84 (30,32\%) no grupo etário de 21 a 30 anos e que uma menor proporção 24 $(8,66 \%)$ pertencem à faixa etária entre 51 a 60 anos de idade, porém, com ocorrência em todas as faixas de idade dos doadores (Figura 7).

A redução do número de doadores soropositivos mais idosos, aponta para a possivel menor contribuição dessa faixa etária, no total das doações efetuadas.

Tabela 8 - Distribuição dos doadores de sangue soropositivos para infeç̧ão por T. cruzi por faixa etária e ano de doação. Região da Grande Florianópolis. Estado de Santa Catarina, 1990 a 1999.

\begin{tabular}{|c|c|c|c|c|c|c|c|c|c|c|c|c|}
\hline \multirow{3}{*}{ ANO } & \multicolumn{12}{|c|}{ FAIXA ETÁRIA (ANOS) } \\
\hline & \multicolumn{2}{|c|}{18 a 20} & \multicolumn{2}{|c|}{21 a 30} & \multicolumn{2}{|c|}{31 a 40} & \multicolumn{2}{|c|}{41 a 50} & \multicolumn{2}{|c|}{51 a 60} & \multicolumn{2}{|c|}{ TOTAL } \\
\hline & $N^{0}$ & $\%$ & $N^{0}$ & $\%$ & $N^{\circ}$ & $\%$ & $N^{\circ}$ & $\%$ & $N^{0}$ & $\%$ & $\mathrm{~N}^{\circ}$ & $\%$ \\
\hline 1990 & 13 & 61.90 & 1 & 4.76 & 3 & 14.29 & 3 & 14.29 & 1 & 4.76 & 21 & 7,58 \\
\hline 1991 & 1 & 5.00 & 4 & 20.00 & 9 & 45.00 & 1 & 5.00 & 5 & 25.00 & 20 & 7,22 \\
\hline 1992 & 12 & 48.00 & 5 & 20.00 & 3 & 12.00 & 3 & 12.00 & 2 & 8. & 25 & 9,03 \\
\hline 1993 & 5 & 16.67 & 9 & 30.00 & 7 & 23.33 & 9 & 30.00 & 0 & 0.00 & 30 & 10,83 \\
\hline 1994 & 6 & 18.75 & 14 & 43.75 & 5 & 15.62 & 4 & 12.50 & 3 & 9.38 & 32 & 11,55 \\
\hline 1995 & 5 & 15.15 & 10 & 30.30 & 5 & 15.15 & 10 & 30.30 & 3 & 9.10 & 33 & 11,91 \\
\hline 1996 & 6 & 20.69 & 9 & 31.03 & 5 & 17.24 & 7 & & 2 & 6.90 & 29 & 10,47 \\
\hline 1997 & 6 & 17.65 & 8 & 23.53 & 9 & 26.47 & 6 & 17.65 & 5 & 14.70 & 34 & 12,27 \\
\hline 1998 & 4 & 10.81 & 16 & 43.24 & 8 & 21.62 & 7 & 18.92 & 2 & 5.45 & 37 & 13,36 \\
\hline 1999 & 4 & 25.00 & 8 & 50.00 & 3 & 18.75 & 0 & 0 & 1 & 6.25 & 16 & 5,78 \\
\hline TOTAL & 62 & 22,39 & 84 & 30,32 & 57 & 20,58 & 50 & 18,05 & 24 & 8,66 & 277 & 100,00 \\
\hline
\end{tabular}

$\mathrm{N}^{\circ}=$ Soropositivos + indeterminados

Fonte: Centro de Hematologia e Hemoterapia do Estado de Santa Catarina - HEMOSC / SES. Hospital Universitário - HU/UFSC. 


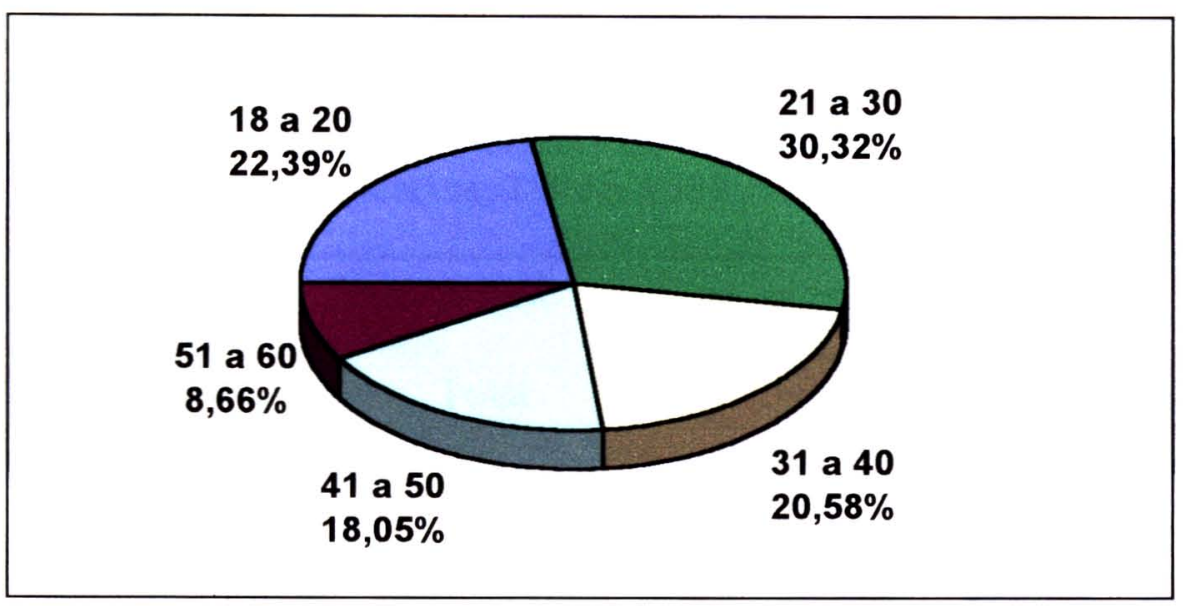

Figura 7 - Distribuição dos doadores de sangue soropositivos para infecção por $T$. cruzi por faixa etária e ano de doação. Região da Grande Florianópolis. Estado de Santa Catarina, 1990 a 1999.

\section{- Sexo}

No período de 1990 a 1999, a distribuição dos casos soropositivos e indeterminados por sexo, entre os doadores na Região da Grande Florianópolis, apresentou o percentual de $82,31 \%$ do sexo masculino, $16,61 \%$ femininos e $1,08 \%$ ignorados (Tabela 9; Figura 8).

Esta elevada proporção de soropositivos do sexo masculino reflete a distribuição semelhante ocorrida entre os doadores de sangue, geralmente observada em todo o país (SIQUEIRA-BATISTA e col. 1996; BRENER e col. 2000). Segundo o Ministério da Saúde, em 1993, $80 \%$ a $83 \%$ dos doadores de sangue brasileiros eram do sexo masculino (MINISTÉRIO DA SAÚDE 1993b). 
Tabela 9 - Distribuição dos doadores de sangue de sangue soropositivos e indeterminados para infecção por $T$. cruzi por sexo, nas Unidades Hemoterápicas (HRF e SHHU/UFSC). Região da Grande Florianópolis. Estado de Santa Catarina, 1990 a 1999.

\begin{tabular}{ccccccccc}
\hline \multirow{2}{*}{ Sexo } & \multicolumn{3}{c}{$\begin{array}{c}\text { Hemocentro Regional de } \\
\end{array}$} & \multicolumn{3}{c}{ Florianópolis } & \multicolumn{3}{c}{$\begin{array}{c}\text { Serviço de Hemoterapia } \\
\text { do HU / UFSC }\end{array}$} & \multicolumn{2}{c}{ Total } \\
\cline { 2 - 10 } & Pos. & Ind. & Total & Pos. & Ind. & Total & N $^{\text {o }}$ & $\%$ \\
\hline Masculino & 111 & 30 & 141 & 28 & 59 & 87 & 228 & 82,31 \\
Feminino & 24 & 8 & 32 & 7 & 7 & 14 & 46 & 16,61 \\
Ignorado* & 1 & 2 & 3 & - & - & - & 3 & 1,08 \\
\hline Total & 136 & 40 & 176 & 35 & 66 & 101 & 277 & 100,00 \\
\hline
\end{tabular}

* Sem registro do sexo.

Fonte: Centro de Hematologia e Hemoterapia do Estado de Santa Catarina HEMOSC / SES. Hospital Universitário - HU/UFSC.

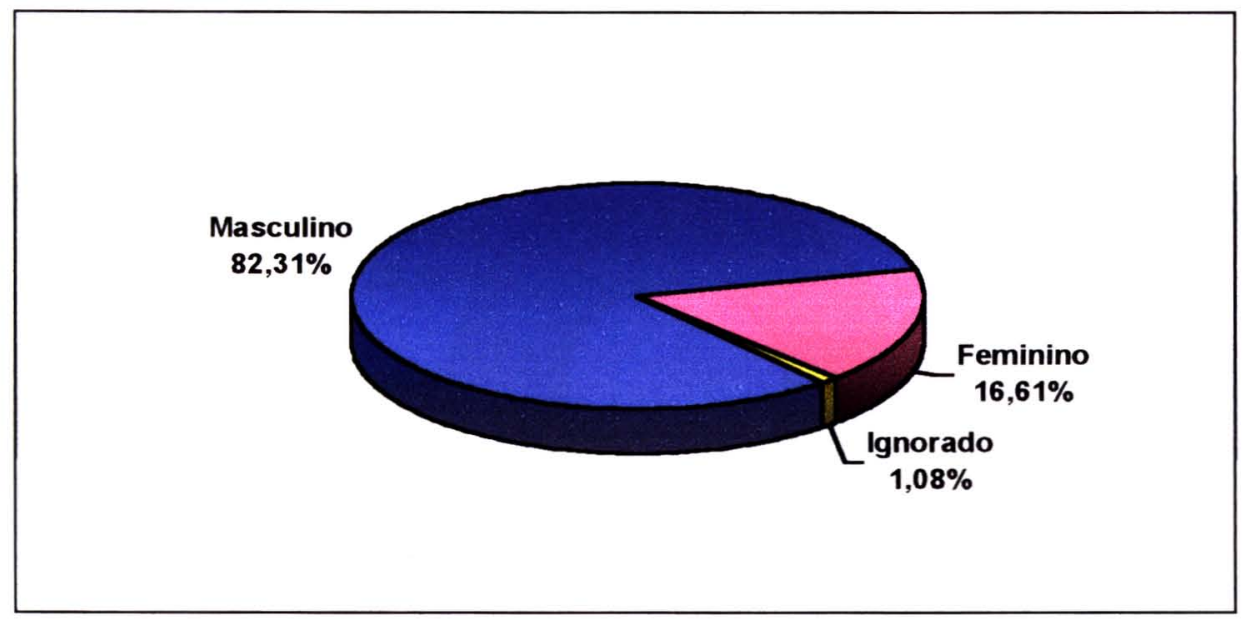

Figura 8 - Distribuição dos doadores de sangue soropositivos e indeterminados para infecção por T. cruzi por sexo. Região da Grande Florianópolis. Estado de Santa Catarina, 1990 a 1999.

\section{- Estado civil}

Dos 277 doadores de sangue soropositivos e indeterminados para T. cruzi observados no período de 1990 a 1999, os casados somaram $127(45,85 \%), 82(29,60 \%)$ eram solteiros, e $68(24,55 \%)$ não possuíam registros na ficha cadastral (Tabela 10; Figura 9). 
Tabela 10 - Distribuição dos doadores de sangue soropositivos e indeterminados para infecção por T. cruzi, quanto ao estado civil nas Unidades Hemoterápicas (Hemocentro Regional de Florianópolis e Serviço de Hemoterapia do HU/UFSC). Região da Grande Florianópolis. Estado de Santa Catarina, 1990 a 1999.

\begin{tabular}{lcccccccc}
\hline \multirow{2}{*}{$\begin{array}{c}\text { Estado } \\
\text { Civil }\end{array}$} & \multicolumn{3}{c}{$\begin{array}{c}\text { Hemocentro Regional de } \\
\text { Florianópolis }\end{array}$} & \multicolumn{3}{c}{$\begin{array}{c}\text { Serviço de Hemoterapia do } \\
\text { HU/UFSC }\end{array}$} & \multicolumn{2}{c}{ Total } \\
\cline { 2 - 9 } & Pos. & Ind. & Total & Pos. & Ind. & Total & $N^{\circ}$ & $\%$ \\
\hline Solteiro & 38 & 10 & 48 & 6 & 28 & 34 & 82 & 29,60 \\
Casado & 73 & 18 & 91 & 12 & 24 & 36 & 127 & 45,85 \\
Ignorado & 25 & 12 & 37 & 17 & 14 & 31 & 68 & 24,55 \\
\hline Total & 136 & 40 & 176 & 35 & 66 & 101 & 277 & 100,00 \\
\hline
\end{tabular}

*Sem registro

Fonte: Centro de Hematologia e Hemoterapia do Estado de Santa Catarina -HEMOSC. Hospital Universitário - HU/UFSC

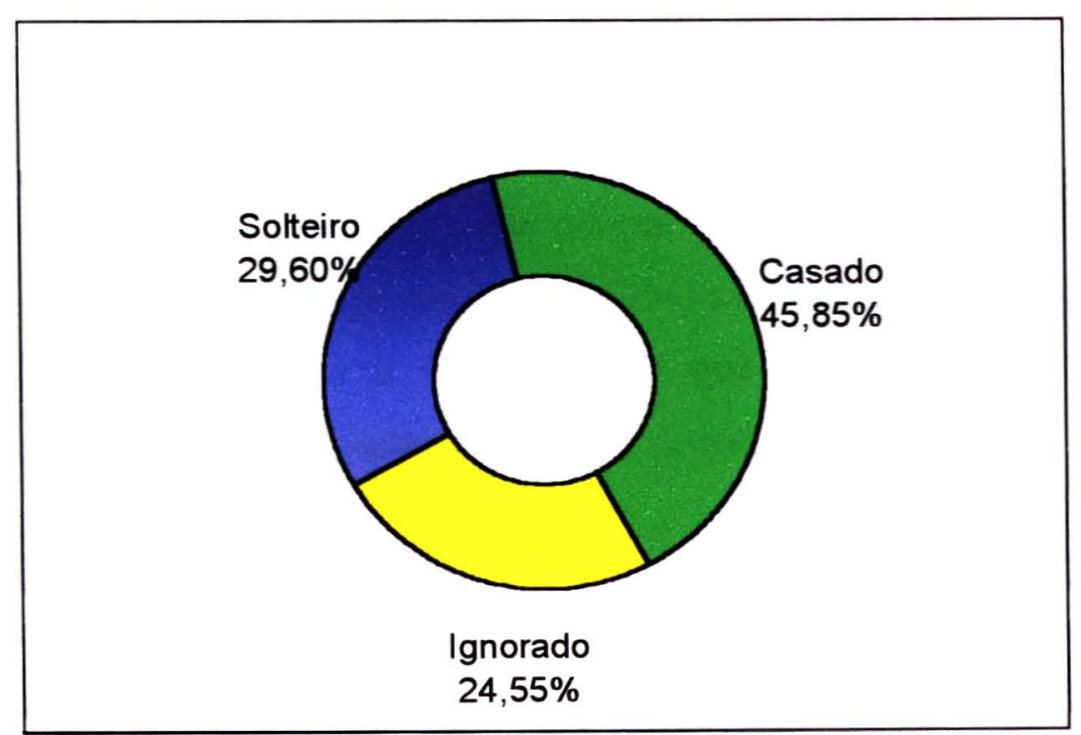

Figura 9 - Distribuição dos doadores de sangue soropositivos e indeterminados para infecção por $T$. cruzi, quanto ao estado civil, nas Unidades Hemoterápicas (HRF e SHHU/UFSC). Região da Grande Florianópolis. Estado de Santa Catarina, 1990 a 1999. 


\section{- Ocupação}

Relativamente à distribuição dos 277 doadores de sangue soropositivos e indeterminados para infecção por T. cruzi encontrados nas Unidades Hemoterápicas (HRF e SHHU/UFSC) da Região da Grande Florianópolis, estudadas no periodo de 1990 a 1999, observou-se o seguinte: 37 (13,36\%) desenvolviam atividades de serviços de turismo, hospedagem, serventia, higiene, embelezamento, segurança e auxiliares de saúde; $34(12,27 \%)$ eram trabalhadores da produção industrial e operadores de máquinas; $27(9,75 \%)$ atividades do serviço militar; 26 (9,39\%) trabalhadores das profissões científicas, técnicas, artísticas ou classificados em outras ocupações como estudantes, autônomos, aposentados; 14 (5.05\%) eram comerciantes ou funcionários públicos; 13 (4,69\%) trabalhadores de serviços administrativos; 12 (4,33\%) motoristas; e com menor ocorrência $8(2,89 \%)$ desenvolvia atividades agropecuárias, florestais, da pesca ou assemelhados.

Observa-se também o elevado percentual de $23,83 \%$ (66) indivíduos, doadores de sangue sem o registro da sua ocupação na ficha cadastral (Tabela 11).

Verifica-se, entretanto, uma distribuição em que o maior percentual $(13,36 \%)$ ocorreu em uma população na área urbana que ocupou profissões que exigem pouca ou nenhuma qualificação; e a de menor proporção $(2,69 \%)$ são trabalhadores agropecuários que exerceram atividades voltadas à área rural, o que se constitui em elementos interessantes para estudos da transmissão vetorial da doença de Chagas. 
Tabela 11 - Distribuição dos doadores de sangue soropositivos e indeterminados para infecção por $T$. cruzi, segundo a ocupação. Região da Grande Florianópolis. Estado de Santa Catarina, 1990 a 1999.

\begin{tabular}{|c|c|c|c|c|c|c|c|c|}
\hline \multirow[t]{2}{*}{ Grupo de Ocupações } & \multicolumn{3}{|c|}{$\begin{array}{l}\text { Hemocentro Regional de } \\
\text { Florianópolis }\end{array}$} & \multicolumn{3}{|c|}{$\begin{array}{c}\text { Serviço de Hemoterapia do } \\
\text { HU/UFSC }\end{array}$} & \multicolumn{2}{|c|}{ Total } \\
\hline & Pos. & Ind & Total & Pos. & Ind. & Total & $\mathrm{N}^{0}$ & $\%$ \\
\hline $\begin{array}{l}\text { Trabalhadores das } \\
\text { profissões cientificas, } \\
\text { técnicas artísticas }\end{array}$ & 14 & 2 & 16 & 3 & 7 & 10 & 26 & 9.39 \\
\hline $\begin{array}{l}\text { Membros dos poderes } \\
\text { legislativo. executivo e } \\
\text { judiciário. Funcionários } \\
\text { Públicos. Diretores de } \\
\text { empresas. }\end{array}$ & 6 & 4 & 10 & 2 & 2 & 4 & 14 & 5,05 \\
\hline $\begin{array}{l}\text { Trabalhadores de serviços } \\
\text { administrativos e } \\
\text { assemelhados }\end{array}$ & 6 & 1 & 7 & - & 6 & 6 & 13 & 4,69 \\
\hline $\begin{array}{l}\text { Trabalhadores do } \\
\text { comércio e assemelhados }\end{array}$ & 6 & 5 & 11 & 1 & 2 & 3 & 14 & 5,05 \\
\hline $\begin{array}{l}\text { Trabalhadores de serviços } \\
\text { de turismo. hospedagem. } \\
\text { serventia, higiene, embe- } \\
\text { lezamento, segurança, } \\
\text { auxiliares de saúde. }\end{array}$ & 24 & 2 & 26 & 7 & 5 & 11 & 37 & 13,36 \\
\hline $\begin{array}{l}\text { Trabalhadores } \\
\text { agropecuários, florestais, } \\
\text { da pesca e assemelhados. }\end{array}$ & 5 & 1 & 6 & - & 2 & 2 & 8 & 2,69 \\
\hline $\begin{array}{l}\text { Trabalhadores da } \\
\text { produção industrial e } \\
\text { operadores de máquinas. }\end{array}$ & 20 & 2 & 22 & 3 & 9 & 12 & 34 & 12.27 \\
\hline $\begin{array}{l}\text { Condutores de veículos e } \\
\text { assemelhados }\end{array}$ & 6 & 2 & 8 & - & 4 & 4 & 12 & 4.33 \\
\hline $\begin{array}{l}\text { Membros das forças } \\
\text { arma-das, policiais e } \\
\text { bombeiros. }\end{array}$ & 12 & 1 & 13 & 4 & 10 & 14 & 27 & 9.75 \\
\hline $\begin{array}{l}\text { Estudantes. autônomos, } \\
\text { aposentados. }\end{array}$ & 9 & 12 & 11 & 5 & 10 & 15 & 26 & 9,39 \\
\hline Ignorados* & 27 & 19 & 46 & 13 & 7 & 20 & 66 & 23.83 \\
\hline Total & 136 & 40 & 176 & 35 & 66 & 101 & 277 & 100,00 \\
\hline
\end{tabular}

* Sem registro

Fonte: Centro de Hematologia e Hemoterapia do Estado de Santa Catarina - HEMOSC. Hospital Universitário - HU/UFSC 


\subsubsection{Prevalência da infecção por $T$. cruzi.}

Na Região da Grande Florianópolis foram observados um total de 146.461 doadores de sangue com um número estimado de 223,44 soropositivos para a infecção chagásica. Destes, 129.367 eram primodoadores contendo 194,75 soropositivos, e 17.094 doadores de repetição, com número estimado de 29,14 doadores soroconvertidos

A taxa de prevalência por 100.000 primodoadores, doadores de repetição e total de doadores, no Hemocentro Regional de Florianópolis, resultou em 114,07, 194,61 e 122,94; e de 438,86, 58,41 e 370,10 no Serviço de Hemoterapia do HU/UFSC (Tabela 12; Anexo VI)

Tabela 12 - Taxa de prevalência da infecção por $T$. cruzi entre primodoadores doadores de repetição e total de doadores,. Região da Grande Florianópolis. Estado de Santa Catarina. 1990 a 1999.

\begin{tabular}{|c|c|c|c|c|c|c|c|}
\hline \multirow[b]{2}{*}{$\begin{array}{l}\text { Unidade } \\
\text { Hemoterápica }\end{array}$} & \multicolumn{4}{|c|}{ Periodo } & \multicolumn{3}{|c|}{ Prevalência* } \\
\hline & & $\begin{array}{l}\text { Primo- } \\
\text { doadores }\end{array}$ & $\begin{array}{c}\mathrm{N}^{\mathrm{o}} \\
\text { Estimado } \\
\text { soro }(+)\end{array}$ & $\begin{array}{c}\text { Doadores } \\
\text { de } \\
\text { Repetição }\end{array}$ & $\begin{array}{c}\mathrm{N}^{\mathbf{0}} \\
\text { Estimado } \\
\text { soro (+) }\end{array}$ & $\begin{array}{c}\text { Total } \\
\text { Doadores }\end{array}$ & $\begin{array}{c}\mathrm{N}^{\circ} \\
\text { Estimado } \\
\text { soro (+) }\end{array}$ \\
\hline $\begin{array}{l}\text { Hemocentro } \\
\text { Regional de } \\
\text { Florianopolis }\end{array}$ & $\begin{array}{c}01.01 .90 \\
\mathrm{a} \\
31.12 .99\end{array}$ & $\begin{array}{c}114.07 \\
(n=114.844)\end{array}$ & 131.01 & $\begin{array}{c}194.61 \\
(n=14.064)\end{array}$ & 27,37 & $\begin{array}{c}122.94 \\
(n=128.908)\end{array}$ & 158.48 \\
\hline $\begin{array}{l}\text { Serviço de } \\
\text { Hemoterapia } \\
\text { do HU/UFSC }\end{array}$ & $\begin{array}{c}01.01 .90 \\
\mathrm{a} \\
31.12 .99 \\
\end{array}$ & $\begin{array}{c}438.86 \\
(n=14.523)\end{array}$ & 63,74 & $\begin{array}{c}58.41 \\
(\mathrm{n}=3.030)\end{array}$ & 1.77 & $\begin{array}{c}370,10 \\
(n=17.553)\end{array}$ & 64.96 \\
\hline $\begin{array}{l}\text { Região da } \\
\text { Grande Flo- } \\
\text { rianopolis** }\end{array}$ & & $\begin{array}{c}150.53 \\
(n=129.367)\end{array}$ & 194,75 & $\begin{array}{c}170.47 \\
(n=17.094)\end{array}$ & 29.14 & $\begin{array}{c}152.56 \\
(n=146.461)\end{array}$ & 223,44 \\
\hline
\end{tabular}

* Prevalência $=\mathrm{n}^{0}$ de soropositivos $/ \mathrm{n}$ ( $\mathrm{n}^{\circ}$ de primodoadores, doadores de repetição ou total de doadores de cada local e periodo estudado). Cálculos - Anexo VI.

** Média ponderada das prevalências encontradas nas Unidades Hemoterápicas (HRF. SHHU/UFSC). dentre os primodoadores, doadores de repetição e total de doadores.

$\mathrm{n}=$ denominador. ou seja. o número de primodoadores, doadores de repetição ou total de doadores de cada local e periodo estudado.

$\mathrm{N}^{\circ}$ estimado = número aproximado de soropositivos. considerando-se também os indeterminados.

Fonte: Centro de Hematologia e Hemoterapia do Estado de Santa Catarina - HEMOSC / SES. Hospital Universitário - HU/UFSC.

Considerando-se, então, a totalidade dos doadores das duas Unidades Hemoterápicas (HRF e SHHU/UFSC), no periodo estudado de 1990 a 1999, observouse como resultado para Região da Grande Florianópolis os valores de 150,53, 170,47 e 152,56, para cada 100.000 primodoadores, doadores de repetição e totais de doadores, respectivamente (Tabela e 13; Figura 10; Anexo VI). 
Tabela 13 - Taxa de prevalência da infecção por $T$. cruzi entre primodoadores, doadores de repetição e total de doadores na Região da Grande Florianópolis. Estado de Santa Catarina. 1990 a 1999.

\begin{tabular}{lcccc}
\hline & $\mathrm{N}^{\circ}$ & $\begin{array}{c}\mathrm{N}^{\circ} \text { Estimado de } \\
\text { soropositivos }\end{array}$ & Prevalência & $\begin{array}{c}\text { Intervalo de 95\% de } \\
\text { Confiança }\end{array}$ \\
\hline $\begin{array}{l}\text { Primodoadores } \\
\begin{array}{l}\text { Doadores de } \\
\text { Repetição }\end{array}\end{array}$ & 129.367 & 194,75 & 150,53 & $129,39-171,68$ \\
\hline $\begin{array}{l}\text { Total de } \\
\text { Doadores }\end{array}$ & 17.094 & 29,14 & 170,47 & $114,29-244,61$ \\
\hline
\end{tabular}

Fonte: Centro de Hematologia e Hemoterapia do Estado de Santa Catarina HEMOSC / SES. Hospital Universitário - HU/UFSC.

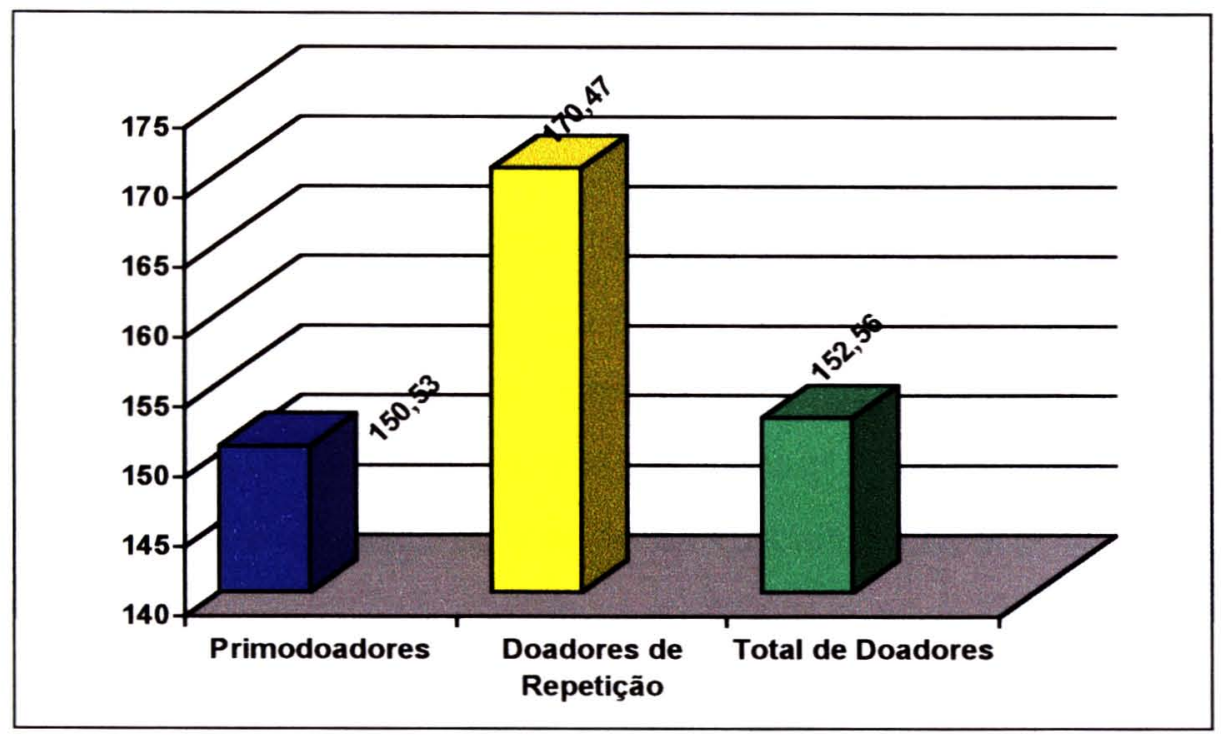

Figura 10 - Taxa de prevalência da infecção por $T$. cruzi entre primodoadores, doadores de repetição e total de doadores na Região da Grande Florianópolis. Estado de Santa Catarina, 1990 a 1999.

Ao se observarem as taxas de prevalência, nota-se que houve no período estudado, uma pequena elevação apresentada nos doadores de repetição, em comparação com as taxas encontradas nos primodoadores, que, por sua vez, é muito semelhante no total de doadores. Demonstra, pelos resultados, a presença da infecção chagásica entre todas as categorias de doadores de sangue na Região da Grande Florianópolis.

Inquérito soroepidemiológico realizado na década de 1970 pela SUCAM, revelou prevalência da infecção chagásica, superior a $8 \%$ na população geral, em várias regiões do Estado de Santa Catarina. Porém, estudos posteriores não confirmaram esses resultados, encontrando percentuais inferiores a $1 \%$, revelando, assim, a inexistência de 
transmissão ativa do $T$. cruzi na Região da Grande Florianópolis (SCHLEMPER JÚNIOR e col. 1983).

Pesquisa realizada mais tarde, por SCHLEMPER JÚNIOR e col., em 1989, em Florianópolis, Santa Catarina, demonstrou uma prevalência de 2,1\% de individuos reagentes para infecção chagásica, o que indica a ocorrência de casos da doença nesta região.

A prevalência da infecção chagásica encontrada entre o total de doadores de sangue na Região da Grande Florianópolis $(0,15 \%)$, pode ser considerada baixa, quando comparada com a registrada no Rio Grande do Sul, que apresentou uma prevalência de 0,9\%, no período de 1986-96 (BASSO 1999), e de 1,0\% observada no periodo de 1988-93, no Estado de São Paulo (WANDERLEY 1999a).

Importante torna-se ressaltar, a prevalência de $170,47 / 100000$ ou $0,17 \%$, observada entre os doadores de repetição, em uma área considerada indene, que consideramos significativa quando comparada aos resultados de $0,21 \%$ encontrados por SOARES (2000), em análise do comportamento sorológico de 27.080 doadores de repetição no Hemocentro Regional de Uberaba, Estado de Minas Gerais.

Portanto, a taxa de prevalência encontrada entre a população de doadores de sangue no período de 1990 a 1999, representa, a nosso ver, a presença da enfermidade na população atualmente residente da Região da Grande Florianópolis, Estado de Santa Catarina.

\subsubsection{Incidência da infecção por $T$. cruzi}

Para o cálculo da incidência junto ao Hemocentro Regional de Florianópolis foi aqui considerado o período de 01.01 .97 a 18.06 .99 , considerando a disponibilidade dos dados onde foram observados, 2 casos soropositivos e 3 indeterminados de infecção chagásica entre os doadores de repetição; e 1 caso soropositivos e 10 indeterminados no Serviço de Hemoterapia do HU/UFSC, no periodo de 01.01.90 1 31.12.99.

Apresentou um resultado de 36,48 por 100.000 doadores de repetição de sangue, no Hemocentro Regional de Florianópolis, enquanto que no Serviço de Hemoterapia do HU/UFSC, foi de 62,49/100.000 doadores de repetição. A incidência da infecção por $T$. cruzi entre os doadores de repetição, observada na Região da Grande Florianópolis, foi de 44,17 por 100.000 doadores de repetição. (Tabela 14; Figura 11; Anexo VII). 
Tabela 14 - Taxa de incidência da infecção por $T$. cruzi entre doadores de repetição nas Unidades Hemoterápicas do Hemocentro Regional de Florianópolis, Serviço de Hemoterapia do HU/UFSC e Região da Grande Florianópolis. Estado de Santa Catarina, 1990 a 1999.

\begin{tabular}{|c|c|c|c|c|c|c|}
\hline \multirow[b]{2}{*}{$\begin{array}{c}\text { Unidade } \\
\text { Hemoterápica }\end{array}$} & \multirow{2}{*}{$\begin{array}{l}\text { Pessoa- } \\
\text { tempo } \\
\text { exposta ao } \\
\text { risco }\end{array}$} & \multicolumn{3}{|c|}{ Doadores } & \multirow[b]{2}{*}{$\begin{array}{c}\text { Taxa de } \\
\text { Incidência** }\end{array}$} & \multirow{2}{*}{$\begin{array}{c}\text { Intervalo de } \\
95 \% \text { de } \\
\text { Confiança }\end{array}$} \\
\hline & & Soro(+) & $\begin{array}{l}\text { Indeter- } \\
\text { minado }\end{array}$ & $\begin{array}{l}\mathrm{N}^{\circ} \text { Estimado } \\
\text { de Soro- } \\
\text { convertidos }\end{array}$ & & \\
\hline $\begin{array}{l}\text { Hemocentro } \\
\text { Regional de } \\
\text { Florianópolis* }\end{array}$ & 6745,78 & 2 & 3 & 2,46 & 36,48 & $\begin{array}{l}6,15- \\
117,64\end{array}$ \\
\hline $\begin{array}{l}\text { Serviço de } \\
\text { Hemoterapia } \\
\text { do HU/UFSC }\end{array}$ & 2832,60 & 1 & 10 & 1,77 & 62,49 & $\begin{array}{l}6,78- \\
241,64\end{array}$ \\
\hline $\begin{array}{l}\text { Região da } \\
\text { Grande } \\
\text { Florianópolis }\end{array}$ & 9578,38 & 3 & 13 & 4,23 & 44,17 & $\begin{array}{l}12,66- \\
110,35\end{array}$ \\
\hline
\end{tabular}

*Período: 01.01.97 a 18.06.99**Cálculo, Anexo VII.

Fonte: Centro de Hematologia e Hemoterapia do Estado de Santa Catarina -HEMOSC / SES. Hospital Universitário - HU/UFSC.

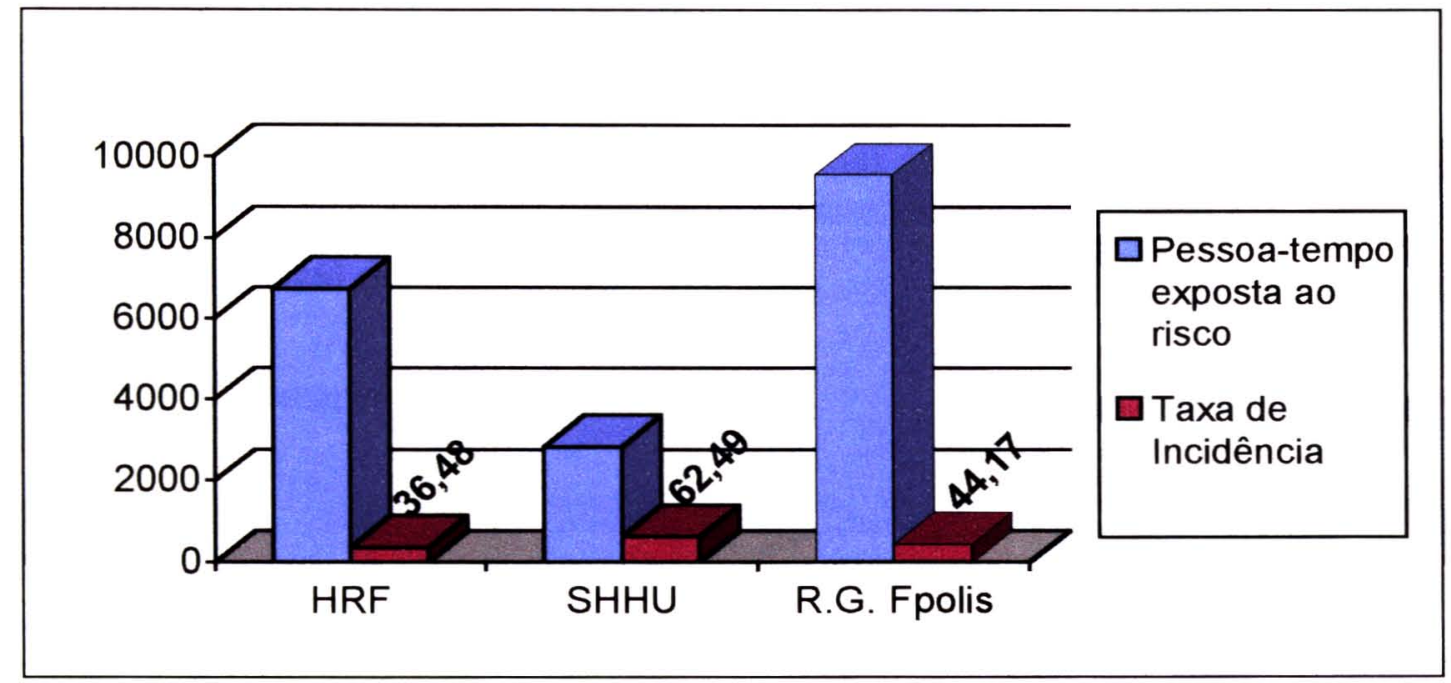

Figura 11 - Taxa de incidência da infecção por T.cruzi entre doadores de repetição no Hemocentro Regional de Florianópolis, Serviço de Hemoterapia do HU/UFSC e Região da Grande Florianópolis. Estado de Santa Catarina, 1990 a 1999.

Esses resultados são considerados elevados se compararmos aos encontrados no estudo realizado no Hemocentro Regional de Uberaba, Minas Gerais, em 1995, onde mostrou que $3(0,01 \%)$ dos doadores de retorno foram soropositivos para infecção por T. cruzi, que assinala também, a incidência da infecção chagásica entre doadores de repetição em regiões de outros Estados do País (SOARES e MORAES SOUZA 2000). 


\subsubsection{Risco residual de transmissão transfusional}

O cálculo do Risco Residual de Transmissão Transfusional, efetuado no conjunto das Unidades Hemoterápicas da Região da Grande Florianópolis, entre os doadores de repetição, estudados no Hemocentro Regional de Florianópolis - HRF, período de 01.01.97 a 18.06.99 e no Serviço de Hemoterapia do HU/UFSC, periodo de 01.01 .90 a 31.12 .99 , indicou um risco de 3,38 possiveis contaminações transfusionais por 100.000 doações ou o risco de 1 (uma) transmissão a cada 29.586 doações (Tabela 15; Figura 12; Anexo VIII).

Apresentou no Hemocentro Regional de Florianópolis, um risco de 2,79 contaminações por 100.000 doações efetuadas, enquanto que no Serviço de Hemoterapia do HU/UFSC, foi de 4,79/100.000 doações.

Tabela 15 - Risco Residual de Transmissão Transfusional da infecção por T. cruzi nas Unidades Hemoterápicas do Hemocentro Regional de Florianópolis, Serviço de Hemoterapia do HU/UFSC e Região da Grande Florianópolis. Estado de Santa Catarina, 1990 a 1999.

\begin{tabular}{lcc}
\hline \multicolumn{1}{c}{ Unidade Hemoterápica } & $\begin{array}{c}\text { Risco Residual de } \\
\text { Transmissão Transfusional }\end{array}$ & $\begin{array}{c}\text { Intervalo de } 95 \% \text { de } \\
\text { Confiança }\end{array}$ \\
\hline $\begin{array}{l}\text { Hemocentro Regional de } \\
\text { Florianópolis }\end{array}$ & 2,79 & $0,47-9,02$ \\
$\begin{array}{l}\text { Serviço de Hemoterapia do } \\
\text { HU / UFSC }\end{array}$ & 4,79 & $0,52-18,53$ \\
$\begin{array}{l}\text { Região da Grande } \\
\text { Florianópolis }\end{array}$ & $3,38^{*}$ & $0,97-8,46$ \\
\hline
\end{tabular}

* Cálculo resultante da média ponderada dos Riscos Residuais de Transmissão Transfusional / · pessoatempo, encontrados no Hemocentro Regional de Florianópolis e Serviço de Hemoterapia do HU/UFSC. 


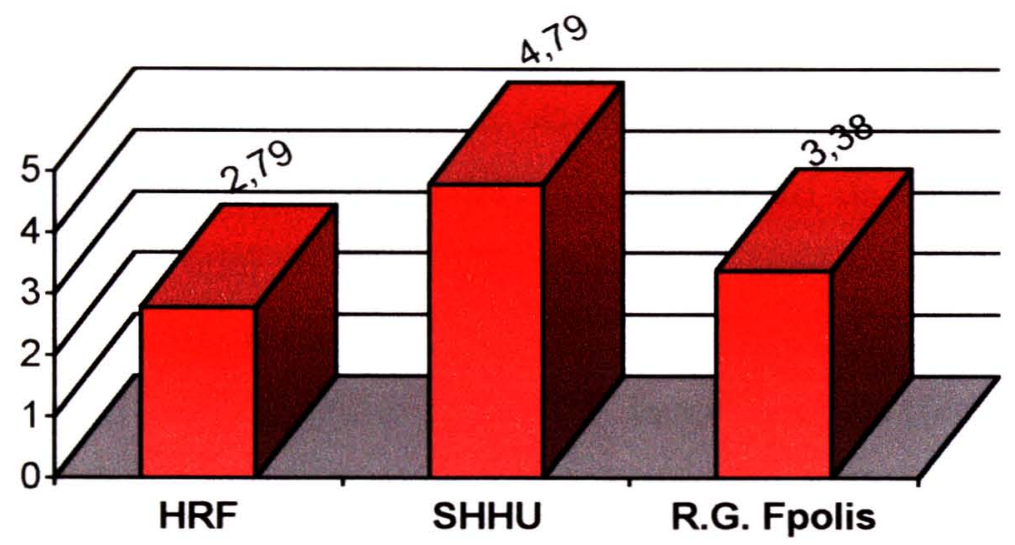

Figura 12 - Risco Residual de Transmissão Transfusional da infecção por $T$. cruzi nas Unidades Hemoterápicas do Hemocentro Regional de Florianópolis, Serviço de Hemoterapia do HU/UFSC e Região da Grande Florianópolis. Estado de Santa Catarina, 1990 a 1999.

Segundo TANOWITZ e col. (1993), a possibilidade de transmissão transfusional do T. cruzi, é maior nas áreas urbanas de regiões endêmicas. Porém, também tem se tornado problema de saúde pública naquelas áreas indenes, livres de transmissão vetorial, mas que tem sofrido com o fenômeno das migrações oriundas de áreas conhecidamente endêmicas. Este fato tem sido observado, nos últimos 15 anos, em regiões dos EUA, consideradas indenes, mas que receberam milhões de migrantes da América Central e do Sul, com altas prevalências da infecção para $T$. cruzi. Estudo realizado em Washington, em 1985, indicou um índice de 4,9\% de imigrantes naturais da Nicarágua e São Salvador com infecção chagásica, indicando que cerca de 50.000 infectados migraram para os EUA nos últimos anos. Indicou também, a prevalência da infecção chagásica de 1:1000 doadores, em bancos de sangue de Los Angeles, EUA. Concluiu ainda que, nas áreas onde a presença desses migrantes contaminados é elevada, tornou-se um problema, mesmo que o parasita não seja endêmico, com conseqüências graves àquelas populações.

Outros estudos foram também desenvolvidos com igual metodologia para estimar o risco residual de transmissão transfusional da doença de Chagas, do vírus HIV e outras enfermidades (COVAS, 1998; CANUTTI JÚNIOR 1998).

Estudos realizados por CANUTTI JÚNIOR (1998), no Hemocentro Regional da Faculdade de Medicina de Marília, Ribeirão Preto, São Paulo, no período de 1994 a 1997, utilizando a mesma metodologia, demonstrou a magnitude do risco residual do $T$. 
cruzi, do vírus da Síndrome da Imunodeficiência Adquirida-SIDA/AIDS, da Hepatite B (HBV), da Hepatite C (HCV), entre outras, decorrente de transfusões de sangue e hemocomponentes obtidos a partir de 5.688 doadores de repetição soronegativos, que procuraram o referido hemocentro. Todas as doações foram examinadas para agentes infecciosos passiveis de transmissão por meio da transfusão de sanguínea, conforme normatiza a Portaria Ministerial $\mathrm{n}^{\circ} 1376$ de 19.11.1993, sendo o $T$. cruzi testado por dois testes com princípios laboratoriais diferentes. Encontrou, para o risco residual de transmissão transfusional da infecção chagásica, o valor de 6,46/100.000 ou 1/15.479 doadores de repetição. Para outros agentes, como o vírus do HIV, foi de 9,68/100.000 ou 1/10.330 doadores de retorno; para o HBV de 27,22/100.000 ou de 1/3.673; e para o HCV de 4,71/100.000 ou 1/21.231 doadores de repetição.

KLEINMAN e SECORD, em 1988, embora já tendo conhecimento de 3 casos de HIV com transmissão por transfusão de sangue procedente de doadores com sorologia negativa, empreenderam estudos em vários centros hemoterápicos da cidade de Los Angeles, EUA, no periodo de março de 1985 a fevereiro de 1987, onde obtiveram o valor de $1 / 68.000$ doadores de repetição, o risco de transmissão transfusional do HIV

Outros estudos, baseados nesse modelo, já haviam sido realizados. SCHREIBER e col. (1996), estudaram no período de janeiro de 1991 a dezembro de 1993, indivíduos que doaram sangue em cinco centros de hemoterapia dos EUA. Observando 586.507 doadores de repetição, encontraram taxas de risco residual para algumas doenças possiveis de transmissão pela transfusão de sangue, como de $0.20 / 100.000$ ou 1/493.000 para o HIV; 0,97/100.000 ou 1/103.000 para Hepatite C (HCV); de 0,16/100.000 ou 1/641.000 para o virus linfotrópico para células humanas (HTLV I/II); e de 1,64/100.000 ou 1/63.000 para a Hepatite B (HBV).

KOERNER e col. (1998), utilizando o modelo descrito anteriormente por SCHREIBER e col (1996), no período de 1990 a 1995, estudaram o risco de transmissão transfusional da Hepatite B (HBC) e Hepatite C (HCV), entre doadores de bancos de sangue, de Badem-Wurttenberg, Alemanha, onde encontraram um risco estimado de $1 / 200.000$ e 1/250.000, para hepatite $B$ e $C$, respectivamente, entre os doadores de repetição daquelas unidades hemoterápicas

Outras enfermidades observadas entre doadores de repetição, após triagem sorológica pelos serviços laboratoriais, também tiveram apurados o risco residual de 
transmissão transfusional, no Hemocentro Regional de Florianópolis, Estado de Santa Catarina.

Utilizando o mesmo modelo estatístico (KUPEK 2001 ${ }^{\mathrm{a}}$ ), no periodo de 1997 a 1999, mostrou o risco residual de transmissão do vírus HIV, de 1:48777 doadores de repetição, no Hemocentro Regional de Florianópolis, Santa Catarina

O mesmo autor estimou, no período de 1991 a 1999, estudando 11.286 doadores de repetição, o risco residual de transmissão transfusional da hepatite B de 1: 2077 doadores de repetição, e de 1: 13721 doadores de retorno, para a hepatite $C$, no Hemocentro Regional de Florianópolis, Centro de Hematologia e Hemoterapia de Santa Catarina-HEMOSC, sul do Brasil. (KUPEK 2001b).

\subsection{Região de Joaçaba}

A Região de Joaçaba, assim como a Grande Florianópolis, foi selecionada para analisar-se o comportamento sorológico da infecção por T. cruzi entre os doadores de sangue.

São apresentados neste capítulo, os resultados obtidos junto à Unidade Hemoterápica, o Hemocentro Regional de Joaçaba - HRJ, que concentra as atividades de hemoterapia das Unidades de Saúde localizadas nos municípios que compõem a Região de Joaçaba ou $8^{\mathrm{a}}$ Regional de Saúde e outros municípios, com sede na cidade de Joaçaba (Figura 2 e 4; Anexos III e IV)

\subsubsection{Hemocentro Regional de Joaçaba}

Nesta Unidade Hemoterápica, a disponibilidade de informações ocorreu somente a partir do ano de 1995, o que limita de certa forma, um análise mais abrangente do estudo nesta região. No Hemocentro Regional de Joaçaba, foram estudadas 31.901 doaçōes, realizadas por 13.368 doadores de sangue, no periodo de 01.01.1995 a 31.12.1999. Destes, 15 doadores apresentaram sorologia positiva e 2 indeterminadas, para infecção por T.cruzi (Tabela 3 e 16) 
Aparentemente, quando efetuada a distribuição dos casos de infecção chagásica no decorrer do periodo estudado houve uma variação importante no percentual de soropositivos, que oscilou de $0,10 \%$, no ano de 1995 a $0,22 \%$ em 1998 , e $0,10 \%$ no final em 1999

Tabela 16 - Distribuição do número de doadores de sangue e infecção por $T$. cruzi, por ano. Unidade Hemoterápica do Hemocentro Regional de Joaçaba. Região de Joaçaba. Estado de Santa Catarina, 1995 a 1999.

\begin{tabular}{cccccc}
\hline \multirow{2}{*}{ Ano } & \multicolumn{2}{c}{ Hemocentro Regional de Joaçaba } & \multicolumn{2}{c}{ Total } \\
\cline { 2 - 6 } & $\mathrm{N}^{\circ}$ & Soro(+) & Indeterminado & $\mathrm{N}^{\circ}$ & $\%$ \\
\hline 1995 & 3033 & 3 & - & 3 & 0,10 \\
1996 & 3350 & 3 & - & 3 & 0,09 \\
1997 & 2338 & 1 & 2 & 3 & 0,13 \\
1998 & 2661 & 6 & - & 6 & 0,22 \\
1999 & 1986 & 2 & - & 2 & 0,10 \\
\hline Total & 13368 & 15 & 2 & 17 & 0,13 \\
\hline
\end{tabular}

Fonte: Centro de Hematologia e Hemoterapia de Santa Catarina - HEMOSC /SES Hemocentro Regional de Joaçaba

Analisando também, a proporção de casos ocorridos ano a ano, apresentou, no decorrer do periodo, uma variação na distribuição percentual do número de doadores de sangue soropositivos e indeterminados, oscilando de 17,65\% nos anos de 1995, 96 e 97 , elevando-se para $35,29 \%$ em 1998, e diminuindo significativamente para $11,76 \%$ em 1999. (Tabela 17; Figura 13)

Tabela 17 - Distribuição do número de doadores de sangue soropositivos e indeterminados por T. cruzi, por ano. Hemocentro Regional de Joaçaba. $8^{\mathrm{a}}$ Regional de Saúde. Estado de Santa Catarina, 1995 a 1999.

\begin{tabular}{cccccc}
\hline \multirow{2}{*}{ Ano } & \multicolumn{3}{c}{ Doadores } & \multicolumn{2}{c}{ Total } \\
\cline { 2 - 6 } & $\mathrm{N}^{\mathrm{y}}$ & Soro(+) & Indeterminado & $\mathrm{N}^{\mathrm{o}}$ & $\%$ \\
\hline 1995 & 3033 & 3 & - & 3 & 17,65 \\
1996 & 3350 & 3 & - & 3 & 17,65 \\
1997 & 2338 & 1 & 2 & 3 & 17,65 \\
1998 & 2661 & 6 & - & 6 & 35,29 \\
1999 & 1986 & 2 & - & 2 & 11,76 \\
\hline Total & 13368 & 15 & 2 & 17 & 100,00 \\
\hline
\end{tabular}

Fonte: Centro de Hematologia e Hemoterapia de Santa Catarina - HEMOSC /SES Hemocentro Regional de Joaçaba 


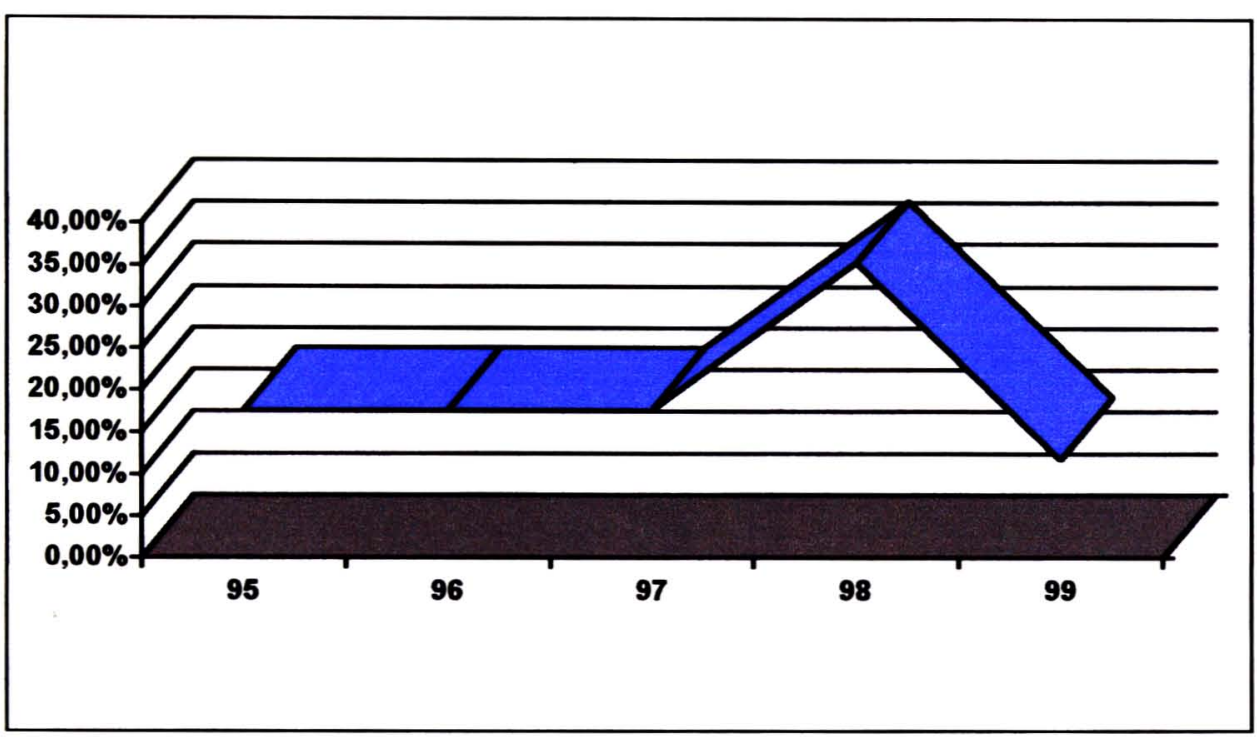

Figura 13 - Distribuição do número de doadores de sangue e infecção por $T$. cruzi no Hemocentro Regional de Joaçaba. $8^{\mathrm{a}}$ Regional de Saúde. Estado de Santa Catarina, 1995 a 1999.

Observa-se portanto, nesta Região, fato semelhante ao ocorrido na Região da Grande Florianópolis, onde houve aumento em termos percentuais da infecção chagásica no período de 1995 a 1998, decrescendo significativamente no ano de 1999, final do período estudado (Tabelas 6 e 17).

\subsubsection{Caracterização da população sorologicamente positiva para Trypanosoma cruzi}

\section{- Naturalidade}

No Hemocentro Regional de Joaçaba, a procedência dos doadores de sangue soropositivos para infecção por $T$. cruzi revela uma proporção considerável de doadores, $58,82 \%$ naturais do Estado de Santa Catarina.

Apresenta também um elevado percentual de doadores procedentes do Estado do Rio Grande do Sul e Bahia, com 23,53 e 17,65, respectivamente (Tabela 18 e Figura 14). 
Tabela 18 - Distribuição quanto à naturalidade dos doadores de sangue soropositivos e indeterminados para infecção por T.cruzi. Hemocentro Regional de Joaçaba. 8 Regional de Saúde. Estado de Santa Catarina, 1995 a 1999.

\begin{tabular}{|c|c|c|c|c|}
\hline \multirow{2}{*}{ Naturalidade } & \multicolumn{2}{|c|}{ Casos } & \multicolumn{2}{|c|}{ Total } \\
\hline & Pos. & Ind. & $\mathrm{N}^{\circ}$ & $\%$ \\
\hline SC & 8 & 2 & 10 & 58,82 \\
\hline RS & 4 & - & 4 & 23,53 \\
\hline BA & 3 & - & 3 & 17,65 \\
\hline Total & 15 & 2 & 17 & 100,00 \\
\hline
\end{tabular}

Fonte: Centro de Hematologia e Hemoterapia de Santa Catarina - HEMOSC / SES. Hemocentro Regional de Joaçaba.

A expressiva percentagem (23,53\%) de doadores originários do Estado do Rio Grande do Sul, pode ser explicada pela proximidade da Região de Joaçaba com áreas endêmicas daquele vizinho Estado; enquanto que a outra (17,65\%), ocorreu possivelmente pela migração de famílias oriundas de áreas endêmicas do Estado da Bahia (CAMARGO e col. 1984; BASSO 1999).

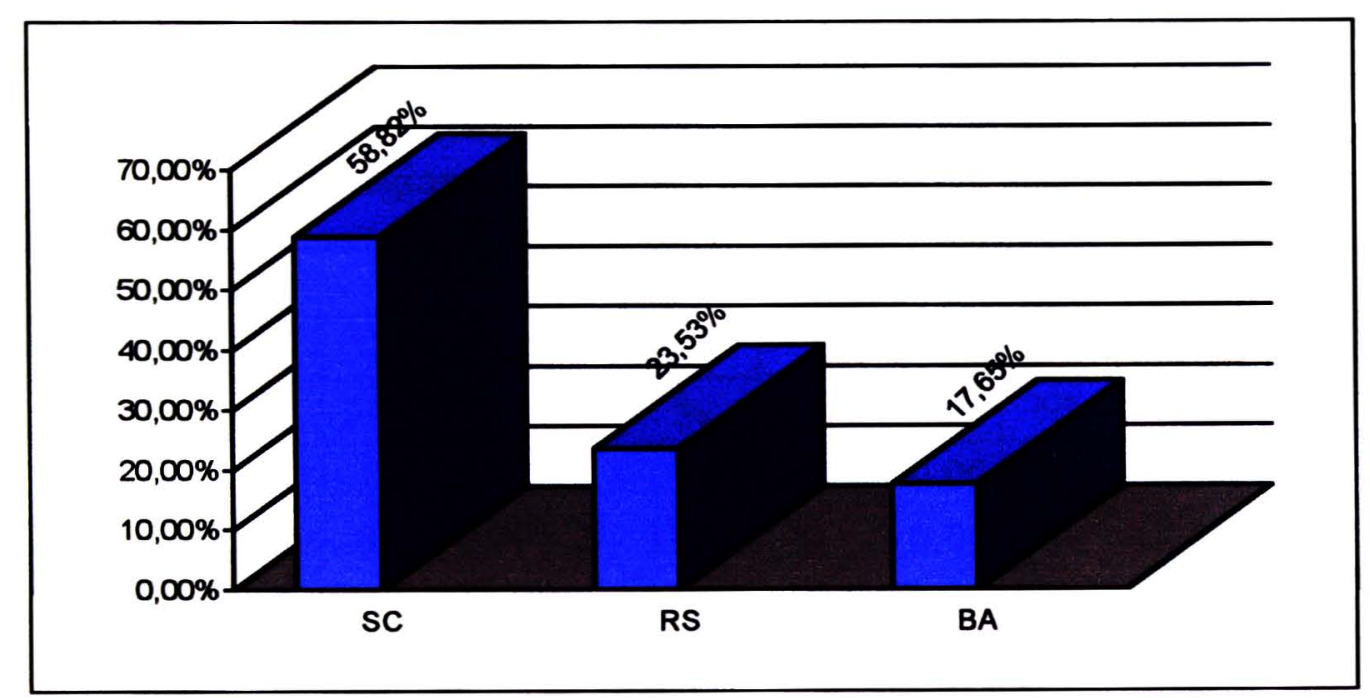

Figura 14 - Distribuição quanto à naturalidade dos doadores de sangue soropositivos e indeterminados para infecção por T.cruzi. Hemocentro Regional de Joaçaba. $8^{\text {a }}$ Regional de Saúde. Estado de Santa Catarina, 1995 a 1999. 


\section{- Faixa etária}

Quanto à distribuição dos doadores soropositivos no período de 1995 a 1999, da Região de Joaçaba, por faixa etária, foi a seguinte: 2 individuos $(11,76 \%)$ pertenciam ao grupo 18 a 20 anos; $2(11,78 \%)$ ao de 21 a 30 anos; $9(52,92 \%)$ entre 31 a 40 anos; 2 $(11,76 \%)$ ao de 41 a 50 anos; e $2(11,78 \%)$ entre 51 a 60 anos de idade. Ou seja, a população de soropositivos é representada, majoritariamente, por individuos da faixa etária de 31 a 40 anos $(52,92 \%)$, seguida da idade mais jovem $(23,53 \%)$ na faixa de 18 a 20 anos de idade. As demais faixas etárias, 18 a 20 anos; 21 a 30 anos; 41 a 50 e 51 a 60 anos apresentaram a mesma proporção, ou seja, 11,76 \% (Tabela 19; Figura 15).

A análise da distribuição etária ficou prejudicada, considerando-se o período de janeiro de 1995 a dezembro de 1999, um tanto pequeno, para analisar uma tendência em termos estatísticos.

Nessa população de doadores de sangue soropositivos à infecção chagásica, houve uma distribuição da ocorrência da enfermidade nas diferentes faixas etárias, com elevada proporção nas idades superiores a 31 anos $(76,48 \%)$, diferente da população estudada na Região da grande Florianópolis, que apresentou um percentual de 47,29\%

Tabela 19 - Distribuição dos doadores de sangue soropositivos e indeterminados para infecção por $T$. cruzi, por ano e faixa etária. Hemocentro Regional de Joaçaba. $8^{\text {a }}$ Regional de Saúde. Estado de Santa Catarina, 1995 a 1999

\begin{tabular}{|c|c|c|c|c|c|c|c|c|c|c|c|c|}
\hline \multirow{3}{*}{ Ano } & \multicolumn{12}{|c|}{ Faixa etária (anos) } \\
\hline & \multicolumn{2}{|c|}{18 a 20} & \multicolumn{2}{|c|}{21 a 30} & \multicolumn{2}{|c|}{31 a 40} & \multicolumn{2}{|c|}{41 a 50} & \multicolumn{2}{|c|}{51 a 60} & \multicolumn{2}{|c|}{ Total } \\
\hline & $N^{0}$ & $\%$ & $\mathrm{~N}^{\mathrm{o}}$ & $\%$ & $N^{\circ}$ & $\%$ & $N^{\circ}$ & $\%$ & $N^{0}$ & $\%$ & $N^{0}$ & $\%$ \\
\hline 1995 & 1 & 5,88 & 1 & 5,89 & 1 & 5,88 & 0 & 0,00 & 0 & 0,00 & 3 & 17,65 \\
\hline 1996 & 0 & 0,00 & 0 & 0,00 & 2 & 11,76 & 0 & 0,00 & 1 & 5,89 & 3 & 17,65 \\
\hline 1997 & 0 & 0,00 & 0 & 0,00 & 2 & 11,76 & 0 & 0,00 & 1 & 5,89 & 3 & 17,65 \\
\hline 1998 & 1 & 5.88 & 1 & 5,89 & 2 & 11,76 & 2 & 11,76 & 0 & 0,00 & 6 & 35,99 \\
\hline 1999 & 0 & 0,00 & 0 & 0,00 & 2 & 11,76 & 0 & 0,00 & 0 & 0,00 & 2 & 11,76 \\
\hline Total & 2 & 11,76 & 2 & 11,78 & 9 & 52,92 & 2 & 11,76 & 2 & 11,78 & 17 & 100,00 \\
\hline
\end{tabular}

$\mathrm{N}^{\mathrm{o}}=$ Soropositivos + indeterminados

Fonte: Centro de Hematologia e Hemoterapia do Estado de Santa Catarina - HEMOSC / SES. Hemocentro Regional de Joaçaba. 


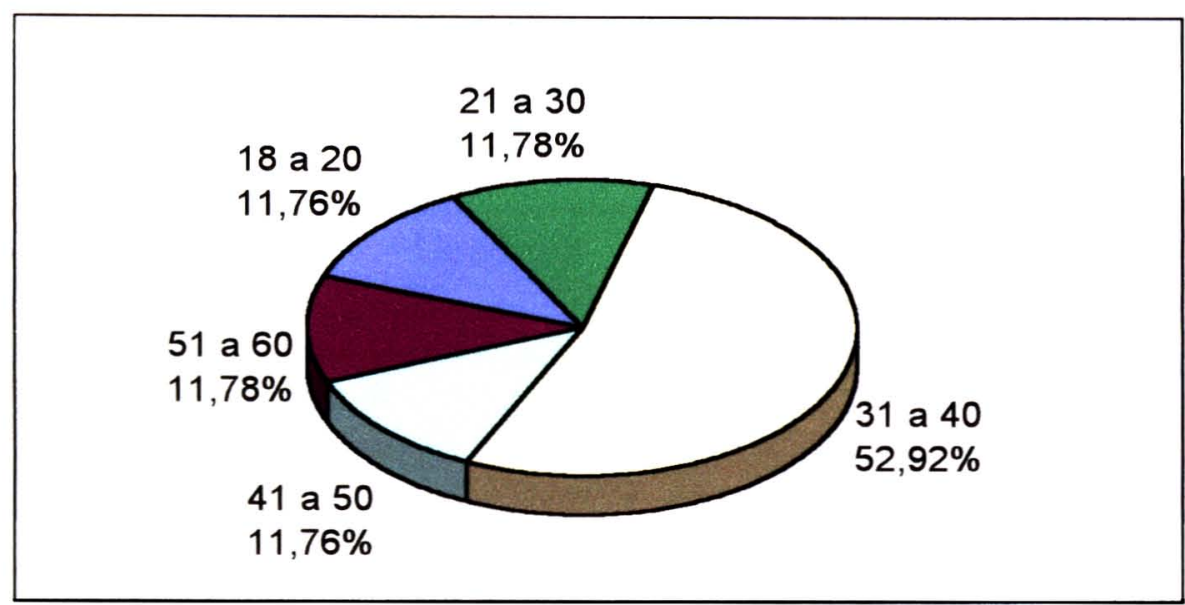

Figura 15 - Distribuição dos doadores de sangue soropositivos e indeterminados para infecção por $T$. cruzi, por faixa etária. Hemocentro Regional de Joaçaba. $8^{a}$ Regional de Saúde. Estado de Santa Catarina, 1995 a 1999.

A menor porcentagem de doadores soropositivos para infecção chagásica no ano de 1999 (11,76\%), e a proporção de indivíduos da faixa etária, menor de 31 anos $(23,54 \%)$, indica, possivelmente, os resultados do Programa de Controle da doença de Chagas com a interrupção da transmissão vetorial em áreas endêmicas do vizinho Estado do Rio Grande do Sul (BASSO 1999), considerando que expressiva percentagem de doadores é procedente daquela região ou da menor disposição da população jovem em voluntariamente doar sangue.

\section{- Sexo}

Dos doadores de sangue soropositivos e indeterminados para infecção por $T$. cruzi, no período estudado de 1995 a 1999, foi observado que 9 (52,94\%) eram do sexo masculino, e $8(47,06 \%)$ do sexo feminino, demonstrando semelhança de proporcionalidade quanto ao gênero dos indivíduos soropositivos (Tabela 20; Figura 16).

Apresentou nesta região, uma proporção maior do sexo feminino do que a encontrada na Região da Grande Florianópolis, demonstrando a participação efetiva das mulheres contribuindo na doação voluntária de sangue para a necessária reposição de estoque no Hemocentro Regional de Joaçaba, Santa Catarina. 
Tabela 20 - Distribuição dos doadores de sangue soropositivos e indeterminados para infecção por T. cruzi, por sexo. Hemocentro Regional de Joaçaba. $8^{\mathrm{a}}$ Regional de Saúde. Estado de Santa Catarina, 1995 a 1999.

\begin{tabular}{lrrrr}
\hline \multirow{2}{*}{ Sexo } & \multicolumn{2}{c}{ Doadores } & \multicolumn{2}{c}{ Total } \\
\cline { 2 - 5 } & Pos. & Ind. & $\mathrm{N}^{\mathbf{0}}$ & $\%$ \\
\hline Masculino & 8 & 1 & 9 & 52,94 \\
Feminino & 7 & 1 & 8 & 47,06 \\
\hline Total & 15 & 2 & 17 & 100,00 \\
\hline
\end{tabular}

Fonte: Centro de Hematologia e Hemoterapia de Santa Catarina - HEMOSC / SES. Hemocentro Regional de Joaçaba

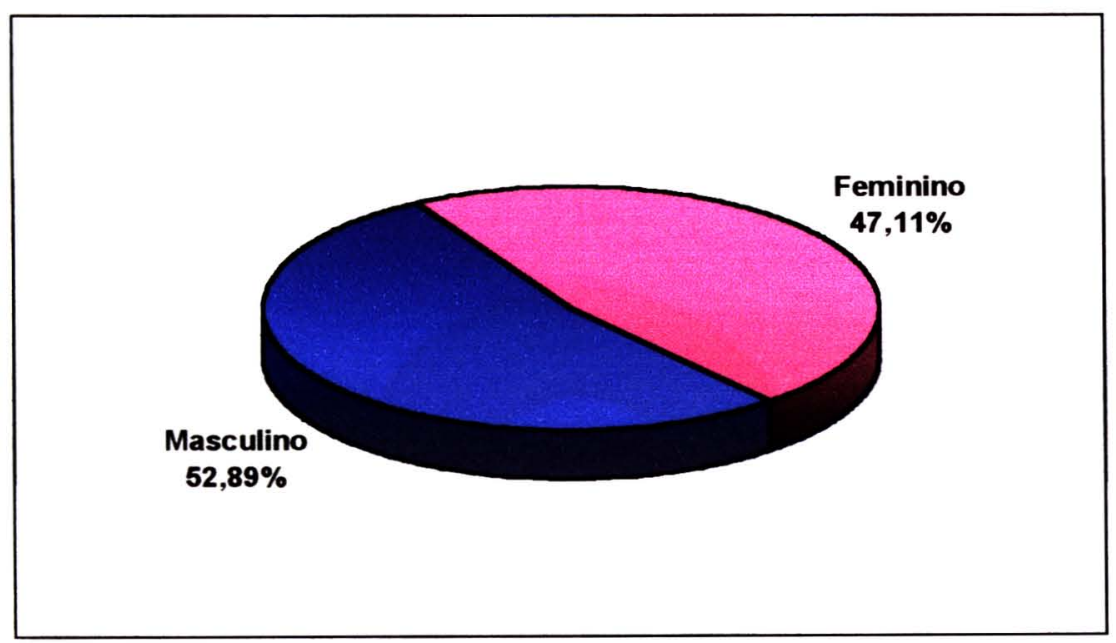

Figura 16 - Distribuição dos doadores de sangue soropositivos e indeterminados para infecção por T. cruzi, por sexo. Hemocentro Regional de Joaçaba. $8^{a}$ regional de Saúde. Estado de Santa Catarina, 1995 a 1999.

\section{- Estado civil}

O estado civil informado pelos doadores soropositivos para infecção chagásica, observados no Hemocentro Regional de Joaçaba, no período de 1995 a 1999, esteve assim distribuído: $10(58,82 \%)$ casados; 4 (23,53\%) solteiros; e $3(17,65 \%)$ não constava a informação (Tabela 21, Figura 17). 
Tabela 21 - Distribuição dos doadores de sangue soropositivos e indeterminados para infecção por $T$. cruzi, quanto ao estado civil. Região de Joaçaba. $8^{a}$ Regional de Saúde. Estado de Santa Catarina, 1995 a 1999.

\begin{tabular}{lccrc}
\hline \multirow{2}{*}{ Estado Civil } & \multicolumn{2}{c}{ Casos } & \multicolumn{2}{c}{ Total } \\
\cline { 2 - 5 } & Soropositivo & Indeterminado & $\mathrm{N}^{\circ}$ & $\%$ \\
\hline Solteiro & 4 & 0 & 4 & 23,53 \\
Casado & 8 & 2 & 10 & 58,82 \\
Ignorado* & 3 & 0 & 3 & 17,65 \\
\hline Total & 17 & 2 & 17 & 100,00 \\
\hline
\end{tabular}

* sem registro

Fonte: Centro de Hematologia e Hemoterapia de Santa Catarina - HEMOSC / SES Hemocentro Regional de Joaçaba

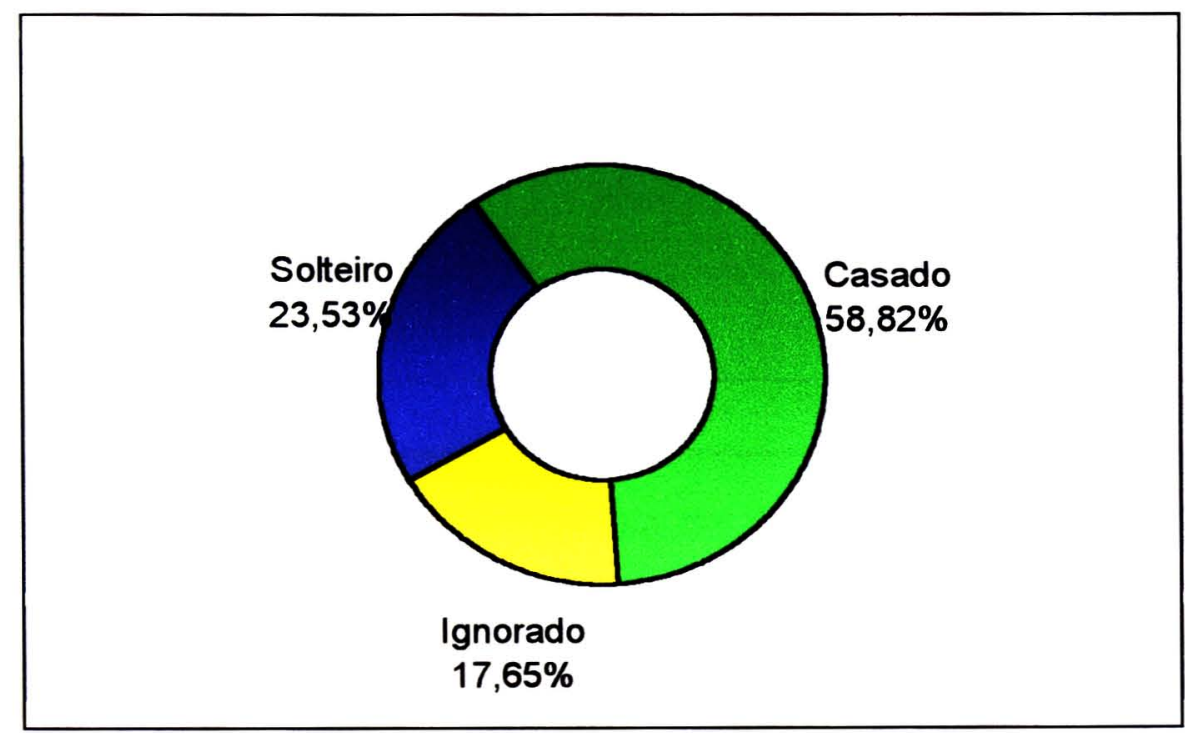

Figura 17 - Distribuição dos doadores de sangue soropositivos e indeterminados para infecção por T. cruzi, quanto ao estado civil. Região

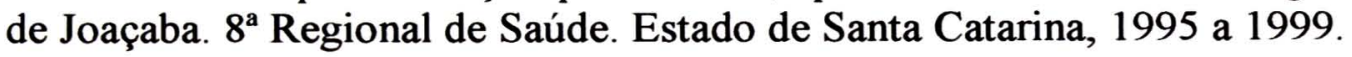

\section{- Ocupação}

Conforme a ocupação declarada dos doadores de sangue soropositivos e indeterminados observados no Hemocentro Regional de Joaçaba, no período de 1995 a 1999, sua distribuição foi a seguinte: 4 (23,53\%) desenvolviam atividades de serviços, turismo e embelezamento ou trabalhos agropecuários; $2(11,17 \%)$ são trabalhadores da 
construção civil ou condutores de veículos; e $5(29,41 \%)$ não constava a informação (Tabela 22).

Tabela 22 - Distribuição dos doadores de sangue soropositivos e indeterminados para infecção por $T$. cruzi, segundo a ocupação. Hemocentro Regional de Joaçaba. $8^{\text {a }}$ Regional de Saúde. Estado de Santa Catarina, 1995 a 1999.

\begin{tabular}{|c|c|c|c|c|}
\hline \multirow{2}{*}{ Grupo de Ocupações } & \multicolumn{2}{|c|}{ Hemocentro Regional de Joaçaba } & \multicolumn{2}{|c|}{ Total } \\
\hline & Soropositivo & Indeterminado & $N^{\circ}$ & $\%$ \\
\hline $\begin{array}{l}\text { Trabalhadores de serviços de } \\
\text { turismo, hospedagem, serventia, } \\
\text { higiene, embelezamento, } \\
\text { segurança, auxiliares de saude. }\end{array}$ & 3 & 1 & 4 & 23,53 \\
\hline $\begin{array}{l}\text { Trabalhadores agropecuários, } \\
\text { florestais, da pesca e } \\
\text { assemelhados. }\end{array}$ & 4 & - & 4 & 23,53 \\
\hline $\begin{array}{l}\text { Trabalhadores da produção } \\
\text { industrial, operadores de } \\
\text { máquinas. }\end{array}$ & 2 & - & 2 & 11,76 \\
\hline $\begin{array}{l}\text { Condutores de veículos e } \\
\text { assemelhados }\end{array}$ & 2 & - & 2 & 11,76 \\
\hline Ignorados* & 4 & 1 & 5 & 29,41 \\
\hline Total & 15 & 2 & 17 & 100,00 \\
\hline
\end{tabular}

Fonte: Centro de Hematologia e Hemoterapia de Santa Catarina - HEMOSC / SES; Hemocentro Regional de Joaçaba.

A distribuição, quanto ao grupo de ocupações, nesta Região, mostra que o maior percentual $(23,53 \%)$ concentra individuos com atividades de serviços ou exercem trabalhos agropecuários, diferentemente do que ocorreu na Região da Grande Florianópolis, onde a grande maioria ocupa atividades de serviços. Isto pode indicar, pela sua posição geográfica, possivelmente, alguma contribuição da transmissão vetorial naquela região, onde foi relatada a presença de triatomíneos no inquérito entomológico realizado na década de 1950 (FERREIRA NETO e col. 1971). 


\subsubsection{Prevalência da infecção por $T$. cruzi}

A taxa de prevalência dos doadores de sangue soropositivos e indeterminados para infecção por $T$. cruzi por 100.000 primodoadores, doadores de repetição e total de doadores, calculados junto ao Hemocentro Regional de Joaçaba, no período de 1995 a 1999, resultou em 171,69, 0,00 e 123,42, respectivamente (Tabela 23; Figura 18; Anexo IX).

Tabela 23 - Taxa de prevalência da infecção por $T$. cruzi entre primodoadores, doadores de repetição e total de doadores. Hemocentro Regional de Joaçaba. 8ª Regional de Saúde. Estado de Santa Catarina, 1995 a 1999.

\begin{tabular}{|c|c|c|c|c|}
\hline Doadores & $\mathrm{N}^{\circ}$ & $\begin{array}{l}\mathrm{N}^{\circ} \text { Estimado de } \\
\text { soropositivos }\end{array}$ & Prevalência & $\begin{array}{c}\text { Intervalo de } 95 \% \text { de } \\
\text { Confiança }\end{array}$ \\
\hline Primodoadores & 9.173 & 15,75 & 171,69 & $97,65-279,86$ \\
\hline $\begin{array}{l}\text { Doadores de } \\
\text { Repetição }\end{array}$ & 4.195 & 0,00 & 0,00 & $0,00-87,93$ \\
\hline Total de Doadores & 13.368 & 16,50 & 123,42 & $71,24-198,99$ \\
\hline
\end{tabular}

Fonte: Centro de Hematologia e Hemoterapia do Estado de Santa Catarina - HEMOSC, Hemocentro Regional de Joaçaba.

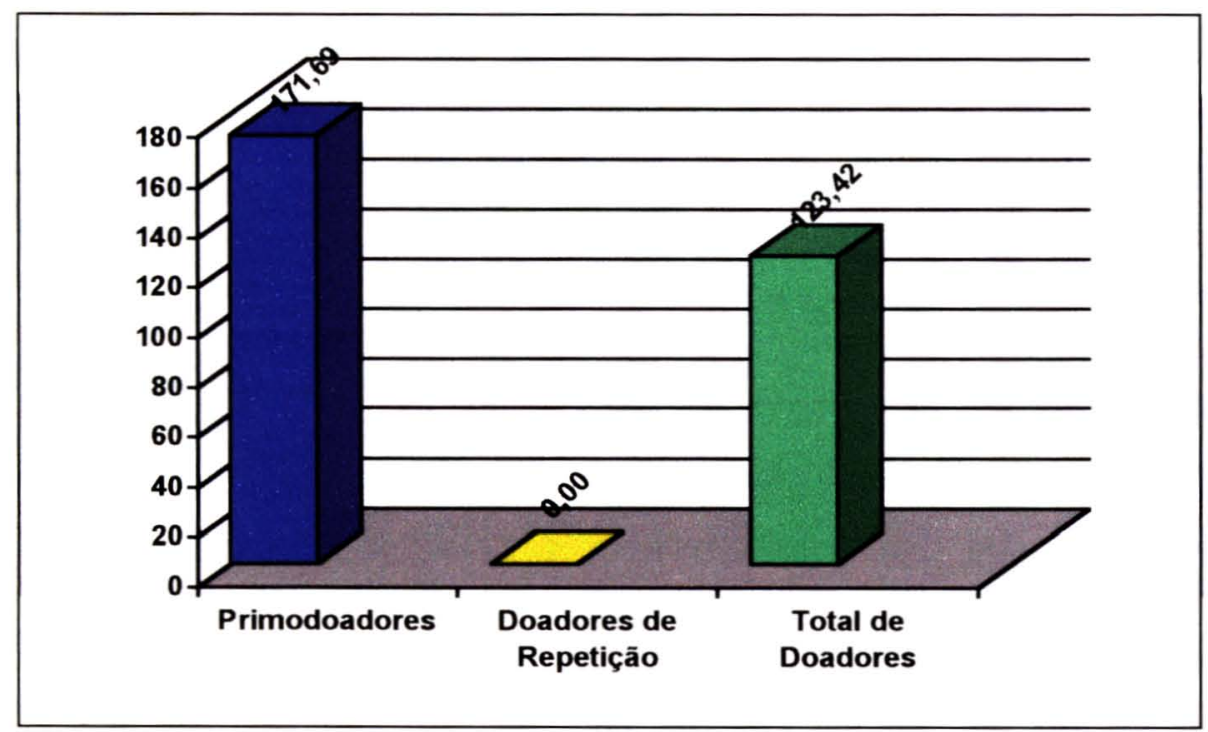

Figura 18 - Taxa de prevalência da infecção por T. cruzi entre primodoadores, doadores de repetição e total de doadores. Hemocentro Regional de Joaçaba. $8^{\text {a }}$ Regional de Saúde. Estado de Santa Catarina, 1995 a 1999 . 
O cálculo concernente à taxa de prevalência em doadores soroconvertidos resultou zero, devido a inexistência de casos observados em doadores de repetição, no Hemocentro Regional de Joaçaba, no período de 1995 a 1999.

Assim, pelos resultados obtidos, observamos a presença da infecção por T. cruzi, somente na população dos primodoadores de sangue, inexistindo esta, entre os doadores de repetição. Contudo, mostra nesta Região, a presença da infecção chagásica na população residente

\subsubsection{Incidência da infecção por $T$. cruzi}

A incidência resultou zero, entre os doadores de repetição estudados, tendo em vista que não foi detectado caso positivo de infecção chagásica, ou seja, não houve soroconversão observada para $T$. cruzi nas doações efetuadas junto ao Hemocentro Regional de Joaçaba, da $8^{\circ}$ Regional de Saúde, no período de 1995 a 1999 (Tabela 24; Anexo X).

Tabela 24 - Taxa de incidência da infecção por T. cruzi entre doadores de repetição no Hemocentro Regional de Joaçaba. $8^{\mathrm{a}}$ Regional de Saúde. Estado de Santa Catarina, 1995 a 1999.

\begin{tabular}{|c|c|c|c|c|c|c|}
\hline \multirow[b]{2}{*}{$\begin{array}{l}\text { Unidade } \\
\text { Hemoterápica }\end{array}$} & \multirow{2}{*}{$\begin{array}{l}\text { Pessoa- } \\
\text { tempo } \\
\text { exposta ao } \\
\text { risco* }\end{array}$} & \multicolumn{3}{|c|}{ Doadores } & \multirow[b]{2}{*}{$\begin{array}{l}\text { Taxa de } \\
\text { Incidência }\end{array}$} & \multirow[b]{2}{*}{$\begin{array}{l}\text { Intervalo } \\
\text { de } 95 \% \text { de } \\
\text { Confiança }\end{array}$} \\
\hline & & Soro(+) & $\begin{array}{l}\text { Indeter- } \\
\text { minado }\end{array}$ & $\begin{array}{c}N^{\circ} \text { Estimado } \\
\text { de Soro- } \\
\text { convertido }\end{array}$ & & \\
\hline $\begin{array}{l}\text { Hemocentro } \\
\text { Regional de } \\
\text { Joaçaba }\end{array}$ & 3790,260 & 0,00 & 1 & 0,00 & 0,00 & $\begin{array}{l}0,00- \\
97,33\end{array}$ \\
\hline
\end{tabular}

* Cálculo. anexo X

Fonie: Centro de Hematologia e Hemoterapia do Estado de Santa Catarina -HEMOSC / SES.

Isto nos parece revelar pura casualidade, conquanto que os exames sorológicos aqui utilizados são os mesmos realizados na Região da Grande Florianópolis, que recebe percentual semelhante de doadores naturais possivelmente de áreas endêmicas do Rio Grande do Sul e outros Estados da Federação (Tabela 7 e 21), aliado ao fato de estar 
localizada próximo a áreas com casos de infecção chagásica, detectados no inquérito sorológico realizado na década de 1970 (CAMARGO e col. 1984).

\subsubsection{Risco de transmissão transfusional}

Assim como a incidência, o risco relativo de transmissão transfusional resultou zero, visto que, no periodo estudado, de 1995 a 1999, não houve caso de infecção chagásica, detectado entre os doadores de repetição (Tabelas 25; Anexo XI)

Tabela 25 - Risco Relativo de Transmissão Transfusional e Intervalo de Confiança, entre os doadores de repetição. Hemocentro Regional de Joaçaba. $8^{\mathrm{a}}$ Regional de Saúde. Estado de Santa Catarina, 1995 a 1999.

\begin{tabular}{c|c|c|c|c|c}
\hline \multicolumn{3}{|c|}{ Doadores } & No Estimado de & $\begin{array}{c}\text { Risco Residual } \\
\text { de Transmissão } \\
\text { Transfusional }\end{array}$ & $\begin{array}{c}\text { Intervalo de 95\% } \\
\text { de Confiança }\end{array}$ \\
\hline $\mathrm{N}^{\circ}$ & Pos. & Ind. & Soroconvertidos & 0,00 & $0,00-7,46$ \\
\hline 13368 & 0,00 & 1 & 0,00 & 0,00 & 0,00 \\
\hline
\end{tabular}

Fonte: Centro de Hematologia e Hemoterapia do Estado de Santa Catarina-HEMOSC / SES

\subsection{Estado de Santa Catarina (Região da Grande Florianópolis e Joaçaba)}

Foram, neste item, analisados conjuntamente os dados coletados nas Unidades Hemoterápicas da Região da Grande Florianópolis, como: o Hemocentro Regional de Florianópolis e Serviço de Hemoterapia do HU/UFSC, localizados na Capital; e aqueles da Região de Joaçaba, do Hemocentro Regional de Joaçaba, o que corresponde, somados, a aproximadamente, $40 \%$ de todas as doações efetuadas no Estado de Santa Catarina, durante o periodo estudado de 1990 a 1999. 


\subsubsection{Caracterização da população sorologicamente positiva para}

\section{Trypanosoma cruzi}

\section{- Naturalidade}

Quanto à naturalidade, os doadores de sangue totalizaram 294 casos soropositivos e indeterminados para infecção por $T$. cruzi, observada no conjunto das Unidades Hemoterápicas estudadas, como o Hemocentro Regional de Florianópolis, Serviço de Hemoterapia do HU/UFSC e Hemocentro Regional de Joaçaba, onde revelou um percentual elevado de, aproximadamente, 60\% naturais do Estado de Santa Catarina.

Apresentou também um expressivo contingente de doadores procedentes de outros Estados, muitos dos quais de áreas endêmicas (CAMARGO e col. 1984; CUNHA e col. 1987; e BECK e col. 1993), o que pode elevar a prevalência da infecção por infecção chagásica entre os doadores de sangue nos hemocentros do Estado de Santa Catarina. Destes, um considerável percentual de doadores é natural dos Estados vizinhos como o Rio Grande do Sul $(20,07 \%)$ e o Paraná $(4,42 \%)$, seguido de São Paulo $(3,06 \%)$, entre outros (Tabela 26; Figura 19).

Esta distribuição da proporção de doadores infectados, naturais de áreas endêmicas, nos orienta para não descartar o risco da infecção chagásica por transmissão transfusional devido a progressiva migração de pessoas infectadas, fenômeno que contribui na presença da enfermidade no Estado de Santa Catarina. 
Tabela 26 - Distribuição quanto à naturalidade dos doadores de sangue soropositivos e indeterminados para infecção por $T$. cruzi, no conjunto das Unidades Hemoterápicas estudadas (HRF, SHHU/UFSC e HRJ). Estado de Santa Catarina, 1990 a 1999.

\begin{tabular}{cccrc}
\hline \multirow{2}{*}{ Naturalidade } & \multicolumn{2}{c}{ Casos } & \multicolumn{2}{c}{ Total } \\
\cline { 2 - 5 } & Soropositivo & Indeterminado & $N^{\circ}$ & $\%$ \\
\hline SC & 103 & 73 & 176 & 59,86 \\
RS & 46 & 13 & 59 & 20,07 \\
PR & 7 & 6 & 13 & 4,42 \\
SP & 6 & 3 & 9 & 3,06 \\
RJ & 5 & 2 & 7 & 2,38 \\
BA & 5 & - & 5 & 1,70 \\
PB & 2 & - & 2 & 0,68 \\
MT & 1 & - & 1 & 0,34 \\
DF & 1 & - & 1 & 0,34 \\
PN & 1 & - & 1 & 0,34 \\
CE & 1 & - & 1 & 0,34 \\
IG* & 8 & 11 & 19 & 6,47 \\
\hline Total & 186 & 108 & 294 & 100,00 \\
\hline
\end{tabular}

* Procedência ignorada

Fonte: Centro de Hematologia e Hemoterapia do Estado de Santa Catarina HEMOSC; Hospital Universitário - HU/UFSC

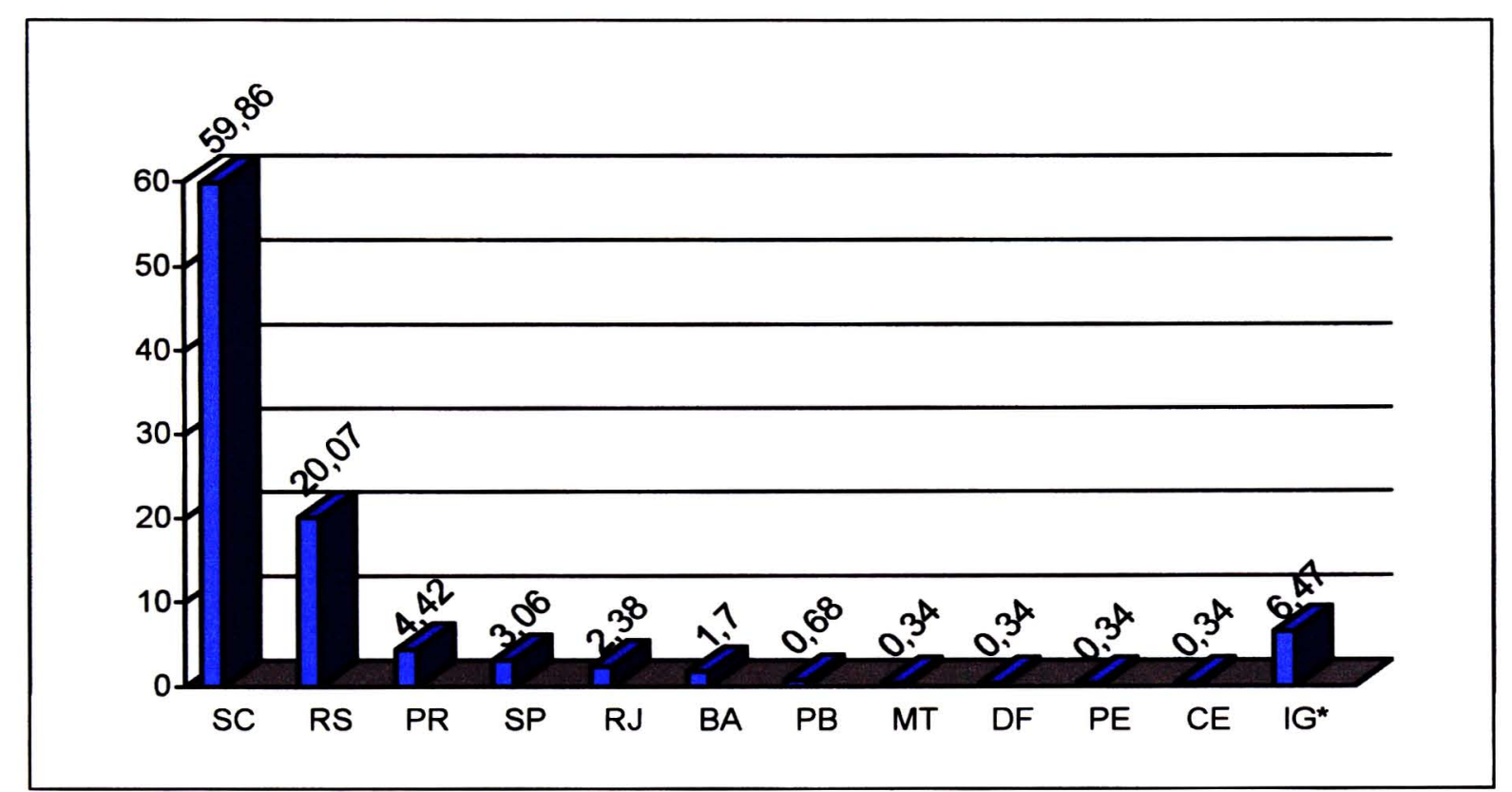

Figura 19 -Distribuição quanto à naturalidade dos doadores de sangue soropositivos e Indeterminados para infecção por $T$. cruzi, no conjunto das Unidades Hemoterápicas estudadas (HRF, SHHU/UFSC e HRJ). Estado de Santa Catarina, 1990 a 1999. 


\section{- Faixa etária}

Ao analisar-se a distribuição dos doadores soropositivos e indeterminados no conjunto das Unidades Hemoterápicas estudadas, no periodo de 1990 a 1999, segundo a faixa etária, observou-se o seguinte: $66(22,45 \%)$ pertenciam ao grupo de 18 a 20 anos de idade; $86(29,25 \%)$ entre 21 a 30 anos; $64(21,77 \%)$ de 31 a 40 anos; $52(17,69 \%)$ entre 41 a 50 anos; $26(8,84 \%)$ entre 51 a 60 anos de idade.

O grupo etário de 21 a 30 anos representou, majoritariamente, a proporção de soropositivos $86(29,25 \%)$, enquanto que aqueles entre 41 a 50 e 51 a 60 anos mostraram proporção menor, de $52(17,79 \%)$ e $26(8,84 \%)$, respectivamente (Tabela 27 ; Figura 20).

No final do periodo, ano de 1999, houve uma expressiva participação (93,75\%) dos grupos mais jovens (18 a 40 anos), enquanto que a faixa etária 41 anos e mais, contribuiu com apenas $(6,25 \%)$.

Tabela 27 - Distribuição dos doadores de sangue soropositivos e indeterminados para infecção por $T$. cruzi por faixa etária e ano de doação, nas Unidades Hemoterápicas estudadas (HRF, SHHU/UFSC e HRJ). Estado de Santa Catarina, 1990 a 1999.

\begin{tabular}{|c|c|c|c|c|c|c|c|c|c|c|c|c|}
\hline \multirow{3}{*}{ Ano } & \multicolumn{12}{|c|}{ Faixa etária (ano) } \\
\hline & \multicolumn{2}{|c|}{18 a 20} & \multicolumn{2}{|c|}{21 a 30} & \multicolumn{2}{|c|}{31 a 40} & \multicolumn{2}{|c|}{41 a 50} & \multicolumn{2}{|c|}{51 a 60} & \multicolumn{2}{|c|}{ Total } \\
\hline & $N^{\circ}$ & $\%$ & $N^{\circ}$ & $\%$ & $N^{\circ}$ & $\%$ & $\mathrm{~N}^{\circ}$ & $\%$ & $N^{\circ}$ & $\%$ & $\mathrm{~N}^{\mathrm{o}}$ & $\%$ \\
\hline 1990 & 13 & 61.90 & 1 & 4.76 & 3 & 14.29 & 3 & 14.29 & 1 & 4.76 & 21 & 7,14 \\
\hline 1991 & 1 & 5.00 & 4 & 20.00 & 9 & 45.00 & 1 & 5.00 & 5 & 25.00 & 20 & 6,80 \\
\hline 1992 & 12 & 48.00 & 5 & 20.00 & 3 & 12.00 & 3 & 12.00 & 2 & 8.00 & 25 & 8,50 \\
\hline 1993 & 5 & 16.67 & 9 & 30.00 & 7 & 23.33 & 9 & 30.00 & 0 & 0.00 & 30 & 10,21 \\
\hline 1994 & 6 & 18.75 & 14 & 43.75 & 5 & 15.62 & 4 & 12.50 & 3 & 9.38 & 32 & 10,88 \\
\hline 1995 & 7 & 18.92 & 11 & 29.73 & 6 & 16.21 & 10 & 27.03 & 3 & 8.11 & 37 & 12,59 \\
\hline 1996 & 6 & 18.75 & 9 & 28.12 & 7 & 21.88 & 7 & 21.88 & 3 & 9.37 & 32 & 10,88 \\
\hline 1997 & 6 & 16.22 & 8 & 21.62 & 11 & 29.72 & 6 & 16.22 & 6 & 16.22 & 37 & 12,59 \\
\hline 1998 & 6 & 13.64 & 17 & 38.64 & 10 & 22.73 & 9 & 20.45 & 2 & 4.54 & 44 & 14,97 \\
\hline 1999 & 4 & 25.00 & 8 & 50.00 & 3 & 18.75 & 0 & 0.00 & 1 & 6.25 & 16 & 5,44 \\
\hline Total & 66 & 22,45 & 86 & 29,25 & 64 & 21,77 & 52 & 17,69 & 26 & 8,84 & 294 & 100,00 \\
\hline
\end{tabular}

Fonte: Centro de Hematologia e Hemoterapia do Estado de Santa Catarina HEMOSC. Hospital Universitário - HU/UFSC 


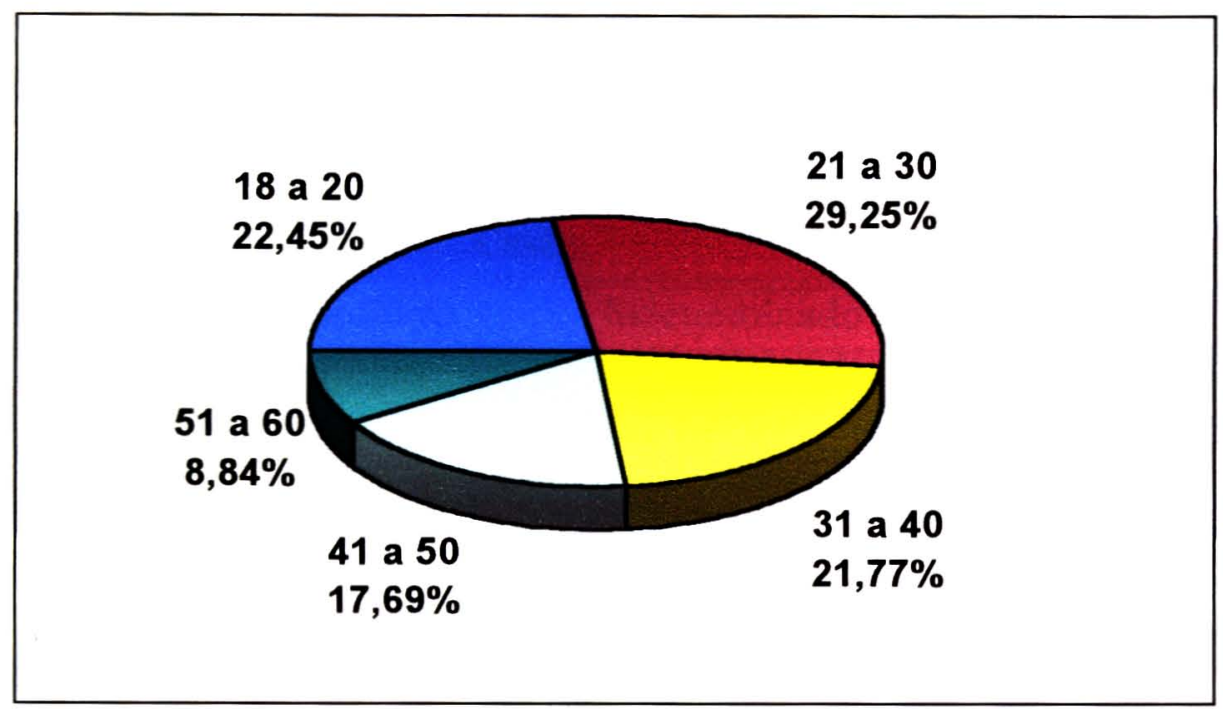

Figura 20 - Distribuição dos doadores de sangue soropositivos e indeterminados para infecção por $T$. cruzi por faixa etária e ano de doação, nas Unidades Hemoterápicas estudadas (HRF, SHHU/UFSC e HRJ). Estado de Santa Catarina, 1990 a 1999.

\section{- Sexo}

Da análise efetuada dos 294 doadores de sangue soropositivos e indeterminados para infecção por T. cruzi, no período de 1990 a 1999, quanto ao gênero, 237 (80,61\%) eram do sexo masculino, $54(18,37 \%)$ do sexo feminino e $3(1,02 \%)$ sem registro evidente na ficha cadastral (Tabela 28; Figura 21)

Proporção semelhante foi encontrada na população estudada na Região da Grande Florianópolis; porém, distante desse percentual foi observado na Região de Joaçaba, Estado de Santa Catarina (Tabelas 9 e 20).

Todavia, uma elevada proporção de soropositivos do sexo masculino se mantém, quando são estudadas em conjunto as duas regiões, devidas, provavelmente, pela ocupação exercida pelos homens daquele grupo às condições ambientais. Segundo LIMA (1981), uma proporção de $96 \%$ de homens foi observada entre doadores de sangue em Brasília. VARELA (1993), constatou também uma expressiva proporção de $74 \%$ de homens entre doadores de sangue no Paraná.

Contudo, não se pode afirmar por esta variável que os homens teriam maior risco de infecção pelo T.cruzi do que as mulheres, pelas observações realizadas. 
Tabela 28 - Distribuição de doadores de sangue soropositivos e indeterminados para infecção por $T$. cruzi, por sexo, nas Unidades Hemoterápicas estudadas (HRF, SHHU/UFSC e HRJ). Estado de Santa Catarina, 1990 a 1999.

\begin{tabular}{lcccc}
\hline \multirow{2}{*}{ Sexo } & \multicolumn{2}{c}{ Casos } & \multicolumn{2}{c}{ Total } \\
\cline { 2 - 5 } & Soropositivo & Indeterminado & $\mathbf{N}^{\circ}$ & $\%$ \\
\hline Masculino & 147 & 90 & 237 & 80,61 \\
Feminino & 38 & 16 & 54 & 18,37 \\
Ignorado* & 1 & 2 & 3 & 1,02 \\
\hline Total & 186 & 108 & 294 & 100,00 \\
\hline
\end{tabular}

* Sem registro

Fonte: Centro de Hematologia e Hemoterapia do Estado de Santa Catarina - HEMOSC. Hospital Universitário - HU/UFSC

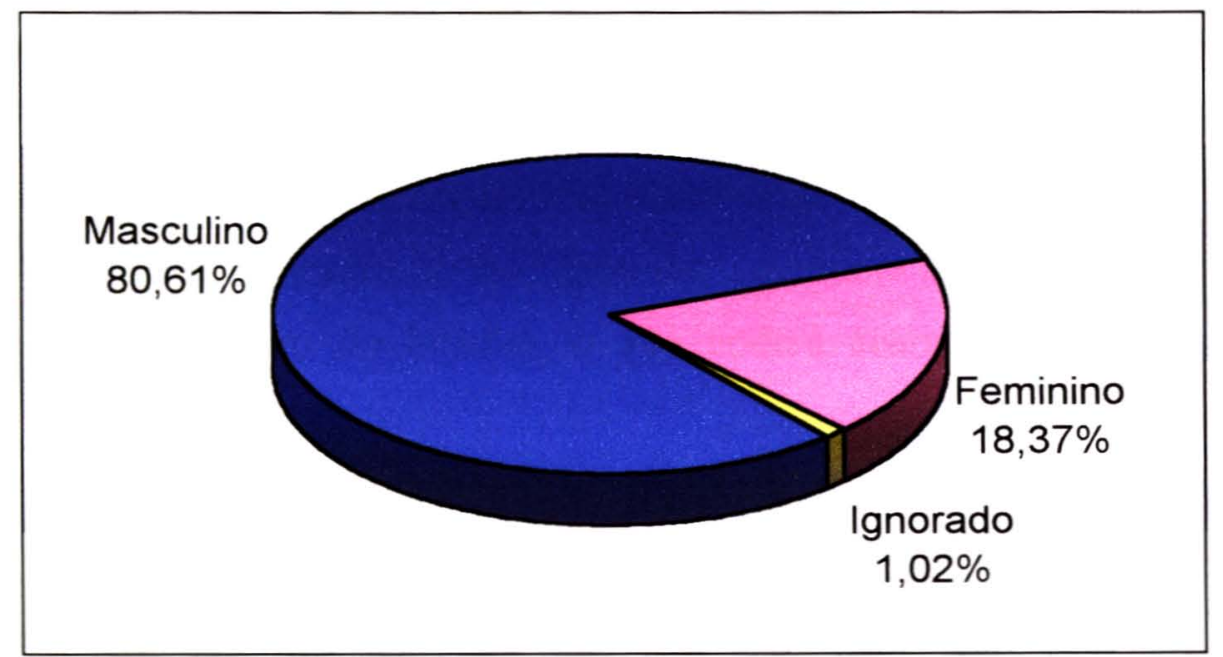

Figura 21 - Distribuição de doadores de sangue soropositivos e indeterminados para infecção por $T$. cruzi, por sexo, nas Unidades Hemoterápicas estudadas (HRF, SHHU/UFSC e HRJ). Estado de Santa Catarina, 1990 a 1999.

\section{- Estado civil}

Quanto ao estado civil, a distribuição dos individuos soropositivos e indeterminados para infecção chagásica na população de doadores de sangue estudada no Estado de Santa Catarina, período de 1990 a 1999, 46,60\% eram casados, 29,25\% solteiros, e 24,15\% sem registro do estado civil (Tabela 29; Figura 22). 
Tabela 29 - Distribuição dos doadores de sangue soropositivos e indeterminados para infecção por $T$. cruzi, quanto ao estado civil, nas Unidades Hemoterápicas estudadas (HRF, SHHU/UFSC e HRJ). Estado de Santa Catarina, 1990 a 1999

\begin{tabular}{lccrc}
\hline \multirow{2}{*}{ Estado Civil } & \multicolumn{2}{c}{ Casos } & \multicolumn{2}{c}{ Total } \\
\cline { 2 - 5 } & Soropositivo & Indeterminado & \multicolumn{1}{c}{$\mathrm{N}^{\circ}$} & $\%$ \\
\hline Solteiro & 48 & 38 & 86 & 29,25 \\
Casado & 93 & 44 & 137 & 46,60 \\
Ignorado* & 45 & 26 & 71 & 24,15 \\
\hline Total & 186 & 108 & 294 & 100,00 \\
\hline
\end{tabular}

* sem registro

Fonte: Centro de Hematologia e Hemoterapia do Estado de Santa Catarina HEMOSC. Hospital Universitário - HU/UFSC

Proporção semelhante é também observada na distribuição dessa variável, nas Regiões da Grande Florianópolis e Joaçaba (Tabelas 10 e 21).

Outro fato interessante, observado na distribuição do estado civil, é o percentual expressivo de casos classificados como "ignorado", devido a ausência de registro dessa variável na Ficha Cadastro do Doador, o que poderá acarretar dificuldades no seu estudo.

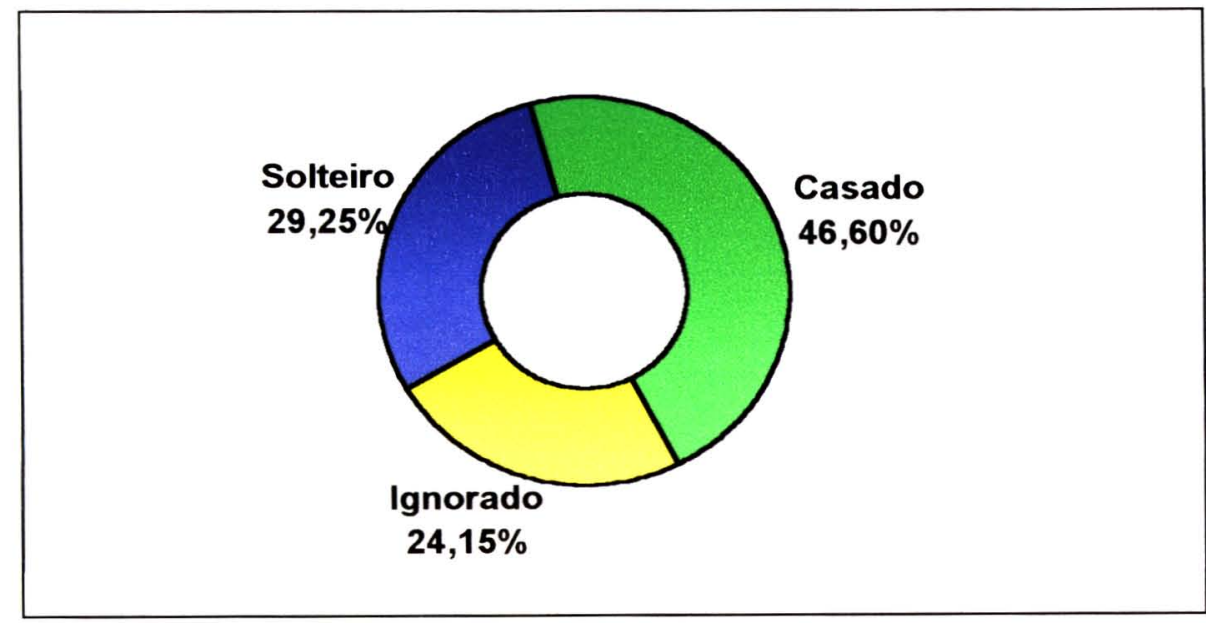

Figura 22 - Distribuição dos doadores de sangue soropositivos e indeterminados para infecção por $T$. cruzi, quanto ao estado civil, no conjunto das Unidades Hemoterápicas estudadas (HRF, SHHU/UFSC e HRJ). Estado de Santa Catarina, 1990 a 1999. 


\section{- Ocupação}

Em termos da ocupação dos 294 casos sorologicamente positivos e indeterminados para T. cruzi, estudados no Estado de Santa Catarina, foi observado que $41(13,95 \%)$ exerciam atividades de serviços de turismo, hospedagem, higiene, embelezamento, segurança e auxiliares de saúde; 36 (12,24\%) eram trabalhadores da produção industrial, operadores de máquinas ou assemelhados; 27 (9,18\%) membros das forças armadas; $26(8,85 \%)$ trabalhadores das profissões científicas, técnicas, artísticas ou outras ocupações como estudantes, autônomos, aposentados; 14 (4,76\%) eram funcionários públicos ou comerciantes ou motoristas; $14(4,42 \%)$ desenvolviam atividades administrativas; e com menor ocorrência 12 (4,08\%) trabalhadores com atividades agropecuárias, florestais, de pesca ou assemelhados (Tabela 30).

Essa distribuição apresentou-se de forma semelhante à encontrada na Região da Grande Florianópolis, porém, diferente daquela da Região de Joaçaba, principalmente aqueles indivíduos que exerciam atividades do grupo de serviços de turismo, higiene, segurança ou assemelhados exercidos na área urbana, e aqueles do grupo de ocupações como os trabalhadores agropecuários, florestais e assemelhados, próprios da área rural (Tabelas 11 e 22). 
Tabela 30 - Distribuição dos doadores de sangue soropositivos e indeterminados para infecção por $T$. cruzi, segundo a ocupação nas Unidades Hemoterápicas estudadas (HRF, SHHU/UFSC e HRJ). Estado de Santa Catarina, 1990 a 1999.

\begin{tabular}{|c|c|c|c|c|}
\hline \multirow{2}{*}{ GRUPO DE OCUPAÇÕES } & \multicolumn{2}{|c|}{ CASOS } & \multicolumn{2}{|c|}{ TOTAL } \\
\hline & SOROPOSITIVO & INDETERMINADO & $\mathrm{N}^{\circ}$ & $\%$ \\
\hline $\begin{array}{l}\text { Trabalhadores das profissões } \\
\text { científicas, técnicas artísticas. }\end{array}$ & 17 & 9 & 26 & 8,85 \\
\hline $\begin{array}{l}\text { Membros dos poderes legis- } \\
\text { lativo, executivo e judiciiário. } \\
\text { Func. Públicos. Diretores de } \\
\text { empresas. }\end{array}$ & 8 & 6 & 14 & 4,76 \\
\hline $\begin{array}{l}\text { Trabalhadores de serviços ad- } \\
\text { ministrativos e assemelhados }\end{array}$ & 6 & 7 & 13 & 4,42 \\
\hline $\begin{array}{l}\text { Trabalhadores do comércio e } \\
\text { assemelhados }\end{array}$ & 7 & 7 & 14 & 4,76 \\
\hline $\begin{array}{l}\text { Trabalhadores de serviços de } \\
\text { turismo, hospedagem, ser- } \\
\text { ventia, higiene, embeleza- } \\
\text { mento, segurança, auxiliares } \\
\text { de saúde. }\end{array}$ & 32 & 9 & 41 & 13,95 \\
\hline $\begin{array}{l}\text { Trabalhadores agropecuários, } \\
\text { florestais, da pesca e asse- } \\
\text { melhados. }\end{array}$ & 9 & 3 & 12 & 4,08 \\
\hline $\begin{array}{l}\text { Trabalhadores da produção } \\
\text { industrial, operadores de má- } \\
\text { quinas. }\end{array}$ & 25 & 11 & 36 & 12,24 \\
\hline $\begin{array}{l}\text { Condutores de veículos e as- } \\
\text { semelhados }\end{array}$ & 8 & 6 & 14 & 4,76 \\
\hline $\begin{array}{l}\text { Membros das forças armadas, } \\
\text { policiais e bombeiros. }\end{array}$ & 16 & 11 & 27 & 9,18 \\
\hline $\begin{array}{l}\text { Estudantes, autônomos, apo- } \\
\text { sentados. }\end{array}$ & 14 & 12 & 26 & 8,85 \\
\hline Ignorados* & 44 & 27 & 71 & 24,15 \\
\hline Total & 186 & 108 & 294 & 100,00 \\
\hline
\end{tabular}

* sem registro

Fonte: Centro de Hematologia e Hemoterapia do Estado de Santa Catarina - HEMOSC. Hospital Universitário - HU/UFSC

Portanto, a população soropositiva observada ao longo deste estudo, representa o contingente de individuos expostos à contaminação que precedeu a triagem sorológica. Possivelmente, pode-se considerar esta população como reservatório da infecção por $T$. cruzi na área urbana, do Estado de Santa Catarina. 


\subsubsection{Prevalência da infecção por $T$. cruzi.}

A prevalência dos doadores de sangue soropositivos e indeterminados para infecção chagásica, por 100.000 primodoadores, doadores de repetição e total doadores, foram calculadas junto às Unidades Hemoterápicas estudadas, resultou, como visto anteriomente, em 114,07, 194,61 e 122,94 no Hemocentro Regional de Florianópolis; 438,86, 58,41 e 370,10 no Serviço de Hemoterapia do HU/UFSC; e 171,69, 0,00 e 123,42 no Hemocentro Regional de Joaçaba, respectivamente.

Considerando a totalidade das doações de sangue efetuadas nas três Unidades Hemoterápicas, observou-se como resultado de prevalência os valores de $151,93 / 100.000$ entre os primodoadores, 136,88/100.000 nos doadores de repetição e 150,12/100. 000 entre o total de doadores. (Tabelas 31 e 32; Figura 23; Anexo XII).

Tabela 31 - Taxa de prevalência da infecção por T.cruzi entre primodoadores, doadores de repetição e total de doadores no Hemocentro Regional de Florianópolis, Serviço de Hemoterapia do HU/UFSC, Hemocentro Regional de Joaçaba. Estado de Santa Catarina. 1990 a 1999.

\begin{tabular}{|c|c|c|c|c|c|c|c|}
\hline \multirow[b]{2}{*}{$\begin{array}{c}\text { Unidade } \\
\text { Hemoterápica }\end{array}$} & \multirow[b]{2}{*}{ Período } & \multicolumn{6}{|c|}{ Prevalência* } \\
\hline & & $\begin{array}{l}\text { Primodoa- } \\
\text { dores }\end{array}$ & $\begin{array}{c}\mathrm{N}^{\mathrm{o}} \\
\text { Estimado } \\
\text { soro }(+)\end{array}$ & $\begin{array}{c}\text { Doadores } \\
\text { de } \\
\text { Repetição }\end{array}$ & $\begin{array}{c}\mathrm{N}^{\mathrm{o}} \\
\text { Estimado } \\
\text { soro }(+)\end{array}$ & $\begin{array}{c}\text { Total } \\
\text { Doadores }\end{array}$ & $\begin{array}{c}\mathrm{N}^{\circ} \\
\text { Estimacic } \\
\text { soro (+) }\end{array}$ \\
\hline $\begin{array}{l}\text { Hemocentro } \\
\text { Regional de } \\
\text { Florianópolis }\end{array}$ & $\begin{array}{c}01.01 .90 \mathrm{a} \\
31.12 .99\end{array}$ & $\begin{array}{c}114,07 \\
(n=114.844)\end{array}$ & 131,01 & $\begin{array}{c}194.61 \\
(n=14.064)\end{array}$ & 27,37 & $\begin{array}{c}122,94 \\
(n=128908)\end{array}$ & 158,48 \\
\hline $\begin{array}{l}\text { Serviço de } \\
\text { Hemoterapia } \\
\text { do HU/UFSC }\end{array}$ & $\begin{array}{c}01.01 .90 \mathrm{a} \\
31.12 .99\end{array}$ & $\begin{array}{c}438.86 \\
(n=14.523)\end{array}$ & 63,74 & $\begin{array}{c}58.41 \\
(n=3.030)\end{array}$ & 1,77 & $\begin{array}{c}370,10 \\
(n=17.553)\end{array}$ & 64.96 \\
\hline $\begin{array}{l}\text { Hemocentro } \\
\text { Regional de } \\
\text { Joaçaba }\end{array}$ & $\begin{array}{c}01.01 .95 \mathrm{a} \\
31.12 .99\end{array}$ & $\begin{array}{c}171,69 \\
(n=9.173)\end{array}$ & 15,75 & $\begin{array}{c}0,00 \\
(\mathrm{n}=4.195)\end{array}$ & 0,00 & $\begin{array}{c}123,42 \\
(n=13.368)\end{array}$ & 16,50 \\
\hline $\begin{array}{l}\text { Estado de } \\
\text { Santa } \\
\text { Catarina** }\end{array}$ & & $\begin{array}{c}151,93 \\
(n=138.540)\end{array}$ & 210.49 & $\begin{array}{c}136,88 \\
(n=21.289)\end{array}$ & 29,14 & $\begin{array}{c}150,12 \\
(n=159829)\end{array}$ & 239,94 \\
\hline
\end{tabular}

* Prevalência $=\mathrm{n}^{\circ}$ de soropositivos $/ \mathrm{n}^{\circ}$ de primodoadores, doadores de repetição ou total de doadores de cada local e periodo estudado

** Média Ponderada das prevalências encontradas nas Unidades Hemoterápicas do Hemocentro Regional de Florianópolis, Serviço de Hemoterapia do HU/UFSC e Hemocentro Regional de Joaçaba, entre os primodoadores, doadores de repetição e total de doadores.

$\mathrm{n}$ =denominador, ou seja, o número de primodoadores, doadores de repetição ou total de doadores de cada local e periodo estudado.

$\mathrm{N}^{\circ}$ estimado = número aproximado de soropositivos considerando-se também os indeterminados.

Fonte: Centro de Hematologia e Hemoterapia do Estado de Santa Catarina - HEMOSC Hospital Universitário - HU/UFSC. 
Tabela 32 - Taxa de prevalência da infecção por T.cruzi entre primodoadores, doadores de repetição e total de doadores estudados no Estado de Santa Catarina, 1990 a 1999.

\begin{tabular}{lcccc}
\hline Doadores & $\mathrm{N}^{\mathrm{o}}$ & $\begin{array}{c}\mathrm{N}^{\circ} \text { Estimado de } \\
\text { soropositivos }\end{array}$ & Prevalência & $\begin{array}{c}\text { Intervalo de } 95 \% \\
\text { de Confiança }\end{array}$ \\
\hline $\begin{array}{l}\text { Primodoadores } \\
\begin{array}{l}\text { Doadores de } \\
\text { Repetição }\end{array}\end{array}$ & 138540 & 210,49 & 151,93 & $140,05-163,82$ \\
\hline Total & 159829 & 239,14 & 136,88 & $91,79-196,47$ \\
\hline
\end{tabular}

Fonte: Centro de Hematologia e Hemoterapia do Estado de Santa Catarina - HEMOSC / SES. Hospital Universitário - HU, da Universidade Federal de Santa Catarina UFSC.

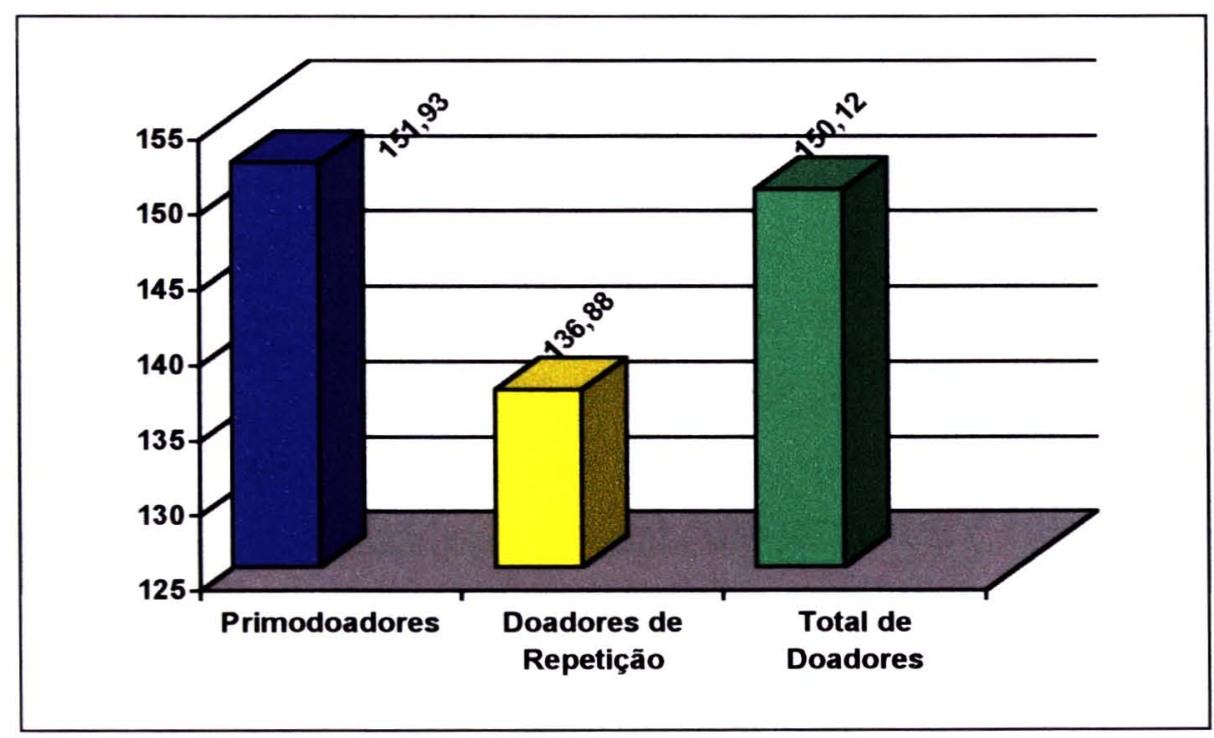

Figura 23 - Taxa de prevalência da infecção por T.cruzi entre primodoadores, doadores de repetição e total de doadores estudados no Estado de Santa Catarina, 1990 a 1999.

A taxa de prevalência encontrada no estudo englobando as três Unidades Hemoterápicas (HRF, SHHU/UFSC e HRJ), não diferem muito entre si, quando calculada entre primodoadores $(151,93 / 100.000)$, e pouco significativa quando observada nos doadores de repetição $(136,88 / 100.000)$.

Comparando-se a prevalência encontrada no total de doadores de sangue estudados no Estado de Santa Catarina (0,15\%), com dados de outras regiões do país, ou deste como um todo, esta pode ser considerada baixa, contudo, mostra presente a infecção por T. cruzi, na população de doadores de sangue residentes no Estado, independentemente da sua naturalidade. 
BECK e col. (1993), encontrou o percentual de 9,20\% de doadores soropositivos para doença de Chagas, analisando 1.140 amostras em banco de sangue na cidade de Santiago, no Rio Grande do Sul.

Estudo realizado junto ao Hemocentro Regional de Uberaba, Minas Gerais, no período de 1998 a 1999, revelou a prevalência de soropositividade para infecção por $T$. cruzi de 0,72\% entre doadores de sangue (SOARES E MORAES-SOUZA 2000).

A prevalência da infecção por $T$. cruzi verificada nos doadores submetidos à triagem sorológica no Estado de São Paulo, foi de 1,0\%, no período de 1988-93 (WANDERLEY 1994 a).

No Brasil, a prevalência geral de doadores chagásicos na hemorrede pública, no ano de 1995 , situou-se em torno de $0,7 \%$, variando de $0,4 \%$ a $1,5 \%$ entre as várias regiões do País (GONTIJO 2000).

Esta soropositividade encontrada entre o doadores de sangue, pode ser explicada pela naturalidade dos indivíduos que migraram, predominantemente, de regiões endêmicas, como dos Estados do Rio Grande do Sul, Paraná, São Paulo, Rio de Janeiro, Bahia, entre outros (Tabela 26).

Considerando a faixa etária da população de doadores de sangue, selecionada entre a idade mínima de 18 e máxima 55 anos, não tivemos assim, informações sobre a ocorrência da enfermidade nas idades mais jovens, o que se constitui num instrumento importante para estudos da transmissão vetorial (WANDERLEY 1994a).

Os doadores que apresentaram reação positiva para infecção chagásica, se constituem, na sua maioria, de individuos jovens, do sexo masculino, casados, ocupando profissões que exigem pequena ou nenhuma qualificação (Tabelas 27, 28, 29 e 30).

Um dos fatores que tem contribuido para a redução da prevalência da infecção chagásica nos serviços de hemoterapia, é o doador de retorno. Nas Unidades Hemoterápicas estudadas no Estado de Santa Catarina, cerca de 13\% dos doadores já fizeram mais de uma doação de sangue, ocasiões em que se submeteram aos exames laboratoriais de triagem (Tabela 3). Acrescenta-se a isto o fato de que na triagem clínica, aproximadamente, $20 \%$ dos candidatos são considerados inaptos, e que neste grupo se concentram os candidatos à primeira doação. As principais causas encontradas nessa triagem que inabilitaram os candidatos à doação foram: o contato de risco para HIV devido o uso de drogas, promiscuidade, manifestações gripais, uso de medicamentos, lesões de pele, anemia, hipertensão, entre outras (HEMOSC, relatório não publicado). 
Em estudos realizados no Hemocentro Regional de Uberaba, Minas Gerais, indicaram ser de $62 \%$ o índice de doadores de repetição e o de $30 \%$, o da triagem clínica. A prevalência dos doadores aptos à triagem clínica, em 1992, foi de $3 \%$, e a prevalência à sorologia positiva de 1,4\% (MORAES-SOUZA e col. 1994).

Outro fator responsável pelo declínio da sorologia positiva é a triagem sorológica, que impede o retorno do doador infectado para doar o seu sangue em outros momentos.

A triagem laboratorial entre doadores de sangue, verificada em 104 Serviços de Hemoterapia do Estado de São Paulo, pesquisados no ano de 1990, indicou que o encontro de prevalência sorológica para $T$. cruzi entre doadores, de $1,3 \%$ (WANDERLEY e col. 1993 e WANDERLEY 1994a), utilizando na sua grande maioria duas técnicas diferentes e adequadas como previsto na legislação em vigor (OMS 1991).

O resultado da prevalência de 150,12/100.000 observado entre os doadores com sorologia positiva para doença de Chagas, encontrado no conjunto das três Unidades Hemoterápicas estudadas no Estado de Santa Catarina, pode até estar superdimensionado, uma vez que, quando são realizadas a triagem sorológica e apenas um dos exames apresenta resultado positivo, o sangue é descartado e o doador entra na estatística dos infectados, embora seu diagnóstico não tenha sido confirmado, considerando que as Portarias 721, de 09/08/89 e 1376, de 19/11/93, do Ministério da Saúde, não obrigam os serviços de hemoterapia desse procedimento. Sabe-se, também, que a reação sorológica para doença de Chagas, embora raramente pelos exames sorológicos atualmente utilizados, pode apresentar resultados falso-positivos com outras patologias

Porém, a totalidade dos resultados dos exames sorológicos encontrados neste estudo, foi considerado "positivo", quando mais de um teste sorológico, resultou reagente para infecção por $T$. cruzi na primeira amostra ou confirmatório numa segunda amostra, de acordo com técnicas utilizadas nos hemocentros estudados.

Estudos realizados por WENDEL (1993), mostraram que doadores com reatividade em apenas um teste representam $1,2 \%$ das sorologias positivas, apresentando baixos títulos de anticorpos e dados clínico-epidemiológicos de pouca elucidação.

No periodo de outubro de 1988 a abril de 1989, MARTELLI e col. (1992), observaram entre 6.172 doadores de sangue testados com exames de Hemaglutinação e Fixação de complemento em 6 bancos de sangue de Goiânia, Brasil, a prevalência de 
$3,3 \%$ entre 1.504 primodoadores; $1,9 \%$ entre 4.668 doadores de repetição; e de 1,9 entre o total de doadores.

O número total de doações de sangue encontrado nas três Unidades Hemoterápicas estudadas no período de 1990 a 1999, foi de 204.025 bolsas de sangue doadas. Destas, foram triadas sorologicamente 294 bolsas positivas para infecção para $T$. cruzi. Considerando que cada uma pode produzir 4 hemocomponentes distintos, 1.176 unidades de hemocomponentes foram descartadas por serem fonte de transmissão transfusional da doença de Chagas. Isso mostra a dimensão do problema, caso estas fossem transfundidas, tanto do ponto de vista econômico quanto social a que estariam expostos os receptores.

Embora a prevalência encontrada no Estado de Santa Catarina, seja bem inferior àquela observada no Estado vizinho, indica contudo, a presença da infecção chagásica entre doadores de sangue nas regiões estudadas.

\subsubsection{Incidência da infecção por $T$. cruzi}

A incidência da infecção por T. cruzi entre os doadores de repetição, no periodo de 01.01 .97 a 18.06 .99 , teve uma taxa de $36,48 / 100000$ doadores no Hemocentro Regional de Florianópolis; 62,49 no Serviço de Hemoterapia do HU/UFSC, no período de 1990-1999; e 0,00 no Hemocentro Regional de Joaçaba, no periodo de 1995 a 1999 Resultou em 31,65/100.000 doadores, quando consideramos o conjunto das três Unidades Hemoterápicas estudadas no Estado de Santa Catarina, onde foram observados 3 doadores soropositivos e 14 indeterminados dentre 17.365 doadores de repetição (Tabela 33; Figura 24; Anexo XIII).

Estudo realizado por SOARES e MORAES-SOUZA, no ano de 2000, junto ao Hemocentro Regional de Uberaba, Minas Gerais, mostrou a incidência da soropusitividade para infecção chagásica de $0,01 \%$, onde foram detectados 3 casos de soroconversão para T. cruzi, entre 27.080 doadores de repetição observados. 
Tabela 33 - Taxa de incidência da infecção por $T$. cruzi entre doadores de repetição no Hemocentro Regional de Florianópolis, Serviço de Hemoterapia do HU/UFSC, Hemocentro Regional de Joaçaba e total estudado no Estado de Santa Catarina, 1990 a 1999.

\begin{tabular}{|c|c|c|c|c|c|c|}
\hline \multirow[b]{2}{*}{$\begin{array}{c}\text { Unidade } \\
\text { Hemoterápica }\end{array}$} & \multirow{2}{*}{$\begin{array}{c}\text { Pessoa- } \\
\text { tempo } \\
\text { exposta ao } \\
\text { risco*** }\end{array}$} & \multicolumn{3}{|c|}{ Doadores de repetição } & \multirow{2}{*}{$\begin{array}{l}\text { Taxa de } \\
\text { Incidência }\end{array}$} & \multirow{2}{*}{$\begin{array}{c}\text { Intervalo de } \\
95 \% \text { de } \\
\text { Confiança }\end{array}$} \\
\hline & & Soro(+) & $\begin{array}{l}\text { Indeter- } \\
\text { minado }\end{array}$ & $\begin{array}{l}\mathrm{N}^{\circ} \text { Estimado } \\
\text { de Soro } \\
\text { Convertidos }\end{array}$ & & \\
\hline $\begin{array}{l}\text { Hemocentro } \\
\text { Regional de } \\
\text { Florianópolis* }\end{array}$ & $\begin{array}{c}6745,785 \\
(n=10 \quad 140)\end{array}$ & 2 & 3 & 2,462 & 36,48 & $6,15-117,64$ \\
\hline $\begin{array}{l}\text { Serviço de } \\
\text { Hemoterapia } \\
\text { do HU/UFSC }\end{array}$ & $\begin{array}{l}2832,604 \\
(n=3030)\end{array}$ & 1 & 10 & 1,770 & 62,49 & $6,78-241,64$ \\
\hline $\begin{array}{l}\text { Hemocentro } \\
\text { Regional de } \\
\text { Joaçaba** }\end{array}$ & $\begin{array}{l}3790,260 \\
(n=4 \quad 195)\end{array}$ & 0 & 1 & 0,00 & 0,00 & $0,00-97,33$ \\
\hline $\begin{array}{l}\text { Estado de } \\
\text { Santa } \\
\text { Catarina }\end{array}$ & $\begin{array}{l}13368,649 \\
(n=17365)\end{array}$ & 3 & 14 & 4,232 & 31,65 & $9,07-79,06$ \\
\hline
\end{tabular}

*Período: 01.01 .97 a 18.06 .99 **Período: 01.01 .95 a $31.12 .99 * * *$ Cálculo, anexo VII. $\mathrm{n}=\mathbf{n}^{\circ}$ de doadores de repetição.

Fonte: Centro de Hematologia e Hemoterapia do Estado de Santa Catarina - HEMOSC; Hospital Universitário - HU/UFSC.

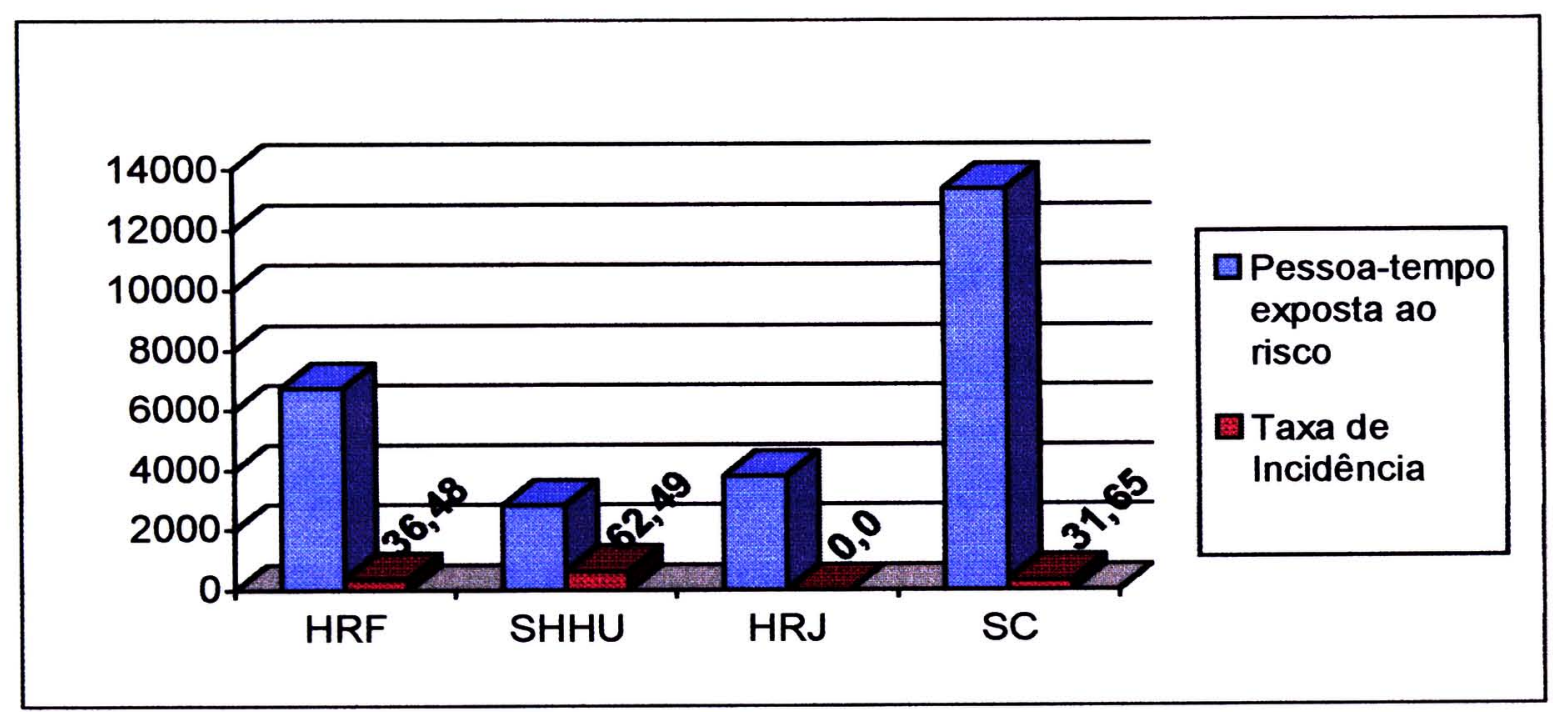

Figura 24 - Taxa de incidência da infecção por $T$. cruzi entre doadores de repetição no Hemocentro Regional de Florianópolis, Serviço de Hemoterapia do HU/UFSC, Hemocentro Regional de Joaçaba e Estado de Santa Catarina (SC), 1990 a 1999. 


\subsubsection{Risco residual de transmissão transfusional}

O cálculo do Risco Residual de Transmissão Transfusional da doença de Chagas, efetuado junto às Unidades Hemoterápicas da Região da Grande Florianópolis e Joaçaba, o que corresponde cerca de $40 \%$, em termos de cobertura das doações efetuadas no período estudado no Estado de Santa Catarina, resultou, conforme observado nas Tabelas 15 e 25, em 2,79 possiveis contaminações por 100.000 doações efetuadas no Hemocentro Regional de Florianópolis; 4,79 no Serviço de Hemoterapia do HU/UFSC; e 0,00 no Hemocentro Regional de Joaçaba.

Considerando a totalidade das doações efetuadas pelos 17.365 doadores de repetição (Tabela 33), indicou para o conjunto das duas regiões estudadas no Estado de Santa Catarina, um Risco Residual de Transmissão Transfusional de 2,42 contaminações por 100.000 doações ou o risco de 1 (uma) possivel transmissão a cada 41.322 doações. Este resultado provém da média ponderada das taxas de incidência ocorrida no Hemocentro Regional de Florianópolis, Serviço de Hemoterapia do HU/UFSC e Hemocentro Regional de Joaçaba, multiplicado pelo período de janela imunológica da infecção por T. cruzi (Tabela 34; Figura 25; Anexo XIV).

Esses resultados mostram a possibilidade de transmissão transfusional da infecção chagásica nos receptores de sangue, observada em estudo retrospectivo efetuada entre doadores de repetição, que realizaram suas doações nas Unidades Hemoterápicas localizadas na Região da Grande Florianópolis, capital do Estado de Santa Catarina.

A possibilidade de transmissão da doença de Chagas por transmissão transfusional é maior nas áreas urbanas de regiões endêmicas, porém se constitui atualmente em problema de saúde pública naquelas áreas livres de transmissão vetorial, mas que sofrem com o fenômeno das migrações oriundas de áreas endêmicas (TANOWITZ 1992; WENDEL e GONZAGA 1993; SCHMUNIIS 1999a,b). 
Tabela 34 - Risco Residual de Transmissão Transfusional da infecção por $T$. cruzi no Hemocentro Regional de Florianópolis, Serviço de Hemoterapia do HU/UFSC, Hemocentro Regional de Joaçaba e total no Estado de Santa Catarina, 1990 a 1999.

\begin{tabular}{lcc}
\hline \multicolumn{1}{c}{ Unidade Hemoterápica } & $\begin{array}{c}\text { Risco Residual de } \\
\text { Transmissão Transfusional }\end{array}$ & $\begin{array}{c}\text { Intervalo de } 95 \% \text { de } \\
\text { Confiança }\end{array}$ \\
\hline $\begin{array}{l}\text { Hemocentro Regional de } \\
\begin{array}{l}\text { Florianópolis* } \\
\text { Serviço de Hemoterapia do }\end{array}\end{array}$ & 2,79 & $0,47-9,02$ \\
$\begin{array}{l}\text { HU/UFSC } \\
\text { Hemocentro Regional de } \\
\text { Joaçaba** }\end{array}$ & 4,79 & $0,52-18,53$ \\
\hline Estado de Santa Catarina*** & 0,00 & $0,00-7,46$ \\
\hline
\end{tabular}

* Período: 01.01.97 a 18.06.99 **Período: 01.01.95 a 31.12 .99

*** Cálculo resultante da média ponderada dos Riscos Residuais de Transmissão Transfusional / $\Sigma$ pessoa-tempo, encontrados no Hemocentro Regional de Florianópolis, Serviço de Hemoterapia do HU/UFSC e Hemocentro Regional de Joaçaba (Anexo VIII).

Fonte: Centro de Hematologia e Hemoterapia do Estado de Santa Catarina - HEMOSC; Hospital Universitário - HU/UFSC.

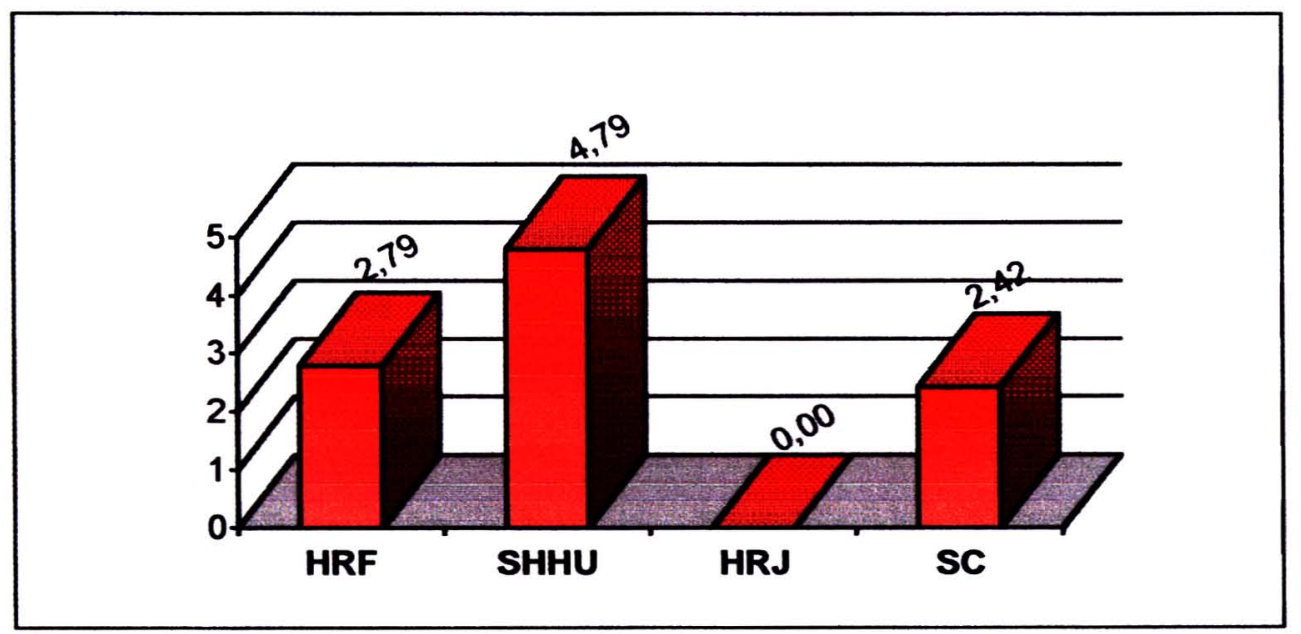

Figura 25 - Risco Residual de Transmissão Transfusional da infecção por $T$. cruzi no Hemocentro Regional de Florianópolis, Serviço de Hemoterapia do HU/UFSC, Hemocentro Regional de Joaçaba e total observado no Estado de Santa Catarina, 1990 a 1999.

Por vários anos de pesquisa, em diversas áreas do Estado de Santa Catarina, tem-se procurado demonstrar a presença da doença de Chagas. Contudo, os resultados dos trabalhos realizados até então, indicam a inexistência da enfermidade em termos endêmicos, dispersando a atenção dos profissionais de saúde, quanto à sua presença.

Todavia, o estudo realizado nas Regiões da Grande Florianópolis e Joaçaba, apresenta resultados que indica a presença da infecção chagásica, entre doadores de 
sangue, nos hemocentros estudados, com indicios de possível transmissão transfusional entre receptores de sangue.

$\mathrm{O}$ aumento do número de transfusões ano a ano se constitui em fenômeno esperado. Neste sentido torna-se evidente a necessidade de se efetuar triagem rigorosa do sangue a ser transfundido, de modo a se evitar casos novos de doenças transmissíveis adquiridas por essa via de transmissão, como também da obrigatoriedade de melhor avaliação dessas transfusões, visando assegurar a plena qualidade do sangue transfundido.

As principais causas de recusas do doador encontradas na triagem clínica tem sido o comportamento de risco para HIV, hematócrito baixo, hipertensão, ingestão de álcool, entre outros.

Observações realizadas, apontaram que o perfil sorológico dos indivíduos inaptos na triagem clínica por critérios de proteção ao receptor, não difere muito do perfil daqueles aptos à mesma triagem, sugerindo que a triagem clínica recusa indivíduos que, embora incluídos entre aqueles que apresentaram fatores de risco de transmissão da doença, não respondam positivamente à sorologia.

Todas as três Unidades Hemoterápicas por nós visitadas para realização do presente estudo, realizavam dois ou mais exames para triagem sorológica da infecção por T. cruzi, utilizando-se das técnicas, como a Hemaglutinação indireta, Imunofluorescência indireta e ELISA. Caso detecte reação positiva em apenas umas das técnicas, a bolsa de sangue é desprezada. Nestes casos, o doador é convocado para, num prazo de 30 dias, realizar nova sorologia. Aqueles com resultados inconclusivos, principalmente do Serviço de Hemoterapia do HU/UFSC, são encaminhados ao Laboratório de Microbiologia e Parasitologia, da UFSC, atualmente reconhecido como Laboratório Referência para doença de Chagas, no Estado de Santa Catarina, para esclarecimentos, e os soropositivos para atendimento médico.

Com relação aos resultados falso-positivos, deve-se considerar o custo direto de se rejeitar doadores, provavelmente, sadios, acrescido ao custo da execução de testes clínicos e laboratoriais adicionais, como também a intensa carga emocional a que é submetido um doador com exame positivo incorreto, além da criação de um grupo de doadores que acarretará um alto custo social, econômico e emocional à sociedade (DIAS, 1993)

O custo de todo processo desde a captação do doador até a dispensação do comnonente sanquínen foi estimado em R\$ 136.06 vara o concentrado de hemácias. e 
até R\$257,76 para uma bolsa de sangue total (GONTIJO 2000).

Aspecto positivo, objetivando diminuir o risco de doenças pela via transfusional, é a diminuição, nos últimos anos, da utilização do sangue total, em favor do fracionamento do sangue para atendimento de vários receptores, diminuindo o risco de doenças, já que vários receptores utilizam o produto retirado de um único doador.

Diante desses fatos, é que 4 hospitais da cidade de São Paulo criaram Comissões de Transfusão, semelhantes às Comissões de Controle da Infecção Hospitalar, que têm como objetivo estabelecer critérios para a indicação de transfusões, com rigorosas normas incorporadas às rotinas hospitalares.

O descarte de candidatos à doação na triagem clínica, quando procedente de área endêmica, tem contribuído, acreditamos, para a diminuição de prevalência na triagem sorológica, já que a transmissão vetorial vem sendo controlada em todo o País (WANDERLEY 1994a).

Outro fator favorável, que reflete o desenvolvimento de recursos tecnológicos, são as unidades de aféreses que permitem a retirada especifica de um componente do sangue, devolvendo os demais ao próprio doador.

Embora tenha-se observado como resultado da análise efetuada junto aos hemocentros estudados no Estado de Santa Catarina, um risco residual de transmissão da doença de Chagas por transfusão de sangue, o que, possivelmente, também poderá ser observado em Serviços Hemoterápicos de outros Estados; podemos afirmar que as orientações emanadas pela legislação normativa do Ministério da Saúde, como a Portaria $n^{\circ} 721 / 89$, alterada pela $n^{\circ} 1376 / 93$, juntamente com a Portaria $n^{\circ} 22 / S E S / 93$, da Secretaria de Estado da Saúde, têm sido rigorosamente obedecidas.

A implantação do Centro de Hematologia e Hemoterapia do Estado de Santa Catarina - HEMOSC, em 1997, que tem como missão "assegurar o fornecimento de sangue, hemocomponentes e serviços hematológicos e hemoterápicos de qualidade", e a conseqüente ampliação de sua rede em 5 grandes Hemocentros Regionais de Hemoterapia, contribui em, aproximadamente, $80 \%$ da cobertura na triagem de doadores de sangue em todo o Estado

Aliado a este fato, com as ações de controle do sangue implementadas pela Divisão de Vigilância Sanitária, da Secretaria de Estado da Saúde, levou os índices de cobertura da seleção de doadores muito próximos a 100\%, no Estado de Santa Catarina, onde pode ser observada claramente a melhoria da qualidade da hemoterapia. 
5 CONCLUSÕES 


\section{CONCLUSÕES}

O estudo da população de doadores de sangue, representado por 159.829 indivíduos que realizaram doações nas Unidades Hemoterápicas do Hemocentro Regional de Florianópolis - HRF, Serviço de Hemoterapia do Hospital Universitário SHHU/UFSC, localizados em Florianópolis e Hemocentro Regional de Joaçaba - HRJ, da Região de Joaçaba, o que corresponde a cerca de $40 \%$ do total das doações efetuadas no Estado, com idade entre 18 a 60 anos, peso superior a 50 quilos, hígida após triagem clínica, natural predominantemente da Região Sul do pais, de ocupação a mais variada possivel, constatou-se a presença de 294 casos positivos e indeterminados da infecção chagásica, e possibilitou concluir:

1. A taxa de prevalência da infecção por T.cruzi entre o total de doadores de sangue na Região da Grande Florianópolis (HRF e SHHU/UFSC) no periodo de 199099, foi de 152,56/100 000 doadores e na Região de Joaçaba (HRJ), no período de 1995 99 , de 123,42/100 000 doadores.

Esses resultados refletem a presença de indivíduos infectados, que são detectados apenas na triagem sorológica dos doadores.

Ocorreu, entretanto, na Região da Grande Florianópolis e na Região de Joaçaba uma diferença pouco acentuada da taxa de prevalência entre primodoadores 150,53 e 171,69/100.000; porém, muito significativa entre doadores de repetição, que foi de 170,47 e 0,00, respectivamente. Contudo, revela a presença da doença de Chagas em moradores do Estado de Santa Catarina, rompendo com a antiga concepção da inexistência de qualquer problema de saúde pública relativo a essa enfermidade.

2. A caracterização da população sorologicamente positiva para T.cruzi, quanto a variável naturalidade estudada, nas 3 Unidades Hemoterápicas (HRF, SHHU/UFSC e HRJ), das Regiões da Grande Florionópolis e Joaçaba, constatou nos 294 doadores submetidos à triagem sorológica, o elevado percentual de, aproximadamente, $60 \%$ dos casos de doadores infectados na população residente, naturais do Estado de Santa Catarina, e considerável percentual de doadores que migraram de outras regiões com possiveis áreas endêmicas para a doença de Chagas. 
3. A distribuição percentual de doadores infectados, segundo a idade, revelou que houve predomínio de doadores infectados na faixa etária de 21 a 30 anos $(30,32 \%)$ na Região da grande Florianópolis, e na de 31 a 40 anos $(52,92 \%)$ na Região de Joaçaba.

4. Quanto ao gênero, a infecção chagásica ocorreu tanto em doadores do sexo masculino como no feminino. Apresentou, todavia, um grande percentual $(82,31 \%)$ do sexo masculino para $16,61 \%$ do sexo feminino e 1,02\%, ignorados na Região da Grande Florianópolis, com pequena diferença de proporção na Região de Joaçaba, onde observou-se que $52,94 \%$ eram do sexo masculino e $47,06 \%$ do sexo feminino.

5. Relativamente à distribuição percentual de doadores soropositivos, segundo o estado civil, o estudo demonstrou que dos doadores triados infectados por $T$. cruzi, houve predominio dos casados, observando-se menor percentual $(45,85 \%)$ na Região da Grande Florianópolis em relação à Região de Joaçaba $(58,82 \%)$.

6. A distribuição percentual de doadores infectados, segundo a variável ocupação, revelou que na Região da Grande Florianópolis as maiores freqüências ocorreram entre trabalhadores do grupo de serviços de turismo, hospedagem, higiene, embelezamento, segurança e auxiliares de saúde $(13,36 \%)$, trabalhadores da produção industrial, operadores de máquinas e assemelhados $(12,27 \%)$, membros das forças armadas, policiais e bombeiros $(9,75 \%)$, trabalhadores das profissões científicas, técnicas, artísticas ou estudantes, autônomos, aposentados $(9,39 \%)$; e que na Região de Joaçaba se apresentaram entre as atividades doméstica, embelezamento ou agricultores, pecuaristas $(23,53 \%)$, trabalhadores da construção civil ou condutores de veículos $(11,76)$, dentre outras.

7. O estudo da taxa incidência demonstrou que ocorreram 44,17 casos de infecção por $T$. cruzi em cada 100.000 doadores de sangue, de repetição, ou de 1 (uma) em cada 2.264 doações efetuadas no Hemocentro Regional de Florianópolis - HRF e Serviço de Hemoterapia do Hospital Universitário - HU/UFSC, na Região da Grande Florianópolis; e que não houve qualquer caso de soroconversão entre os 4.195 doadores de repetição no Hemocentro Regional de Joaçaba - HRJ, na Região de Joaçaba, no período estudado. 
Observou-se também que houve a incidência de 31,65 casos de sorologia positiva para $T$. cruzi por 100.000 doadores de sangue de repetição ou de 1 (um) caso em cada 3.159 doações efetuadas, entre os doadores de repetição estudados conjuntamente no Hemocentro Regional de Florianópolis-HRF, Serviço de Hemoterapia do Hospital Universitário-HU/UFSC e Hemocentro Regional de Joaçaba.

8. A alta prevalência $(171,69 / 100.000)$ em primodoadores e a baixa ou nula incidência $(0,00)$ nos doadores de repetição na Região de Joaçaba, pode ser explicada pelo pelo fato de estar situada próxima de áreas consideradas endêmicas dos Estados vizinhos do Rio Grande do Sul e Paraná, e que naquela Unidade Hemoterápica (HRJ), os casos foram detectados numa primeira análise sorológica entre os primodoadores, não tendo ocorrido nenhuma soroconversão entre os doadores de repetição estudados.

A taxa de prevalência e incidência mais elevada no Serviço de Hemoterapia do HU/UFSC aponta para o fato deste contar com apoio do Laboratório de Protozoologia do Departamento de Microbiologia e Parasitologia - MIP/UFSC, referência para o Estado de Santa Catarina, na confirmação diagnóstica.

9. O Risco Residual de Transmissão Transfusional da doença de Chagas em doadores de repetição, constatado no estudo realizado junto às Unidades Hemoterápicas localizadas na Região da Grande Florianópolis e Joaçaba, foi:

9.1. na Região da Grande Florianópolis, de 3,38/100.000, em um Intervalo de $95 \%$ de Confiança de 0,97 - 8,46/100.000, mostrando o risco de 3,38 possíveis contaminações por $T$. cruzi em cada 100.000 transfusões de sangue, ou de 1 (uma) transfusão infectada a cada 29.586 doações;

9.2. na Regiâo de Joaçaba, de 0,00/100.000 em um Intervalo de $95 \%$ de Confiança de $0,00-7,46 / 100.000$, demonstrando que entre os 4.195 doadores de repetição observados, o risco foi zero, visto que não se constatou nenhum caso de soroconversão no periodo estudado; e

9.3. no Estado de Santa Catarina, considerando as 3 Unidades Hemoterápicas estudadas, foi de: 2,42/100.000 doadores de repetição, em um Intervalo de $95 \%$ de Confiança de $0,69-6,06 / 100.000$, indicando que ocorreu o risco de 2,42 possíveis contaminações por T. cruzi em cada 100.000 transfusões de sangue total efetuadas, ou de 1(uma) transfusão infectada em cada 41.322 doações. 
O Risco Residual de transmissão transfusional da doença de Chagas, observado de 3,38/100.000 doadores de repetição na Região da Grande Florianópolis e de 2,42/100.000 no Estado de Santa Catarina, significa que há existência do risco por essa via de transmissão, o que traduz a importância que deve ser destinada a essa doença no Estado de Santa Catarina, considerado até então indene, livre de transmissão. 
6 CONSIDERAÇÕES FINAIS E RECOMENDAÇÕES 


\section{CONSIDERAÇÕES FINAIS E RECOMENDAÇÕES:}

Por análise realizada dos casos de infecção por $T$. cruzi detectados entre doadores de sangue e sua procedência, no periodo de 1990 a 1999 , ficou comprovada a existência da enfermidade em moradores no Estado de Santa Catarina e sua possível transmissão transfusional.

O estudo constata a falta de conhecimento epidemiológico da doença de Chagas pelos profissionais de saúde e a falta de intervenções dos casos diagnosticados, aliados a fatores sócio-culturais, faz com que se tenha a concepção de Estado indene para a enfermidade.

A taxa de prevalência observada de 122,94, 370,10 e 171,69/100.000 doadores, observada no Hemocentro Regional de Florianópolis - HRF, Serviço de Hemoterapia do Hospital Universitário - HU/UFSC e Hemocentro Regional de Joaçaba - HRJ, respectivamente, corresponde a uma população de doadores, aparentemente, sã em um estado de saúde que permite doar sangue após entrevista clínica, resultado neste caso verdadeiramente alarmante.

Das 204.025 bolsas de sangue doadas, foram triadas sorologicamente 294 bolsas positivas para infecção por $T$. cruzi. Considerando que cada uma pode produzir 4 (quatro) hemocomponentes distintos, 1.176 unidades de hemocomponentes foram descartadas por ser fonte de transmissão transfusional da doença de Chagas. Isso mostra a dimensão do problema, caso estas fossem transfundidas, tanto do ponto de vista econômico quanto social a que estariam expostos os receptores. Assim, o descarte dos doadores soropositivos detectados na triagem sorológica, aliados àqueles recusados na triagem clínica, minimiza o risco de transmissão de $T$. cruzi pelo sangue transfundido.

Considerando a realidade do trabalho de rotina diagnóstica da infecção por $T$. cruzi nas Unidades Hemoterápicas estudadas, poder-se-ia sugerir que os todos resultados diagnósticos indeterminados e/ou duvidosos fossem encaminhados ao Centro de Referência existente no Estado de Santa Catarina, para esclarecimentos.

Ainda que a população de doadores de sangue seja uma parcela da população geral, pré-selecionada por avaliação clinica, composta, basicamente, por indivíduos, aparentemente, hígidos da faixa etária de 18 a 60 anos e do sexo masculino, ela pode indicar a situação epidemiológica na população geral de algumas doenças transmitidas pelo sangue, como a doença de Chagas, Sifilis, Hepatites B e C e HTLV-I/II, facilmente disponivel que se submete a triagem sorológica voluntariamente. Constituem-se, 
portanto, populações convenientes para os estudos da ocorrência das infecções rastreadas pelas Unidades Hemoterápicas, como observada no presente estudo.

As notificações da doença de Chagas no Estado, concentradas na Divisão de Vigilância Epidemiológica - DVS/SES, não permite uma análise profunda, pois que apresenta elevada subnotificação, sugerindo a inexistência e a conseqüente diminuta importância destinada à enfermidade em Santa Catarina.

Convém ressaltar que as medidas utilizadas para controle da triagem dos doadores, até o momento, não têm sido suficientes para evitar as conseqüências da migração oriunda de áreas endêmicas, expondo o Estado de Santa Catarina ao risco de possivel transmissão transfusional.

Certamente, também não poderá ser descartada totalmente a possibilidade de transmissão vetorial, haja vista a carência de trabalhos científicos realizados que assegurem sua inexistência.

A pesquisa de possiveis casos autóctones de transmissão da doença de Chagas deverá ser desenvolvida junto à população residente, em ambientes onde a investigação epidemiológica indique sua ocorrência.

Tendo em vista o número de casos importados de regiões comprovadamente endêmicas e a possível transmissão que poderá ocorrer, torna-se necessária, além da atenção dispensada ao controle da transmissão transfusional, também da possível transmissão congênita entendida como mecanismo de perpetuação da infecção, pela identificação de gestantes chagásicas no pré-natal e tratamento de recém-nascidos infectados.

A atenção destinada ao controle de transmissão da doença de Chagas no Estado de Santa Catarina é pouco evidente, traduzido apenas pelo diagnóstico na triagem sorológica efetuada junto aos doadores em Bancos de Sangue, inexistindo sequer controle pré-natal no diagnóstico de Chagas, congênito ou em doenças cardíacas.

Disponibilizar o banco de dados com o registro das observações de um conglomerado de doadores soropositivos para T. cruzi, residentes na Região da Grande Florianópolis e Joaçaba, Estado de Santa Catarina, aos serviços de epidemiologia.

Desenvolver efetivamente ações de investigação epidemiológica de todos os casos sorologicamente positivos para infecção por $T$. cruzi, diagnosticados quando da triagem sorológica dos doadores de sangue nas Unidades Hemoterápicas de Santa Catarina, e que deverão ser igualmente desenvolvidas juntamente com a comunidade, para esclarecimentos e contribuições à vigilância epidemiológica. 
Informações dos últimos anos indicam uma melhoria do controle do sangue, seu melhor aproveitamento e o incremento no uso de suas frações em transfusões, através do aperfeiçoamento da hemoterapia no Estado, particularmente a partir da década de 1980, com o advento da Síndrome da Imunodeficiência Adquirida - SIDA/AIDS.

O desenvolvimento de técnicas sorológicas capazes de detectar a presença do agente causador da doença de Chagas, em conjunto com outros cuidados dedicados à hemoterapia, pode garantir ao máximo o descarte de doadores infectados.

Alertar a comunidade científica e profissionais de saúde quanto à necessidade de considerar presente a doença de Chagas no Estado de Santa Catarina.

Para o tratamento, acompanhamento do paciente com sorologia positiva para doença de Chagas e o controle da enfermidade no Estado de Santa Catarina, deverá ser estruturado um sistema de atendimento ao indivíduo infectado, no contexto do Sistema Único de Saúde - SUS. 


\section{REFERÊNCIAS}




\section{REFERÊNCIAS}

Alencar JE. História natural da Doença de Chagas no Estado do Ceará. Fortaleza: Imprensa Universitária / UFC; 1977. p.14 - 72.

Amato Neto V. Doença da Chagas e transfusão de sangue. In: Cançado JR. Doença de Chagas. Belo Horizonte: Imprensa Oficial do Estado de Minas Gerais; 1968. p.131 42.

Amato Neto V. Doença de Chagas pós-transfusional [editorial]. Rev Hosp Clin Fac Med São Paulo 1988; 43: 135-7.

Amato Neto V. Conduta frente ao doador chagásico. Rev Soc Bras Med Trop 1993; 26 Supl. 2: 86-7.

Andrade ALSS, Martelli CMT, Pinheiro ED, Santana CL. Borges FP, Zicker F. Rastreamento sorológico para doenças infecciosas em banco de sangue como indicador de morbidade populacional. Rev Saúde Pública 1989; 23: 20-5.

Andrade ALSS, Martelli CMT, Luquetti AO, Oliveira OS, Silva AS, Zicker F. Triagem sorológica para o Tripanosoma cruzi entre doadores de sangue do Brasil central. Bol Oficina Sanit Panam 1992; 113: 19-27.

Andrade ALSS, Martelli CMT. Método epidemiológico na investigação da infecção congênita pelo Trypanosoma cruzi. Cad Saúde Pública 1994; 10 Supl 2: 345-51.

Angulo IL. Tavares ICB. Pesquisa em hematologia na Região de São José do Rio Preto. Bol Soc Bras Hematol Hemoter 1993; 15 (162): 26-9.

Aragão MB. Domiciliação de triatomíneos ou pré-adaptação à antropofilia e à ornitofilia? Rev Saúde Publica 1983a; 17: 51-5.

Aragão MB. Distribuição geográfica da antropofilia o Pantrongylus megistus. Ciênc Cult Saúde 1983b 5: 15-20. 
Baldy JLS, Takaoka L, Pereira JD, Pereira JD, Calixto AA, Duarte E F. Prevalência da infecção por Trypanosoma cruzi em 1975, em dois bancos de sangue de Londrina, Paraná. Brasil. Rev Saúde Pública 1978; 12: 409 - 16.

Barata JMS, Rocha RM, Rodrigues VLL, Ferraz Filho AM. Primeiro caso autóctone de tripanossomíase americana no Estado do Acre (Brasil) e sua relação com as cepas isoladas do caso humano e de triatomineos silvestres da área. Rev Saúde Pública 1988; 22: 401-10.

Barraco MA, Souza Bueno AM, Steindel M. Estudos preliminares dos hemócitos e hemolinfas de ninfas silvestres contaminadas e não contaminadas de Panstrongylus megistus (Hemíptera: Reduviidae) na ilha de Santa Catarina. In: $11^{\text {a }}$ Reunião Annual Sobre Pesquisas Básicas em Doença de Chagas; 1984; Caxambú, Minas Gerais. VE-04

Barrett VJ, Leiby DA, Odom $几$, Otani MM, Rowe JD, Roote JT et al. Negligible prevalence of antibodies against Trypanosoma cruzi among blood donors in the southeastern United States. Am J Clin Patol 1997; 499-503.

Barreto MP. Epidemiologia. In: Brener Z, Andrade, ZA. Trypanosoma cruzi e Doença de Chagas. Rio de Janeiro: Guanabara Koogan; 1979. p. 89 - 151.

Baruffa G. Prevalência da infecção chagásica no Banco de Sangue da Santa Casa de Misericórdia de Pelotas, Rio Grande do Sul, Brasil. Rev Inst Med Trop São Paulo 1979; 21: $37-42$

Baruffa $G$. Inquérito sorológico e entomológico da infeç̧ão pelo $T$. cruzi na região Sul do Rio Grande do Sul, Brasil. Ann Soc Belge Méd Trop 1985; 65 Supl 1: 171-9.

Baruffa G. A Doença de Chagas no Rio Grande do Sul. Arq Bras Cardiol 1994; 63: 457 $-60$

Basombrio MA, Nasser J, Segura MA, Marco D, Negrette OS, Padilla M, Mora MC. La transmission de la enfermedad de Chagas en Salta y a deteccion de casos congênitos. Medicina B Aires 1999; 59 Supl 2: 143-6. 
Basso RMC. Prevalência da infecção pelo Trypanosoma cruzi entre doadores de sangue do Rio Grande do Sul, de 1975 a 1996. São Paulo; 1999. [Dissertação de mestrado - Faculdade de Saúde Pública da USP].

Beck ST, Meneghetti BS, Osaida I. Índice de sorologia positiva para doença de Chagas em doadores do banco de sangue da cidade de Santiago (RS). Rev Soc Bras Med Trop 1993; 26: 100 .

Bellotti G, Bochi EA. Doença de Chagas: novas perspectivas. Rev Soc Cardiol Estado São Paulo 1994; 4: 205-6.

Bergoglio RM. Enfermedad de Chagas postransfusional: experiência clínica de 48 casos. Prensa Méd Argent 1984; 71: 49-52.

Biocca EF, Sequira AS. Embarazo y Chagas congénito. Rev Argent Transf 1985; 11 : 209-16.

Bittencourt A. Transmissão materno-infantil. Rev Soc Bras Med Trop 1987; 20 Supl 2: 5-7.

Blanco SB, Segura EL, Gurtler RE. El control de la transmission congênita de Trypanosoma cruzi na Argentina. Medicina B Aires 1999; 59 Supl 2: 138-42.

Bonametti AM, Castelo Filho A, Ramos LR, Baldy JLS, Matsuo T. Infecção por Trypanosoma cruzi em candidatos a doador de sangue. Rev Saúde Pública 1998; 32: 566-71.

Brasil. Constituição 1988. Constituiçâo da República Federativa do Brasil. Brasília (DF): Senado Federal; 1988a.

Brasil. Lei n. 7.649, de 25 de janeiro de 1988. Estabelece a obrigatoriedade do cadastro dos doadores de sangue, bem como a realização de exames laboratoriais no sangue coletado, visando prevenir a propagação de doenças. Diário Oficial da República Federativa do Brasil, Brasília (DF), 27 jan. 1988b. Seção 1, p. 52. 
Brasil. Decreto $n^{\circ} 879$, de 22 de julho de 1993, regulamenta a Lei $n^{\circ} 8489$, de 18 de novembro de 1992, que dispõe sobre a retirada e o transplante de tecidos órgãos e partes do corpo humano com fins terapêuticos científicos e humanitários. Diário Oficial da República Federativa do Brasil, Brasília (DF), 23 jul. 1993. Seção I, p. 10298-300.

Brener S. O controle das doenças passiveis de transmissão através da transfusão de sangue - O papel da Fundação Hemominas. Rev Soc Bras Med Trop 1993; 26 Supl 2: $72-4$.

Brener Z, Andrade ZA, Barra-Neto M. Trypanosoma cruzi e Doença de Chagas. $2^{a}$ ed. Rio de Janeiro: Guanabara Koogan; 2000.

Brofen E, Chiari E. Potencial de risco de transmissão transfusional da doença de Chagas em Belo Horizonte (MG). Rev Soc Bras Med Trop 1998; 21:29-32.

Bustamante IM. Distribuição geográfica dos transmissores da doença de Chagas no Brasil e sua relação com certos fatores climáticos: epidemiologia e profilaxia da enfermidade. Rev Bras Malar Doenças Trop 1957; 9:191-210.

Camargo ME. Fluorescent antibody test for the sorodiagnosis of American trypanosomiasis. Technical modification emplouing preserved culture forms of Trypanosoma cruzi in a slide test. Rev Inst Med Trop São Paulo 1966; 8: 227-34.

Camargo ME, Hoshino-Shimizu S, Correa NS, Peres BA. Hemaglutination test for Chagas' disease with chromium chloride, formalin-treated erythocytes, sensitized with Trypanosoma cruzi extracts. Rev Inst Med Trop São Paulo 1971; 13: 45-50.

Camargo ME, Silva GR, Castilho EA, Silveira AC. Inquérito sorológico da prevalência de infecção Chagásica no Brasil, 1975/80. Rev Inst Med_Trop São Paulo 1984; 26 : 192 204.

Camargo ME. Diagnóstico sorológico da doença de Chagas. Ars Curandi Cardiol 1998; 9: 29-38.

Campos EP, Maestá I, Schmidt FCL, Sogayar R, Campos CEOP. Doença de Chagas aguda pós-transfusional sem miocardite. Relato de caso. Rev Soc Bras Med Trop 1988; 21: 205-8. 
Canutti Júnior V. Risco transfusional: metodologia e estudo. In: Covas DT, Zago MA, editores. Atualização em hemoterapia, Ribeirão Preto: Gráfica Canavaci; 1998. v. 5, p. $90-9$.

Carneiro M, Antunes CMF. Avaliação de eficácia do Programa de Controle da Doença de Chagas: aspectos metodológicos. Cad Saúde Pública 1994; Supl 2: 261-72.

Carrasco R, Miguez H, Camacho C, Echalar L, Revollo S, Ampuero T et al. Prevalence of Trypanosoma cruzi infection in blood banks of seven departaments of Bolivia. Mem Inst Oswaldo Cruz 1990; 85: 69-73.

Caruso MML. O desmatamento da Ilha de Santa Catarina de 1500 aos dias atuais. $2^{\mathrm{a}}$ ed. Florianópolis: Editora da Universidade Federal de Santa Catarina; 1990.

Carvalho ME, Latorre MRDO, Ferreira CS, Mello CS, Barata JMS. Soroprevalência de infecção chagásica de Triatoma infenstans após medidas de controle. Rev Saúde Pública $2000 ; 34: 15-20$

Carvalho ME. Sorologia de infecção chagásica no Programa de Controle do Estado de São Paulo, Brasil. São Paulo; 2000. [Tese de Doutorado - Faculdade de Saúde Pública da USP].

Castro Filho J, Silveira AC. Distribuição da doença de Chagas no Brasil. Rev Bras Malariol Doenças Trop 1979; 31: 85-98.

Cerisola JA, Rabinovich A, Alvarez M, Corletto CA, Bruneda L. Enfermedade de Chagas y la transfusión de sangre. Bol Oficina Sanitária Panam 1972; 73: 203-21.

Chieffi PP e Amato Neto V. Prevenção referente às modalidades alternativas de transmissão do Trypanosoma cruzi. São Paulo. CLR Balieiro Editores, 2000.

Contreras M. ABC of transfusion. 2. ed. London: BMJ Publishing Group; 1992.

Contreras FT, Kasten FL, Gutiérrez MMS, Gutiérrez RH. Prevalência de infeccion a Trypanosoma cruzi en donadores de sangue en el estado de Jalisco, México. Rev Soc Bras Med Tropical 1993; 26: 89-92 
Corrêa $\mathrm{AD}$, Miranda Filho N. A propósito das vias de transmissão da moléstia de Chagas. J Bras Med 1995; 69: 150-4

Coura JR. Doença de Chagas como endemia urbana. In: Cançado JR, Chuster M. Cardiopatia chagásica. Belo Horizonte: Fundação Carlos Chagas. 1984. p.356-61.

Covas DT. A medicina transfusional no Brasil. Medicina Ribeirão Preto 1993; 26: 48990

Covas DT. Risco de transmissão do HIV-1 pelas transfusões de sangue. In: Covas DT Zago MA, editores. Atualização em hemoterapia, Ribeirão Preto: Gráfica Canavaci; 1998. v.5, p. 100-6

Cunha TC, Souto PE, Bonini N, Dalcin RMP, Loudero MAS, Borba DMD. Megaesófago, megacolon e alterações eletrocardiográficas em candidatos a doadores de sangue com reações sorológicas positivas para doença de Chagas, no município de Santa Maria, Rio Grande do Sul. Rev Goiana Med 1987; 3: 17-24.

Cummings PD, Wallace EL, Schorr JB, Dodd RY. Exposure o patientes to human immunodeficiency virus through the transfusion of blood components that test antibody negative. N Engl JMed 1989; 321: 941-6.

Dean AG, Coulombier D, Brendel KA, Smith DC, Burton H, Dicher RR et al. Epi Info, Version 6: a woud processing database, and statistic program for epidemiology ou microcomputers [computer program] Atlanta: Centers for Disease Control and Prevention; 1994.

Dias E. Doença de Chagas um grande problema de saúde pública. Bras Med 1947; 61: 162-4

Dias E. Os riscos da propagação da Doença de Chagas pelos serviços de transfusão de sangue. Bol Oficina Sanit Panam 1949; 28: 910 - 1.

Dias JCP. Doença de Chagas:clinica e terapêutica. Brasilia (DF): Ministério da Saúde / Superintendência de Campanhas de Saúde Pública (SUCAM); 1970. 
Dias JCP, Garcia ARL. Vigilancia epidemiológica com participación comunitária: un programa de enfermedad de Chagas. Bol Oficina Sani. Panam 1978; 84: 533-44.

Dias JCP. Mecanismos de transmissão. In: Brener Z, Andrade Z. Trypanosoma cruzi e doença de Chagas. Rio de Janeiro: Guanabara Koogan; 1979.

Dias JCP, Dias RB. Doença de Chagas: uma visão sócio- econômica e cultural. In: Na. Congresso Internacional de Doença de Chagas, Rio de Janeiro, 1979.

Dias JCP, Brener S. Chagas'disease and blood transfusion. Mem Inst Oswaldo Cruz 1984,79 Supl: $139-47$

Dias JCP. Aspectos sócio-culturales y econômicos relativos al vector de la enfermidad de Chagas. In: Carcavalo RV et al. Fatores biológicos y ecológicos en la enfermedad de Chagas. Buenos Aires: Centro Americano de Ecologia Humana y Salud; 1985. p.289305

Dias JCP, Dias RB. Participação da comunidade no controle da Doença de Chagas. Ann Soc Belge Med Trop 1985; 65:127-35 apud Ministério da Saúde. A saúde no Brasil. Brasília (DF): Centro de Documentação do Ministério da Saúde p. 205-11.

Dias JCP. Control of Chagas' disease in Brazil. Parasitol Today 1987; $3: 336-41$

Dias JCP. The indeterminate form of human chronic Chagas disease. Rev Soc Bras Med Trop 1989; 22: 147-65.

Dias JCP. Doença de Chagas: clinica e terapêutica. Ministério da Saúde, Brasília, 1990.

Dias JCP, Jatene AD. Doença de Chagas no Brasil: situação atual e perspectivas. Rev Soc Bras Med Trop 1992; 25 Supl 3: 6-8.

Dias JCP. Aspectos clínicos, sociais e trabalhistas da Doença de Chagas em áreas endêmicas sob controle do Estado de Minas Gerais, Brasil. Rev Soc Bras Med Trop $1993 ; 26: 93-9$ 
Dias JCP. Doença de Chagas: epidemiologia e prevenção. Arq Bras Cardiol 1994; 63: 451-5.

Dias JCP, Schofield CJ. Controle da transmissão transfusional da doença de Chagas na Inciativa do Cone Sul. Rev Soc Bras Med Trop 1998; 3: 373-83.

Fernandes CD, Tiecher FM, Fernandes DD, Henriques NMP, Steindel M. High rates of positive hemoculturres in children and teenagers seropositive for Trypanosoma cruzi in the State of Rio Grande do Sul, Brazil (reserch note). Mem Inst Oswaldo Cruz 1999; 94: $7-8$.

Ferreira CS, Carvalho ME. Padronização do uso do papel-filtro como suporte de material para reações sorológicas. Rev Bras Malariole Doenças Trop 1982;34:82-6.

Ferreira Neto JA, Ferreira M, Leal H, Martins CM, Nascimento MF. Novos dados sôbre a distribuição geográfica dos triatomineos em Santa Catarina, Brasil. Rev Soc Bras Med Trop 1971; 175-81.

Ferreira AW, Avila SLM. Diagnóstico de laboratório da doença de Chagas. Rev Soc Cardiol Estado São Paulo 1994; 4: 101 -5.

Forattini OP. Biogeografia, origem e distribuição da domiciliação de triatomíneos no Brasil. Rev Saúde Pública 1980; 14: 265 - 99.

Forattini OP, Rocha e Silva EO, Barata JMS, Boainain E. Nota sobre novo caso autóctone de Tripanossomiase americana no litoral sul do Estado de São Paulo, Brasil. Rev Saúde Pública 1981; 15:350-2

Forattini OP, Barata JM. Hábitos alimentares, infecção natural e distribuição de triatomineos domiciliados na Região Central do Brasil. Rev Saúde Pública 1982; 16: 171-204.

França SB, Abreu DMX. Morbidade hospitalar por Doença de Chagas no Brasil. Rev Soc Bras Med Trop 1996, 29: 109 - 15. 
Freitas JLP, Amato Neto V, Sonntag R, Biancalana A, Nussensvelg V, Barreto JG. Primeiras verificações de transmissão acidental da moléstia de Chagas ao homem por transfusão de sangre. Rev Paul Med 1952; 40: 64-8.

Fuchs AP, Fioratti VL, Mello VA, Boainain E. Diagnóstico sorológico na Doença de Chagas: estudo comparativo de diferentes técnicas. Rev Inst Med Trop São Paulo 1980; 22: $242-5$.

Fundação IBGE. Censo demográfico: ano 1998. Rio de Janeiro; 1999.

Furtado VP. Política Nacional de Sangue. Bol Soc Bras Hematol Hemoter 1989; 11(153): 96-7.

Goldenberg S, Krieger MA. Doença de Chagas: novas perspectivas no diagnóstico imunológico. Biotecnologia Ciências Desenvolvimento. Rio de Janeiro 1998; p. 26-7.

Gonçalves Júnior FL, Boccato Rsbs, Pedro LJ, Papaiordanou PMO, Souza CA, Gonçalves NSP, Pelegrino Junior J. Prevalências do HBsAg, do anti-HBC e do antiHCV na população de candidatos a doadores de sangue do Hemocentro-Campinas. Rev Inst Med Trop São Paulo 1993; 35: 45-51.

Gonçalves Júnior FL. Prevenção das hepatitis pós-transfusionais. In: Covas DT, Zago MA, editores. Atualização em hemoterapia, Ribeirão Preto: Gráfica Canavaci; 1998. v. 5 , p. $107-120$.

Gontijo ED. Triagem sorológica da doença de Chagas em unidades hemoterápicas: minimizando o sofrimento desnecessário de sangue dos falsos-positivos e quantidade de sangue seguro. Rev Soc Bras Med Trop 2000; 30 Supl 2: 92-3.

Grijalva MJ, Chiriboga R, Racines JR, Escalante L, Rowland EC. Short report: screening for Trypanosoma cruzi in the blood supply by the red cross blood bank in Quito Ecuador Am J Trop Med Hyg 1997; 57: 740-1.

Grisard EC. Estudo da variabilidade do gene mini-exon e produção de cepas transfectadas de Trypanosoma rangeli Tejera, 1920. Belo Horizonte; 1999. [Tese de Doutorado - Instituto de Ciências da UFMG]. 
Guajardo U, Silva J, Lorca M, Atias A. Prevalência de la infección por Trypanosoma cruzi en el Banco de sangre del Hospital de Salamanca (IV Region) Chile. Parasitol Dia $1984 ; 8: 105-7$

Guhl F, Jaramillo C, Mogollón JH, Rodriguez Jr, Sánchez N, Marinkelle J. Rastreo seroepidemiológico de donantes de sangre chagásicos en una zona endémica (Norte de Santander, Colombia). Rev Latinoam Microbiol 1987; 29: 63-6.

Kleinman S, Secord K. Risk of human immunodeliciency virus (HIV) transmission by anti-HIV negative blood: estimates using the lookback methodology. Transfusion 1988; 28: 499-501.

Kleinman S, Busch MP, Korelitz JJ, Schreiber GB. The Incidence/window period model and its use to assess the risk of transfusion-transmitted human immunodeficiency virus and hepatitis C virus infection. Transf Med Rev 1997; 11:155-72.

Koerner K, Cardoso M, Dengler T, Kerowgan M, Kubanek B. Estimated risk of transmission of hepatitis C virus by blood transfusion. Vox Sang 1998; 74: 213-6.

Korelitz JJ, Williams AE, Busch MP, Ownby HE, Zuck TF, Matijas LJ et a1. Demographic characteristics and prevalence of serologic markers among donors who use the confidential unit exclusion process: The retrovirus epidemiology donor study. Transfusion 1994; 34: 870-6.

Korelitz JJ, Busch MP, Kleinman SH. A method for estimating hepatitis B virus incidence rates in volunteer blood donors. Transfusion 1997; 37: 634-40.

Kupek E. HIV soroprevalence among blood donors in southern Brazil in the decade of 1990. Braz J Infect Dis 2000; 4: 217-25.

Kupek E. The reduction of HIV transfusion risk in southern Brazil in the 1990s. Transfus Med 2001 a; 11: 75-8.

Kupek E. Residual transfusion risk for hepatitis B and C in southern Brazil, 1991-99. $J$ Viral Hepatitis $2001 \mathrm{~b} ; 8: 78-82$ 
Lackritz EM, Satten GA, Aberlee-Grasse J, Dodd RY, Raimondi VP Janssen RS et al. Estimated risk of transmission of the human immunodeficiency virus by screened blood in the United States. N Engl JMed 1995; 333: 1721-5.

Langhi Júnior DM. Prevenção da Doença de Chagas transfusional. In: Covas DT, Zago MA, editores. Atualização em hemoterapia, Ribeirão Preto: Gráfica Canavaci; 1998. v. $5,121-32$.

Leal H, Ferreira Neto JA, Martins CM. Dados ecológicos sobre os triatomineos silvestres na ilha de Santa Catarina (Brasil). Rev Inst Med Trop São Paulo 1961; 3: 213 20 .

Lima LMA, Sacramento HS, Gama MP, Muniz JD. Inquérito sorológico para a doença de Chagas em doadores de sangue na Unidade Integrada de Saúde de Sobradinho (U.I.S.S.), DF. Rev Goiana Med 1981; 27: 201-15.

Lopes MH. Doador de sangue infectado: doença de Chagas. Rev Soc Bras Med Trop 1996; 2 Supl.2: 29-32.

Lorca M, Lorca J, Child R, Atias A, Canales M, Lorca E, Gutierre J. Prevalência de la infección por Trypanosoma cruzi en pacientes politransfundidos. Rev Med Chile 1988; 116: $112-6$.

Luquetti AO, Rassi A Diagnóstico laboratorial da infecção pelo Trypanosoma cruzi. In: Brener Z, Andrade ZA, Barral Neto M. Trypanosoma cruzi e doença de Chagas. $2^{\mathrm{a}}$ ed. Rio de Janeiro. Guanabara Koogan; 2000 p. 344-78.

Luz ZMP, Coutinho MC, Cançado JR, Kretli AU. Alta positividade de hemoculturas repetidas em pacientes chagásicos crônicos não tratados. Rev Soc Bras Med Trop 1993; 26 Supl 2: 66-7

Luz ZMP, Coutinho M C, Cançado J R, Krettli A U. Hemocultura: técnica sensivel na deteç̧ão do Trypanosoma cruzi em pacientes chagásicos na fase crônica da doença de Chagas. Rev Soc Bras Med Trop 1994; 27: 143-8. 
Martelli CMT, Andrade ALSS, Silva SA. Zicker F. Risk factors for Trypanosoma cruzi infection among blood donors in central Brazil. Mem Inst Oswaldo Cruz 1992; 87: 33943.

Martin AA. La enfermedad de Chagas transfusional. Parasitol Dia 1991; 15 (3/4): 67-8.

Miles MA. Disease control has no frontiers. Parasitol Today 1992; 8: 221- 2.

Ministério da Saúde. Comissão Nacional de Hemoterapia. Portaria n ${ }^{\circ} 4$, de 25 de novembro de 1969. Define normas sobre o atendimento de doadores para operação de coleta de sangue. Diário Oficial da República Federativa do Brasil, Brasília (DF), 15 jan. 1969. Seção 1, p. 343-5.

Ministério da Saúde. Relatório final da $8^{\mathrm{a}}$ Conferência Nacional de Saúde; 1986; Brasília (DF). Brasília; 1986.

Ministério da Saúde. Portaria $\mathrm{n}^{\circ} 721 / \mathrm{GM}$ de 09 de agosto de 1989. Aprova normas técnicas para a coleta, processamento e transfusão de sangue, componentes e derivados e dá outras providências. Diário Oficial da República Federativa do Brasil, Brasília (DF), 11 ago. 1989. Seção 1, p. 13643 -50.

Ministério da Saúde. Portaria n. 1.376, de 19 de novembro de 1993. Aprova alteração na Portaria $\mathrm{n}^{\circ} 721 / \mathrm{GM}$, de 09 de agosto de 1989 , que aprova as normas técnicas para a coleta, processamento e transfusão de sangue componentes e derivados e dá outras providências. Diário Oficial da República Federativa do Brasil, Brasilia (DF), 2 dez 1993a. Seção 1, p. 18405-15.

Ministério da Saúde. Bol Epidemiol 1993 1(3): 1-39.

Ministério da Saúde. Agência Nacional de Vigilância Sanitária. Definiçôes de Unidades Hemoterápicas. [on line]. Disponivel em http:llwww anvisa gov.br/anvisa hensocad/ Descrição. Especificação.jsp-Microsolft. Internet. [2001 jul 30].

Ministério do Trabalho e Emprego. CBO - Classificação Brasileira de Ocupações. [on line]. Disponivel em http//www.tem.gov.Br/Temas/CBO.Internet. [2002 abril 20]. 
Moraes-Souza H, Morais CA, Mineo JR. Prevalência da infecção chagásica em doadores de sangue no Triângulo Mineiro. Rev Soc Bras Med Trop 1985; 18: 11-6.

Moraes-Souza H. Transmissão da doença de Chagas por transfusão de sangue e seu controle. Rev Soc Bras Med Trop 1987; 20 Supl. 2: M1-M4.

Moraes-Souza H. Doença de Chagas transfusional no Brasil. Rev Soc Bras Med Trop 1992; 25 Supl 3: 31-2.

Moraes-Souza H. Situação atual do controle da doença de Chagas transfusional. Rev Soc Bras Med Trop 1994; 27 Supl. 2: 102-4.

Moraes-Souza H, Wanderley DMV, Brener S, Nascimento RD, Antunes CMF, Dias JCP. Hemoterapia e doença de Chagas transfusional no Brasil. Bol Oficina Sanit Panam 1994; 116: 406-18.

Moraes-Souza H. Chagas infection transmission control: Situation of transfucional transmission in Brazil and other countries of Latin America. Mem Inst Oswaldo Cruz 1999; 94 Supl.1: 419-23.

Nascimento HG, Vitorello DA, Schlemper Júnior B, Steindel M. Estudo clínico dos primeiros casos autóctones da Doença de Chagas em Santa Catarina. In: $25^{\mathrm{a}}$ Congresso da Sociedade Brasileira de Medicina Tropical; 1999 fev 26-mar 2; Florianópolis (SC). p. 170

Oliveira OV, Oliveira FO, Ferreira Neto JA. Apresentação do primeiro caso autóctone de doença de Chagas diagnosticado em Santa Catarina, Brasil. Rev Saúde Pública 1970; 4: $211-4$.

[OMS] Organización Mundial de la Salud. Control de la Enfermedad de Chagas. Ginebra; 1991. (OMS-Série de Informes Técnicos, 811).

Pellegrino J. O perigo da transmissão da Doença de Chagas pela transfusão de sangue. Primeiras comprovações sorológicas de esquizotripanose em doadores de sangue. Rev Bras Med 1949; 6: 297-301. 
Pereira MG. Características da mortalidade urbana por doença de Chagas, Distrito Federal, Brasil. Bol Oficina Sanit Panam 1984; 96: 213-21.

Pereira MG. Epidemiologia: teoria e prática. Rio de Janeiro. Guanabara Koogan: 1995.

Pessoa SB, Martins AV. Parasitologia médica. $11^{\mathrm{a}}$ ed. Rio de Janeiro: Guanabara Koogan; 1982. p. 143-63.

Pinotti HW, Félix VN, Domene CE, Raia AA. Megaesôfago chagásico póstransfusional. Rev Goiana Med 1982; 28: 61-6.

Pinto AYN, Harada G, Valente SAS, Valente VC, Abudi JEA, Gomes FS. Cardiopatia chagásica aguda em microepidemia familiar em Abaetetuba, PA. Rev Soc Bras Med Trop 1999; 32: Supl 1:82.

Pinto AYN, Harada GS, Valente VC, Abudi JEA, Gomes FG, Souza GCR et all. Acometimento cardíaco em pacientes com doença de Chagas aguda em microepidemia familiar em Abaetetuba, na Amazônia Brasileira. Rev Soc Bras Med Trop 2001; 34: 413-9.

Pinto PLS, Amato Neto V, Moreira AAB, Branco MCT, Marchi CR, Silva MFS et al. Seleção de doadores de sangue. Divergências de resultados de provas sorológicas para diagnóstico da doença de Chagas J Bras Med 1993; 64: 157-60.

Platero F, Flores C, Contreras MC, Sandorval L, Salinas P, Estay N et al. Enfermedad de Chagas in Chile. Dectores urbanos. V - Frecuencia de infección por Trypanosoma cruzi en donantes de sangre y madres y recién nacidos en el Hospital de Iquique. (IReion 1982-1983). Bol Chil Parasitol 1983; 38: 76-8.

Ponce C. La enfermedad de Chagas transfusional en Honduras y otros paises de America Central. Medicina B Aires 1999; 59 Supl: 135-7.

Ramirez LE, Lages-Siva E, Pianetti GM, Rabelo RM, Moraes-Souza H. Quimioprofilaxia da doença de Chagas transfusional através da associação da violeta genciana, ascoato de sodio e luz artificial. Bol Rev Soc Bras Hematol Hemoter 1992; 14 (161): $265-70$. 
Rassi A, Luquetti AO, Rassi AJr, Rassi SG, Rassi AG. Chagas'disease: clinical features. In: Wendel Z, Brener ME, Camargo A, Rassi, editors. Chagas'disease (American Trypanosomiasis): its impact on tranfusion and clinical medicine. São Paulo: ISBT; 1992. p. 81-101.

Ribeiro-dos-Santos G, Nishiya AS, Sabino EC, Chamone DF, Sáez-Alquézar A. An improved, PCR-based strategy for the detection of Trypanosoma cruzi in humn blood samples. Ann Trop Med Parasitol 1999; 93: 689-94.

Romero $\mathrm{T}$, Weir MJ, Lusardo $\mathrm{M}$, Ramos $\mathrm{C}$, Rodrigues $\mathrm{N}$. Infección chagásica en donantes de sangre en el estado de Zulia, Venezuela, 1980-1988. Kasmera 1992; 20: 94111

Rosenfeld LGM. Transmissão de AIDS e outras moléstias infecciosas por transfusão de sangue e seus derivados. Bol Soc Bras Hemat Hemoterapia 1989; 11 (152): 54-6.

Ruiz I, Agurto M, Arismendi M, Manasalva M, Herskovic P, Astorga B. Seropositividad para enfermedad de Chagas en donantes del banco de sangre de un hospital pediátrico de Santiago. Parasitol Dia 1984; 8: 77-8.

Saéz-Alquézar A, Bassit L, Tanaka VM, Morawa TM, Dorthiac-Liacer P, Charmoce DAF. Soroprevalência do virus da hepatite $B$ em doadores de sangue na Fundação Prósangue Hemocentro de São Paulo. Rev Bras Hematol Hemoter Resumos de Conferências e Temas Livres, Hemo 1994; 16: 165.

Saéz-Alquézar A, Otani MM, Sabino EC, Ribeiro-dos-Santos, Salles N, Chamone DF. Evaluation of the performance of Brazilian Blood Banks in testing for Chagas'disease. Vox Sang 1998; 74:228-31.

Sagua H, González J, Araya J, Fuentes A. Soropositividad chagásica en banco de sangre de zona endêmica. Alguns aspectos epidemiológicos de los hemodonantes Bol Chil Parasitol 1982; 37: 24-6.

Salgado AA, Peregrino J. Distribuição geográfica: inquérito sorológico. In: Cançado J R. Doença de Chagas. Belo Horizonte: Imprensa Oficial do Estado de Minas Gerais; 1968. p. $143-57$ 
Salles NA, Sabino EC, Cliquet MG, Eluf-Neto J, Mayer A, Almeida-Neto C et al. Risk of exposure to Chagas'disease among seroreactive Brazilian blood donors. Transfusion 1996; 36: 969-73.

São Thiago PT. Considerações sobre a não existência da doença de Chagas em Santa Catarina. Rev Soc Bras Med Trop 1982; 15: 33-8.

Schlemper Júnior BR, Ishida MMI, Steindel M, Gargioni R. Elevados índices de infecção de tratomíneos silvestres e comportamento morfológico de cepas silvestres de Trypanosoma cruzi de Santa Catarina. In: $11^{\text {a }}$ Reunião Anual Pesquisa Básica em Doenças de Chagas; 1974; Caxambú, Minas Gerais. p. 38.

Schlemper Júnior BR. Estudos esperimentais de quimioprofilaxia da transmissão da Doença de Chagas por transfusão sanguinea. Rev Patol Trop 1978; 7: 55-111.

Schlemper Júnior BR, Piazza RMF, Garcia ACM. Soroepidemiologia da doença de Chagas em Santa Catarina. Rev Soc Bras Med Trop 1983; 16: 196-201

Schlemper Júnior BR, Ishida MMI, Steindel M, Gargioni R. Primeiro encontro de Panstrogylus megistus colonizando ecótopo artificial em Santa Catarina: dados preliminares. In: $36^{\circ}$ Reunião Anual da Sociedade Brasileira para o Progresso da Ciência; 1984a; Florianópolis. p. 890.

Schlemper Júnior BR, Ishida MMI, Steindel M, Gargioni R. Comportamento morfobiológico de cepas silvestres do Trypanosoma cruzi de Santa Catarina. In: $11^{\text {a }}$ Reunião Anual Pesquisa Básica em Doenças de Chagas; 1984b; Caxambú, Brasil. p. 3-26.

Schlemper Júnior BR, Steindel M, Gargioni R, Farias CJM, Oliveira R, Trianon IX. Reservatórios e vetores silvestres do Trypanosoma cruzi e suas relações com o domicilio humano na ilha de Santa Catarina. Arq Catarinense Med 1985; 2 (14): 91-5.

Schlemper Júnior BR, Steindel M. Aspectos epidemiológicos de um foco de colonização de Panstrongylus megistus em anexo domiciliar na Ilha de Santa Catarina. Mem Inst Oswaldo Cruz 1986; 81 Supl: 177. 
Schlemper Júnior BR, Ishida MMI, Steindel M, Piazza RMF. Inquérito sorológico humano para Doença de Chagas no Distrito de Lagoa da Conceição, Florianópolis Santa Catarina. In: $25^{\circ}$ Congresso da Sociedade Brasileira de Medicina Tropical; 1989 fev $26-\operatorname{mar} 2$; Florianópolis-SC. p. 167.

Schmuñis GA. Trypanosoma cruzi, the etiologic agent of Chagas' disease: status in the blood supply in endemic and non endemic countries. Transfusion 1991; 31: 547-57.

Schmuñis GA. La Trypanosomiase americana como problema de saúde pública. In: [OPAS] Organización Panamericana de la salud. Washington (DC); 1994. p.3-31 (Publicación Cientifica, 547).

Schmuñis G, Bittencourt AL, Azougue E, Lorca M, Sarazua WM. Transmissão congênita. Rev Soc Bras Med Trop 1994; 27 : 57.

Schmuñis GA. Prevention of transfusional Trypanosoma cruzi infection in Latin America. Mem Inst Oswaldo Cruz 1999a; 94 Supl 2: 93-101.

Schmuñis GA. Riesgo de la Enfermedad de Chagas atraves de las transfusiones en la Américas. Medicina B Aires 1999b; 59 Supl 2: 125-34.

Schreiber GB, Busch MP, Kleinman SH, Korelitz JJ. The risk of transfusion-transmitted viral infections. New Engl J Med 1996; 334: 1685-90.

Secretaria de Estado do Desenvolvimento Econômico e Integração do Mercosul. Diretoria de Geografia, Cartografia e Estatistica. Sintese estatística de Santa Catarina. Florianópolis; 1999.

Secretaria de Estado da Saúde. Decreto n 3.041, de 07 de março de 1989. Regulamenta os art. 17 a 19 da Lei $n^{\circ} 6.320$, de 20 de dezembro de 1983, que dispõe sobre normas gerais de saúde, estabelece penalidades e dá outras providências. Diário Oficial do Estado de Santa Catarina, Florianópolis, 8 mar 1989. Seção 1, p. 1. 
Secretaria de Estado da Saúde. Portaria $n^{\circ}$ 22/SES/93. Determina a implantação estadual, do Sistema Informatizado de Vigilância Sanitária e Vigilância Epidemiológica das atividades hemoterápicas, a partir do cruzamento de dados obtidos nos estabelecimentos de hemoterapia sobre doadores, receptores e manipuladores diretos e/ou indiretos dos produtos hemoterápicos em relação as seguintes doenças infectocontagiosas: Doença de Chagas, sífilis, hepatite B, Síndrome da Imunodeficiência Adquirida (SIDA) outras que se fizerem nececessárias e forem exigidas legalmente. Diário Oficial do Estado de Santa Catarina, Florianópolis, 28 dez 1993a. Secão 1, p. 23.

Secretaria de Estado da Saúde. Portaria $n^{\circ}$ 23/SES/93. Aprova a Norma Técnica Especial (NTE) para controle da qualidade do sangue, componentes e derivados, visando entre outros, a diminuição da ocorrência de doenças hemotransmissíveis, contemplado no parágrafo $2^{\circ}$ do art. $3^{\circ}$ do Decreto $\mathrm{n}^{\circ} 24.983$, de 14 de março de 1985 , que regulamenta os art. 20,21, 22, 23, todos da lei 6.320, de 20 de dezembro de 1993 . Diário Oficial do Estado de Santa Catarina, Florianópolis, 28 dez 1993b. p. 24.

Secretaria de Estado da Saúde. Portaria $n^{\circ}$ 754/SES/2001. Reconhece o Laboratório de Protozoologia do Departamento de Microbiologia e Parasitologia - MIP da Universidade Federal de Santa Catarina-UFSC como sendo o Laboratório de Referência no Estado de Santa Catarina para o diagnóstico da Doença de Chagas e Leishmaniose. Diário Oficial do Estado de Santa Catarina, Florianópolis, 20 agosto 2001. Seção 1, p. 17.

Shikanai-Yasuda MA, Marcondes B, Guedes LA, Siqueira GS, Dias JCP, Amato Neto $\mathrm{V}$ et al. Possible oral transmission or acute Chagas'Disease in Brasil. Rev Inst Med Trop São Paulo 1999; 33: 351-7.

Shulman IA, Appleman MD. Transmission of parasitic and bacterial infections through blood transfusio within the U. S. Crit. Rev Clin Lab Sci 1991; 28: 447-59.

Siqueira-Batista R, Quintas LEM. Enfermidade de Chagas aguda: clínica, diagnóstico e tratamento. Arq Bras Med 1995; 69: 171-3.

Siqueira-Batista R, Corrêa AD, Huggins DW. Moléstia de Chagas. Rio de Janeiro: Cultura Médica; 1996. 
Silla SMR, Achutti ALR, Dalmaz A, Breidenbach M, Ferrari R. Controle da transmissão da doença de Chagas por transfusão de sangue no Rio Grande do Sul. Arq Bras Med 1988; 62: 357-60.

Silva NN, Clausell DT, Nólibos H, Mello AL, Ossanai J, Rapone $\mathrm{T}$ et al. Surto epidêmico da doença de Chagas com provável contaminação oral. Rev Inst Med Trop São Paulo 1968; 10: 265-76.

Silveira AC. Epidemiologia e controle da Doença de Chagas. In: Ministério da Saúde. $A$ saúde no Brasil. Brasilia (DF): Centro de Documentação do Ministério da Saúde; 1983. p. $212-8$.

Silveira AC, Sakamoto T. Importância médico-social da Doença de Chagas no Brasil e de seu controle. Rev Bras Malariol Doenças Trop 1983; 35: 127-34.

Silveira AC, Feitosa VR, Borges R. Distribuição de triatomineos capturados no ambiente domiciliar, no periodo 1975/83, Brasil. Rev Bras Malariol Doenças Trop $1984 ; 36: 15-312$

Silveira AC. E após a erradicação dos triatomíneos exclusivamente domiciliados? Doença de Chagas: vigilância entomológica. Rev Soc Bras Med Trop 1992; Supl 3: 30.

Silveira A, Vinhaes M. Doença de Chagas: aspectos epidemiológicos e de controle. Rev Soc Bras Med Trop 1998; 31 Supl: 15-60.

Soares S, Moraes Souza H. Triagem sorológica de doadores para a doença de Chagas; experiência do Hemocentro Regional de Uberaba. Rev Soc Bras Med Trop 2000; Supl 2: 93-4.

Souza HM, Moraes CA, Mineo JR. Prevalência da infecção chagásica em doadores de sangue no Triânculo Mineiro. Rev Soc Bras Med Trop 1985; 18: 11-6.

Steindel M, Gargioni R, Farias CJM, Oliveira R, Schlemper Júnior BR. Reservatórios e vetores silvestres do Trypanosoma cruzi na Ilha de Santa Catarina: resultados preliminares. In: $11^{a}$ Reunião Amual sobre Pesquisas Básicas em Doença de Chagas; 1984; Caxambu, Brasil p. 37. 
Steindel M, Gargioni R, Farias JM. Schlemper Júnior BR. Colonização de Panstrongylus megistus em ecótopos artificiais (galinheiros) na Ilha de Santa Catarina. In: Anais do $11^{\circ}$ Congresso da Sociedade Brasileira de Parasitologia; 1985; Fortaleza, Brasil. p. 151

Steindel M. Caracterização de cepas de Trypanosoma rangeli e Trypanosoma cruzi isoladas de reservatórios e vetores silvestres em Santa Catarina. Minas Gerais; 1993. [Tese de Doutorado - Universidade de Minas Gerais]

Steindel M, Toma HK, Carvalho Pinto CJ, Grisard EC, Schlemper Júnior BR. Colonização de ecótopos artificiais pelo Panstrongylus megistus na ilha de Santa Catarina, Florianópolis, Brasil. Rev Inst Med Trop São Paulo 1994; 30: 43-50.

Steffens MA S. Triagem soroepidemiológica das doenças hemotransmissiveis em doadores de sangue na Grande Florianópolis Santa Catarina. Itajaí; 1994. [Monografia apresentada para obtenção do Título de Especialista em Epidemiologia - UNIVALI, Itajai-SC].

Takoaka AMN, Takoaka L, Marzochi MCA. Prevalência da doença de Chagas em bancos de sangue através da reação de fixação de complemento e imunofluorescência indireta. Rev Soc Bras Med Trop 1979/80; 8: 107-12.

Tanowitz HB, Kirchff LV Simon D, Morris SA, Weiss LM, Wittner $M$. Chagas'disease. Clin Microbiol Rev 1993; 5: 400-19.

Tello P, Fernandez P, Sandoval L, Ampuero G, Pizarro T, Schenome H. Incidência de la infección por Trypanosoma cruzi en madres e hijos de un sector del Area Norte de Santiago. Bol Chil Parasitol 1982; 37: 23-4.

Tolezano JE, Ueda M, Mitsuka H, Paschoal SMP, Moraes CR, Martins MA et al. A tripanosomíase americana e sua transmissão transfusional. Rev Inst Adolfo Lutz 1980; 40: $83-8$

Tolezano JE, Chiattone CS, Nunes EV, Ferrari LF, Guilherme CS, Chieffi PP et al. Quantificação do risco mínimo de aquisição da doença de Chagas transfusional através do xenodiagnóstico em doadores de sangue com sorologia positiva. Bol Soc Bras Hematol Hemoter 1992; 14: $271-4$. 
Valente SAS, Leão RQ, Valente VC, Pinto AYN, Crescente JAB et al. Microepidemia familiar com 11 casos de doença de Chagas em Abaetetuba, Estado do Pará com suspeita de transmissão oral. Rev Soc Bras Med Trop 1999. 32 Supl 1: 83-4.

Valente VC, Pinto AYN e Valente SAS. Novo episódio familiar com 7 casos de doença de Chagas aguda e autóctone em Bagre, Estado do Pará com suspeita de transmissão oral. Rev Soc Bras Med Trop 2000. 33 Supl 1: 388-9.

Varella AL, Meurer F, Pimentel SK, Almeida PTR. Considerações sobre sorologia positiva e auto exclusão em doadores de sangue. Bol Rev Soc Bras Hematol Hemoter $1993 ; 15: 14-20$

Vasconcelos HCFF, Yoshida CFT, Vanderborght BOM, Schatzmayr HC. Hepatites B and $\mathrm{C}$ prevallences among blood donous South Region of Brazil. Mem Inst Osvaldo Cruz 1994; 89: 503-7.

Wanderley DMV, Camargo LMA, Carvalho ME. Doença de Chagas: registro de um caso agudo transfusional. Rev Inst Med Trop São Paulo 1988; 30: 437-40.

Wanderley DMV, Carvalho ME, Mantegazza E, Yasumaru S, Barata LCB. Infecção chagásica transfusional detectada no programa de controle da doença de Chagas no Estado de São Paulo (Brasil). Rev Saúde Pública 1992; 26: 203-5.

Wanderley DMV, Gonzales TT, Pereira MSCA, Nascimento RD. Morais-Souza H. Controle da hemoterapia e da doença de Chagas Transfusional: 1988 e 1990. Rev Saúde Pública 1993; 27:430-5.

Wanderley DMV. Perspectivas de controle da doença de Chagas no Estado de São Paulo. São Paulo; 1994a.. [Tese de Doutorado - Faculdade de Saúde Pública da USP].

Wanderley DMV. Epidemiologia da doença de Chagas. Rev Soc Cardiol Estado São Paulo 1994b; 4: 77-84.

Weinborn ME, Beltran R, Contreras MC, Salinas P, Sandoval L, Torres E et al. Enfermedad de Chagas in Chile. Sectores urbanos. IV - Frecuencia de infección chagásica en donantes de sangre y en madres y recién ncidos atendidos en el Hospital de Arica (I Region, 1982-1983). Bol Chil Parasitol 1983; 38: 73-4. 
Wendel S, Brener Z, Camargo ME, Rassi A. Chagas disease (American Trypanossomiasis): its impact on transfusion and clinical medicine. ISBT BRAZIL'92 SBHH (Sociedade Brasileira de Hematologia e Hemoterapia), São Paulo; 1992.

Wendel S. Triagem sorológica e doadores de sangue para doença de Chagas: O dilema da notificação e aconselhamento do doador reativo. Rev Soc Bras Med Trop 1993; 26 Supl 2: 74-5.

Wendel S, Gonzaga AL. Chagas'disease and blood transfusion: a new world problem? Vox Sang 1993; 64:1-12.

[WHO] World Health Organization. Chagas disease. Frequency and geographical distribution. Wkly Epidemiol Rec 1990; 65 (34): 257-61.

[WHO] World Health Organization. Chagas disease. Interruption of transmission, Chile. Wkly Epidemiol Rec 1995; 70 (3): 13-20.

World Bank. World development report-1993: investing in health. New York: Oxford University Press; 1993.

Yasuda MAS. Chagas: novas características da endemia em centros urbanos. Médicos 1998; $1: 26-31$.

Zuck TF, Thomson RA, Schreiber GB, Gilcher RO, Kleinman SH, Murphy EL, Ownby HE, et al. The retrovirus epidemiology donor study (REDS): rationale and methods. Transfusion 1995; 35: 944-51. 
ANEXOS 
ANEXO I - Lista de Regionais de Saúde e municípios da Figura 1.

1" REGIONAL DE SAÚdE

AMAI - Associação dos Municípios do Alto Irani

Abelardo Luz

Bom Jesus

Coronel Martins

Entre Rios

Faxinal dos Guedes

Galvão

Ipuaçu

Jupiá

Lageado Grande

Marema

Ouro Verde

Passos Maia

Ponte Serrada

São Domingos

Vargeão

Xanxerê

Xaxim

$2^{a}$ REGIONAL DE SAÚdE

AMARP - Associação dos Municípios do Alto Vale do Rio do Peixe

Arroio Trinta

Curitibanos

Fraiburgo

Frei Rogério

Iomerê

Lebon Régis

Macieira

Ponte Alta do Norte

Rio dasAntas

Salto Veloso

São Cristóvão do Sul

Timbó Grande

Videira 
$3^{*}$ REGIONAL DE SAÚDE

AMAUC - Associação dos Municípios do Alto Uruguai Catarinense

Alto Bela Vista

Arabutã

Arvoredo

Concórdia

Ipira

Ipumirim

Irani

Itá

Jaborá

Lindóia do Sul

Paial

Peritiba

Piratuba

Presidente Castelo Branco

Seara

Xavantina

4" REGIONAL DE SAÚDE

AMAVI - Associação dos Municípios do Alto Vale do Itajaí

Agrolândia

Agronômica

Atalanta

Aurora

Braço do Trombudo

Chapadão do Lageado

Dona Emma

Ibirama

Imbuia

Ituporanga

José Boiteux

Laurentino

Lontras

Mirim Doce

Petrolândia

Pouso Redondo

Presidente Getúlio

Presidente Nereu

Rio do Campo

Rio do Oeste

Rio do Sul

Salete

Santa Terezinha

Taió 
Trombudo Central

Vidal Ramos

Vitor Meireles

Witmarsum

5 REGIONAL DE SAÚDE

AMEOSC - Associação dos Municípios do Extremo Oeste Catarinense

\author{
Anchieta \\ Bandeirante \\ Barra Bonita \\ Belmonte \\ Descanso \\ Dionísio Cerqueira \\ Guaraciaba \\ Guarajá do Sul \\ Iporã do Oeste \\ Itapiranga \\ Mondaí \\ Palma Sola \\ Paraíso \\ Princesa \\ Riqueza \\ Romelândia \\ Santa Helena \\ São João do Oeste \\ São Miguel d'Oeste \\ Tunápolis
}

$6^{a}$ REGIONAL DE SAÚdE

AMESC - Associação dos Municípios do Extremo Sul Catarinense

\author{
Araranguá \\ Balneário Arroio do Silva \\ Balneário Gaivota \\ Ermo \\ Jacinto Machado \\ Maracajá \\ Meleiro \\ Morro Grande \\ Passo de Torres \\ Praia Grande \\ Santa Rosa do Sul \\ São João do Sul \\ Sombrio \\ Timbé do Sul \\ Turvo
}


$7^{\star}$ REGIONAL DE SAÚdE

AMFRI - Associação dos Municípios da Foz do Rio Itajai

Balneário Camboriú

Bombinhas

Camboriú

Ilhota

Itajai

Itapema

Luiz Alves

Navegantes

Penha

Piçarras

Porto Belo

8* REGIONAL DE SAÚDE

AMMOC - Associação dos Municípios do Meio Oeste Catarinense

Abdon Batista

Água Doce

Brunópolis

Campos Novos

Capinzal

Catanduvas

Erval Velho

Herval d'Oeste

Ibian

Ibicaré

Joaçaba

Lacerdópolis

Luzerna

Monte Carlo

Ouro

Pinheiro Preto

Tangará

Treze Tílias

Vargem

Vargem Bonita

Zortéa

$9^{a}$ REGIONAL DE SAÚDE

AMMVI - Associação do Municípios do Médio Vale do Itajaí

Apiúna

Ascurra

Benedito Novo

Blumenau

Botuverá 
Brusque

Doutor Pedrinho

Gaspar

Guabiruba

Indaial

Pomerode

Rio dos Cedros

Rodeio

Timbó

$10^{a}$ REGIONAL DE SAÚDE

AMOSC - Associação dos Municípios do Oeste de Santa Catarina

Águas de Chapecó

Águas Frias

Bom Jesus do Oeste

Caibí

Campo Erê

Caxambú do Sul

Chapecó

Cordilheira Alta

Coronel Freitas

Cunha Porã

Cunhataí

Flôr do Sertão

Formosa do Sul

Guatambu

Iraceminha

Irati

Jardinópolis

Maravilha

Modelo

Nova Erechim

Nova Itaperaba

Novo Horizonte

Palmitos

Pinhalzinho

Planalto Alegre

Quilombo

Saltinho

Santa Terezinha do Progresso

Santiago do Sul

São Bernardino

São Carlos

São Lourenço d'Oeste

São Miguel da Boa Vista

Saudades 
Serra Alta

Sul Brasil

Tigrinhos

União do Oeste

11² REGIONAL DE SAÚDE

AMPLA - Associação dos Municípios do Planalto Norte Catarinense

Itaiópolis

Mafra

Castelo Branco

Papanduva

$12^{a}$ REGIONAL DE SAÚDE

AMREC - Associação dos Municípios da Região Carbonífera

Cocal do Sul

Criciúma

Forquilhinha

Içara

Lauro Muller

Morro da Fumaça

Nova Veneza

Siderópolis

Treviso

Urussanga

$13^{2}$ REGIONAL DE SAÚDE

AMUNESC - Associação do Municípios do Nordeste de Santa Catarina

Araquari

Balneário da Barra do Sul

Campo Alegre

Garuva

Itapoá

Joinville

Rio Negrinho

São Bento do Sul

São Francisco do Sul

$14^{2}$ REGIONAL DE SAÚDE

AMUREL - Associação do Municípios da Região Laguna

Armazém

Braço do Norte 
Capivari de Baixo

Grão Pará

Gravatal

Imaruí

Imbituba

Jaguaruna

Laguna

Orleans

Pedras Grandes

Rio Fortuna

Sangão

Santa Rosa de Lima

São Ludgero

São Martinho

Treze de Maio

Tubarão

15 REGIONAL DE SAÚDE

AMURES - Associação dos Municípios da Região Serrana

Anita Garibaldi

Bocaina do Sul

Bom Jardim da Serra

Bom Retiro

Campo Belo do Sul

Capão Alto

Celso Ramos

Cerro Negro

Correia Pinto

Lages

Otacílio Costa

Painel

Palmeira

Ponte Alta

Rio Rufino

São Joaquim

São José do Cerrito

Urubici

Urupema

16 ${ }^{a}$ REGIONAL DE SAÚDE

AMURC - Associação dos Municípios da Região do Contestado

Bela Vista do Toldo

Caçador

Camon 
Canoinhas

Irineópolis

Major Vieira

Matos Costa

Porto União

Santa Cecilia

Très Barras

$17^{\star}$ REGIONAL DE SAÚDE

AMVALI - Associação dos Municípios do Vale do Itapocu

Barra Velha

Corupá

Guaramirim

Jaraguá do Sul

Massaranduba

São João Itaperiú

Schroeder

\title{
18* REGIONAL DE SAÚDE
}

GRANFPOLIS - Associação dos Municípios da Região da Grande Florianópolis

\author{
Águas Mornas \\ Alfredo Wagner \\ Angelina \\ Anitápolis \\ Antônio Carlos \\ Biguaçu \\ Canelinha \\ Florianópolis \\ Garopaba \\ Governador Celso Ramos \\ Leoberto Leal \\ Major Gercino \\ Nova Trento \\ Palhoça \\ Paulo Lopes \\ Rancho Queimado \\ Santo Amaro da Imperatriz \\ São Bonifácio \\ São João Batista \\ São José \\ São Pedro de Alcântara \\ Tijucas
}


ANEXO II - Lista de municípios, população e área geográfica da Figura 3. 18a Regional de Saúde. Região da Grande Florianópolis.

REGIONAL DE SAÚDE DA REGIÃO DA GRANDE FLORIANÓPOLIS

\begin{tabular}{lcc}
\hline \multicolumn{1}{c}{ MUNICÍPIOS } & POPULAÇÃO* & ÁREA $\left(\mathrm{km}^{2}\right)$ \\
\hline 01 - Águas Mornas & 4.966 & 362,4 \\
02 - Alfredo Wagner & 8.779 & 731,8 \\
03 - Angelina & 5.983 & 519,4 \\
04 - Anitápolis & 3.199 & 576,6 \\
05 - Antônio Carlos & 6.163 & 228,4 \\
06 - Biguaçu & 42.852 & 324,0 \\
07 - Canelinha & 8.252 & 152,3 \\
08 - Florianópolis & 278.576 & 434,7 \\
09 - Garopaba & 12.514 & 114,0 \\
10 - Governador Celso Ramos & 11.602 & 96,4 \\
11 - Leoberto Leal & 4.076 & 293,3 \\
12 - Major Gercino & 3.380 & 286,8 \\
13 - Nova Trento & 9.556 & 405,4 \\
14 - Palhoça & 86.861 & 325,5 \\
15 - Paulo Lopes & 5.615 & 450,6 \\
16 - Rancho Queimado & 2.493 & 268,3 \\
17 - Santo Amaro da Imperatriz & 15.589 & 310,3 \\
18 - São Bonifácio & 2.973 & 461,6 \\
19 - São João Batista & 13.909 & 222,7 \\
20 - São José & 152.734 & 115,7 \\
21 - São Pedro de Alcântara & 3.587 & 140,6 \\
22 - Tijucas & 20.588 & 280,1 \\
& & \\
\hline TOTAL & 704.247 & $7.100,9$ \\
\hline
\end{tabular}

* População residente em 01.07.98, conforme estimativa da população do IBGE.

Fonte: Secretaria de Estado do Desenvolvimento Econômico e Integração ao Mercosul Diretoria de Geografia, Cartografia e Estatística 


\section{ANEXO III - Lista de municípios, população e área geográfica da Figura 4. 8a Regional de Saúde. Região de Joaçaba.}

REGIONAL DE SAÚDE DA REGIT̃O DE JOAÇABA

\begin{tabular}{lcc}
\hline \multicolumn{1}{c}{ MUNICÍPIOS } & POPULAÇÃO* & ÁREA $\left(\mathrm{km}^{2}\right)$ \\
\hline 01 - Abdon Batista & 2.970 & 236,0 \\
02 - Água Doce & 6.238 & $1.311,5$ \\
03 - Brunópolis & 3.494 & 335,5 \\
04 - Campos Novos & 28.492 & $1.751,2$ \\
05 - Capinzal & 16.659 & 227,9 \\
06 - Catanduvas & 7.041 & 198,2 \\
07 - Erval Velho & 4.150 & 232,7 \\
08 - Herval d'Oeste & 19.446 & 212,4 \\
09 - Ibian & 1.830 & 147,1 \\
10 - Ibicaré & 3.742 & 155,9 \\
11 -Joaçaba & 23.069 & 243,2 \\
12 - Lacerdópolis & 2.180 & 68,9 \\
13 - Luzerna & 5.384 & 116,7 \\
14 - Monte Carlo & 8.084 & 168,5 \\
15 - Ouro & 6.265 & 207,1 \\
16 - Pinheiro Preto & 2.882 & 65,7 \\
17 - Tangará & 8.652 & 423,0 \\
18 - Treze Tílias & 4.883 & 183,7 \\
19 - Vargem & 3.553 & 352,6 \\
20 - Vargem Bonita & 5.330 & 298,9 \\
21 - Zortéa & 2.344 & 190,1 \\
\hline TOTAL & 166.688 & $7.126,8$ \\
\hline
\end{tabular}

* População residente em 01.07.98, conforme estimativa da população do IBGE.

Fonte: Secretaria de Estado do Desenvolvimento Econômico e Integração ao Mercosul, Diretoria de Geografia, Cartografia e Estatística 
ANEXO IV - Hospitais atendidos pelo Hemocentro Regional de Florianópolis - HRF, Serviço de Hemoterapia do Hospital Universitário - SHHU/UFSC e Hemocentro Regional de Joaçaba - HRJ. Estado de Santa Catarina, 2000.

\section{Hospitais atendidos pelo Hemocentro Regional de Florianópolis - HRF}

- Hospital Governador Celso Ramos - Florianópolis, SC

- Hospital Regional Dr. Homero de Miranda Gomes - São José, SC

- Instituto de Cardiologia - São José, SC

- Hospital Infantil Joana de Gusmão - Florianópolis, SC

- Maternidade Carmela Dutra - Florianópolis, SC

- Hospital Nereu Ramos - Florianópolis, SC

- Hospital Florianópolis - Florianópolis, SC

- Hospital de Caridade - Florianópolis, SC

- Maternidade Carlos Correa - Florianópolis, SC

- Casa de Saúde São Sebastião - Florianópolis, SC

- Hospital Lara Ribas - Polícia Militar - Florianópolis, SC

- Hospital da Guarnição de Florianópolis - Exército - Florianópolis, SC

- Hospital de Apoio-CEPON, Hemocentro Regional de FlorianópolisFlorianópolis, SC

- Hospital Universitário - HU / UFSC - Florianópolis, SC

- Hospital de Imbituba - Imbituba, SC

- Hospital e Maternidade Chiquinha Galotti - Tijucas, SC

- Hospital Nossa Senhora da Imaculada Conceição - Nova Trento, SC

- Sociedade Hospitalar São Francisco de Assis - Santo Amaro da Imperatriz, SC

- Hospital São Sebastião - Anitápolis, SC

- Fundação Hospitalar Municipal de Canelinha - Canelinha, SC

- Fundação Médico Assistencial do Trabalhador Rural - São Bonifácio, SC

- Hospital Municipal José Locks - São João Batista, SC

- Hospital Santa Tereza - São Pedro de Alcântara, SC

- Fundação Hospitalar Santa Otília - Orleans, SC

- Hospital de Caridade Bom Jesus dos Passos - Laguna, SC

- Hospital e Maternidade Noss Senhora da Conceição - Angelina, SC

- Hospital Santa Inês - Balneário Camboriú, SC

- Hospital São Francisco de Assis Ltda - Camboriú, SC

- Hospital São João Batista - Imarui, SC

- Hospital de Psiquiatria de Santa Catarina - Colônia Sant'Ana - São José, SC

Hospitais atendidos pelo Servico de Hemoterapia do Hospital Universitário - SHHU/UFSC - Florianópolis

- Hospital Universitário - HU / UFSC 
Hospitais atendidos pelo Hemocentro Regional de Joaçaba - HRJ

- Hospital Frei Rogério, Tangará - SC

- Hospital Maicê - Sociedade Franco Brasileira, Caçador - SC

- Hospital São José, Capinzal - SC

- Hospital Nossa Senhora das Dores, Capinzal - SC

- Sociedade Beneficiente Piratuba, Ipira - SC

- Hospital Santa Terezinha, Joaçaba - SC

- Sociedade Beneficiente Hospitalar Peritiba, Peritiba - SC

- Hospital Nossa Senhora do Anjos, Rio das Antas - SC

- Hospital São Lucas Ltda, Tangará - SC

- Hospital Divino Salvador, Videira - SC

- Hospital Santa Maria Ltda, Videira - SC

- Hospital Nossa Senhora do Perp. Socorro, Catanduvas - SC

- Hospital Rural Nossa Senhora de Fátima, Erval velho - SC

- Hospital Beneficiente São Roque, Arroio Trinta - SC

- Hospital Jonas Ramos, Caçador - SC

- Hospital Hélio Ramos Ortiz, Curitibanos - SC

- Soc. Franco Bras. Hospital Div. Esp. Santo, Fraiburgo - SC

- Fund. Méd. Social Rural de Salto Veloso, Salto Veloso - SC

- Hospital e Maternidade de Santa Cecilia, Santa Cecília - SC

- Hospital São Francisco, Concórdia - SC

- Hospital Sarto Antônio Ltda, Ipumirim - SC

- Hospital São Jorge Ltda, Irani - SC

- Hospital Beneficente Santo Antônio, Jabora - SC

- Soc. de Assist. Hospital Cristo Rei, Pres. Castelo Branco - SC

- Hospital Nossa Senhora da Paz, Água Doce - SC

- Fundação Hospitalar Dr. José Athanazio, Campos Novos - SC

- Hospital Maternidade Santa Brigida Ltda, Campos Novos - SC

- Hospital São Roque Soc. Beneficente, Luzerna - SC

- Unidade Mista de Saúde N. Sra. Da Salete, Monte Carlo - SC

- Fund. Médica Social Rural Treze Tílias, Treze Tílias - SC

- Hospital São Damião Ltda, Vargem Bonita - SC

- Hospital de Arabutã, Arabutã - SC

- Hospital e Maternidade São Miguel Ltda, Joaçaba - SC

- Fundação Hospitalar Lindóia do Sul, Lindóia do Sul - SC

- Hospital e Mat. Municipal Santo Antônio, Lebon Regis - SC 


\section{ANEXO V - Ficha Cadastro do Doador}

ESTADO DE SANTA CATARINA

CADASTRO DO DOADOR

N DE REGISTRO

NOME

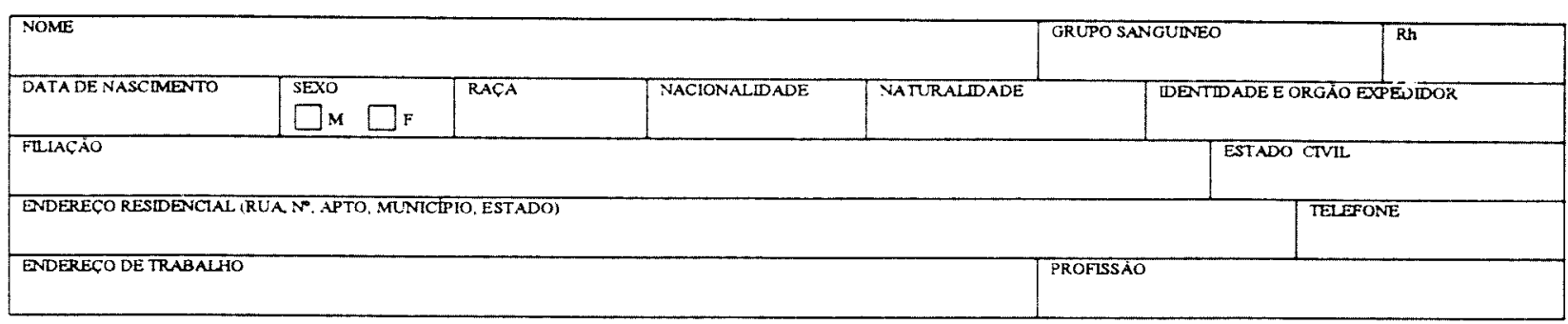

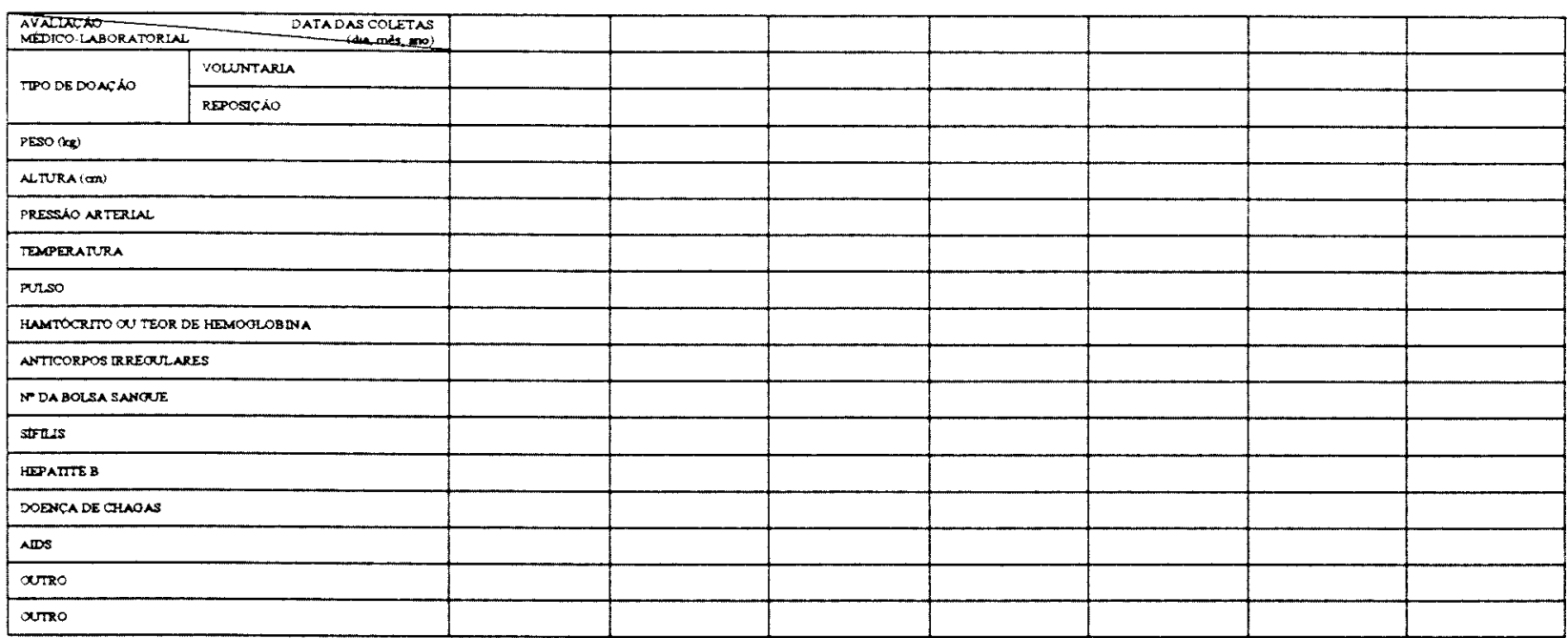

\begin{tabular}{|c|c|c|c|c|c|c|c|c|c|c|c|c|c|c|c|c|c|c|c|c|c|c|}
\hline$c$ & 7 mor & DATA Ade mas mos & & & & & & & & & & & & & & & & & & & & \\
\hline 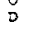 & 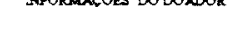 & 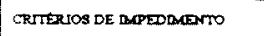 & $\sin$ & NAO & & $\sin$ & NaOo & & $\pi$ & NaO & & $\sin$ & NaD & & $\sin$ & NASO & & $\sin$ & NAOO & & & N\$O \\
\hline 01 & NBORTO & $\begin{array}{l}\text { TDAPOR RRSO - ATE (3) MESESS } \\
\text { APS }\end{array}$ & & & & & & & & & & & & & & & & & & & & \\
\hline 02 & Aarverisn & TRPOORARTO-ATE (6) ZESES & & & & & & & & & & & & & & & & & & & & \\
\hline 03 & ans & DERATITVO & & & & & & & & & & & & & & & & & & & & \\
\hline 04 & $\begin{array}{l}\text { NCOOLSANO- INTOXCACAO } \\
\text { NCOOLLCA }\end{array}$ & DERantrivo & & & & & & & & & & & & & & & & & & & & \\
\hline 05 & NERTOA & $\begin{array}{l}\text { TBAPORAROO-DURANTE } \\
\text { MWNIFSTACOSS }\end{array}$ & & & & & & & & & & & & & & & & & & & & \\
\hline 06 & 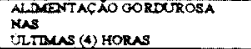 & Traporarto & & & & & & & & & & & & & & & & & & & & \\
\hline 07 & Mendentacio & TEMPORARTO & & & & & & & & & & & & & & & & & & & & \\
\hline 08 & ASAA BRONQUNCA & DERNTIVO & & & & & & & & & & & & & & & & & & & & \\
\hline 09 & BDAL & DEFNITIVO & & & & & & & & & & & & & & & & & & & & \\
\hline 10 & BRUCEOCSE & 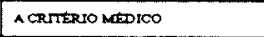 & & & & & & & & & & & & & & & & & & & & \\
\hline 11 & CANCER DE QUNACUER TROO & DERMTITVO & & & & & & & & & & & & & & & & & & & & \\
\hline 12 & CORTOLA GRANDE & $\begin{array}{l}\text { TEMPORARZO - ATE (6) MESSES } \\
\text { APOSS }\end{array}$ & & & & & & & & & & & & & & & & & & & & \\
\hline 13 & CTRURO OA MBDHA & TDMPORARSO-ATE (3) MESES & & & & & & & & & & & & & & & & & & & & \\
\hline 14 & 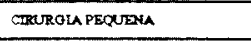 & $\begin{array}{l}\text { TPMPORARTO - ATE (J) MESES } \\
\text { APOSS }\end{array}$ & & & & & & & & & & & & & & & & & & & & \\
\hline 15 & COLAGENOSES & A CRTIERIO MEDICO & & & & & & & & & & & & & & & & & & & & \\
\hline 16 & 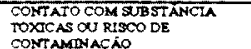 & TEMPORARIO & & & & & & & & & & & & & & & & & & & & \\
\hline 17 & DWBETE & \begin{tabular}{|l|} 
DERMTITVO \\
\end{tabular} & & & $\overrightarrow{\mathrm{H}}$ & & & 焉 & & & $\overrightarrow{\vec{z}}$ & & & 莒 & & & $\vec{I}$ & & & & & \\
\hline 18 & 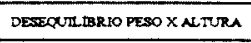 & Acrrtisto matico & & & 商 & & & 产 & & & 衰 & & & 离 & & & 离 & & & & & \\
\hline 19 & $\begin{array}{l}\text { DESSTTENCA - MLL ESTAR NA } \\
\text { RINADAA }\end{array}$ & TEMPORARIO & & & 㖰 & & & , & & & 鄫 & & & 曖 & & & 要 & & & & & \\
\hline 20 & 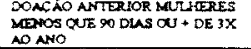 & TEPOORARSO & & & 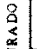 & & & $\alpha$ & & & $\mid \begin{array}{l}3 \\
0 \\
2 \\
2\end{array}$ & & & 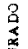 & & & 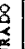 & & & & & \\
\hline 21 & 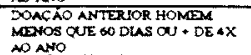 & tapornso & & & $\frac{3}{3}$ & & & 要 & & & $\frac{2}{3}$ & & & 䇉 & & & 菌 & & & & & \\
\hline 22 & $\begin{array}{l}\text { DOENGA CARDLACA OU } \\
\text { COROMARHANA }\end{array}$ & DERTITVO & & & 范 & & & 型 & & & 嫼 & & & & & & 2 & & & & & \\
\hline
\end{tabular}

(continuação) 
(continua)

\begin{tabular}{|c|c|c|c|c|c|c|c|c|c|c|c|c|c|c|c|c|}
\hline$c$ & & 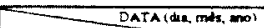 & & & & & & & & & & & & & & atins \\
\hline $\begin{array}{l}: \\
0\end{array}$ & MPORMAFOES DO DONDOR & & & & & & & & & & & & & & & \\
\hline & & 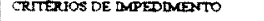 & $\sin$ & Nho & $\sin$ & NAO & $\sin$ & NAO & $\sin$ & WhO & $\sin$ & NAOO & $\sin$ & WAOO & $\sin x$ & NaO \\
\hline 23 & DOENAA DA TRESDEE & A CRITERO MEDICO & & & & & & & & & & & & & & \\
\hline 34 & DOENCA DE CHAOAS & DERMTTIVO & & & & & & & & & & & & & & \\
\hline 25 & DOENGA DO FOADO & ACRMENO MEDTCO & & & & & & & & & & & & & & \\
\hline 26 & DOENGA ORAVE - DUTRA & A CRTISRIO MEDICO & & & & & & & & & & & & & & \\
\hline${ }^{27}$ & DOEVAMENTAL & ACRTIERO MEDTCO & & & & & & & & & & & & & & \\
\hline 28 & DEREGA RENAL & A CRISERTO MEDTCO & & & & & & & & & & & & & & \\
\hline$=9$ & $\begin{array}{l}\text { DROOAS ENDVVENOSAS } \\
\text { DASAM DEPENDENCA }\end{array}$ & DERMTIVO & & & & & & & & & & & & & & \\
\hline so & gPLEPSA & Deranthvo & & & & & & & & & & & & & & \\
\hline 3 & EETRACAO DENTARIA & TEMPORARTO - ATE (1) SEMANA & & & & & & & & & & & & & & \\
\hline 32 & OESTACHO DU RUERPERTO & 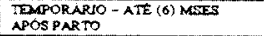 & & & & & & & & & & & & & & \\
\hline 3 & ORPFE E SU AS MANFESTACOES & 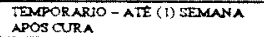 & & & & & & & & & & & & & & \\
\hline 34 & 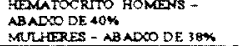 & TEMPORARIO & & & & & & & & & & & & & & \\
\hline 33 & HEMORRAOINS - TENDENCIAS & A GRTERRIO MEDTCO & & & & & & & & & & & & & & \\
\hline 36 & $\begin{array}{l}\text { HDPATTE EM QUALQUER } \\
\text { EPOCA }\end{array}$ & DERNTIVO & & & & & & & & & & & & & & \\
\hline 37 & HOMOSSEOUN & DERMTITVO & & & & & & & & & & & & & & \\
\hline 38 & ICERTCA EM QUNAQUER & ACRUIERIO MEDICO & & & & & & & & & & & & & & \\
\hline 39 & MANEACAO PASSTIA & TFMPORABIO-ATE (2) ANOS & & & & & & & & & & & & & & \\
\hline .0 & anuNoOLOBNAS - USO & 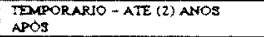 & & & & & & & & & & & & & & \\
\hline 9 & DNDE AMPRTOR A 18 ANOS & 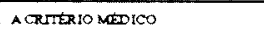 & & & & & & & & & & & & & & \\
\hline$\$ 2$ & DNOE STPESTOR A DOO NNOS & A CRITERO MEDICO & & & & & & & & & & & & & & \\
\hline 4 & REUMA ACMAA DE 2 HORAS & trapornarto & & & & & & & & & & & & & & \\
\hline s4 & LEPRA (CHANESENASE) & A CRrtEno meorco & & & & & & & & & & & & & & \\
\hline 45 & Menaris & COMSOL TAR MORMAS & & & & & & & & & & & & & & \\
\hline 46 & MEDCANAETOS - ysO & CONGR,TAR NORMAS & & & & & & & & & & & & & & \\
\hline 47 & MENSTRUACAO & TEMoriatio & & & & & & & & & & & & & & \\
\hline 48 & MONONUCZEOSE & A CRertero mentco & & & & & & & & & & & & & & \\
\hline 49 & 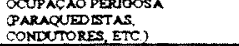 & CONSGrTAR NORMAS & & & & & & & & & & & & & & \\
\hline 50 & 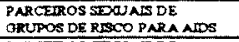 & DEFITIVO & & & & & & & & & & & & & & \\
\hline$s 1$ & 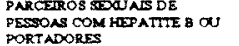 & TRMPORARTO - ATE (6) MESSES & & & & & & & & & & & & & & \\
\hline 52 & 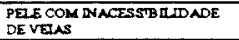 & TMPORARTO & & & & & & & & & & & & & & \\
\hline$" 3$ & $\begin{array}{l}\text { PEEE LESONADA NO LOCA DA } \\
\text { PUNCAO }\end{array}$ & troporisto & & & & & & & & & & & & & & \\
\hline$\$$ & $\begin{array}{l}\text { PEBO COM PERDA ACDMA DE } \\
\text { 10\% }\end{array}$ & ACrmitrso & & & & & & & & & & & & & & \\
\hline 3 & PESO AFEROR A $15 \mathrm{KW}$ & ACRTRPRO MEDTCO & & & & & & & & & & & & & & \\
\hline 56 & PRESADWRTOS OU EX & DEPNTTVO & & & & & & & & & & & & & & \\
\hline 57 & PRESSGO ARTRIN, ANORMAL & CONSERTAR NORMAS & & & & & & & & & & & & & & \\
\hline 5 & PYLDO ABAXXO DE $60 \mathrm{BPM}$ & TEMPORARio & & & & & & & & & & & & & & \\
\hline 39 & PrSO ACDAA DE $110 \mathrm{BPM}$ & TEMPORABro & & & & & & & & & & & & & & \\
\hline so & strus & 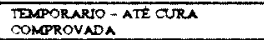 & & & & & & & & & & & & & & \\
\hline 61 & TAUUAODA & TDOPORARIO-AIE 10 ANOS & & & & & & & & & & & & & & \\
\hline 62 & TEMPEATURA NATAR & TEQORArJo & & & & & & & & & & & & & & \\
\hline 53 & TENDENCTA A DESOCANOS & Trapornato & & & & & & & & & & & & & & \\
\hline$\infty$ & 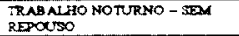 & Trapornto & & & & & & & & & & & & & & \\
\hline ss & TRANSFUSAO ANTERO OR & $\begin{array}{l}\text { TPMPOORARO - ATE } 10 \text { ANOS } \\
\text { PPOS }\end{array}$ & & & & & & & & & & & & & & \\
\hline 66 & TUBERCIRAse & ACRn & & & & & & & & & & & & & & \\
\hline 5 & URERA ONTRODUODENAL & A CRTERTO MEDICO & & & & & & & & & & & & & & \\
\hline 58 & vacenss & CONSUR TAR NORMAS & & & & & & & & & & & & & & \\
\hline 69 & $\operatorname{armio}$ & & & & & & & & & & & & & & & \\
\hline 70 & anno & & & & & & & & & & & & & & & \\
\hline & APTO & & & & & & & & & & & & & & & \\
\hline & NAPTO & & & & & & & & & & & & & & & \\
\hline & CODHOOS DE DAPEDD & & & & & & & & & & & & & & & \\
\hline
\end{tabular}
DECLNEACAOD DO DOADOR RECLAMR PRESENTE ON OUTURAMENTE, CONTRAO

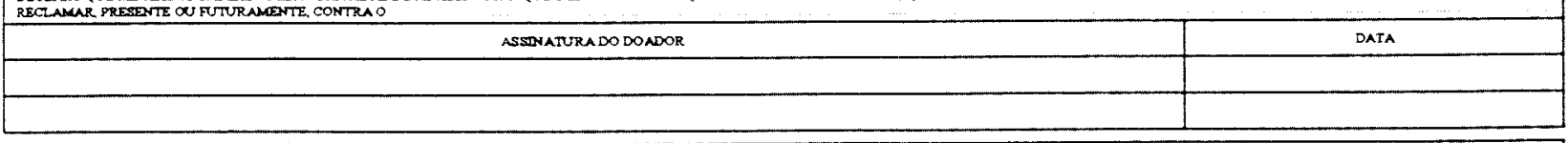

ORSERYACOES 
ANEXO VI - Prevalência da infecção por $T$. cruzi entre doadores, primodoadores e doadores de repetição no Hemocentro Regional de Florianópolis - HRF, Serviço de Hemoterapia do HU/UFSC e Região da Grande Florianópolis. Estado de Santa Catarina. (cálculos)

Cálculos efetuados de acordo com o proposto na metodologia:

Considerando para fins de precisão dos cálculos, os doadores com resultados de exame "indeterminados", teremos:

Soropositivos + (Taxa confirmação $\times$ Indeterminados $)$

Prevalência $=$

Doadores de sangue observados

\section{Prevalência no Hemocentro Regional de Florianópolis - HRF:}

Período: 01.01 .90 a 31.12 .99

Prevalência $=$

(Primodoadores)

Soropositivos + (Taxa confirmação $\mathrm{x}$ Indeterminados)

Primodoadores observados

$\mathrm{N}^{\mathrm{o}}$ soropositivos $=$ confirmados $(\mathrm{C}) \ldots \ldots \ldots \ldots=114$

$\mathrm{N}^{\circ}$ Não confirmados $=$ desconfirmados $(D)=87$

$\mathrm{N}^{\mathrm{O}}$ Indeterminados (I) ............................ $=30$

$\mathrm{N}^{\circ}$ primodoadores ...... (128908-14 064) $=114844$

Taxa de confirmação (indeterminados) $=\frac{\mathrm{C}}{\mathrm{C}+\mathrm{D}}=\frac{114}{114+87}=0,567$

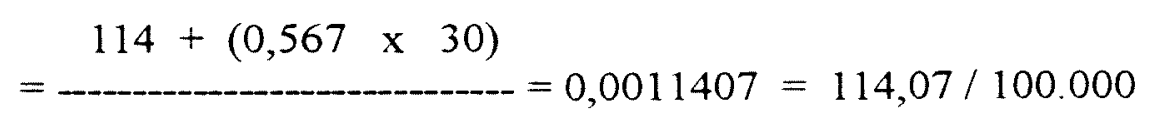

114844 
Prevalência $=$

Soropositivos + (Taxa confirmação $\times$ Indeterminados)

(Doadores de repetição) Doadores de repetição observados

$\mathrm{N}^{\circ}$ soropositivos $=$ confirmados $(\mathrm{C}) \ldots \ldots \ldots \ldots \ldots \ldots . \ldots 22$

$\mathrm{N}^{\circ}$ Não confirmados $=$ desconfirmados (D) ..... $=19$

$\mathrm{N}^{\mathrm{o}}$ Indeterminados (I) ................................... $=10$

$\mathrm{N}^{\circ}$ doadores de repetição $(128908-114844)=14064$

Taxa de confirmação (indeterminados) $=\frac{C}{C+D}=\frac{22}{22+19}=0,537$ $=\frac{22+(0,537 \times 10)}{14064}=0,0019461=194,61 / 100.000$

Prevalência $=$

(Total de Doadores)

Soropositivos + (Taxa confirmação $\mathrm{x}$ Indeterminados)

$\mathrm{N}^{\circ}$ soropositivos $=$ confirmados $(\mathrm{C}) \ldots \ldots \ldots . . .=136$

$\mathrm{N}^{\circ}$ Não confirmados $=$ desconfirmados (D) $=106$

$\mathrm{N}^{\circ}$ Indeterminados (I) ............................ $=40$

$\mathrm{N}^{\circ}$ doadores ............................................ $=128908$

Taxa de confirmação (indeterminados) $=\frac{C}{C+D}=\frac{136}{136+106}=0,562$

$$
=\frac{136+(0,562 \times 40)}{128908}=0,0012294=122,94 / 100000
$$


Prevalência no Servico Hemoterapia do Hospital Universitário SHHU/UFSC:

Periodo: 01.01 .90 a 31.12 .99

Prevalência $=$
(Primodoadores)

Soropositivos + (Taxa confirmação $\mathrm{x}$ Indeterminados)

Doadores observados

$\mathrm{N}^{\mathrm{o}}$ soropositivos $=$ confirmados $(\mathrm{C}) \ldots \ldots \ldots \ldots=34$

$\mathrm{N}^{\mathrm{o}}$ Não confirmados $=$ desconfirmados $(\mathrm{D})=30$

$\mathrm{N}^{\circ}$ Indeterminados (I) ........................... $=56$

$\mathrm{N}^{\mathrm{o}}$ primodoadores …....... $(17553-3030)=14523$

Taxa de confirmação (indeterminados) $=\frac{\mathrm{C}}{\mathrm{C}+\mathrm{D}}=\frac{34}{34+30}=0,531$

$$
=\frac{34+(0,531 \times 56)}{14523}=0,0043886=438,86 / 100000
$$

Prevalência $=$

(Doadores de repetição)

Soropositivos + (Taxa confirmação $\times$ Indeterminados)

$\mathrm{N}^{\circ}$ soropositivos $=$ confirmados $(\mathrm{C})$.......... $=01$

$N^{\circ}$ Não confirmados $=$ desconfirmados $(D)=12$

$\mathrm{N}^{\mathrm{N}}$ Indeterminados (I) .............................. $=10$

$\mathrm{N}^{\circ}$ doadores de repetição.. $17553-14523=3030$

Taxa de confirmação (indeterminados) $=\frac{\mathrm{C}}{\mathrm{C}+\mathrm{D}}=\frac{1}{1+12}=0,077$

$$
=\frac{01+(0,077 \times 10)}{3030}=0,0005841=58,41 / 100000
$$




Prevalência $=$ Soropositivos $+($ Taxa confirmação $\times$ Indeterminados $)$
(Total de doadores $)$

$\mathrm{N}^{\mathrm{o}}$ soropositivos $=$ confirmados $(\mathrm{C}) \ldots \ldots \ldots \ldots=35$

$\mathrm{N}^{\circ}$ Não confirmados $=$ desconfirmados $(\mathrm{D})=42$

$\mathrm{N}^{\circ}$ Indeterminados (I) ............................. $=66$

$\mathrm{N}^{\mathrm{o}}$ doadores.......................................... $=17553$

Taxa de confirmação (indeterminados) $=\frac{\mathrm{C}}{\mathrm{C}+\mathrm{D}}=\frac{35}{35+42}=0,454$ $=\frac{35+(0,454 \times 66)}{17.553}=0,00037010=370,10 / 100000$

\section{Prevalência na Região da Grande Florianópolis (HRF e SHHU/UFSC):}

Período: 01.01 .90 a 31.12 .99

O cálculo resultante da média ponderada das Taxas de Prevalência encontradas entre primodoadores, doadores de repetição e total de doadores no Hemocentro Regional de Florianópolis e Serviço de Hemoterapia do HU/UFSC.

(Região da Grande Florianópolis* = Hemocentro Regional de Florianópolis + Serviço de Hemoterapia do HU/UFSC)

Prevalência $=$

Prev. HRF $x$ Primodoadores + Prev. HU/UFSC $x$ Primodoadores

(Primodoadores) Doadores HRF + Doadores HU/UFSC

$$
\begin{aligned}
& =\frac{114,08 \times 114844+438,86 \times 14523}{114844+14523} \\
& =150,53 / 100000 \text { doações. }
\end{aligned}
$$


Prev. HRF x Doadores rep. + Prev. HU/UFSC x Doadores

Prevalência rep.

(Doadores de repetição) Doadores rep. HRF + Doadores rep. HU/UFSC + Doadores rep. HRJ

$$
\begin{aligned}
& =\frac{194,61 \times 14064+58,41 \times 3030}{14064+3030} \\
& =170,47 / 100000 \text { doações. }
\end{aligned}
$$

Prev. HRF x Doadores + Prev. HU/UFSC x Doadores

Prevalência $=$

(Total de doadores) Doadores HRF + Doadores HU/UFSC

$$
\begin{aligned}
& =\frac{122,94 \times 128908+370,10 \times 17553}{128908+17553} \\
& =152,56 / 100000 \text { doações. }
\end{aligned}
$$




\section{ANEXO VII - Incidência da infecção por $T$. cruzi no Hemocentro Regional de Florianópolis, Serviço de Hemoterapia do HU/UFSC e Região da Grande Florianópolis. Estado de Santa Catarina (cálculos).}

Região da Grande Florianópolis, capital do Estado de Santa Catarina, considerando o Hemocentro Regional de Florianópolis - HRF e Serviço de Hemoterapia do HU/UFSC.

Para os cálculos da incidência utilizou-se o modelo descrito por Canutti Júnior (1998), como:

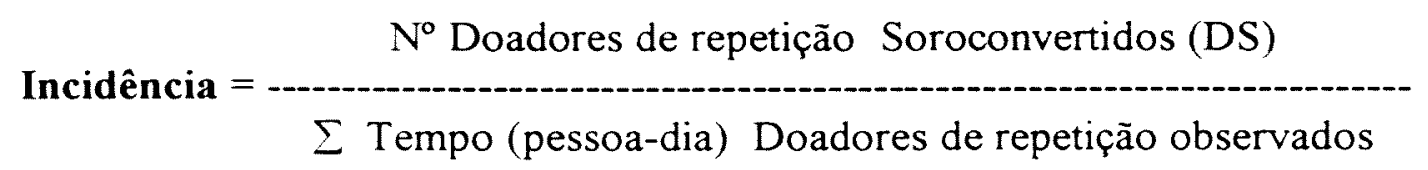

Entendendo que a soroconversão se dá em média, na metade do tempo entre a penúltima e última doação, teremos a incidência ajustada, como:

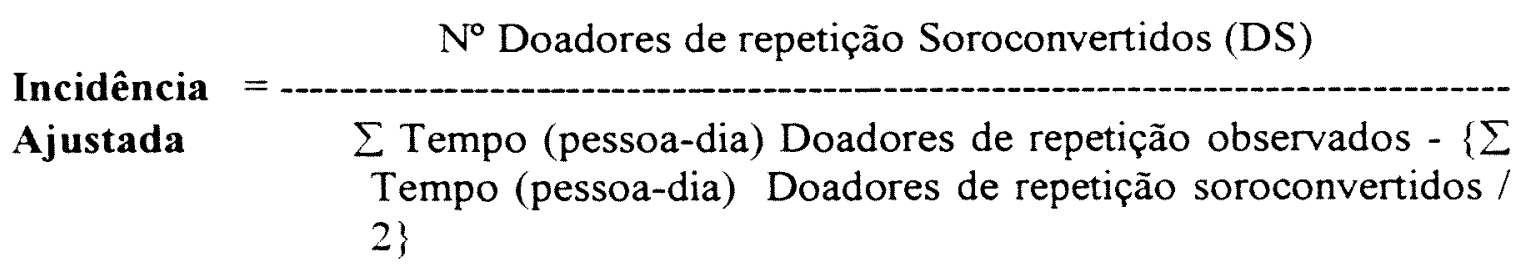

Considerando para fins de precisão dos cálculos, os doadores de repetição com resultados de exame "indeterminados", teremos:

$N^{\circ}$ Doadores de repetição Soroconvertidos + (Taxa confirmação $x$ Indeterminados)

\footnotetext{
Incidência $=$

Ajustada $\sum$ Tempo (pessoa-dia) Doadores de repetição observados - $\{\Sigma$

Tempo (pessoa-dia) Doadores de repetição soroconvertidos / 2$\}$
} 


\section{Incidência no Hemocentro Regional de Florianópolis - HRF}

Periodo: 01.01 .97 a 18.06 .99 (KUPEK, 200 lb)

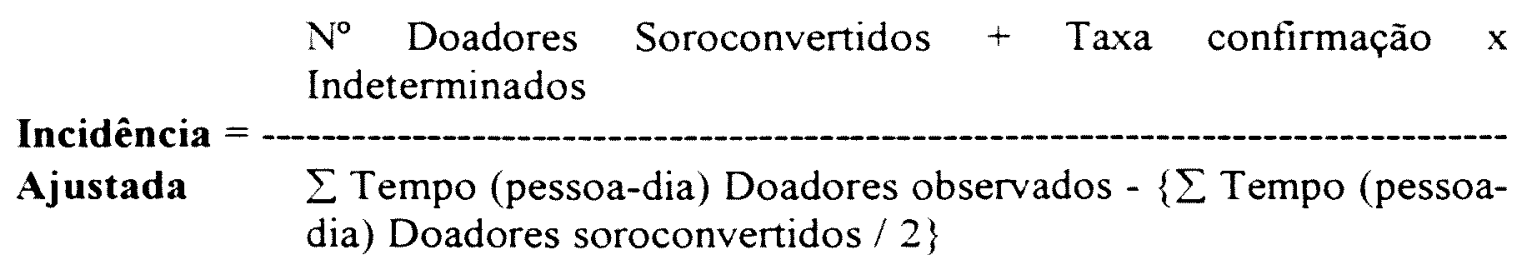
$\mathrm{N}^{\mathrm{o}}$ soroconvertido $=$ confirmados $(\mathrm{C}) \ldots \ldots \ldots=2 \rightarrow \sum$ Tempo $($ pessoa-dia $)=1,351$
$\mathrm{N}^{\circ}$ Não confirmados $=$ desconfirmados $(D)=11 \rightarrow \sum$ Tempo $($ pessoa-dia $)=8,633$
Indeterminados (I) $=3 \rightarrow \Sigma$ Tempo $($ pessoa-dia) $=3,088$
$\mathrm{N}^{\circ}$ doadores $=10 \quad 140 \rightarrow \Sigma$ Tempo $($ pessoa-dia $)=$ 6733,626

Taxa de confirmaçäc (indeterminados) $=\frac{\mathrm{C}}{\mathrm{C}+\mathrm{D}}=\frac{2}{2+11}=0,1538$

Incidência $=$

$$
2+(0,1538 \times 3)
$$

Ajustada $6733,626+1,351+8,633+3,088-\{1,351+(3,088 \times 0,1538) / 2\}$

Incidència Ajustada $=0,0003648=36,48 / 100000$ (doadores de repetição)

Incidência no Servico Hemoterapia do Hospital Universitário SHHU/UFSC:

Periodo: 01.01.90 a 31.12.99

\footnotetext{
$\mathrm{N}^{\circ}$ Doadores Soroconvertidos + (Taxa confirmação $\mathrm{x}$ Indeterminados)

Incidência $=$

Ajustada $\Sigma$ Tempo (pessoa-dia) Doadores observados - $\{\Sigma$ Tempo (pessoadia) Doadores soroconvertidos $/ 2\}$
} 


$$
\begin{aligned}
& N^{\circ} \text { soropositivos }=\text { confirmados }(\mathrm{C}) \ldots \ldots \ldots . . .=1 \rightarrow \sum \text { Tempo }(\text { pessoa-dia })=0,345 \\
& N^{o} \text { Não confirmados }=\text { desconfirmados }(D)=12 \rightarrow \Sigma \text { Tempo (pessoa-dia) }= \\
& 10,458
\end{aligned}
$$

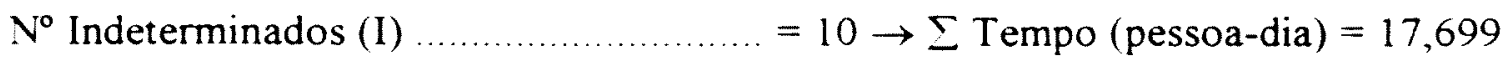

$$
\begin{aligned}
& \mathrm{N}^{0} \text { doadores .................................... }=3030 \rightarrow \Sigma \text { Tempo }(\text { pessoa-dia })=2804,956
\end{aligned}
$$

Taxa de confirmação (indeterminados) $=\frac{C}{C+D}=\frac{1}{1+12}=0,077$

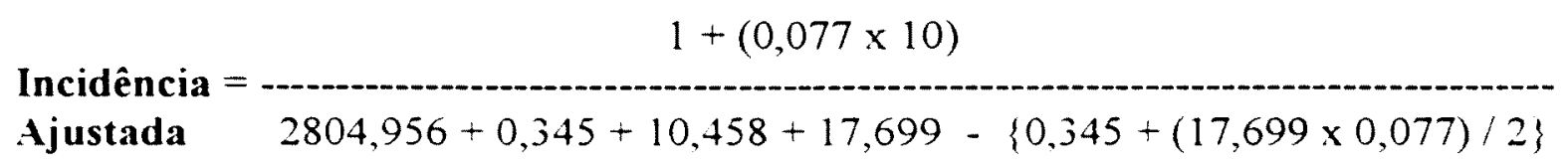

\begin{tabular}{|c|c|}
\hline $\begin{array}{l}\text { Incidência na } \\
\text { Região da Grande }\end{array}$ & $\begin{array}{c}\text { Incidência } \times \quad \sum \text { (pessoa-dia) HRF }+ \text { Incidência } x \\
\sum(\text { pessoa-dia) HU/UFSC }\end{array}$ \\
\hline \multirow{3}{*}{$\begin{array}{l}\text { Região da Grande } \\
\text { Florianópolis }\end{array}$} & $\Sigma$ (pessoa-dia) HRF $+\Sigma($ pessoa-dia $) H U / U F S C$ \\
\hline & $36,48 \times 6745,785+62,49 \times 2832,604$ \\
\hline & $6745,785+2832,604$ \\
\hline
\end{tabular}

Incidência Ajustada $=0,0006249=62,49 / 100000$ (doadores de repetição)

\section{Incidência na Região da Grande Florianópolis - HRF}

Resultou uma incidência de sorologia positiva por $T$. cruzi de 44,17 por cada 100000 doadores de sangue de repetição na Região da Grande Florianópolis, considerando-se a média ponderada da incidência encontrada na Unidade Hemoterápica do Hemocentro Regional de Florianópolis - HRF e Serviço de Hemoterapia do Hospital Universitário - HU/UFSC. 
ANEXO VIII - Risco Residual de Transmissão Transfusional do $T$. cruzi no Hemocentro Regional de Florianópolis HRF, Serviço de Hemoterapia do HU/UFSC e Região da Grande Florianópolis. Estado de Santa Catarina (cálculos).

$\underline{\text { Risco Residual }(R R)=\text { Incidência ajustada } \times \quad \text { Periodo janela imunológica }}$

$\underline{\text { Risco Residual de Transmissão Transfusional no Hemocentro }}$ Regional de Florianópolis - HRF

Risco Residual $(R R)=$ Incidência ajustada $x$ Periodo janela imunológica

$=36,48 \times 28 / 365$

$=2,79$ (possiveis contaminações por 100.000 doações efetuadas)

$\underline{\text { Risco Residual de Transmissão Transfusional no Servico de }}$ Hemoterapia do HU/UFSC

Risco Residual $(R R)=$ Incidência ajustada $\times$ Periodo janela imunológica

$=62,48 \times 28 / 365$

$=4,79$ (possiveis contaminações por 100.000 doações efetuadas) 


\section{Risco Residual de Transmissão Transfusional na Região da Grande Florianópolis}

Cálculo resultante da média ponderada do Risco Residual de Transmissão Transfusional / $\sum$ pessoa-tempo, encontrado no Hemocentro Regional de Florianópolis e Serviço de Hemoterapia do HU/UFSC.

(Região da Grande Florianópolis* = Hemocentro Regional de Florianópolis + Serviço de Hemoterapia do HU/UFSC)

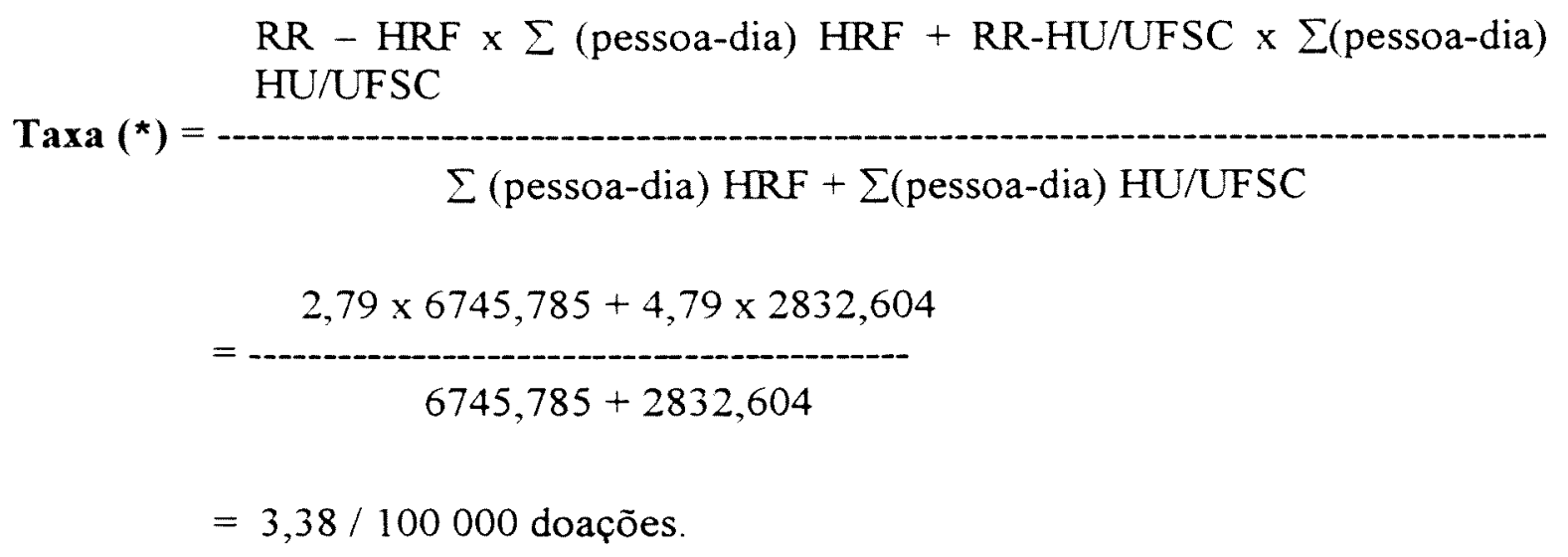




\section{ANEXO IX - Prevalência da infecção por $T$. cruzi no Hemocentro Regional de Joaçaba - HRJ. Região de Joaçaba. Estado de Santa Catarina (cálculos).}

\section{Prevalência no Hemocentro Regional de Joacaba-HRJ}

Periodo: 01.01 .95 a 31.12 .99

$\begin{array}{lc}\text { Prevalência }= & \text { Soropositivos }+ \\ \begin{array}{l}\text { (Primodoadores) } \\ \text { (Taxa confirmação } \times \text { Indeterminados })\end{array}\end{array}$

$$
\begin{aligned}
& \mathrm{N}^{\circ} \text { soropositivos }=\text { confirmados }(\mathrm{C}) \ldots \ldots \ldots \ldots=15 \\
& \mathrm{~N}^{\circ} \text { Não confirmados }=\text { desconfirmados (D) }=05 \\
& \mathrm{~N}^{\circ} \text { Indeterminados (I) .......................... }=01 \\
& \mathrm{~N}^{\circ} \text { primodoadores }(13.368-4.195)=9173
\end{aligned}
$$

Taxa de confirmação (indeterminados) $=\frac{C}{-C+D}=\frac{15}{15+5}=0,750$

$$
=\frac{15+(0,750 \times 1)}{9173}=0,0017169=171,69 / 100000
$$

Prevalência $=$

(Doadores de repetição)

Soropositivos + (Taxa confirmação $\mathrm{x}$ Indeterminados)

$\mathrm{N}^{\circ}$ soropositivos $=$ confirmados $(\mathrm{C}) \ldots \ldots \ldots . . .=0$

$N^{\circ}$ Não confirmados $=$ desconfirmados $(D)=0$

$\mathrm{N}^{\circ}$ Indeterminados (I) ........................... $=01$

$\mathrm{N}^{\circ}$ doadores de repetição......................... $=4195$

Taxa de confirmação (indeterminados) $=\frac{C}{C+D}=\frac{0}{-0+0}=0,0$ 


$$
=\frac{0+(0,0 \times 1)}{4195}=0,0 \text { (zero) } / 4195 \text { doadores de repetição }
$$

\section{Prevalência $=$}

(Total de doadores)

Soropositivos + ( Taxa confirmação $\mathrm{x}$ Indeterminados)

$\mathrm{N}^{\mathrm{o}}$ soropositivos $=$ confirmados $(\mathrm{C}) \ldots \ldots \ldots . . .=15$

$\mathrm{N}^{\circ}$ Não confirmados $=$ desconfirmados $(\mathrm{D})=05$

$\mathrm{N}^{\circ}$ Indeterminados (I)

$=02$

$\mathrm{N}^{\circ}$ doadores.

$=13368$

Taxa de confirmação (indeterminados) $=\frac{C}{C+D}=\frac{15}{15+5}=0,750$

$$
=\frac{15+(0,750 \times 2)}{13.368}=0,0012342=123,42 / 100000
$$


ANEXO X - Incidência da infecção por $T$. cruzi no Hemocentro Regional de Joaçaba - HRJ. Região de Joaçaba. Estado de Santa Catarina (cálculos).

Para os cálculos da incidência utilizou-se 0 modelo descrito por CANUTTI JÚNIOR (1998), como:

Incidência $=\frac{N^{\circ} \text { Doadores de repetição Soroconvertidos (DS) }}{\sum \text { Tempo (pessoa-dia) Doadores de repetição observados }}$

$N^{\circ}$ Doadores de repetição Soroconvertidos (DS)

Incidência $=$

Ajustada

$\Sigma$ Tempo (pessoa-dia) Doadores de repetição observados -

$\{\Sigma$ Tempo (pessoa-dia) Doadores de repetição soroconvertidos /

$2\}$

$\mathrm{x}$

$N^{o}$ Doadores de repetição Soroconvertidos + (Taxa confirmação

Indeterminados)

Incidência $=$

Ajustada

$\sum$ Tempo (pessoa-dia) Doadores de repetição observados $-\{\Sigma$

Tempo (pessoa-dia) Doadores de repetição soroconvertidos / 2$\}$

Incidência no Hemocentro Regional de Joacaba - HRJ:

Período: 01.01 .95 a 31.12 .99

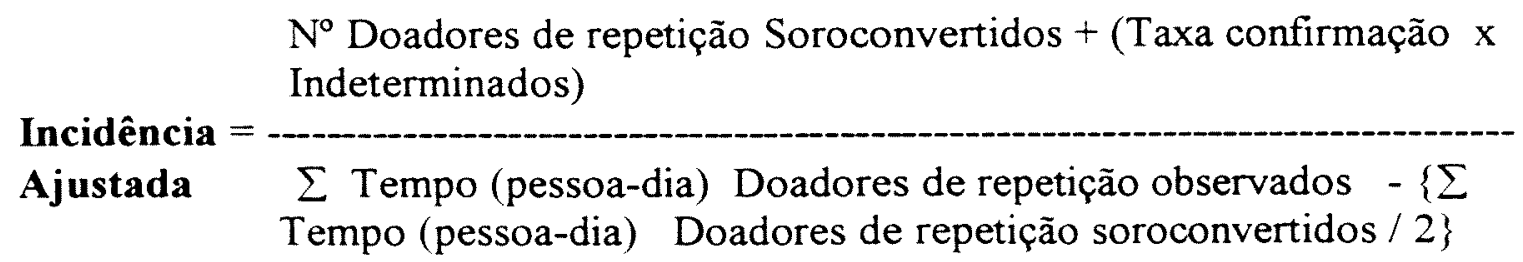

$N^{\circ}$ doadores de repetição, soroconvertidos $(C)=0 \rightarrow \sum$ Tempo (pessoa-dia) $=0,0$ 
$\mathrm{N}^{\mathrm{o}}$ Não confirmados $=$ desconfirmados $(\mathrm{D}) \ldots . .=0 \rightarrow \sum$ Tempo $($ pessoa-dia $)=0,0$

Indeterminados (I) $=1 \rightarrow \sum$ Tempo $($ pessoa-dia $)=0,737$

$\mathrm{N}^{\circ}$ doadores. $=4195 \rightarrow \Sigma$ Tempo $($ pessoa-dia $)=3790,260$

Taxa de confirmação (indeterminados) $=\frac{C}{C+D}=\frac{0}{0+0}=0,00$
Incidência $=$
Ajustada

$$
3790,260+0,00+0,00+0,737-\{0,00+(0,737 \times 0.00) / 2\}
$$

$0+(0.00 \times 1)$

Incidência Ajustada $=0,00$ (zero)

O cálculo da "incidência" resultou zero, pois não houve qualquer caso de soroconversão em doador de repetição no período estudado, de 1995 a 1999. 
ANEXO XI - Risco Residual de Transmissão Transfusional do $T$. cruzi no Hemocentro Regional de Joaçaba. Região de Joaçaba. Estado de Santa Catarina (cálculos).

$\underline{\text { Risco Residual }(R R)=\text { Incidência ajustada } x \quad \text { Período janela imunológica }}$

\section{$\underline{\text { Risco Residual de Transmissão Transfusional no }}$}

\section{Hemocentro Regional de Joacaba - HRJ:}

Risco Residual $(R R)=$ Incidência ajustada $x \quad$ Periodo janela imunológica

$=0,00 \times 28 / 365$

$=0,00$ (possiveis contaminações por 100.000 doações efetuadas) 
ANEXO XII - Prevalência da infecção por $T$. cruzi entre primodoadores, doadores de repetição e total de doadores, no Hemocentro Regional de Florianópolis HRF, Serviço de Hemoterapia do Hospital Universitário - HU/UFSC, Hemocentro Regional de Joaçaba - HRJ e Estado de Santa Catarina (cálculos).

Cálculos efetuados de acordo com o proposto na metodologia:

Soropositivos + (Taxa confirmação $x$ Indeterminados)

Doadores observados

\section{Prevalência no Hemocentro Regional de Florianópolis - HRF:}

Período: 01.01 .90 a 31.12 .99

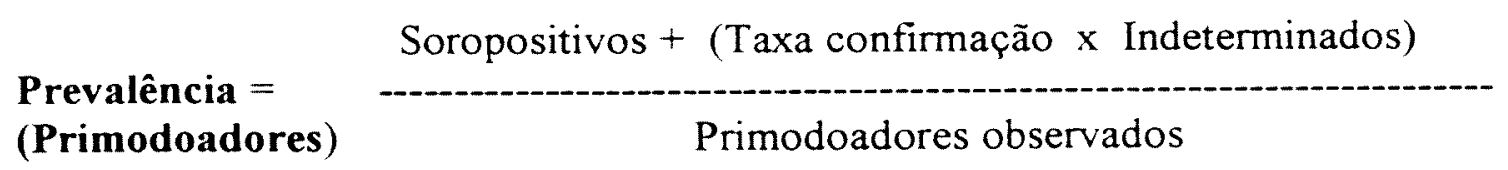

$\mathrm{N}^{\mathrm{o}}$ soropositivos $=$ confirmados $(\mathrm{C}) \ldots \ldots \ldots=114$

$N^{\circ}$ Não confirmados $=$ desconfirmados $(D)=87$

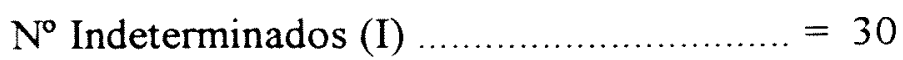

$N^{\circ}$ primodoadores ...... (128908-14064) $=114844$

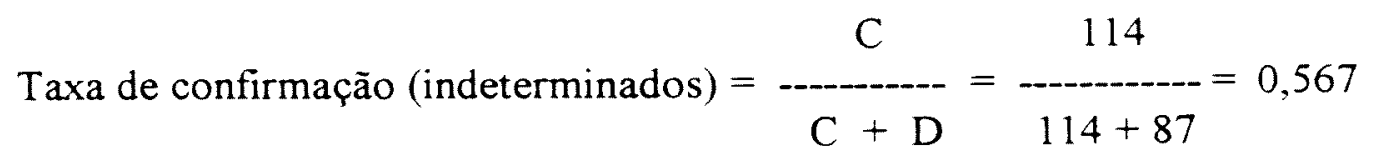

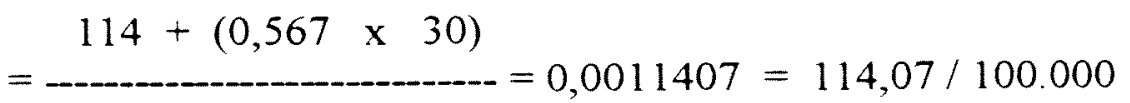

114844 
Prevalência $=$

Soropositivos + (Taxa confirmação $\times$ Indeterminados)

(Doadores de repetição)

Doadores de repetição observados

$\mathrm{N}^{\mathrm{o}}$ soropositivos $=$ confirmados $(\mathrm{C}) \ldots \ldots \ldots \ldots \ldots . \ldots 22$

$\mathrm{N}^{\mathrm{o}}$ Não confirmados $=$ desconfirmados $(\mathrm{D}) \ldots \ldots=19$

$\mathrm{N}^{\circ}$ Indeterminados (I) ............................... $=10$

$N^{o}$ doadores de repetição $(128908-114844)=14064$

Taxa de confirmação (indeterminados) $=\frac{\text { C }}{- \text { C }_{-1}+\mathrm{D}}=\frac{22}{22+19}=0,537$

$=\frac{22+(0,537 \times 10)}{14064}=0,0019461=194,61 / 100.000$

Prevalência $=$

Soropositivos + ( Taxa confirmação $\mathrm{x}$ Indeterminados)

(Total de Doadores) Doadores observados

$\mathrm{N}^{\mathrm{o}}$ soropositivos $=$ confirmados $(\mathrm{C}) \ldots \ldots \ldots . . .=136$

$N^{o}$ Não confirmados $=$ desconfirmados $(D)=106$

$\mathrm{N}^{\circ}$ Indeterminados (I) ........................... $=40$

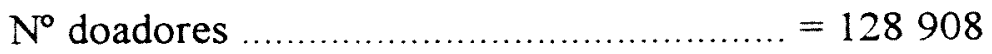

Taxa de confirmação (indeterminados) $=\frac{\text { C }}{-C+D}=\frac{136}{136+106}=0,562$

$=\frac{136+(0,562 \times 40)}{128908}=0,0012294=122,94 / 100000$ 
Prevalência no Serviço Hemoterapia do Hospital Universitário SHHU/UFSC:

Periodo: 01.01 .90 a 31.12 .99

Prevalência $=$
$\begin{aligned} & \text { (Primodoadores) } \\ & \text { Soropositivos }+(\text { Taxa confirmação } \times \text { Indeterminados })\end{aligned}$

$\mathrm{N}^{\circ}$ soropositivos $=$ confirmados $(\mathrm{C}) \ldots \ldots \ldots \ldots=34$

$\mathrm{N}^{\circ}$ Não confirmados $=$ desconfirmados $(\mathrm{D})=30$

$\mathrm{N}^{\circ}$ Indeterminados (I) ............................ $=56$

$\mathrm{N}^{\circ}$ primodoadores …....... $(17553-3030)=14523$

Taxa de confirmação (indeterminados) $=\frac{\mathrm{C}}{\mathrm{C}+\mathrm{D}}=\frac{34}{34+30}=0,531$

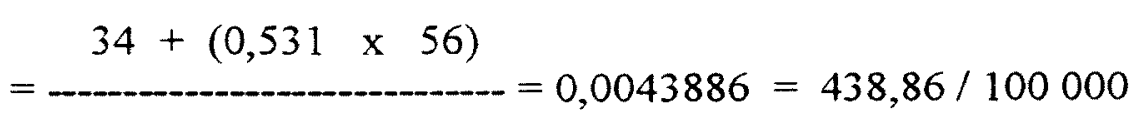

14523

Prevalência $=$

(Doadores de repetição) Doadores observados

№ soropositivos $=$ confirmados $(C) \ldots \ldots \ldots . . .=01$

$\mathrm{N}^{\circ}$ Não confirmados $=$ desconfirmados $(\mathrm{D})=12$

$\mathrm{N}^{\circ}$ Indeterminados (I) ............................ $=10$

$\mathrm{N}^{\circ}$ doadores de repetição. $.17553-14523=3030$

Taxa de confirmação (indeterminados) $=\frac{\mathrm{C}}{\mathrm{C}+\mathrm{D}}=\frac{1}{1+12}=0,077$ 


$$
=\frac{01+(0,077 \times 10)}{3030}=0,0005841=58,41 / 100000
$$

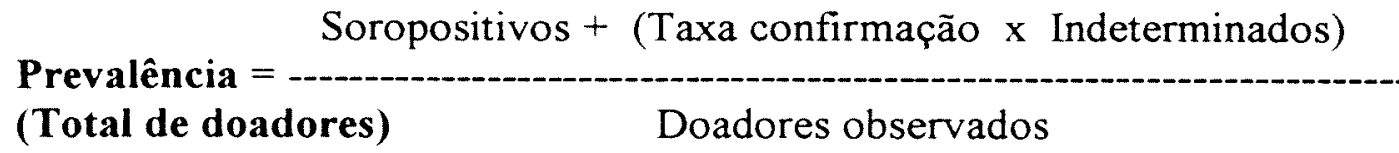

$N^{\circ}$ soropositivos $=$ confirmados $(C) \ldots \ldots \ldots . \ldots=35$

$N^{\circ}$ Não confirmados $=$ desconfirmados $(D)=42$

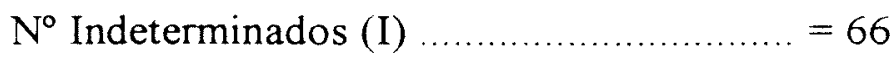

$\mathrm{N}^{\circ}$ doadores..................................... $=17.553$

Taxa de confirmação (indeterminados) $=\frac{C}{C+D}=\frac{35}{35+42}=0,454$

$=\frac{35+(0,454 \times 66)}{17.553}=0,00037010=370,10 / 100000$

\section{Prevalência no Hemocentro Regional de Joacaba-HRJ:}

Periodo: 01.01.95 a 31.12 .99

Prevalência $=$

Soropositivos + (Taxa confirmação $\mathrm{x}$ Indeterminados)

(Primodoadores)

Primodoadores observados

$\mathrm{N}^{\mathrm{o}}$ soropositivos $=$ confirmados $(\mathrm{C}) \ldots \ldots \ldots \ldots=15$

$\mathrm{N}^{\mathrm{o}}$ Não confirmados $=$ desconfirmados $(\mathrm{D})=05$

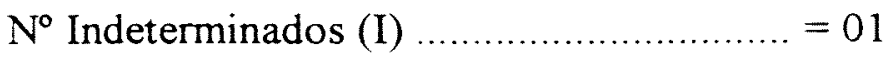

$\mathrm{N}^{\circ}$ primodoadores $(13.368-4.195)=9173$

Taxa de confirmação (indeterminados) $=\frac{C}{C+D}=\frac{15}{15+5}=0,750$ 


$$
=\frac{15+(0,750 \times 1)}{9173}=0,0017169=171,69 / 100000
$$

Prevalência $=$

Soropositivos + (Taxa confirmação $\mathrm{x}$ Indeterminados)

(Doadores de repetição) Doadores de repetição observados

$\mathrm{N}^{\mathrm{o}}$ soropositivos $=$ confirmados $(\mathrm{C}) \ldots \ldots \ldots . . .=0$

$N^{0}$ Não confirmados $=$ desconfirmados $(D)=0$

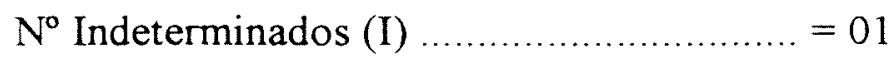

$\mathrm{N}^{\mathrm{o}}$ doadores de repetição ....................... $=4195$

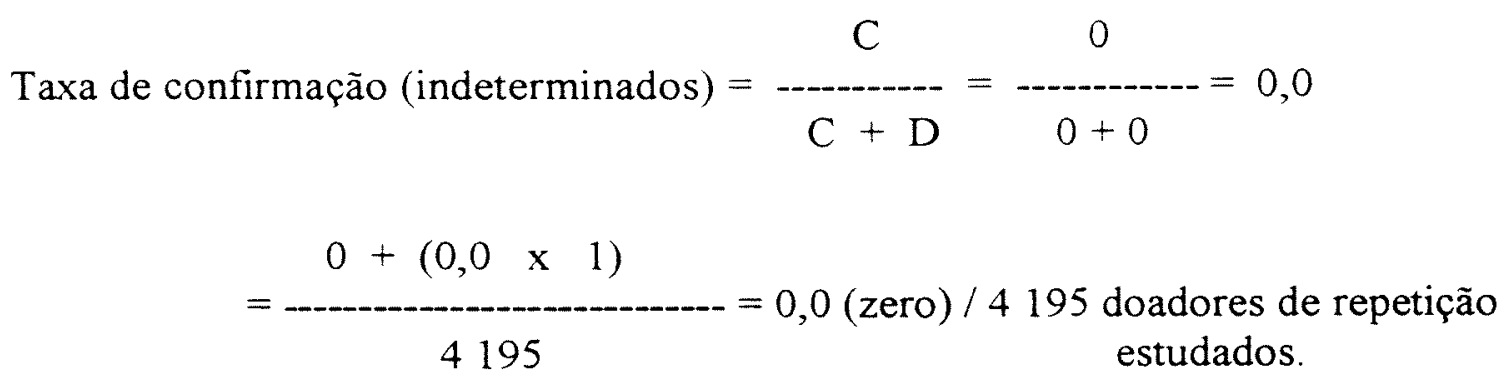

Prevalência $=$

Soropositivos + ( Taxa confirmação $\mathrm{x}$ Indeterminados)

(Total de doadores)

Doadores observados

$\mathrm{N}^{\mathrm{o}}$ soropositivos $=$ confirmados $(\mathrm{C}) \ldots \ldots \ldots . .=15$

$N^{\circ}$ Não confirmados $=$ desconfirmados $(D)=05$

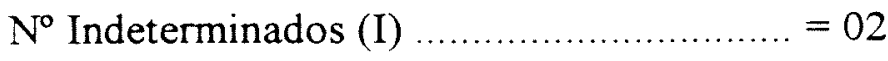

$\mathrm{N}^{\circ}$ doadores .................................... $=13368$

Taxa de confirmação (indeterminados) $=\frac{\text { C }}{\text { C }+ \text { D }}=\frac{15}{15+5}=0,750$

$$
=\frac{15+(0,750 \times 2)}{13368}=0,0012342=123,42 / 100000
$$


Prevalência no Estado de Santa Catarina (HRF, SHHU/UFSC e HRJ):

Período: 01.01.90 a 31.12.99 (HRF e SHHU/UFSC) e ( 01.01 .95 a 31.12 .99 (HRJ)

O cálculo é resultante da média ponderada das Taxas de Prevalência encontradas entre primodoadores, doadores de repetição e total de doadores, no Hemocentro Regional de Florianópolis, Serviço de Hemoterapia do HU/UFSC e Hemocentro Regional de Joaçaba.

(Estado de Santa Catarina $=$ Hemocentro Regional de Florianópolis + Serviço de Hemoterapia do HU/UFSC + Hemocentro Regional de Joaçaba)

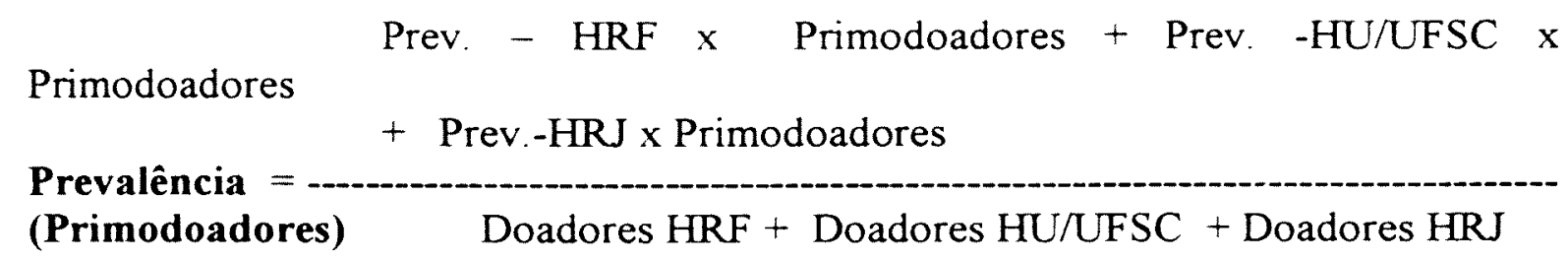

$$
\begin{aligned}
& =\frac{114,07 \times 114844+438,86 \times 14523+171,69 \times 9173}{114844+14523+9173} \\
& =151,93 / 100000 \text { doações. }
\end{aligned}
$$


Prev. - HRF x Doadores rep. + Prev. -HU/UFSC x Doadores

Prevalência =

Rep. + Prev.-HRJ x Doadores rep.

(Doadores de repetição) Doadores rep. HRF + Doadores rep. HU/UFSC + Doadores rep. HRJ

$$
\begin{aligned}
& =\frac{194,61 \times 14064+58,41 \times 3030+0,00 \times 4195}{14064+3030+4195} \\
& =136,88 / 100000 \text { doações. }
\end{aligned}
$$

Prevalência =

Prev. - HRF $x$ Doadores + Prev. -HU/UFSC $x$ Doadores

+ Prev.-HRJ x Doadores

(Total de doadores) Doadores HRF + Doadores HU/UFSC + Doadores HRJ

$$
\begin{aligned}
& =\frac{122,94 \times 128908+370,10 \times 17553+123,42 \times 13368}{128908+17553+13368} \\
& =150,124 / 100000 \text { doações. }
\end{aligned}
$$


ANEXO XIII - Incidência da infecção por $T$. cruzi no Hemocentro Regional de Florianópolis-HRF, Serviço de Hemoterapia do HU/UFSC, Hemocentro Regional de Joaçaba-HRJ e Estado de Santa Catarina (cálculos).

Para os cálculos da incidência utilizou-se o modelo descrito por Canutti Júnior (1998), como:

Incidência $=\frac{N^{0} \text { Doadores de repetição Soroconvertidos (DS) }}{\sum \text { Tempo }(\text { pessoa-dia) Doadores de repetição observados }}$

Entendendo que a soroconversão se dá em média, na metade do tempo entre a penúltima e última doação, teremos a incidência ajustada, como:

$\begin{array}{ll}\text { Incidência } & N^{0} \text { Doadores de repetição Soroconvertidos (DS) } \\ \text { Ajustada } & \sum \text { Tempo (pessoa-dia) Doadores de repetição observados - } \\ \left\{\sum \text { Tempo (pessoa-dia) Doadores de repetição soroconvertidos } / 2\right\} & \text { D }\end{array}$

Considerando para fins de precisão dos cálculos os doadores de repetição com resultados de exame "indeterminados", teremos:

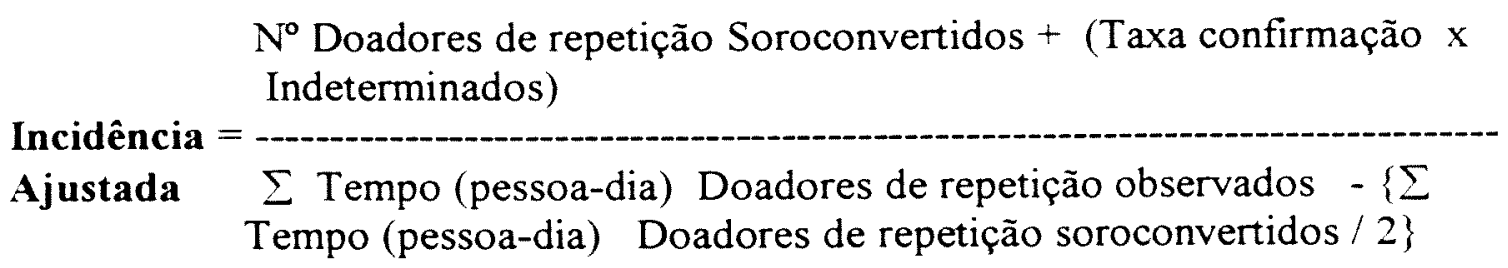

\section{Incidência no Hemocentro Regional de Florianópolis - HRF}

Periodo: 01.01 .97 a 18.06 .99 (Kupek, 2001) 


\begin{abstract}
$N^{\circ}$ Doadores de repetição Soroconvertidos + (Taxa confirmação $x$ Indeterminados)

Incidência $=$

Ajustada $\Sigma$ Tempo (pessoa-dia) Doadores de repetição observados $-\{\Sigma$ Tempo (pessoa-dia) Doadores de repetição soroconvertidos $/ 2\}$

$\mathrm{N}^{\mathrm{o}}$ soropositivos $=$ confirmados $(\mathrm{C}) \ldots \ldots \ldots . . .=2 \rightarrow \Sigma$ Tempo $($ pessoa-dia $)=1,351$

$N^{\circ}$ Não confirmados $=$ desconfirmados $(D)=11 \rightarrow \sum$ Tempo $($ pessoa-dia $)=8,633$

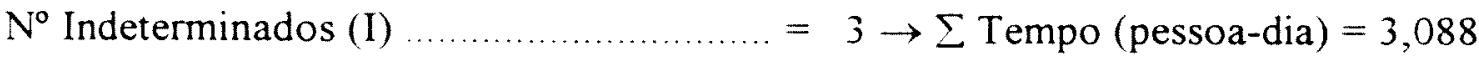

No doadores. $=10140 \rightarrow \Sigma$ Tempo $($ pessoa-dia $)=6733,626$
\end{abstract}

Taxa de confirmação (indeterminados) $=\frac{C}{C+D}=\frac{2}{2+11}=0,1538$

Incidência $=$

$$
2+(0,1538 \times 3)
$$

Ajustada $\quad 6733,626+1,351+8,633+3,088-\{1,351+(3,088 \times 0,1538) / 2\}$

Incidència Ajustada $=0,0003648=36,48 / 100000$ (doadores de repetição)

Resultou uma incidência de infecção por T. cruzi de 36,48 por 100000 doadores de sangue de repetição, na Unidade Hemoterápica do Hemocentro Regional de Florianópolis, no periodo estudado de 01.01 .97 a 18.06.99.

Incidência no Servico Hemoterapia do Hospital Universitário SHHU/UFSC:

Periodo: 01.01.90 a 31.12 .99

\footnotetext{
$\mathrm{N}^{\circ}$ Doadores de repetição Soroconvertidos + Taxa confirmação $\mathrm{x}$ Indeterminados

Incidência $=$

Ajustada $\quad \sum$ Tempo (pessoa-dia) Doadores de repetição observados $-\left\{\sum\right.$

Tempo (pessoa-dia) Doadores de repetição soroconvertidos $/ 2\}$
} 
$\mathrm{N}^{\mathrm{s}}$ soropositivos $=$ confirmados $(\mathrm{C}) \ldots \ldots \ldots . . .=1 \rightarrow \sum$ Tempo $($ pessoa-dia $)=0,345$

$\mathrm{N}^{\mathrm{o}}$ Não confirmados $=$ desconfirmados $(\mathrm{D})=12 \rightarrow \sum$ Tempo $($ pessoa-dia $)=10,458$

Indeterminados (I) $=10 \rightarrow \sum$ Tempo $($ pessoa-dia $)=17,699$

$\mathrm{N}^{\mathrm{o}}$ doadores $=3.030 \rightarrow \Sigma$ Tempo $($ pessoa-dia $)=2804,956$

Taxa de confirmação (indeterminados) $=\frac{C}{C+D}=\frac{1}{1+12}=0,0 / 7$

$$
1+(0,077 \times 10)
$$

Incidência $=$

Ajustada $2804,956+0,345+10,458+17,699-\{0,345+(17,699 \times 0,077) / 2\}$

Incidência Ajustada $=0,0006249=62,49 / 100.000$ (doadores de repetição)

Houve uma incidência de infecção de $T$. cruzi de 62,49 por cada 100.000 doadores de sangue de repetição na Unidade Hemoterápica do Serviço de Heınoterapia do HU/UFSC, no período estudado de 1990 a 1999.

\section{Incidência no Hemocentro Regional de Joacaba - HRJ:}

Periodo: 01.01 .95 a 31.12 .99

$N^{\circ}$ Doadores de repetição Soroconvertidos + (Taxa confirmação $x$ Indeterminados)

Incidência $=$

Ajustada $\sum$ Tempo (pessoa-dia) Doadores de repetição observados - $\{\Sigma$ Tempo (pessoa-dia) Doadores de repetição soroconvertidos $/ 2\}$

$\mathrm{N}^{\circ}$ doadores de repetição, soroconvertidos $=\operatorname{confirmados}(\mathrm{C})=0 \rightarrow \sum$ Tempo

$$
(\text { pessoa-dia })=0,00
$$

$\mathrm{N}^{\circ}$ Não confirmados $=$ desconfirmados $(\mathrm{D})=0 \rightarrow \sum$ Tempo $($ pessoa-dia $)=0,00$

Indeterminados (I) $=1 \rightarrow \sum$ Tempo $($ pessoa-dia) $=0,737$

$\mathrm{N}^{\circ}$ doadores $=4195 \rightarrow \Sigma$ Tempo $($ pessoa-dia $)=3790,260$ 
Taxa de confirmação (indeterminados) $=\frac{C}{C+D}=0.00$

Incidência $=$

$$
0+(0,00 \times 1)
$$

Ajustada

$$
3790,260+0,00+0,00+0,737-\{0,00+(0,737 \times 0,00) / 2\}
$$

Incidência Ajustada $=0,00$ (zero)

O cálculo da incidência resultou zero, pois não houve qualquer caso de soroconversão em doador de repetição no periodo estudado.

\section{Incidência no Estado de Santa Catarina (HRF, SHHU/UFSC e HRJ):}

Cálculo resultante da média ponderada da Incidência / $\Sigma$ pessoa-tempo, encontrada no Hemocentro Regional de Florianópolis, Serviço de Hemoterapia do HU/UFSC e Hemocentro Regional de Joaçaba.

(Estado de Santa Catarina* $=$ Hemocentro Regional de Florianópolis + Serviço de Hemoterapia do HU/UFSC + Hemocentro Regional de Joaçaba)

$$
\begin{aligned}
& \text { Incidência } \times \sum \text { (pessoa-dia) } H R F+\text { Incidência } \times \sum \text { (pessoa-dia) } \\
& \text { HU/UFSC + Incidência } \times \sum \text { (pessoa-dia) HRJ } \\
& \text { Taxa }\left(^{*}\right)=1 \text { (pessoa-dia) HRF }+\sum \text { (pessoa-dia) HU/UFSC }+\Sigma(\text { pessoa-dia }) \text { HRJ } \\
& =\frac{36,48 \times 6745,785+62,49 \times 2832,604+0,00 \times 3790,260}{6745,785+2832,604+3790,260} \\
& =31,65 / 100000 \text { doações. }
\end{aligned}
$$


ANEXO XIV - Risco Residual de Transmissão Transfusional do $T$. cruzi no Hemocentro Regional de Florianópolis HRF, Serviço de Hemoterapia do HU/UFSC, Hemocentro Regional de Joaçaba - HRJ e Estado de Santa Catarina. (cálculos)

$\underline{\text { Risco Residual }(R R)=\text { Incidència ajustada } \times \text { Periodo janela imunológica }}$

Risco Residual de Transmissão Transfusional no Hemocentro Regional de Florianópolis - HRF:

Risco Residual $(\mathrm{RR})=$ Incidência ajustada $\mathrm{x}$ Período janela imunológica

$$
\begin{aligned}
& =36,48 \times 28 / 365 \\
& =2,79 \text { (possiveis contaminações por } 100.000 \text { doações } \\
& \text { efetuadas) }
\end{aligned}
$$

Risco Residual de Transmissão Transfusional no Servico de Hemoterapia do

$$
\text { HU/UFSC: }
$$

Risco Residual $(\mathrm{RR})=$ Incidência ajustada $\quad \mathrm{x}$ Período janela imunológica

$$
\begin{aligned}
& =62,49 \times 28 / 365 \\
& =4,79 \text { (possiveis contaminações por } 100.000 \text { doações } \\
& \text { efetuadas) }
\end{aligned}
$$

\section{Risco Residual de Transmissão Transfusional no Hemocentro Regional de Joacaba - HRJ}

$$
\begin{aligned}
\text { Risco Residual (RR) } & =\text { Incidência ajustada } \times \text { Período janela imunológica } \\
& =0,00 \times 28 / 365 \\
& =0,00
\end{aligned}
$$




\section{Risco Residual de Transmissão Transfusional no Estado de Santa Catarina:}

Cálculo resultante da média ponderada do Risco Residual de Transmissão Transfusional / $\sum$ pessoa-tempo, encontrado no Hemocentro Regional de Florianópolis, Serviço de Hemoterapia do HU/UFSC e Hemocentro Regional de Joaçaba.

(Estado de Santa Catarina* = Hemocentro Regional de Florianópolis + Serviço de Hemoterapia do HU/UFSC + Hemocentro Regional de Joaçaba)

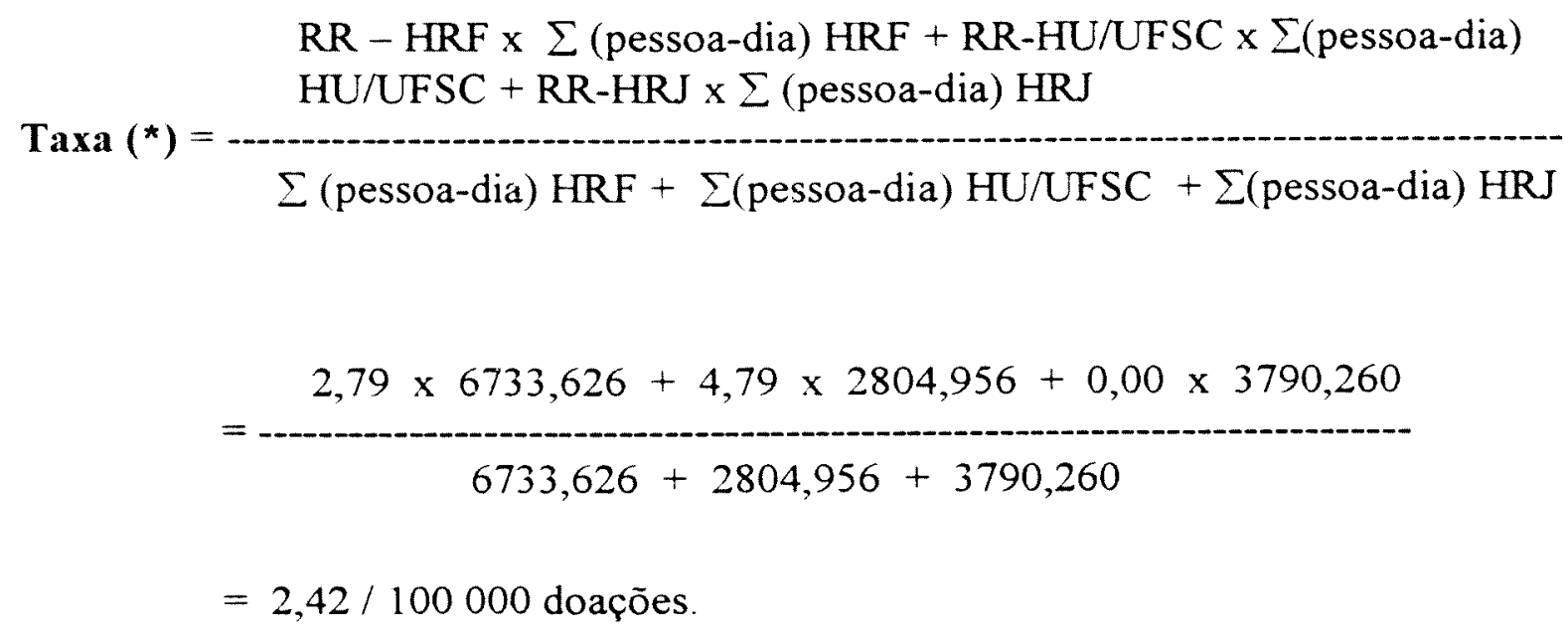

ou

$$
\begin{aligned}
\operatorname{RR}(\mathrm{SC}) & =\text { Incidência }(\mathrm{SC}) \times 28 / 365 \\
& =31,65 \times 28 / 365 \\
& =2,42 / 100.000 \text { doações. }
\end{aligned}
$$




\section{ANEXO XV - Classificação das Unidades Hemoterápicas, de acordo com a natureza ou modalidade de serviços, atualizada segundo o Ministério da Saúde:}

Hemocentro Coordenador - Estrutura de âmbito central, de natureza pública localizada preferencialmente na capital, referência do Estado na área de hemoterapia e/ou hematologia com a finalidade de prestar assistência e apoio hemoterápico e/ou hematológico à rede de serviços de saúde, inclusive aos serviços de maior complexidade e tecnologia. Deverá prestar serviços de ensino e pesquisa, formação de recursos humanos, de controle de qualidade de suporte técnico, de integração das instituições públicas e filantrópicas.

Hemocentro Regional - Estrutura de complexidade intermediária de natureza pública, para atuação macrorregional na área hemoterápica e/ou hematológica e/ou prestando apoio à assistência à rede de serviços de saúde. Deverá coordenar e desenvolver as ações estabelecidas na política de sangue de uma macrorregião de saúde, constituindo-se na descentralização do Hemocentro Coordenador, de forma hierarquizada.

Núcleo de Hemoterapia - Localização na capital ou no interior do Estado, preferencialmente intrahospitalar, de natureza pública ou privada, com função de prestar assistência hemoterápica e/ou hematológica, recrutar doadores, processar o sangue, realizar os testes necessários e armazenar hemocomponentes, podendo ou não distribuir hemocomponentes.

Agência Transfusional - Tipo I - Estrutura intra ou extrahospitalar, abastecida pela Unidade Hemoterápica à qual está vinculada, com função de realizar testes prétransfusionais e transfusões. Armazena hemocomponentes liberados para atender à demanda transfusional de serviços de saúde. 
Agência Transfusional - Tipo II - Executa procedimento transfusional intra hospitalar, vinculado a uma Unidade Hemoterápica, que enviará os hemocomponentes com os testes pré-transfusionais já realizados.

Central Sorológica - Laboratórios públicos ou privados com a tarefa de desenvolver o controle sorológico do sangue a ser transfundido. Além disso, devem apoiar as entidades de assistência que necessitam de diagnóstico sorológico.

Unidade de Coleta - Estruturas especiais para coleta de sangue, de natureza pública ou privada, podendo ser intra ou extra-hospitalar. Se extra-hospitalar pode ser móvel ou fixa. Envia o produto para outra unidade de maior complexidade, onde o sangue será processado e os testes necessários realizados - Unidade Fixa Unidade Móvel.

Unidade de Coleta e Transfusão - Estrutura de atendimento de coleta de transfusão localizada em hospitais isolados ou pequenos municípios, de natureza pública ou privada, onde a demanda de serviços não justifique a instalação de uma estrutura complexa de hemoterapia. Envia o sangue para outra unidade de maior complexidade, onde será realizado o processamento, testes sorológicos e imunohematológicos.

Hemocentro - Estrutura de àmbito macrorregional, a nivel de Regionais de Saúde com finalidade de prestação de serviços de ensino, de pesquisa, de controle de qualidade, de suporte técnico, de formação de recursos humanos de integração das estruturas públicas e filantrópicas, de assessoramento da DVS em seu trabalho na área hematológica-hemoterápica, de promoção de um trabalho de auto-suficiência de insumos básicos para difusão de normas técnicas adequadas;

Núcleos de Hematologia-Hemoterapia - entidades de complexidade intermediária para atuação na área hematológica-hemoterápica e que poderão ter o hemocentro regional como referência para atendimento a pacientes hematológicos mais graves ou com intercorrências de resolução mais complexa, e que na área 
hematológica, deverão coletar, fracionar e distribuir sangue e derivados e poderão ter o hemocentro como referência para confirmação sorológica, unidades de aféreses e controle de qualidade;

Serviço de Hemoterapia - órgão executivo da atividade hemoterápica com competência para proceder coleta e transfusão de sangue e/ou derivados;

Banco de Sangue - estrutura com competência para realizar coleta de sangue e/ou derivados, em área fisica, e fora desta, e a sua transfusão;

Agência Transfusional - Estruturas de atendimento transfusional geralmente localizadas em hospitais isolados ou pequenos municipios onde a demanda de serviços não justifique a instalação de uma estrutura complexa de hemoterapia, sendo que o suprimento de sangue a essas Agências será realizado por intermédio dos Núcleos ou Hemocentros Regionais (MINISTERIO DA SAÚDE/AGÊNCIA NACIONAL DE VIGILÂNCIA SANITÁRIA, 2001). 